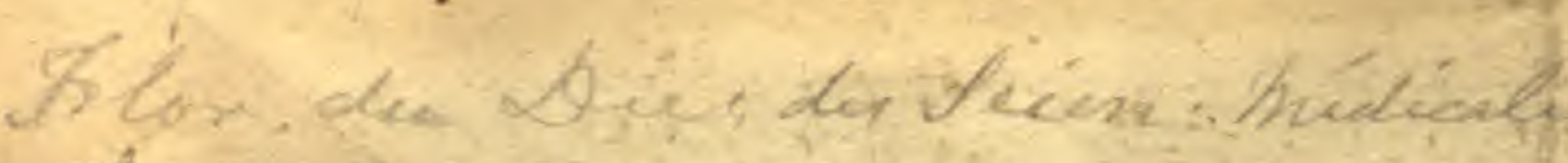

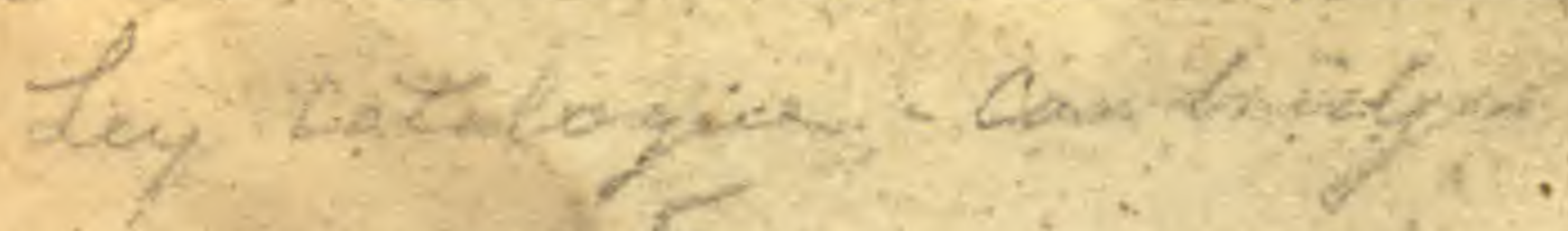
600 pente

Baw thes Kowoll irst rdafe sole colt epl. $24 / 1 / 88$.

Palo de Aren bow fored.

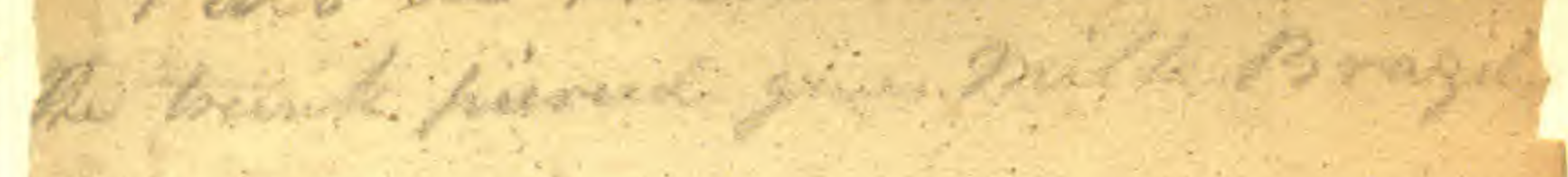


AMSRIOAS LIBRA IX BARVTGZ

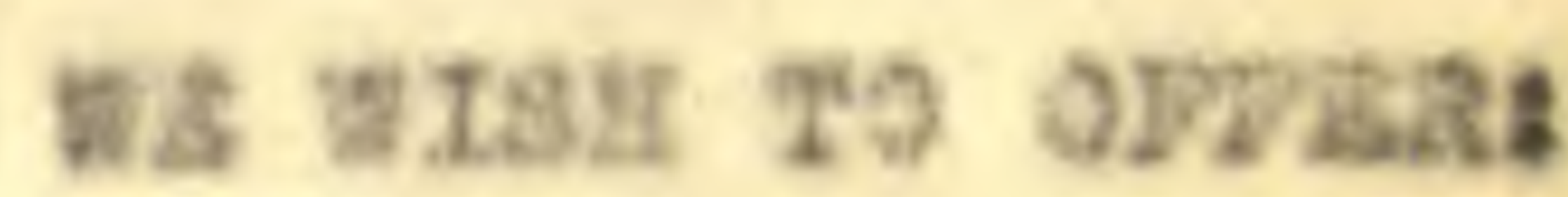

$117=48$, th $3 t_{0}$

Tow York $29, \mathrm{X}, \mathrm{X}$.

whan drdening plonso quote Rer "a16

atsoreaz, BOTARX

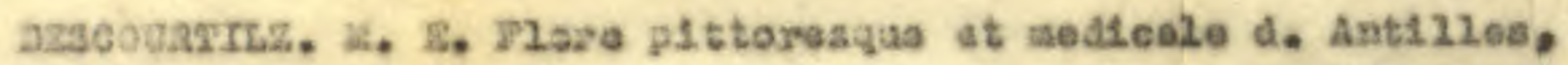

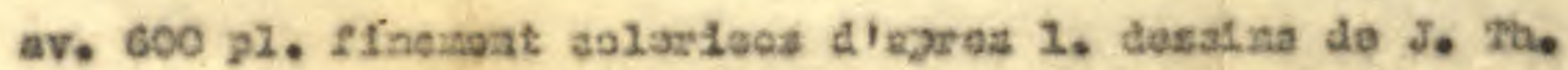

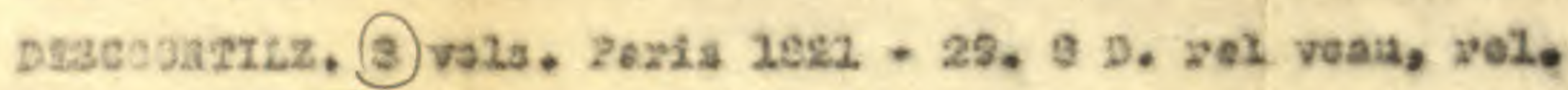

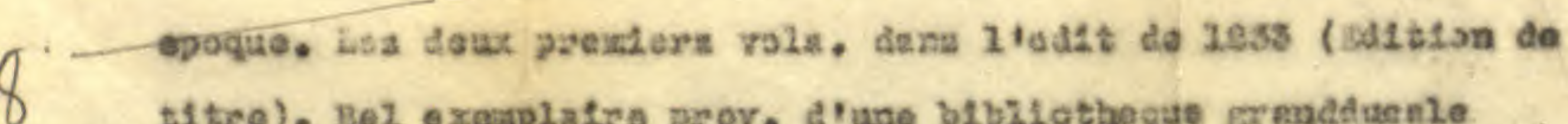

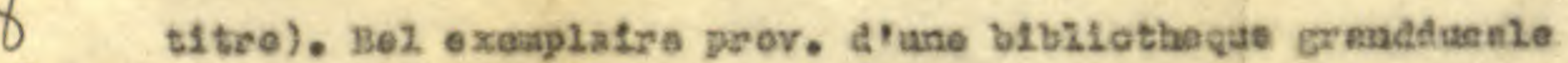

? nuase. Potite antaup, atat parfalt.

\section{Priee 9675.00}

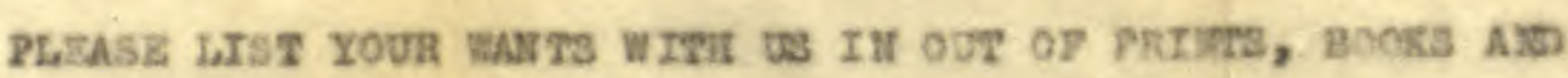

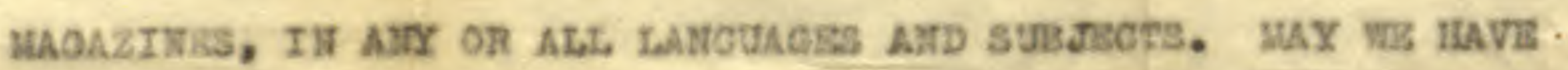

Your ORnsk.

accarding to pritgel we have thes edition ent there shemed be 8 vos. instead of Toree as bisted above - our set bought? 
FLORE MÉDICALE

DES

AN T I LLES. 


\section{3}

\section{FLORE MÉDICALE}

D E S

\section{ANTILLES,}

O U

\section{TRAITÉ DES PLANTES USUELLES}

DES COLONIES FRANCAISES, ANGLAISES, ESPAGNOLES ET PORTUGA ISES;

\section{P AR M. E. DESCOURTILZ...,}

Docteur en médecine de la facultí de Paris, ancten MÉDECIN DU GOUVERNEMENT A $S^{r}$.-DOMINGUE E'T FONDATEUR DU iYcée colonial, médecin de l'hospice civil de Beaumont ET MEMBRE DE PLUSIEURS SOCIÉTÉS SAVANTES;

\section{Qeinte par Y. Eh. Descourtilg.}

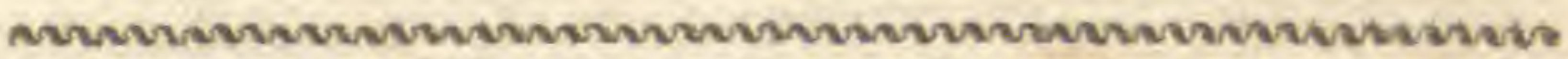

Le jus exprimé de la canne à sucre, celui du citron et reau limpide des ruisseaux qui serpentent dans tons les jardins, fournissent à l'instant une boisson salùtaire, qqu'une feuille fraîche et roulée du bananier ou qu'un pétale détaché de la popotte, peuvent retenir.... Partout dans ces climats fortunés, le Caraïhe tronrait sous ses pas, les plantes que réclamait la maladie d'un père, d'un parent ou d'un amil.... Ces insulaires avaient-ils d'autres moyens curatifs ?....

( Discouas PAÉLIMTIARB,)

Imperitissima gentes, herbas in auxilium vulnerum, morborumque noverunt. C. Cels, ad Præs.

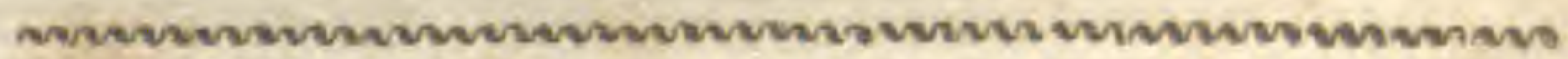

TOME PREMIER.

\section{PAR I S,}

Chez $\left\{\begin{array}{l}\text { Prchard, Libraire, quai Voltaire, no. } 21 ; \\ \text { Mme veuve Prchard, Libraire, quai Malaquais, no. 15; } \\ \text { Gauthier, au Cabinet littéraire de la Tente, Palais- } \\ \text { Royal, Galerie de Bois, no. } 197 \text {; }\end{array}\right.$

Et chez L'Auteun, rue Saint-Louis, au Marais, n, 16.

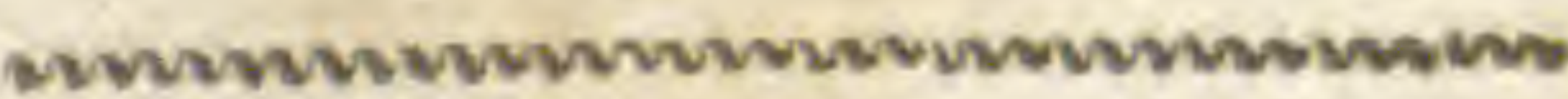

$182 x$. 
Ayant mis cet ouvrage sous la protection des lois, je déclare que je poursuivrai les contrefacteurs des exemplaires qui ne seront pas signés par l'Auteur.

Imprimerie de Vigor RENAUDIERE, rue des Saints-Pères, No. 10.

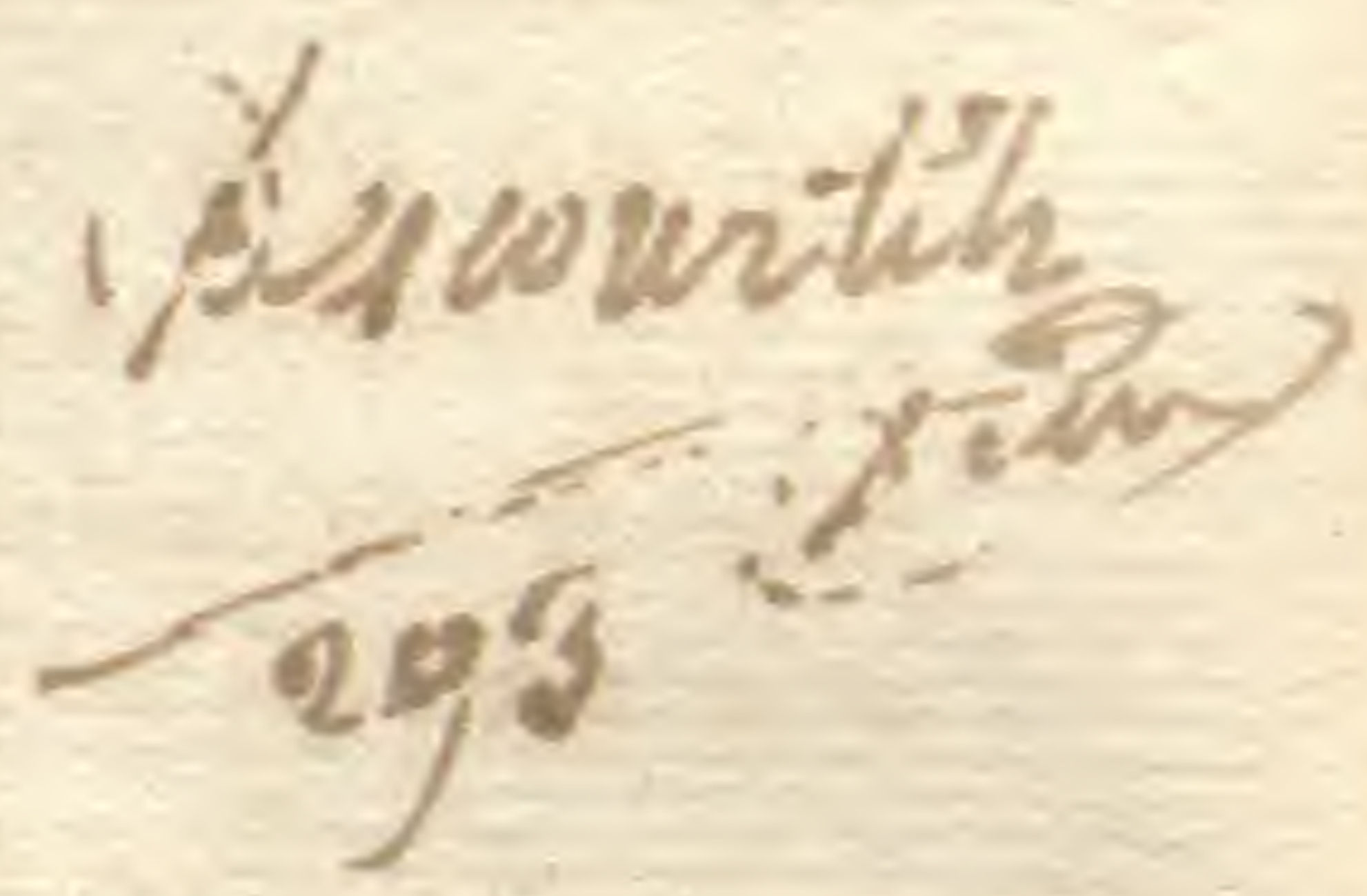




\section{DISCOURS PRÉLIMINAIRE.}

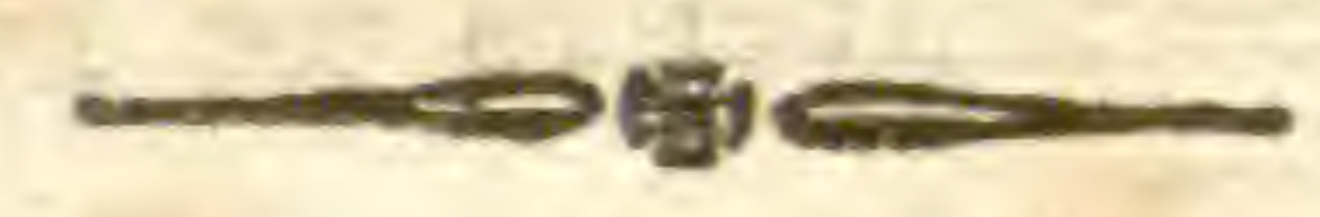

7) Dans les temps les plus anciens, on ne connut

» d'autre thérapeutique, que l'application des plan-

》tes, et l'usage de leurs sucs; c'est ce qui a

" fait dire, sans doute, que la botanique prou-

ग) vait que Dieu a fait naître, dans chaque pays, les

" plantes les plus nécessaires aux hommes et aux

》) animaux de ce même pays; et que par les plantes.

ग) qui se trouvent le plus communément dans un lieu,

》 on peut conjecturer, presque avec certitude, quelles

ग) sont les maladies qui y règnent le plus ordinaire-

》ment (1). ग

Ainsi, que l'on consulte l'expérience des siècles. passés, on voit que Salomon, Hypocrate, Gallien, Hérophile, Erasistrate, Asclépiade, Dioscoride, et grand nombre d'autres médecins illustres, ont. consacrés leurs veilles à étudier et analiser les plantes, et sont parvenus à y trouver la santé pour des hom-

(1) Mémoires de Trévoux, janvier 1702 , pag. 160.Pline, L. XXV. init. - L. XXVI. Sect. 6. - Théologie. phys, Liv. X, pag. 594,595 , et not. 25 . 
mes qui vivaient plus long-temps que nous, bien qu'ils commissent les mêmes excès, qu'ils fussent enclins à nos mêmes vices, et sujets à nos mêmes maladies.

C'est, guidé par ces lumières de l'antiquité, et les exemples de ces fondateurs de la médecine, que le docteur Mérat, marchant sur leurs traces, n'a pas hésité à dire : c Dans l'état actuel de la médecine, 》 un praticien éclairé qui posséderait bien sa matière ว) médicale indigène, pourrait rigoureusement se ग) passer des productions lointaines, et trouverait 》) autour de lui, de quoi remplir suffisamment les 》) indications que les phénomènes morbifiques lui ग) présentent journellement ( 1 ). ग

Mais il est à croire qu'en accordant une confiance aussi étendue aux substances qui peuvent composer la matière médicale d'un pays, ce savant de nos jours, n'a pas prétenda qu'il fallait la chercher dans la multitude des plantes qu'analise la chimie, et dont la nomenclature formerait un énorme dietionnaire que la curiosité feuilleterait peut-être avec plaisir, et que la mémoire verrait avec épouvante.

Fort du sentiment du célèbre Hoffmann, Mérat a reconnu la supériorité d'une thérapeutique végétale simple, sur les préparations chimiques les plus rares et les plus recherchées (2). Il a pensé avec $P_{\text {inel, }}$ ce patron cher aux enfans d'Epidaure, que « l'usage des remèdes simples, si conforme au bon

(1) Voy. Mérat, nouvelle Flore des environs de Paris.

(2) Médecine raisonnée ; Hoffmann. 
" goût et à une saine doctrine, a du moins l'avan》) tage de produire les effets les plus directs, et. 2) de ne point compliquerl'histoire d'une maladie(1).J. Si les animaux ont reçu en naissant l'instinct nécessaire pour découvrir dans les diverses régions qu'ils. habitent, des préservatifs ou des remèdes contre les maux auxquels ils sont exposés, Dieu n'a pas moins fait en faveur des hommes.

En effet, tandis que dans nos climats on a toujours vu le chien mâcher le chiendent pour rectifier ses digestions, ou se procurer quelques évacuations; qu'aux Antilles les ramiers mangent impunément les baies de l'Azédarach qui sont délétères pour l'homme; que les cabrits y recherchent les. tithymales, et les broutent sans en être incommodés; que les chèvres, d'abord agitées et furieuses, deviennent plus calmes après avoir pâturé de l'ellébore (2); que ces mêmes animaux bondissent sans cesse, et même ne peuvent se livren au sommeil lorsqu'ils ont mangé des graines de café (3); qu'en Egypte, on a vu l'ichneumon. aller chercher dans le Mungo l'antidote du venin du serpent dont il avait été piqué en le poursui-

(1) Pinel : Nosogr. phil., classe 1 re fièvres, t. 1, p. 104. et 105 .

(2) On sait que Mélampus, chargé de guérir de leur: frénésie les filles du roi Prétus, leur administra de l'ellébore.

(3) Un abbé en fit prendre à tous ses moines pour les: empêcher de dormir en psalmodiant. 


\section{(8)}

vant pour en faire sa nourriture; et que dans les solitudes des forêts équatoriales on a vu le cochon marron atteint par la flèche du Caraỉbe, ou le plomb de l'Européen, guérir sa blessure en la frottant avec la séve résineuse qu'il faisait couler de l'écorce du sucrier de montagne, vulgairement appolé bois cochon; l'homme né pour errer sur la terre et y vivre de son industrie, assujéti aux peines de la vie et à la fragilité de son existence, a été soumis à la nécessité de chercher des secours contre les maladies, et in en a déconvert la source salutaire dans les plantes qui se trouvaient à ses côtés (1).

Ce u'est pas l'arrivée des Européens aux Antilles qui a procuré au Caraibe des moyens curatifs pour tous ses maux; son instinct les lui avaii, depuis longtemps, fait connaître.

Ce n'est pas à l'établissement d'aučune officine, ou d'aacune pharmacie, que le vieux et robuste Africain doit sa force et sa santé; c'est à la découverte et à r'emploi des simples qu'il a reconnues propres à détourner de lui toute affecion morbin̈que.

(1) Quoiqu'un instinct particulier porte les animaux à bronter les plantes qui peuvent les guérir, ce serait une erreur de croire qu'un médecin botaniste dût se faire précéder, dans ses excursions, par des bêtes à cornes, ou par d'autres animaux à pâture, pour s'assurer de l'innocuité des simples; car telle plante peut convenir aux derniers, et devenir des poisons pour l'homme. Les animaux ont, dans ce cas, un avantage sur l'honme; c'est que l'instinct les détourne d'une plante vénéneuse, qu'ils savent éviter en pâturant. 
C'est pourquoi, si le simple usage de quelques plantes produit, chez les animaux, les effets les plus surprenans; si, imparfaite encore dans les mains de I'homme à demi-sauvage, la botanique usuelle opère de véritables prodiges, que n'a-t-on pas le droit d'en attendre, quand elle agit, perfectionnée par les études et les expériences de l'homme civilisé, du médecin surtout, obligé, par état, de la connaître dans toute son étendue, et, par honneur, d'en accroître la gloire?

La botanique est assurément une des connaissances les plus essentielles que doive ácquérir l'étudiant en médecine. Si le botaniste curieux passe de jouissance en jouissance en parcourant les bois et les prairies, en escaladant, non sans danger, les rochers des plus hautes montagnes, dans l'espoir d'y découvrir quelques plantes nouvelles; combien plus grande sera sa joie, si, médecin, il rencontre quelques simples dont la vertu médicale lui est connue, et dont il projette de faire usage en faveur de l'humanité souffrante!

La botanique n'attache pas seulement le médecin et le naturaliste; elle fixe aussi l'attention de l'agricole et du manufacturier. L'homme du monde luimême ne veut point être étranger à une occupation aimable qui charme les loisirs consacrés à la promenade, que cette étude rend attrayante et moins monotone. Combien cette science est agréable en Amérique, où la richesse de la végétation jette si souvent en extase ! La vue d'un sol émaillé des plus brillantes fleurs; l'aspect des arbres les plus majestueux des s forêts sombres et silencienses, où la hache ne s'est 
jamais fait entendre, et oú circule un air embaumé qui réveille les sensations; font succéder le plus souvent une douce et tendre mélancolie à une tristesse profonde ; ce qui rend les herborisations convenables aux hypocondriaques.

Jetez vos regards dans les bosquets enchanteurs des colonies : ici s'élèvent de majestueux palmiers, dont la cime déliée et ondoyante se balance dans les nues; plus loin le feuillage glauque des aloës et des ananas contraste avec le vert gai et éblouissant des plantes riveraines des ruisseaux qu'elles recouvrent en dôme, et dont on ne reconnaît la présence qu'à leur fraîcheur et à leur gazouillement.

Là d'immenses mapous, le baobab, et d'énormes. fromagers, à tronc droit et colossal, offrent au commerce et aux besoins de l'homme des canots d'une seule pièce, destinés à voguer surles mers, et à éprouver leur inconstance. C'est au milieu de ces belles. campagnes, sous un ciel d'azur, qu'on voit les colibris étincelans disputer aux oiseaux-mouches, qui bourdonnent sans se fixer, le nectar des fleurs suaves de l'oranger, du citronnier, du campêche, du jamboisier, du karatas, du frangipanier et de tant d'autres, tandis que certains oiseaux cherchent des produits du règne végétal plus avancés; et trouvent dans la pulpe de la caïmite, de la gouyave, de la cirouelle, du corossol et de la banane, de quoi les rafraîchir et les désaltérer.

Plus loin, de riches plaines cultivées s'étendent jusqu'à l'horizon bordé par des masses imposantes de montagnes mamellonées et verdoyantes à demi 


\section{(ii)}

perdues dans les nues. Des guirlandes de diverses conleurs unissent la cime des arbres à la terre, recouverte elle-même d'un tapis de fleurs d'or, d'azur et de pourpre.

C'est au milieu des Lagons, à Saint-Domingue, sur les bords des canaux de la rivière tranquille et profonde de l'Esterre, ombragée par des masses de bambous touffus, et formant de chaque rive des demi cintres de verdure, que j'aimais surtout à herboriser.

Le silence profond qui règne dans ces lieux agrestes, n'est troublé que par le chant de quelques moqueurs : les cris des crabiers et des aigrettes, ou le roucoulement des tourterelles, qui arrivent des savanes brûlées pour étancher leur soif ardente.

Ce fut probablement au milieu de ces réduits champêtres que les premiers insulaires cherchèrent des secours contre leurs maladies, dans des végétaux vers lesquels une impulsion naturelle les dirigeait; les plus rusés d'entre eux s'arrogèrent un titre qui les élevait au dessus de la foule : e'est ainsi que de pâtres ou hattiers, on les traita de médicastres ou makendals, jusqu'à l'instant où des voyageurs instruits s'emparèrent de ce domaine de la science.

Oui, la botanique peut, elle seule, mettre l'homme à même d'utiliser les ressources qu'offre partout à l'art de guérir la bienfaisante nature. Il serait honteux qu'à l'inspection d'une plante dont il aurait prescrit l'usage, le médecin (d'une campagne où il ne se rencontre pas de pharmaciens ) ne pût assigner à ce végétal un nom, une classe, une famille, un genre. $\mathrm{Et}$, pour le médecin de ville, quoi de plus dange- 
reux et de plus humiliant, que de se trouver, par son ignorance, hors d'état de relever une erreur, ou de rectifier une méprise de l'apothicaire ou de l'herboriste (1)?

Le médecin qui veut l'être utilement, doit étudier les prinoipes de la botanique, apprendre à assigner à chaque plante les propriétés que l'expérience lui a reconnues. Sans la première de ces connaissances, la seconde lui serait inutile : que lui servirait, par exemple, de savoir que la pariétaire est une plante émolliente, s'il ne connaît pas la pariétaire? « Il y 》) aurait moins d'inconvéniens, dit avec raison Mérat,

》 qu'un médecin ne ŝut pas un mot d'anatomie, que ग) s'il ne connaissait pas les végétaux dont il fait un 》) usage journalier. »

Mais dans cette botamique, si utile lorsqu'on en connaît bien les propriétés, le mal existe à côté du bien, comme les plantes vénéneuses à côté des plantes salutaires (2). L'orgueil scientifrque eut assez de vains mots, des mots purement techniques, pour exprimer de prétendues connaissances qui ne se rattachentqu'aux

(1) De erroribus in pharmacopolis ex neglecto studio botanico obviis (M. Alberti), Diss. in-4.0, Halet, 1733.

(2) Le québec vénéneux offre dans sa racine l'antidote de son poison. Le manioc mortifere, après l'extraction du suc de sa racine, donne un aliment sain et agréable! Ah! pourquoi toujours refuser au Createur le tribut des hommages qu'on ne craint pas de décerner à l'homme, en oubliant la bonté du Tout-Puissant! cependant eminet in minimis, maximus ipse Deus: 


\section{$\{13\}$}

descriptions, sans rien fixer par rapport à l'application. Négligeant les préceptes des grands maîtres, les botanistes obligent le savant $P_{A R}$ M ENTIER à leur adresser l'invitation de « diriger constamment leurs re2) cherches vers le bien public, et de faire en sorte sur》) tout que la botanique ne soit pas dans leurs mains 》) une vaine nomenclature ( 1 ) ; ils forcent M. ALIBERT à leur rappeler que crl'art de concourir aux pro》 grès de la thérapeutique ne consiste pas à accroître 2) le nombre des plantes qu'elle emploie, mais à étu» dier convenablement leur mode d'action sur l'éco》 nomie animale (2), " C'est dans cette même conviction, que Fourcrox, ce chimiste, non moins illustre qu'amateur zélé de la science, n`hésita pas à publier que « l'art de formuler est malheureusement ») une affiche dans laquelle le médecin a trop sonvent 》) l'intention manifeste de montrer son érudition, sa 》) science, ses grandes ressources. Plus la médecine » s'est éloignée de sa première simplicité, dit-il, plus 2) l'art de formuler s'est étendu, s'est compliqué. Il 2) est donc la preuve de la décadence de l'art de guérir » ou de son incertitude (3). »

D'après ces autorités respectables, d'après l'expérience de l'homme primitif, qui pourrait révoquer en doute que la médecine la plus naturelle est celle

(1) Parmentier, Code pharmaceutique, pag. 195.

(2) Alibert, Nouv. Élem. de Thérapeut., tom. II, pag. 499.

(3) Fourcrox, Encyclop. Métho. p. o. Mat. 
que l'on tire du règne végétal ? Les plantes ont besoin de peu d'apprêts, tandis qu'il faut aux minéraux les secours de la chimie. L'animal, l'homme de la nature rencontrent dans le premier champles plantes capables de les guérir; tandis que, faute de connaître celles des pays où ils exercent, certains praticiens ignorans ou routiniers, formulent l'ambre-gris'on le castoréum préférablement à la valériane et au tilleul qui ont les mêmes propriétés.

Les avantages de la botanique en général, et de l'étude des matières médicales pour toutes les parties du globe ainsi reconnus, il m'a été facile de concevoir le plan de celle des Antilles, que j'ai habitées pendant six ans, et qui me sont devenues chères par les connaissances botaniques que j'y ai acquises, et par les expériences que j'y ai faites. C'est au soulagement deleurs habitans que j'ai dû principalement consacrer la flore que j'ai recueillie chez eux. Heureux si la science y trouve, dans quelques plantes inconnues encore, des avantages pour elle et des remèdes véritablement convenables à des hommes nés sous un autre hémisphère!

Mais, pour faire sentir l'utilité de cette Flore médicale des Antilles, il me suffira peut-être de rappeler combien Poupée-Desportes, ce médecin dontle souvenir est encoresi cher aux colons, insista surla nécessité d'un Traité des plantes usuelles des colonies, surtout si ce Traité était accompagné de. dessins; mais Poupée-Desportes n'est pas le seul qui ait songé au bienêtre des colons dont l'éloignement n'a altéré en rien leur amour pour la mère-patrie, Gilbert, dans son 
Histoire médicale de l'armée de Saint-Domingue, publiée en l'an X, partage la même opinion.

c Le médecin, dit-il, doit toujours s'occuper à

»Saint-Domingue de la substitution des médicamens

ग) indigènes aux exotiques, ceux-ci parvenant fort

נ) rarement ou fort difficilement dans la colonie, en

3) temps de guerre surtout : il est donc important

3) qu'il connaisse assez la botanique usuelle, pour

2) être en état dé faire des substitutions bien enten-

ग dues. 》

On publie tous les jours des traités sur les plantes usuelles d'Eurape : celles des Antilles seraient-elles abandonnées et mises en oubli? Les colonies nous seront-elles toujours étrangères? Les possessions françaises y seront-elles toujours envahies? Dans tous les cas, ne seront-elles pas désormais habitées par des peuples civilisés qui sauront tonjours accueillir avec reconnaissance des ouvrages où l'étude et fla pratique déposant le fruit de leurs veilles, leur auront préparé des objets de jouissance ou d'utilité, et leur indiqueront des préservatifs et des remèdes pour les maux auxquels il sont assujétis?

Nul autre pays, plus que les Antilles, n'offre à l'homme, dans l'état de santé, plus de plantes et de fruits destinés à la lui conserver, ou quand il l'a perdue, plus propres à la lui rendre. $\mathrm{Nul}$ pays par conséquent, n'est plus digne d'une Flore médicale particulière.... Ici, pour étancher la soif excitée par les feux de la Zône-Torride, la feuille du bananier ou le pétale pourpré de sa popotte se roulent pour porter aux lèvres desséchées l'eau limpide qui ser- 
pente dans tous les jardins, et dans laquelle on a exprimé le jus rafraîchissant du citron et celui de la canne à sucre. Là, le tamarin, l'oranger, la grenade, apaisent ces exaltations des systèmes produites par la chaleur, et qui conduisent aux fièvres angéioténiques ou ataxiques. Partout dans ces climats fortunés, le Caraibe trouvait sous ses pas la plante que réclamait la maladie de son père, d'un parent, d'un ami ! Ces insulaires avaient-ils d'autres moyens curatifs?

Combien de fois j'ai vu dans l'épidémie meurtrière de la fièvre jaune, des mulàtresses arracher à la mort tous ceux qu'elles traitaient par l'emploi des plantes indigènes, ou par les procédés du pays. J'ai obtenu. d'une de ces mulâtresses renommée dans les mornes des Escaliers (Saint-Domingue), par des eures qui tenaient du prodige, des recettes dont j'ai fait usage avec le plus grand succès après des rectifications convenables ( 1 ).

(1) Reléguée dans un rocher caverneux où elle donnait clandestinement ses consultations, depuis la mort de sa mère, elle semblait avoir hérité de sa routine, et adopté son genre de vie; elle ne sortait de son antre qu'avec regrets, pour se glisser et fureter au travers des lianes qui recouvrent les précipicẹs, afin d'y recueillir les simples dont elle composait ses divers remèdes. Six petites chaudières, quelques vases d'argile grossièrement faits, formaient son modeste laboratoire. Douée d'un tact naturel, qu'on ne peut acquérìr, pas même par l'étude, qui ne fait que le diriger et le perfectionner, je lui ai vu 
J'ai dû à un mulâttre, également célèbre dans les mangles des Gonaïves, la découverte d'un canton d 1 Port à Piment où croissent les simples les plus précieuses, et entre autres le mercure végétal (Lobelia) l'un des plus puissans antisyphillitiques. Je me suis enfin trouvé à Saint-Domingue, dans un moment oú, manquant de drogues pharmaceutiques, les médeeins furent obligés de recourir aux ressources du pays, et de remettre les malades entre les mains des naturels, en employant leurs recettes. Je dois à la justice de dire que nous n'avons eu qu'à nous applaudir de cette innovation, quò natura vergit, è̀ ducere opportet.

C'est ainsi que dans les colonies, les chirurgiens des armées ont remplacé, pour le pansement des vésicatoires, la feuille de bette par celle du bananier, les bandes, par celles du latanier, les attelles flexibles par les tâches du palmiste. C'est d'aprés l'examen le plus scrupuleux des recettes obtenues des naturels qu'on prescrira dans les fièvres bilieuses les limonades aux citrons, anx tamarins, à l'oseille de Guinée; dans les phlegmasies muqueuses, les

opérer des cures merveilleuses : aussi discrète que méfiante, je ne pouvais obtenir d'elle aucuns renseignemens; cependant au moyen du léger sacrifice de dessins de plantes de l'artibonite, qu'elle convoitait, j'obtins plusieurs formules que je corrigeai, et dont l'usage fut couronné des résultats les plus satisfaisans. Tous les peuples ont des guérisseurs. (Voyez, le mot Femme. Dict. des Sc. Médic, , tom. XIV, p. 654.) 


\section{( 18 )}

adoucissans mucilagineux, tels que les fleurs du gombo (Hibiscus esculentus, Linn.) qu'on peut sulstituer avec avantage aux guimauves et au lin d'Earope.

On emploiera avec fruit, selon Gilbert, pour la composition des apozèmes apéritifs la chicorée sauvage, la racine de patience, le cresson de savane, et l'on rendra ces boissons laxatives en y ajoutant de la casse ou de la pulpe de tamarins.

La classe des purgatifs offrira le coccis (Ruellia); la liane à Bauduit (Convolvulus scamonia) le croton médecinier (Jutropha carcas); le ricin, le pois à gratter (Dolichos pruriens), purgatifs vermifuges, etc.

On pourra composer la tisane commune avec les feuilles et les tiges du réglisse du pays (Abrus pre. catorius); les boissons rafraîchissantes ou tempérantes avec la chicorée blanche du pays (Lactuca $C a$ nadensis), les épinards sauvages (Amarantus oleraceus), le laman (Solanum ?...) les boissons rafraîchissantes acidulées avec toutes les parties de l'alléluia (Oxalis acetosa), l'oseile de Guinée (Ketmia sabdarifera, Linn. ).

On appliquera avec succès les propriétés vulnérairesdel'herbeàblé(Saccarum vulnerarium, Tussac); du thé de Saint-Domingue (Capraria biflora), de l'herbe à plomb (Lantana camara). Chaque classe, en un mot, renferme les analogues d'Europe, par exemple, la verveine (Verbena Jamaicensis), le manioc fraîchement rapé ( Jatropha maniot), les deux absinthes du pays (Parthenium histerophorus et ambrosia artemisifolia) employées en cataplasmes, 


\section{(19)}

fournissent d'excellens résolutifs. Ces deux dernières plantes sont des amers dont l'usage intérieur, en infusion, ne peut qu'être avantageux lorsque les circonstances l'exigent.

Les cataplasmes maturatifs se composent avec la mantègue et les oignons du lys indigène (Pancratium caribceum, Linn.) ou la feuille de raquette ( $\mathrm{Cac}$ tus opuntia) ou celles du cacte à cochenille (Cactus coccifera) plus faciles à employer parce qu'elles sont sans épines.

Les plaies récentes se pansent heureusement, avec le suc du Karatas (Agave); des bains de Guildive ont opéré souvent des miracles dans les paralysies et les affections rhumatismales chroniques. Le savon noir et le tafia forment un liniment avantageux dans les mêmes circonstances. Les fumigations de graine de coton (Gossipium) présentent un fondant d'une efficacité éprouvée dans les tumeurs blanches indolentes.

Les bols toniques se composent sur-le-champ avec la limaille de fer, l'écorce de citronier en poudre, et un sirop simple.

Les bols et opiats fébrifuges peuvent se faire avec les écorces fines du citronier, de l'oranger, les fleurs desséchées de la poincillade (Poinciana putcherrima) et le quinquina (Cinchona caribcea). L'infusion théiforme du café (Cofea arabica) est un tonique très-recommandable. La graine de sapotille (Achras sapota, Linn.). Celle du ooli ( $\mathrm{Se}$ samum orientale, Linn.) et la racine d'herbe à

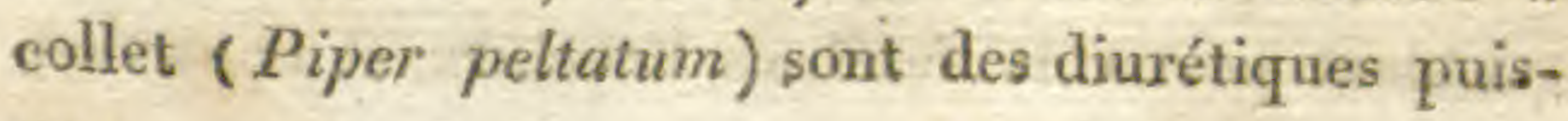
sans. 


\section{(20)}

Les feuilles du ricin (Ricinus palma-christi) trempées dans du vinaigre froid, et appliquées sur le front et la tête, sont un réfrigérant puissant dans les céphalagies occasionnées par l'action solaire, ou tout autre transport trop vif da sang vers le cerveau. Elles excitent une transpiration très-abondante de la partie sur laquelle elles sont appliquées.

'Toutes les prescriptions qui m'ont paru rentrer dans mon sujet, sont du docteur Gilbert, à l'humanité duquel il m'est bien doux de rendre ici hommage pour le zèle et le courage qu'il n'a cessé de déployer, en exposant ses jours au milieu des dangers et des affreux ravages de la fièvre jaune.

Cependant, pour ne pas assigner au hasard les propriétés des simples, trois de nos sens doivent concourir à l'analise d'une plante à laquelle on suppose quelque vertu médicinale, la vue, le goût et lodorat. Il ne faudrait pourtant pas décider des propriétés de cette plante à sa seule inspection, car on pourrait tomber dans des erreurs funestes, ou faire revivre des préjugés ridicules, La famille des orchidées, par exemple, offre des espèces nuisibles à l'économie, et d'autres dont elle peut tirer beaucoup d'avantages. On a cru long-temps queles bulbes du satyrion ayant beaucoup de ressemblance avec les testicules de l'homme, cette espèce devait être évidemment aphrodisiaque ou stimulante de l'organe sexuel masculin, mais l'expérience a fait jus* tice d'une semblable absurdité. Il n'en est pas de même des plantes à feuillage terne et villeux, qui semblent porter le deuil de la nature et le eachet de la réprobation. 


\section{(21)}

L'odorat peut occasionner de semblables méprises, quoique l'organe olfactif semble interdire les plantes dont l'odeur est vireuse, et recommander au contraire les simples aromatiques, comme douées de vertus propres à fortifier les systèmes.

Le goât paraitrait devoir être un guide plus sûr à suivre. A la dégustation d'une plante, nos organes excités nous avertissent qu'elle est àcre, acerbe, astringente, volatile, acide, ete., et nous commençons alors à présumer quelle est sa propriété ; car les plantes aromatiques chaudes sont le plus souvent sudorifiques, fébrifuges et toniques. Celles volatiles et piquantes sont estimées errhines, céphaliques et antiscorbutiques; celles âcres sont réputées corrosives, tandis que les amères aromatiques sont toniques et vermifuges.

La décomposition chimique altérant les corps, nous ne pouvons avoir, par ce moyen, qu'une idée superficielle des parties constituantes; il n'y a donc que l'expérience, ou plutôt l'administration de ces plantes dans les maladies qui offre un résúltat fixe et certain. Ergò experientiä medicus. C'est pourquoi il ne suffit pas d'une seule application de la vertu de la plante pour statuer irrévocablement sur sa propriété ; car souvent elle aura été administrée au moment des efforts de la nature pour rétablir l'équilibre chez le sujet malade, mais il faut en répếter l'emploi dans les mêmés circonstances, et à des époques différentes de la maladie.

Je me suis bien gardó d'adopter, pour ma Flore médicale des Antilles, la classification par oxdre 


\section{(22)}

alphabétique, j’ai préféré ranger les plantes d'après leurs propriétés incontestables ; mais j'ai adopté le système le plus généralement reçu. L'ordre alphabétique présente une nomenclature informe de plantes quin'ont aucun rapport entre elles, quant aux vertus dont la nature les a pourvues; avec ce vice de coordonation, chaque description historique est isolée, et n'offre aucune connexion avec la plante qui la précède et celle qui la suit.

Ce mode de nomenclature, où les plantes de toutes les classes se trouvent confondues, et qu'il faut. posséder à fond pour en tirer parti, au lieu d'éviter des recherches dans un danger pressant, embarrasse, suspend même souvent la décision, entrave la formule du médecin qui exerce dans un climat nouveau pour lui, s'il n'en connaît pas encore les plantes usuelles.

Un praticien, par exemple, arrive d'Europe aux Antilles : il est appelé pour traiter une péripneumonie, au commencement de laquelle les mucilagineux doivent être prescrits; qui lui dira que le gombo peut être substitué à la graine de lin, les fleurs de l'urène à celles de la molène? Survient-il une hémorragie? il veut recourir aux astringens? Si la première plante qu'il emploie n'opère pas assez puissamment, et qu'il veuille lui en associer une autre de la même classe, mais dont les vertus soient plus héroïques, ira-t-il perdre un temps précieux à compulser un vocabulaire pour trouver cette analogue dont il a besoin sur-le-champ, et qui s'offrirait d'elle-même si ces plantes étaient rangées par classes? Au contraire, à 


\section{( 23 )}

eôté de la mauve adoucissante, l'ordre alphabétique lui présentera le perfide manceniller, et que si c'est un amer qu'il doit ordonner, après l'absinthe il rencontrera l'ahouai (1).

J'ai cru devoir, pour éviter cet inconvénient, ranger les plantes de ma Flore d'après leurs propriétés et l'action directe ou indirecte qu'elles exercent sur nos organes : j'ai cru devoir encore indiquer succinctement, en tête de chaque article, les caractères distinctifs de chaque plante, afin de ne pas surcharger la mémoire de phrases didactiques de plusieurs auteurs qui souvent se contredisent, et qui, pour faire parade de leur érudition, altèrent le véritable type de la plante par des détails trop nombreux. J'ai porté l'attention jusqu'à désigner, autant que possible, les parages où les plantes se plaisent à végéter dè préférence, parce qu'il m'a semblé que c'était faire connaitre aux amateurs de leur culture, la nature du sol qui leur convient. J'ai dû enfin, pour prouver ma serupuleuse exactitude dans une matière aussi délicate qu'une thérapeutique indigène, stipuler les doses auxquelles il faut les employer, et le mode de les préparer.

Dans une pinte d'apozème, par exemple, les racines se prescrivent par once, les bois et les écorces

(1) Je suis loin de vouloir critiquer ici la classification de la Flore du Dictionnaire des Sciences médicales, puisque c'est seulement par ce mode de classification, qu'on pouvait ranger les plantes indiquées dans claque volume: par leurs lettres initiales. 


\section{(24)}

par demi-once, les fruits doux par le nombré, et lés aromates par vingt grains.

J'ai consulté, pour ces indications médicales, plusieurs autêrs de pharmacopées américaines parmi lesquels brillent les noms de Plumier, de Nicolson, de Poupée-Desportes. J'ai eu, sur cet objet, des conférences avec M. Daubertès, chirurgien-major de l'hôpital militaire de la Providence au Cap (SaintDomingne ), naturaliste zélé, mais encore plus instruit; avec MM. Monier, médéein en chef des hôpitaux du Port-au-Prince, Clemenceau, Sai, Bouilli, chirurgiens des hôpitaux de Saint-Mare, et autres qui méritent les plus grands éloges pour leurs travaux assidus, et leur zèle constant à braver la chaleur excessive du clinıt, à l'époque reculée où la science y était eneore à son berceau. J'ai répété moi-même dans les hôpitaux confiés à mes soins, les observations de ces illustres praticiens ; et dans cet ouvrage que tous ont désiré, je n'ai tenu compte que des espèces qui leur étaient familières, et dont ils avaient éprquvé les propriétés.

Outre que ma méthode rend plus facile la recherche des analogues, elle convient, je crois, à tous les systèmes ; car on reconnaît généralement aux plantes des vertus purgatives, béchiques, errhines, sialalogues, toniques, etc. J'ai d'ailleurs, pour moi, les conseils et les exemples des grands maîtres de l'art, Geoffroi, Linné, Chomel, et plus récemment encore Murrai, Spielmann, Alibert, Hildenbrand, Schwilgué, Swiédaur, tous observateurs exacts et profonds, qui, en rappelant la science à ses vrais 


\section{(25)}

principes, ont adopté ce mode d'organisation méthodique.

On a dit beaucoup de mal de l'histoire des plantes usuelles de Chomel, dont pourtant la méthode didactique est fondée sur l'expérience, et non sur des conjectures. Il est vrai qu'on peut lui reprocher parfois de l'exagération, et mêmequelques erreurs quant aux vertus imaginaires qu'il accorde à certaines plantes sur la foi d'auteurs qui l'avaient précédé : mais Chomel vivaitdans un temps où la saine philosophien'avait point encore éclairé la science de sa judicieuse critique. Au reste, ses succès dans la thérapeutique prouvent en faveur de son livre. Pourquoi ne point respecter la mémoire de ce médecin studieux, et lui imputer des ridicules, parce qu'il n'est plus un auteur de nos jours?....

L'ouvrage de Chomel ne m'a pas été d'une grande ressource, celui de Poupée-Desportes avait plus de rapport avec le mien, et quoique les recettes polypharmaques de ce médecin soient en général trop prolixes et trop surchargées, j'ai profité cependant de ses heureuses découvertes, et des expériences qu'il fit pendant trente ans aux Antilles, dans une pratique dont les succès font le plus bel éloge.

J'ai également puisé aux sources de plusieurs autres médecins, recommandables et véridiques dans leurs malheurs comme dans leurs succès. J'y ai recueilli des faits propres à justifier mes observations cliniques particulières.

En adoptant ce mode de classification, je me suis toutefois attaché à garder un juste milieu entre la bo- 


\section{(26)}

tanique thérapeutique des anciens, et celle purement descriptive de nos jours. A l'époque où la science était encore éloignée de l'état de perfection auquel l'ont élevée des botanistes vraiment passionnés pour elle, on avait une crédulité aveugle pour les vertus de certaines plantes; on exaltait bénévolement leurs propriétés: aujourd'hui, on tombedans l'excès contraire; on n'écrit plus l'histoire des plantes que pour les décrier, que pour leur refuser des avantages mille fois confirmés par l'expérience. Cependant ces mêmes détracteurs feront-ils la médecine sans l'auxiliaire des plantes qu'ils semblent mépriser et condamner impitoyablement à l'oubli? comme s'il y avait quelque chose d'inutile dans la nature! En vérité, cette dénégation est une ingratitude marquée pour les soins paternels de l'Auteur de toutes choses! Quis ut Deus !

On cite encore avec vénération Hippocrate en médecine, Ambroise Paré en chirurgie; leurs traitemens sont approuvés, et on se refuse à reconnaître les propriétés des plantes dont ils ont recommandé l'étude et l'usage. On enrichit la langue française d'une multitude d'expressions grecques d'une nouvelle composition, et on rejette avec mépris les mots tirés de la même langue, parce qu'ils sont anciens. Un souris sardonique erre sur les lévres de nos nouveaux docteurs, à la seule prononciation des mots ophtalmiques et hépatiques qui désignent, d'une manière si précise, les plantes destinées à combattre les affections des yeux et celles du foie; tandis que, par un caprice inconcevable, ils s'extasient en entendant les 
mots non moins anciens, céphalalgie, hydrophobie, qu'ils n'ont point encore exilés du domaine de la science, et tandis aussi que ces érudits du moment se prosternent devant les mots azote et hydrogène, parce que ces mots sont de leur création. On va plus loin, on proscrit des mots devenus essentiellement français, par un usage qui remonte à l'établissement de l'art en France, et pourtant on ordonne chaque jour des potions stomachiques dans lesquelles entre l'eau de menthe; d'autres antispasmodiques dans lesquelles on formule l'eau de tilleul. Pourquoi donc ze pas conserver en tête des classes où on range ces végétaux, ces dénominations expressives et simples qui indiquent si bien leurs propriétés? encore si les noms nouveaux exprimaient des idées plus claires, plus positives! certes ce n'est point par une semblable réforme que la science a fait des progrès.

De nos jours M. Virey, d'accord avec les plus célèbres médecins de la capitale (1), en tonnant contre tous ces novateurs minutieux et scrupuleux à l'excès, qui sont plutôt, dit-il, les détracteurs que les prosélytes de la science; ne reconnaît-il pas également aux plantes, des propriétés directes et indirectes sur nos organes (2)? C'est donc à tort que certains néologues refusent aux plantes des propriétés sanitaires que plu-

(1) Mot botanique du Nouveau Diclion. d'Hist. nat., t. ... pag. $17^{8}$.

(2) Voyez, Bulletin de Pharmacie, mai $1813, n^{\circ} .5$, pag. 192 et suivantes. 


\section{(28)}

sieurs siècles leur ont méritées, et qu'ils les regardent comme superflues dans la nouvelle pratique de la médecine, en outrant leur inutilité. Certes, on fera une différence énorme dans l'administration interne ou externe des euphorbes avec les guimauves, de la bryone avec la tanaisie, de la sauge avec les graminées : emploiera-t-on l'huile caustique de la noix d'acajou dans un collyre? relevera-t-on les forces languissantes de l'estomac avec la molène, au lieu d'employer l'absinthe et le quinquina? Le papayer, la cévadille, et autres vermifuges héroïques, n'aurontils pas la préférence sur le feuillage inerte et insipide du bambou? Je sais qu'il fautêtre circonspect, avant de prononcer sur les vertus d'une plante; mais quand un usage journalier en a démontré les avantages, on ne peut déclamer contre, sans être accusé de pyrrhonisme.

Je sais que toutes les plantes n'ont pas de propriétés bien reconnues, et je suis loin d'épouser les erreurs et les préjugés du peuple qui attribue, par exemple, à la melisse, cueillie avant le soleil, le pouvoir des philtres amoureux. Ne soyons donc pas exclusivement enthousiastes d'un système aux dépens d'un plus nouveau, etécoutons les auteurs célêbres qui savent conserver aux végétaux des propriétés qu'on ne devrait pas leur refuser. Si l'on ne peut douter en Europe de celles de la bardane, de la patience, de la scabieuse, de la pensée sauvage, qu'on recommande sans cesse comme toniques et dépuratives, oubliera-t-on aux Antilles les services que rendent tous les jours la salseparcille et le gayac? refusera-t-on à la moutarde ses 


\section{(29)}

qualités errhines et sialalogues, ou, si l'on veut, irritantes, puisqu'on l'emploie sans cesse dans les sinapismes?

Qu'on appelle poudres irritantes, an lieu de poudres errhinesle tabac, l'ellébore, etc., que m'importe, c'est une guerre de mots, car si je veux agacer la membrane pituitaire et provoquer l'éternument j'emploie le tabac; on refuse à l'origan, au serpolet, au thym, à la marjolaine, le nom de plantes céphaliques, et j'observe qu'on les indique néanmoins de préférence dans les affections de la tête, dans les céphalalgies catarrhales, et lorsqu'il s'agit de porter à la peau. Le mot céphalique indique le siége des maladies auxquelles elles conviennent plus particulièrement, ne vaut-il pas bien celui banal de stimulante ou de tonique...?

Pour moi je souris de pitié quand j'entends un étudiant, porteur d'appareil à pansemens, répéter, comme un perroquet, il n'y a plus de plantes vulnéraires! et comment, ignorant présomptueux, nommerez-vous donc celles qu'on emploie dans les décoctions qui servent à panser les blessés ? allez, si vous l'osez dire à un praticien consomméde Charleston, que le polygala n'est plus un alexitère; quaud celui-ci l'a cent fois employé avec succès contrela morsure du serpent à sonnette (crotalus horridus. Lin.), allez soutenir à un Martiniquais ou à tout autre habitant des Antilles que le sucrier de montagne (bois cochon) n'est plus un vulnéraire, quand cette propriété lui a fait donner le nom de l'animal qui le premier la lui 


\section{(3०)}

a reconnu (1); mais c'est assez combattre des abus aujourd'hui trop accrédités pour que ma voix soit entendue. Toutefois le nouveau système, abstraction faite de ses dénominations, me paraît préférable à l'ancien, puisqu'il évite la confusion des principes.

N'ayant point l'intention de fronder l'opinion des savans médecins qui ont écrit sur la matière médicale, f’ai cru devoir marcher après eux dans la carrière qu'ils m'ont ouverte. Cependant, malgré tous mes soins, je dois m'attendre que ma nomenclature trouvera des critiques, peut-être même des détracteurs; car tel voudrait qu'on parlât uniquement des plantes

(1) Certes, j'accorderais plus de confiance à certaines mulâtresses exercées par une longue pratique et beaucoup d'assiduité dans les hôpitaux, qu'à certains médicastres imberbes que la mer vomit quelquefois sur les plages de nos colonies. Il ne débarque que trop souvent aux Antilles, de ces êtres impudens, ineptes et dangereux qui n'ont fait d'autres études que celles d'observations superficielles pendant le court trajet de leur traversée en servant d'infirmier au chirurgien d'un bâtiment marchand, qui souvent n'a pas eu un seul malade à traiter. Néanmoins, ces parasites, en mettant le pied à terre, osent se munir d'un lancetier, et les voilà en exercice!!! Ainsi de l'art le plus noble et le plus précieux à l'humanité, ils en font, par les abus qu'on y tolère, un art dérisoire et méprisé. J'ai cité dans mes Voyages d'un naturaliste (Paris, 1809 , chez Dufart.) plusieurs de ces traits d'une impéritie coupable, qui ont coûté la vie à des malhenreux $23 \mathrm{sez}$ aveugles pour confier leur existence à de semblables empiriques. 


\section{(3i)}

usuelles; tel autre demanderait plus de détails botaniques; celui-ci ne reconnaît de propriétés qu'aux plantes de son petit répertoire; celui-là que celles dont il a chargé ses formules; un autre encore s'imagine avoir trouvé une panacée dans une espèce jusqu'alors inconnue; le paysagiste enfin désirerait qu'on donnât le port de chaque arbre indépendamment des détails botaniques de grandeur naturelle.

La thérapeutique d'Alibert et le manuel médical de Nysten, m'ont particulièrement servi de guides dans la nomenclature que j'ai adoptée. Voici donc comzaent j'ai cru devoir diviser mes classes.

\section{LA $1^{\text {Te }}$ CLASSE TRAYTE}

Des plantes qui excitent la tonicité du système des voies digestives : elle comprend,

10. Les stomachiques aromatiques.

$\begin{array}{lll}2^{\circ} . & i d . & \text { amères fébrifuges. } \\ 3^{\circ} . & i d . & \text { antiscorbutiques. } \\ 4^{\circ} . & i d . & \text { vermifuges. } \\ \text { 5.. } & i d . & \text { astringentes ou styptiques: }\end{array}$

\section{LA 2e. CLASSE}

Des plantes qui agissent sur la moitilité ou contractilité musculaire de l'estomac: elle renferme les plantés purgatives Émétiques. 


\section{LA 3e. CLASSE}

Des plantes qui agissent sur la moitilité ou contractilité musculaire du canal intestinal, en irritant la membrane muqueuse : elle réunit,

10. Les purgatives laxatives.

$2^{\circ}$ id. cathartiques.

3o. id. drastiques.

$4^{\circ}$. id. hépatiques.

\section{LA $4^{\text {e. CLASSE }}$}

Des substances végétales qui peuvent agir sur l'estomac ou le canal intestinal, par leurs qualités vénéneuses ou médicamenteuses : telles sont les

$1^{\circ}$. Plantes toxiques corrosives.
$2^{\circ}$ id. $\quad$ narcotiques.

\section{LA 5e. CLASSE}

Des substances végétales réputées, aux Antilles, propres à servir d'antidotes aux poisons pris intérieurement : elle renferme les plantes dites ALEXitìnes INTERNES.

\section{LA Ge. CLASSE}

Des végétaux possédant la vértu de neutraliser les effets délétères par morsure ou piqûre, des poisons externes sur les propriétés du système Dermoïde : telles sont les anțivénÉneuses NeUtralisantes. 


\section{LiA $7^{e}$. CLASSE}

Des substances végétales qui agissent d'une manière directe ou spéciale sur les propriétés vitales des voies urinaires. De ce nombre sont les espèces diurétiques, savoir :

10. Diurétiques excitantes des organes excréteurs de l'urine.

$2^{\circ}$. Diurétiques sédatives des organes excréteurs de l'urine.

$$
\text { LA 8e. CLASSE }
$$

Des substances végétales qui agissent en débarrassant le système de la respiration, des matières surabondantes et visqueuses qui le surchargent. (Plantes dites béchiques ou pectorales) parmi lesquelles se distinguent,

10. Les Béchiques adoucissantes ou sédatives de la muqueuse bronchique.

20. Les Béchiques incisives ou excitantes de la muqueuse bronchique.

3o. Les Béchiques aromatiques ou toniques de la muqueuse bronchique.

$$
\text { LA } 9 \text { e. CLASSE }
$$

Des végétaux qui agissent spécialement sur lés propriétés vitales du système de la circulation, pour modérer l'excès de la chaleur animale; ou

Plantes dites rAFRAîCHISSANTES, savoir :

10. Les espèces rafrâ̂chissantes aQueuses ou DÉLAYANTES. 


\section{(34)}

$2^{\circ}$. Les espèces rafraîchissantes émulsives ou tempérantes.

3o. id. rafraîchissantes acides.

\section{LA 10e. CLASSE}

Des espèces végétales qui agissent d'une manière spéciale sur les propriétés vitales du système nerveux, ou plantes antispasmodiques, savoir :

$1^{\circ}$. Les espèces antispasmodiques aromatiques. $2^{\circ}$. id. antispasmodiques fétides.

3o. id. antispasmodiques narcotiques.

\section{LA 11e. CLASSE}

Des substances végétales spécialement dirigées sur les propriétés vitales de l'organe de la vue, ou plantes antiophthalmiques, savoir :

$1^{\circ}$. Antiophthalmiques émollientes.

$\begin{array}{lll}2^{\circ} . & i d . & \text { résolutives. } \\ 3^{\circ} . & i d . & \text { astringenteset fortifiantes. }\end{array}$

\section{LA $12^{\mathrm{e}}$. CLASSE}

Des végétaux spécialement dirigés sur les propriétés vitales de l'organe de l'ouie, ou plantes dites antiacoustiques, savoir:

$1^{\circ}$. Antiacoustiques émollientes.

$2^{\circ}$. id. id istimulantes. 


\section{LA $7^{\text {e. CLASSE }}$}

Des substances végétales qui agissent d'une manière directe ou spéciale sur les propriétés vitales des voies urinaires. De ce nombre sont les espèces diurétiques, savoir :

1. Diurétiques excitantes des organes excrétemrs de l'urine.

$2^{n}$. Diurétiques sédatives des organes excréteurs de l'urine.

\section{LA 8e. CLASSE}

Des substances végétales qui agissent en débarrassant le système de la respiration, des matières surabondantes et visqueuses qui le surchargent. (Plantes dites bécuręes ou pectorales ) parmi lesquelles se distinguent,

10. Les Béchiques adoucissantes ou sédatives de la muqueuse bronchique.

20. Les Béchiques incisives ou excitantes de la muqueuse bronchique.

3o. Les Béchiques aromatiques ou toniques de la muqueuse bronehique.

\section{LA $9^{\text {e. CLASSE }}$}

Des végétaux qui agissent spécialement sur les propriétés vitales du système de la circulation, pour modérer l'excès de la chaleur animale; ou

Plantes dites rafraîchissantes, savoir :

10. Les espéces rafraîchisgadites aqueuses ou Délayantes. 


\section{(34)}

$2^{\circ}$. Les espèces rafraichissantes émulsives ou tempérantes.

3o. id. rafraîchissantes acides.

\section{La 10e, CLASSE}

Des espèces végétales qui agissent d'une manière spéciale sur les propriétés vitales du système nerveux, ou plantes antispasmodiques, savoir :

$1^{\circ}$. Les espèces antispasmodiques aromatiques. $2^{0}$. id. antispasmodiques fétides. 3o. id. antispasmodiques narcotiques.

\section{LA 11 ${ }^{\mathrm{e}}$. CLASSE}

Des substances végétales spécialement dirigées sur les propriétés vitales de l'organe de la vue, ou plantes antiophthalmiques, savoir :
$1^{\circ}$. Antiophthalmiques émollientes.
$2^{\circ}$.
id.
résolutives.
3o. id.
astringenteset fortifiantes.

\section{LA $12^{\mathrm{e}}$. CLASSE}

Des végétaux spécialement dirigés sur les propriétés vitales de l'organe de l'ouie, ou plantes dites antiacoustiques, savoir :

$2^{\circ}$. Antiacoustiques émollientes.

$2^{\circ}$. $i d$. 


\section{LA 13e. CLASSE}

Des substances spécialement dirigées sur les propriétés vitales de l'organe de l'odorat, en irritant ou titillant la membrane muqueuse nasale :

$1^{\circ}$. Plantes dites sternutatoires irritantes.

$2^{\circ}$. id. errhines titillantes ou sérifuges.

\section{LA 14e. CLASSE}

Des substances végétales spécialement dirigées sur les propriétés vitales de l'organe du goût ; comme excitantes des organes salivaires, de la muqueuse buccale et de la gutturale.

Plantes dites masticatoires ou sialalogues.

$$
\text { LA } \simeq 5 \text { e. CLASSE }
$$

Des végétaux spécialement dirigés sur les propriétés vitales de l'organe du toucher.

Plantes dites tactiles excitantes.

\section{La 16e. GLASSE}

Des substances végétales qui agissent d'une manière spéciale sur les propriétés vitales du système Dermoïde considéré comme organe absorbant.

Plantes dites iatraleptiques. 


\section{La I7., CLASSE}

Des substances végétales spéeialement dirigées sur les propriétés vitales du système Dermoïde considéré comme organe exhalant.

Plantes dites sudorifiques.

$x^{\text {er. }}$. Degré diaphorétiques.

$2^{\text {e. }} \quad i d$. sudorifiques.

\section{LA 18. CLASSE}

Des substances, végétales spécialement dirigées sữ les propriétés vitales du système Dermoïde absorbant; en modifiant les plaies et protégeant leur cicatrisation.

\section{Plantes dites détersives.}

\section{LA $19^{\text {E. CLASSE }}$}

Des végétaux qu'on peut diriger spécialement sur les propriétés vitales đu système Dermoide considéré comme organe sensible.

Plantes dites ÉPISPASTIQues.

10. Épispastiques rubéfiantes.

$2^{\circ}$. .nin id. vesicantes.

\section{LA 20e. CLASSE}

Des plantes exeitant une exsudation séreuse à la surface de la peau sans déterminer la vésication.

Plantes dites émollientes. 


\section{(35)}

\section{LA 13 e. CLASSE}

Des substances spécialement dirigées sur les propriétés vitales de l'organe de l'odorat, en irritant ou titillant la membrane muqueuse nasale :

$1^{\circ}$. Plantes dites sternutatoires irritantes.

$2^{\circ}$. id. errhines titillantes ou sérifuges.

$$
\text { LA } 14 \text { e. CLASSE }
$$

Des substances végétales spécialement dirigées sur les propriétés vitales de l'organe du goût; comme excitantes des organes salivaires, de la muqueuse buccale et de la gutturale.

Plantes dites masticatoires ou sialalogues.

$$
\text { LA I5e. CLASSE }
$$

Des végétaux spécialement dirigés sur les propriétés vitales de l'organe du toucher.

Plantes dites tactiles excitantes.

$$
\text { LA 16e. CLASSE }
$$

Des substances végétales qui agissent d'une manière spéciale sur les propriétés vitales du système Dermö̈de considéré comme organe absorbant.

Plantes dites iatraleptiques. 


\section{LA I $7^{\text {e. CLASSE }}$}

Des substances végétales spécialement dirigées sur les propriétés vitales du système Dermoïde considéré comme organe exhalant.

Plantes dites sudorifiques.

$1^{e r}$. Degré diaphorétiques.

$2^{e}$. $\quad i d$. sudorifiques.

\section{LA 18 e. CLASSE}

Des substances végétales spécialement dirigées sur les propriétés vitales du système Dermoïde absorbant; en modifiant les plaies et protégeant leur cicatrisation.

Plantes dites détersives.

$$
\text { LA } 19^{e} \text {. CLASSR }
$$

Des végétaux qu'on peut diriger spécialement sur les propriétés vitales du système Dermoide considéré comme organe sensible.

Plantes dites Épispastiques.

10. Épispastiques rubéfiantes,

2. id. resicantes.

\section{LA 20e. CLASSE}

Des plantes excitant une exsudation séreuse à la surface de la peau sans déterminer la vésication.

Plantes dites émollientes. 
Des plantes propres à rétablir la fluidité des humeurs coagulées, et portées à l'extérieur en un seul point.

Plantes dites résolutives.

$$
\text { LA 22e. CLASSE }
$$

Des substances végétales spécialement dirigées sur les propriétés vitales de l'appareil génital de l'homme.

Plantes dites aphrodisiaques ou stimulantes directes des organes de la génération.

$$
\text { LA 23e. CLASSE }
$$

Des substances végétales spécialement dirigées sur les propriétés vitales de l'appareil génital de l'homme.

Plantes dites antiaphrodisiaques ou réfrigérantes directes ou sédatives des organes génitaux masculins.

$$
\text { LA } 24^{\mathrm{e}} \text {. CLASSE }
$$

Des substances végétales qui agissent sur les propriétés vitales de l'appareil génital de la femme.

Plantes dites emménagogues ou excitantes directes de la matrice et de ses dépendances 


\section{(38)}

\section{LA 25e. CLASSE}

Des substances végétales propres à calmer l'irritation ou à éteindre la sensibilité des organes génitaux féminins.

Plantes dites antihystériques ou réfrigérantes directes ou sédatives de la matrice et de ses dépendances.

Je n'ai point hésité à comprendre sous les premiers numéros, les plantes essentiellement douées de vertus non équivoques, et reconnues aux Antilles par les gens de l'art et par les habitans. J'en donne la figure tellement exacte, que l'on pourrait, à la rigueur, se passer de la description botanique. Afin de multiplier les ressources, en cas d'urgence, $\mathrm{j}$ 'ai pensé qu'on serait bien aise de trouver aussi, à la fin de chaque classe, les espèces analogues quoique moins éprouvées.

Chaque contrée produit les plantes nécessaires à ses habitans. J'ai donc éliminé de la thérapeutique des Antilles tontes les drogues des autres parties du monde, afin d'affranchir ces colonies dela nécessitéde payerun tributàl'étranger, ou d'aller chercher, soit en France soit en Asie, ce qu'il faut poursoulager un Américain.

Aux Antilles les plantes ne sont pas. les mèmes qu'en Europe; elles en diffèrent sous beaucoup de rapports; mais, par un bienfait de la Providence qui veille sur les besoins de ses créatures, en quelque endroit de l'univers qu'elle les ait placées, on y retrouve avec de certaines modifications, les verveines, les centaurées, les véroniques, les matricaires, les 


\section{$\left(39^{-}\right)$}

aristoloches, etc., et on remarque avec admiration que ces analogues, quoiqu'ayec des caractères bien distincts, possèdent des vertus à peu près semblables. Le cresson, et un menyanthe, plantes si nécessaires au traitement du scorbut, croissent et fleurissent en Amérique comme en Europe, surle bord desruisseaux et des étangs.

Si la scrupuleuse observance des règles de l'hygiène prévient aux Antilles beaucoup de maladies, combien elles seront peu gîaves, lorsqu'à leur invasion, on les combattra avec les plantes dont les vertus sont constatées par l'expérience. Tout le soin consiste a faire un juste choix, selon le besoin, parmi les espèces nommées puirgatives, apéritives, antispasmodiquesetautrés qui composent ma Flore médicale des Antilles, de laquelle j'ai écarté une foule d'espèces à vertus imaginaires. Cependant il ne faut pas croire que ces mêmes plantes, quoique classées d'après leurs propriétésreconnues, produisent toujours l'effet annoncé par leur désignation. Il est des circonstances où le médecin seul, peut en faire la juste application, et c'est ce choix qui confirme leurs propriétés.

Comme la description la plus exacte et la plus minutieuse ne saurait inspirer assez heureusement undessinateur, pour composer son esquisse, d'après le protocole botanique; et qu'elle peut au contraire, donner lieu à desméprises dansl'analise d'une plante (souvent suspecte ou dangereuse), rien ne vient mieux au secours de son étude que le dessin de la plante ellemême. Cette collection figurée soulage la mémoire, flatte la vue et conduit à des résultats assurés. J'ai vu 


\section{$(40)$}

en France, dans l'ancienne province du Gatinois, où j'exerce, un malade me présenter du caucalis, qu'uu officier de santé lui avait remis pour de la cigüe ; cet officier de santé eût-il commis cette erreur, d'abord si la faculté exigeait d'eux, l'étude indispensable dela botanique ; puis enfin, s'il eût eu sous les yeux le dessin fidèle de la plante qu'il administrait à son ma. lade, au lieu de celle que lui-même avait preserite !

Comment dans ces cas d'uhe grossière impéritie nẹ pas gémir sur le sort de l'humanité, et ne pas applandir au censeur judicieux des abus en médecine, l'inimitable Molière?

Chaque article de la Flore médicale des Antilles commence par l'analise de la plante. Comparant ensuite les caractères génériques, le leeteur, à la vue de la figure, est bien certain de ne point donner à faux.

La figure de la plante comprend presque toujours :

$\mathrm{x}^{\mathrm{o}}$. La tige de cette plante, afin d'indiquer son port.

$2^{\circ}$. La fleur de grandeur naturelle.

$3^{\circ}$. Les détails de la fructification. Une graine entière, puis ouverte.

$4^{\circ}$. Enfin les caractères particuliers qui peuvent la faire reconnaître, examinés au microscope.

Dans l'intention d'étendrel'utilité de cet ouvrage, en faveur des colons aux besoins desquels il est plas particulièrement destiné, j'ai joint, autant que je l'ai $\mathrm{pu}$, aux noms latins, les noms français vulgaires et caraibes. Il est donc physiquement impossible qu'au moyen des détails botaniques et surtout des dessibs 


\section{(41)}

fiits par moi d'après nature, réduits sous mes yeux et peints avec le plus grand soin par mon fils, élève du célèbre Wanspaendonck, on ne reconnaisse pas la plante dont on lira la description.

L'avantage du dessin colorié, sur le dessin au noir étant inappréciable, j'ai cru devoir m'imposer ce surcroît de dépense pour approcher de la perfection. Commenten effet imiter en noir la délicatesse du duvet du pois à gratter, le soyeux du dessous de la feuille du caïmitier, les nuances du vert de certaines feuilles?

Puisse mon ouvrage être agréable au public, mes vœux seront remplis. Le travail m'en est d'autant plus cher, qu'il m'a sauvé des massacres de Saint-Domingue! Compris dans la condamnation à mort prononcée contre tous les blancs, mis à nu pour être immolé, j'eus le bonheurqu'on se rappelât que mes services en médecine pourraient être utiles, attendu que j'étais auteur d'un traité sur les plantes usuelles des colonies et que les pharmacies y ayant été brûlées, je pourrais remplacer les médicamens exotiques, en indiquant aux infirmiers, les plantes nécessaires aux hôpitaux. C'est à cette époque malheureuse que mes collections d'histoire naturelle du continent américain, de l'île espagnole de Cuba, de Saint-Domingue ; les préparations anatomiques du crocodile des Antilles que $j$ 'avais destinées pour le sabinet du jardin du Roi, ainsi que plus de deux milles dessins grand in-fol. mis au net, ont été dévorés par les flammes. Heureusement ceux qui appartenaient à la Flore que je publie, avaient été confiés au consul français à Cadix, peu de jours avant l'incendie général, qui a fait disparaitre 


\section{(42)}

jusqu'aux traces des blancs sur cette terre de douleur, abreuvée de leur sang innocent.

Je dois avouer ici, que pour remplacer celles de mes deseriptions qui ont été perdues dans le désordre qui précéda et accompagna cet envoi, je me suis vu contraint à les emprunter des auteurs les plus véridiques. Tels que le Nouveau Dictionnaire d'Histoire naturelle, Plumier, Linnée, Lamarck, Tournefort, Nicolson, Chevalier, Poupée-Desportes, Tussac, et autres que je ne citerai pasà chaque article, afin d'éviter des répétitions oiseuses.

Je dois témoigner encore ma reconnaissance au savant Tussac, qui dans nos excursions eommunes à Saint-Domingue, á bien voulu m'aider de ses conseils, et de son instruction. J'offre par le même motif, l'expression du même sentiment à MM. Poiteau, et Turpin; le dernier surtout aurait un droit bien fondé à me reprocher mon ingratitude, si j'étais capable d'en avoir, puisque je ne me suis point fait scrupule de consulter quelques uns des beaux dessins qui font rechercher la Flore du dictiounaire des sciences médicales, quand le mauvais étaț de conservation des miens m'a forcé dè les écarter.

Puisse le lecteur ne pas me reprocher d'avoir intercallé dans cet ouvrage quelques citations poétiques, mon but a été de ne pas trop le fatiguer par des tirades didáctiques, et de le distraire, de le reposer, en semant de quelques fleurs la route monotone qu'il a à parcourir pour arriver à la fin de chaque article, D'ailleurs le dieu des vers a dit Montègre, est aussi le dieu de la médecine (Gazette de santé 21 uin 1814.) 
Si, comme je crois pouvoir l'espérer, le public daigne accueillir favorablement cette édition, je donnerai ensuite par appendix les figures des plantes qui ne sont qu'indiquées, parce que leurs propriétés ne sont pas aussi universellement reconnues que celles des autres.

Heureux si en offrant à ma patrie ce fruit de mes observations et de mes travaux, comme un pendant nécessaire de la belle Flore de M. Panckoucke, je puis mériter qu'on m'applique la maxime : cum desunt vires, semper laudanda voluntas. Lorsqueles forces manquent, on dait toujours tenir compte de la bonne Folonté. 
Extrâit du Rapport de l'Académie royale des Scientes, Séance du lundi 14 Mai 1821 , sUR LA FLORE MÉDICALE DESAintILLES, par M. Descourtilz, Doct. méd., etc.

Les plantés décrites par M. Descountinz sont au nom= bre de 600 , divisées en 25 classes ou ordres, d'après leur inode d'action présumé, ou leurs effetś thérapeutiques. Chaque espèce est désignée par un nom français et par celui qu'elle porte aux Antilles. L'auteur indique en même temps la classe et le genre auxquels elles appartiennent dans les ouvrages de Tournefort, Linnæus et de M. de Jussieu. Les descriptions sont faites avec soin.

Quoique la matière médicale soit le principal but de l'auteur, il n'a pas négligé d'indiquer les usages auxquels les mêmes plantes sont employées, soit dans les arts, soit dans l'économie domestique. Il traite aussi de leur culture, et il indique la nature des terrains qui leur conviennent. Sous tous les rapports, la Flore de M. DEscouritiż nous a offert beaucoup d'intérêt.

Nous peñsons que M. Descourtinz mérite les encouragemens de l'Académie, et qu'il faut l'engager à publier tun ourrage intéressant pour les botanistes et pour les médecins qui voudront connaître les divers usages auxquels on emploie les plantes qui croissent aux Antilles.

\section{Signé Desfontaines; Dumíriti, Rapporteur.}

L'Académie approuve le Rapport, et en adopte les conclusions.

Certifie conforme à $1^{\dagger}$ original :

Le Secrétaire perpétuel, Conseiller d'Etat, Officier de l'Ordre royal de la Légion d' Honneur,

Sigtié B. Cuvier. 


\section{FLORE MÉDICALE}

\section{DES ANTILLES,}

o $\mathrm{U}$

\section{TRAITÉ DES PLANTES USUELLES}

DES COLONIES FRANÇAISES, ANGLAISES, RSPAGNOLES ET PORTUGAISES.

\section{CLASSE PREMIÈRE.}

Des plantes Qui excitent la tonicité des voies DIGESTIVES.

$x^{\circ}$. Stomachiques aromatrques:

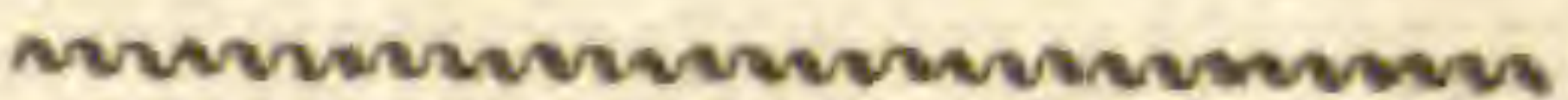

SOMMAIRE.

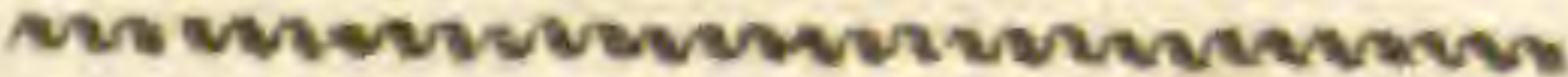

Les connexions directes et sympathiques du système des voies digestives avec les autres organes, prouvées par l'altération du mouvement vital, si l'estomac est pathologiquement altéré, on doit con. clure que les substances qui peuvent augmenter ces mëmes forces vitales sont les stomachiques ou toniques, dont on distingue plusieurs espèces, indiquées d'après leur manière d'agir.

Nous nous contenterons d'offrir une seule livraison des stomachiques aromatiques dans ce volume, puisque la plus grande partie de ces végétaux bal- 


\section{(2)}

samiques, trouvent une place utile, et plus conve-. nable dans les classes spéciales des béchiques, des. anti-spasmodiques, des alexitères et des aphrodisiaques.

Les plantes aromatiques et les spiritueux conviennent dans les ataxies; comme celles amères et celles astringantes sont particulièrement indíquées dans tous les cas d'adynamie. En général, on doit diriger les puissances des toniques, d'après les différens modes d'altération des fonctions du malade.

Nota. La classe des stomachiques comprend:

10. Les stomachiques aromatiques.

$\begin{array}{lll}2^{\circ} . & i d . & \text { amères ou fébrifuges. } \\ 30^{\circ} & i d . & \text { anti-scorbutiques. } \\ 4^{\circ} . & i d . & \text { anthelmintiques. } \\ 5^{\circ}, & i d . & \text { astringentes. }\end{array}$




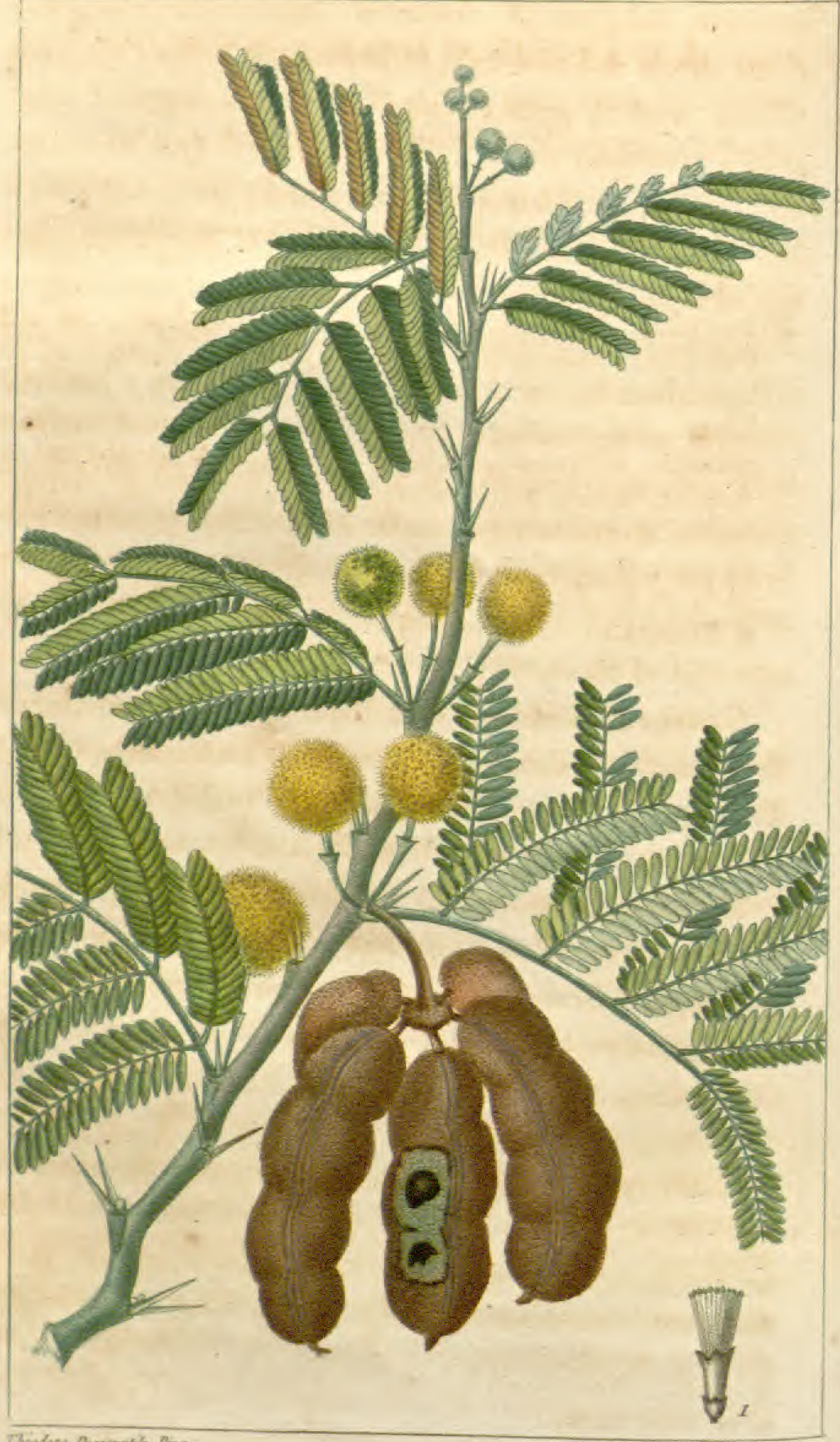

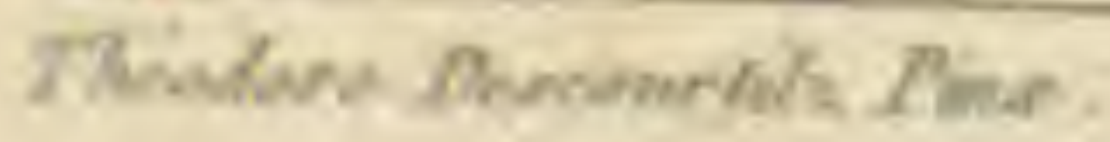




\section{ACACIE ODORANTE. (1)}

(Stomachique aromatique.)

EN GREC $\alpha * a x i \alpha$ DE $\alpha * y$, ÉPINE, AIGUILLON.

Srnonymie. Mimosa odorata farnesiana. Lin., cl. 23. Polygamie monœcie. - Juss., class. 14 , ordre $2^{e}$. les léguminenses. - Acacia globularia, luten, odorata, Plum., vol. 7, p. 70.- Acacia arborescens Americana spinosa siliquosa, foliis tamarindi. (Nicolson.) Acacia indica foliis scorpioidis leguminosæ, siliquis fuscis teretibus, resinosis. H. L. Bar (Tournefort), cl. 20, - Bauhin חıve $\xi$, lib. 2, sect. 1. - Les Anglais et les Espagnols lui conservent le nom générique d'ACACIA.

Caractères botamiques. Epis stipulaires distincts, feuilles bipinnées, les partielles à huit paires de follioles, épis globuleux sessilles. (Vivace.) Linn. par Joliclerc.

Histome natureile L'acacie odorante, est un arbrisseau de douze à quinze pieds de hauteur, tortueux, fort branchu et armé de fortes épines, cachées quelquefois par des touffes de feuilles, d'un vert in:

(1) En comparant l'Acacie odorante des Antilles, avec celle d'Egypte, décrite dans la Flore du Dictionnaire des sciences médicales, on serait tenté de trouver de la ressemblance entre ces deux espèces, parce que le feuillage et la floraison ont beaucoup de rapport, mais les siliques diffèrent essentiellement; l'Acacie d'Egypte offre des siliques à renflemens étranglés, celle des Antilles a des gousses cylindriques à compartimens relevés, enchassés, d'un noir violet. 


\section{(4)}

constant, et souvent décoloré. Il se plaît dans les savanes arides des Antilles, et sur les bords de la mer. Lorsque l'air est calme, la brise de terre souffle matin et soir les parfums de l'acacie odorante à plusieurs lieues en pleine mer, et console le marin, en lui annonçant les attérages. Cette fleur décèle aussi sa présence sur terre, quoiqu'étant dérobée à la vue par les cierges et d'autres mimoses épineuses qui se plaisent, comme elle, sur les terrains maigres des hattes. Son odeur suave, qui a beaucoup de rapport avec celle du violier jaune d'Europe, embaume l'air des contrées qui favorisent sa végétation. L'indiscret pourtant, en cuefllant ses fleurs odorantes est puni quelquefois de son imprévoyance par la piqûre d'épines très-aiguës dont certaines parties de la tige sont hérissées. Rosa non vidi mai senza la spina.

Caractères physiques. Les racines de l'acacie ont une écorce brune, et d'une odeur d'ail insupportable; elles sont multipliées et traçantes. Les feuilles doublement ailées, en portent de partielles à huit paires opposées, longues de deux on trois lignes.

Les fleurs axillaires, monopétales et polyandriques sont très-odorantes; d'un jaune éelatant; pédonculées fécondes ou stériles, elles sont quelquefois solitaires, mais souvent grouppées en bouquets globuleux, formés par une infinité de fleurons dont les calices portent une touffe d'étamines. Ces petits fleurons réunis offrent une masse sphérique dont les anthères sont couvertes d'une poussière jaune. Le pistil, qui se trouve dans la fleur, prodnit, lorsqu'elle est passée, une silique courte, ronde, articulée, 


\section{( 5 )}

pourvue intérieurement de loges transversales, renfermant, dans une pulpe visqueuse, plusieurs semences oblongues et noirâtres. Dans quelques variétés ces siliques se trouvent disposées en cercle ou en bracelets; les épines au nombre de trois ou quatre sont axillaires.

Analyse chimique. Le suc qu'on retire des gousses vertes est amer et astringent. L'écorce des racines contient du tannin soluble dans l'eau bouillante; combiné avec une substance extractive verdâtre qui décompose les sels martiaux, à l'exemple de la noix de gale et des autres astringens, il donne un précipité noir employé par les teinturiers et les tanneurs.

Proprietés particulières. Les fleurs de lacacie odorante, ne servent point seulement à embaumer les appartemens des dames créoles, elles en camposent des sachets et en parfument leur linge.

Les feuilles de cette espéce comme celle des mimoses en général, sont sensibles à l'impression du soleil qui les fait ouvrir et s'écarter, tandis qu'elles se rapprochent et se ferment en adhérant l'une contre l'autre dès que l'astre brillant se cachant dans le vaste sein des mers et privant l'hémisphère de ses rayons, rend à la nature et aux colons une fraîcheur que ces derniers ont tant de fois appelée pendant le jour.

On voit les troupeaux de bøufs, de cabrits, de moutons, les chevaux même, rechercher avec avidité le feuillage tendre de l'acacie odorante, qui ne leur est point nuísible.

On compose avec les gousses vertes, la gomme qui 


\section{(6)}

suinte de l'arbre sans incision, un peu de bois de campêche, et le jus de citron, une encre très-noire et qui ne change point de teinte, si on fixe la couleur avec un peu de sulfate de zinc ou de cuivre. $\mathrm{Le}$ bois procure un bon chauffage.

Propriétís médicinalass. On emploie les fleurs en infusion theiforme, dans les cardialgies nerveuses et dans les dyspepsies. Les siliques encore vertes, pastées à la presse, fournissent un suc astringent, qui, réduit en consistance d'extrait, se prescrit avec succès dans les diarrhées et autres flux excessifs pour ealmer l'éréthisme des membranes muqueuses. On l'ajoute aux collyres à la fin des ophtalmies séreuses, et on le recommande en fomentations dans les anasarques, les chutes du rectum et celles de l'utérus.

Son écorce est recherchée par les Nègres qui en ceignent les articulations pour apaiser les douleurs de ces parties. Sans ajouter foi à la vertu, peut-être trop exagérée de ces épithèmes, j’ai ordonné son écorce avec succès, en décoction pour les bains qure je prescrivais dans certaines fièvres ataxiques. L'eau du bain devient nébuleuse par la solution des principes résineux de l'écorce.

Il y a d'autres espéces d'acacie que l'on rencontre dans les forêts des Antilles dont les vertus, quoique indiquées astringentes, ont besoin de passer encore aú creuset de l'observateur. Parmi ces espèces on remarque le mimosa tortuosa ( Linn.), à épis stipulaires, feuilles bipinnées, 4 juguées; glandule entre les dernières pinnzles, à six paires' de folioles, et épis globuleux. (Jamaïque. Vivace.) 


\section{(7)}

\section{Expligation de ra pianche première.}

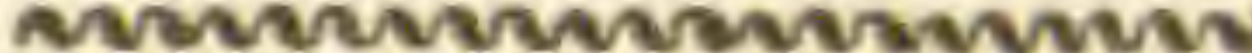

Le rameau d'acacie odorante est réduit à moitié grandeur naturelle.

1. Fleuron séparé et grossi.

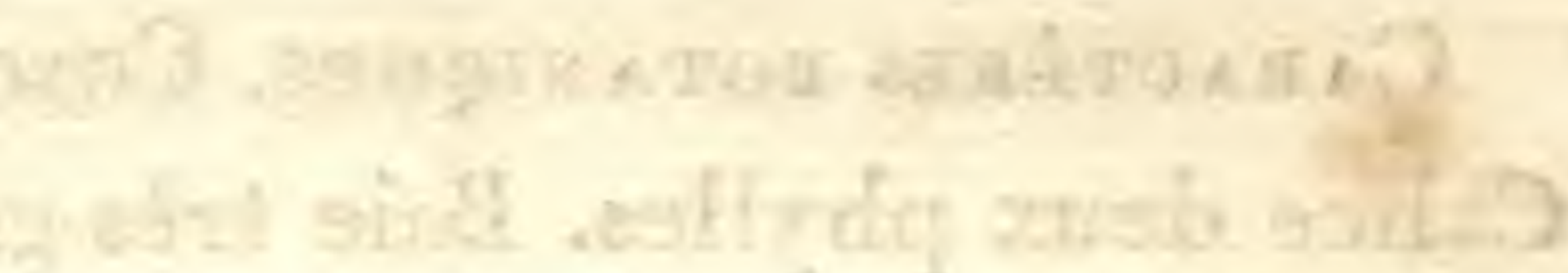

(i

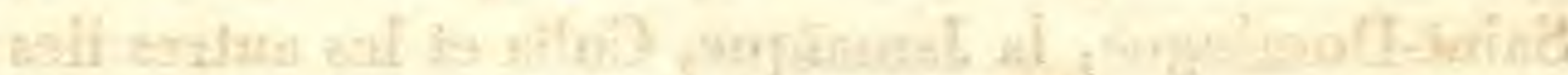

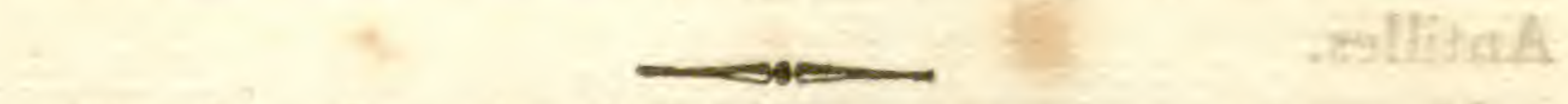

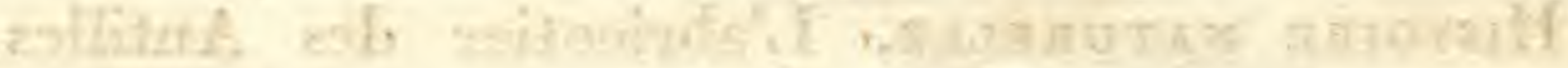

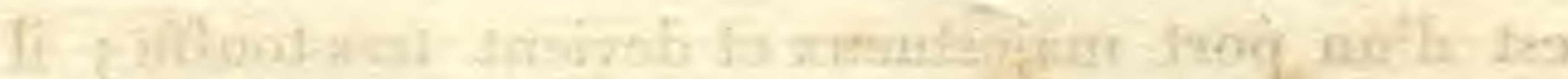

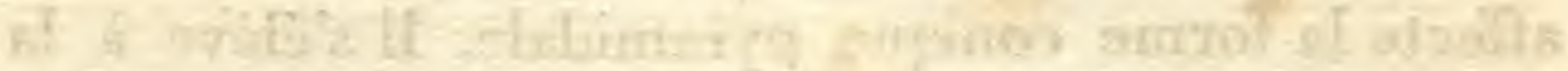

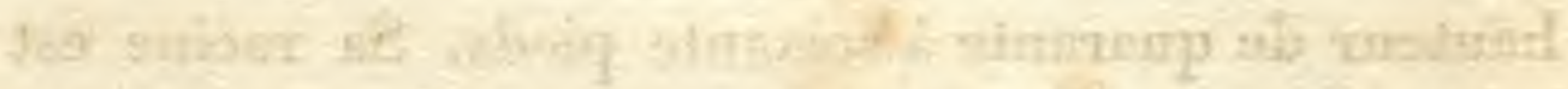

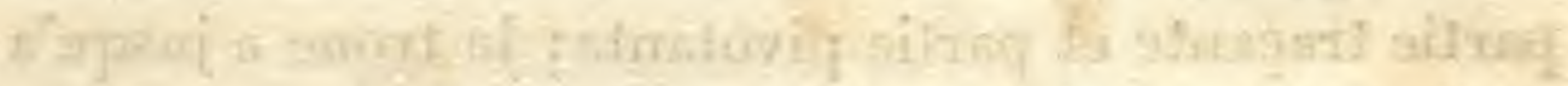

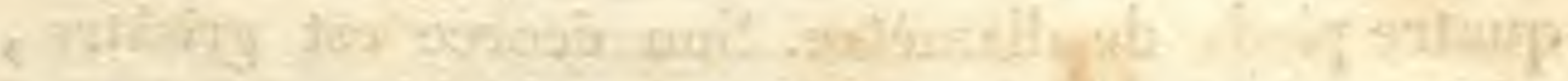

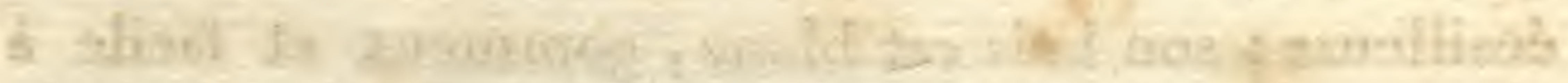

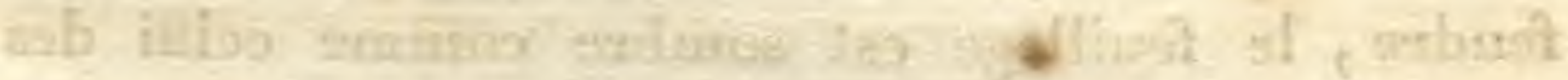

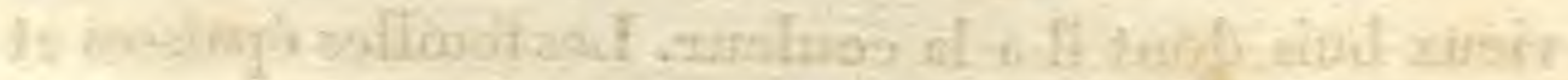

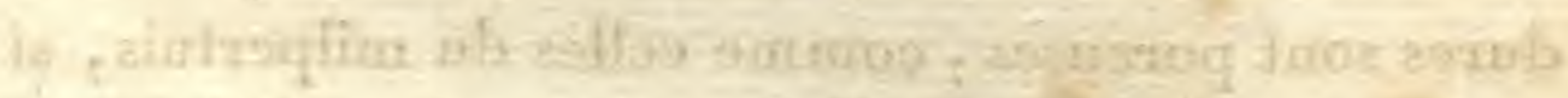

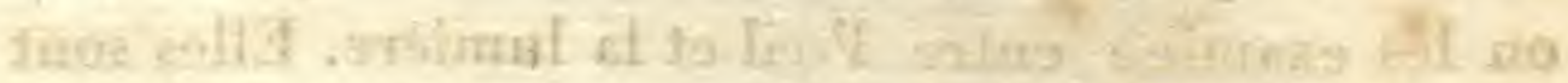

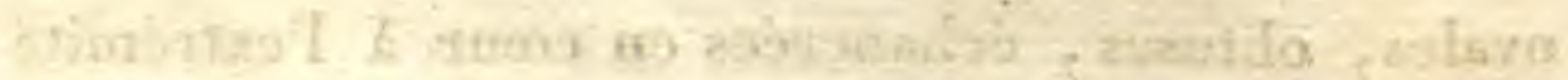

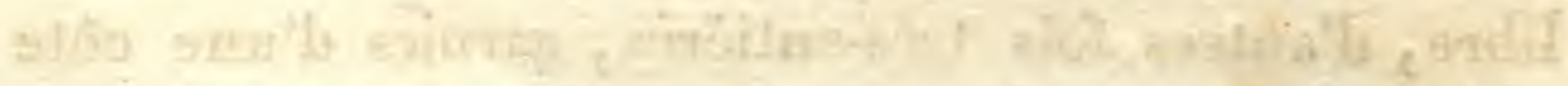

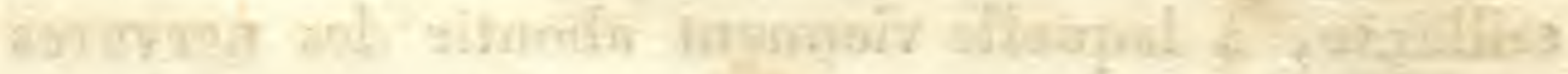

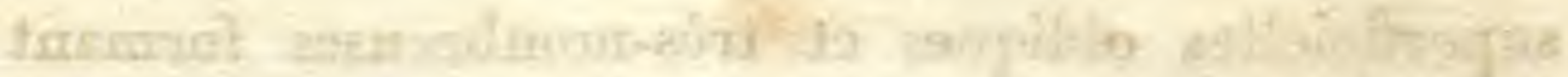

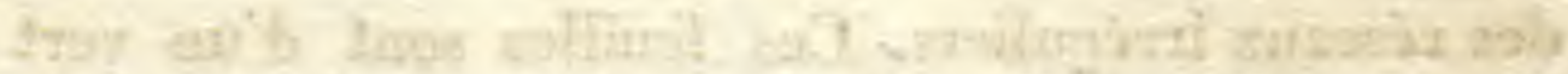




\section{ABRICOTIER DES ANTILLES.}

(Stomachique aromatique.)

Srnonymie. Mammea americana, Lin.-Mammei magno fructu, persicæ sapore. Plum., vol. 6, pag. 104.Manchiboni des Caraïbes. Carrère. - Malus persica. Sloan. - Mammea Brwn. - Mammay. Dalec. Ord. class. 5, sect. 9. Tournef. - Class. 13, Polyandrie monogynie. Lin. - Fam. 54, les Cistes. Adanson. -Fam. des Guttiers. Jussieu.

Caractères botaniques. Corolle de quatre pétales. Calice deux phylles. Baie très-grande à quatre spermes. Etamines plus courtes que les pétales (Vivace) Saint-Domingue, la Jamaïque, Cuba et les autres îles Antilles.

Historre naturelle. L'abricotier des Antilles est d'un port majestueux et devient très-touffu ; il affecte la forme conique pyramidale. Il s'élève à la hauteur de quarante à soixante pieds. Sa racine est partie traçante et partie pivotante; le trone a jusqu'a quatre pieds de diamètre. Son écorce est grisâtre, écailleuse; son bois est blanc, gommeux et facile à fendre, le feuillage est sombre comme celui des vieux buis dont il a la couleur. Les feuilles épaisses et dures sont poreuses, comme celles du milpertuis, si on les examine entre l'œil et la lumière. Elles sont ovales, obtuses, échancrées en cœur à l'extrémité libre, d'autres fois très-entières, garnies d'une côte saillante, à laquelle viennent aboutir des nervures superficielles obliques et très-nombreuses formant des réseaux irréguliers. Ces feuilles sont d'un vert 


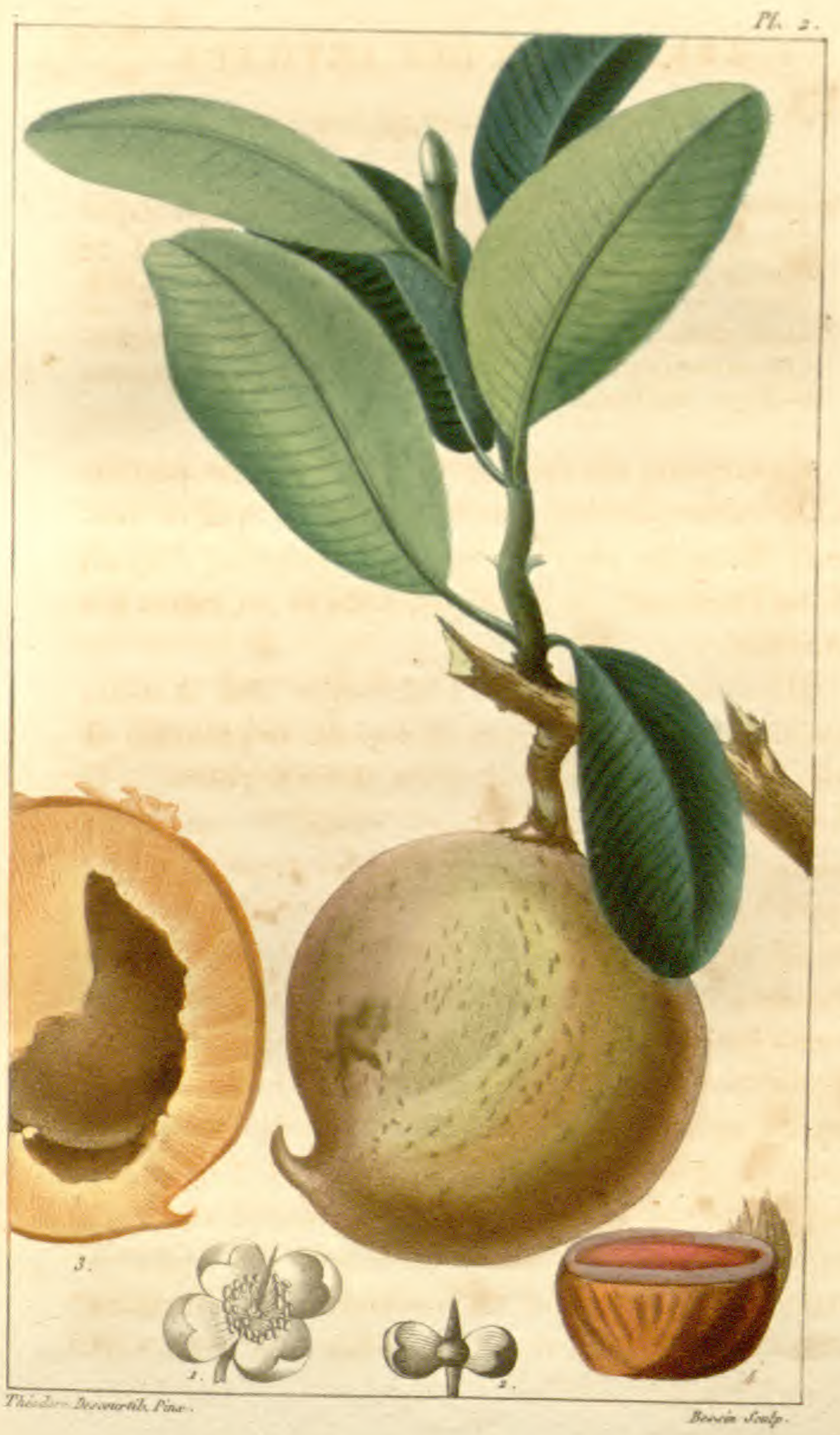

A B 
très.foncé en dessus, clair en dessous. Elles ont de huit à neuf pouces de longueur, sur quatre à cinq de largeur.

Le Mammea porte des fleurs hermaphrodites, et souvent des fleurs mâles ou femelles distinctes. Les fleurs rosacées sont composées de quatre pétales arrondis, obtus, creusés en cuiller, blancs, d'une odeur suave et d'un goût astringent, le pistil arrondi est environné d'étamines, dont les anthères sont jaunes : le calice entier, est divisé en deux parties.

Le pistil devient un fruit charnu, succulent, sphérique, de trois à six pouces de diamètre, et est couvert d'une pellicule peu épaisse, d'un gris jaunâtre, grumeleuse et qui blanchit en mûrissant.

La partie comestible est spongieuse, d'un janne rutilant, en se rapprochant du centre, puis blanchâtre excentriquement, traversée par des veines lactées d'une odeur pénétrante et aromatique, et d'une saveur douce. La pulpe auricolore, recouvre depuis un jusqu'à trois noyaux ovales, convexes supérieurement, et concaves du côté qu'ils se touchent, composés de plusieurs filamens posés en tout sens les uns sur les autres, de dix-huit lignes de largeur sur près de trois pouces de longueur, lisses en dedans, d'un beau rouge carmin à l'intérieur où se trouve renfermée une amande ligneuse, d'un goût âcre, de couleur brunâtre, bilobée; on se sert du suc dè celte amande pour tracer sur le linge des lettres que rien ne peut effacer.

Propriétís particultères. La fleur de l'abricotier des Antilles, jone un grand rôle dans la compo- 


\section{(10)}

sition des liqueurs de la Martinique. C'est son arome agréable, qui donne à la fine créole sa juste célébrité.

D'autres composent un ratafia plus économique, et cependant très-agréable, avec le suc d'abricots, le gingembre, la fleur d'orange et l'alcohol.

Le bois facile à fendre, fournit à peu de frais, du merrain, des essentes, des poutres et autres matériaux utiles. Il découle du corps de l'arbre, par incision, un suc gommeux, que les Nègres recherchent pour détruire les chiques dont ils sont incommodés, principalement dans les mornes où cet arbre se rencontre le plus souvent.

Propriétés médicinales. La forme du fruit change : il est rond et quelquefois cordiforme. On le mange rarement crû, parce que sa chair est compacte et indigeste, mais on le fait infuser, avant le repas, dans du vin sucré, aromatisé avec la canelle et le gérofle, ou en compôte. On le sert aussi candi, alors il est stomachique, et prévient les dyspepsies.

Explication de la planche seconde.

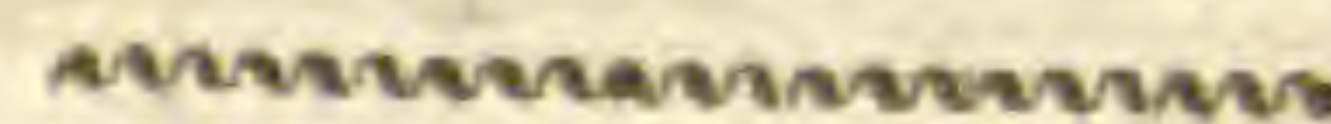

Le rameau d'abricotier est représenté au quart de grandeur naturelle.

1. Fleur entière réduite à moitié.

2. Calice contenant le pistil qui surmonte l'ovaire.

3. Fruit ouvert pour laisser voir deux noyaux renfermés dans une même loge.

4. Noyau coupé transversalement. La figure de l'amande est marquée par des points. 
Pl. 3 .

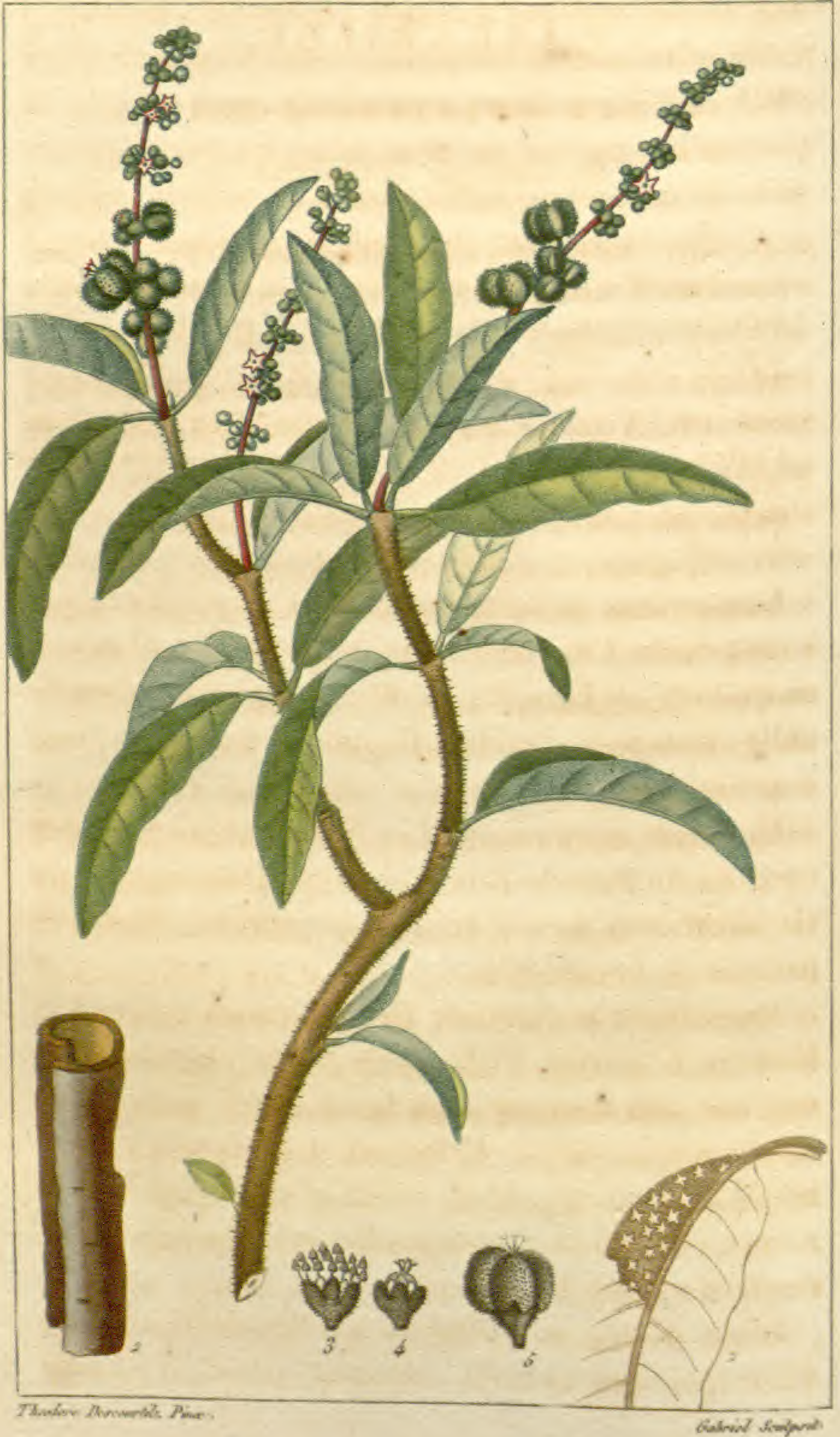

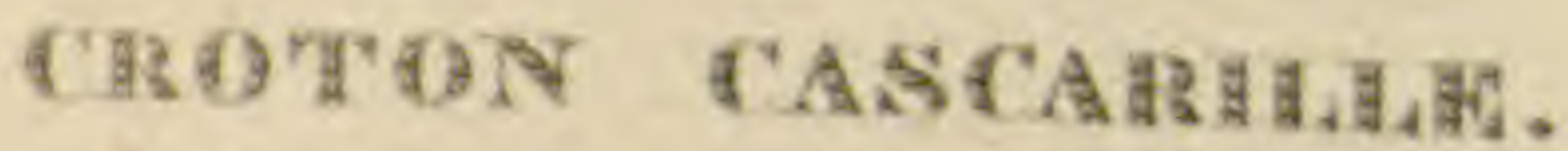




\section{A S A A I L L E,}

S AUGE DU PORT-DE-PAIX.

( Stomachique aromatique.)

Synonymie. Ricinö̈des americana æleagni folio (Plum. Spec. 20. Tournef., append. 656.) - Croton casearilla foliis lanceolatis, acutis, integerrimis, petiolatis, subtùs tomentosis, caule arborea : Lin., class. 21, monoecie, Monadelphie. - Euphorbes, Jussieu, class. 15,

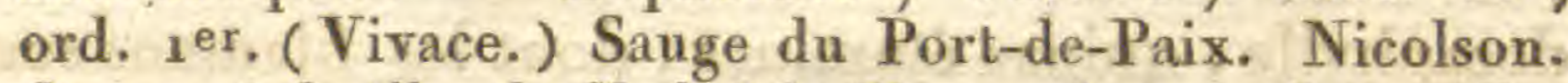
Croton à feuilles de Chalef de Tournefort. - Cascarilla. Anglais et Espagnol. - Chacrelle, cascalote, quinquina gris aromatique. Ecorce éleutérienne.

Caractìres botanigues. Mâle. Calice cylindrique à cinq dents. Corolle de cinq pétales, dix étamines ou quinze. - Femelle. Calice polyphille; Corolle nulle; trois styles bifides; Capsules à trois loges, une semence.

Histoine naturelie. Les Nègres guérisseurs des environs du Port-de-Paix (île de St.-Domingue), où cet arbrisseau forme des bocages entiers, font une panacée de la cascarille.

Proprítés physiques. Cet arbrisseau s'élève à la hauteur de quatre à six pieds, il se plaît dans les endroits secs et arides; son trone court, mais épais, est d'un gris cendré. Il fournit des branches nombreuses, cassantes, d'une odeur aromatique. Les rameanx, cylindriques, sont feuillés et recouverts d'une écorce d'nn gris blanc.

Les feuilles, eomparables à celles de l'amandier d'Europe, sont entières, alternes, pétiolées, ovales 


\section{(12)}

lancéolées, luisantes, âpres au toucher par la présence de nombreuses écailles stelliformes ou en forme de chausse-trape de diverses grandeurs, d'un blane argenté avec un point noir au milieu, d'un vert d'aigue marine en dessus et argentées en dessous. Cette découverte est due à $\mathbf{M}$. Turpin.

Les fleurs monoïques sont petites, blanches ou purpurines, disposées en épis à l'extrénité des rameaux. Les fleurs mâles offrent un calice double, decaphylle, quinze étamines, dont les filamens sont fasciculés à leur base. Les fleurs femelles offrent un calice double, trois styles bifides, et une capsule obronde, à trois lobes latéraux arrondis, à trois loges bivalves, contenant chacune une semence ovoïde noirâtre.

Ataryse chimique. D'après Tromssdorff. La cascarille contient, du mucilage, un principe amer, de la résine et une huile volatile, ce qui prouve que l'alcohol est le meilleur menstrue à employer pour en obtenir les propriétés.

Propriétés médrcinales. L'écorce aromatique de la cascarille, est le plus généralement employée en médecine. On l'envoie en Europe par fragmens roulés, comme celle de la canelle, mais seulement de la longueur de deux on trois pouces. Elle est pen épaisse, d'une cassure résineuse, d'un gris cendré à l'extérieur; de couleur de rouille en dedans, et sous l'épiderme qui est rugueux.

Cette écorce âcre, d'un goût amer, est d'une odeur aromatique fort agréable, et comme ambrée, surtout lorsqu'on la brûle. C'est un excellent fébri- 


\section{( 13 )}

fuge, qui remplace d'autant plus avantageusement le quinquina et le simarouba, qu'à une dose plus faible, elle produit les mêmes effets, sans qu'il soit nécessaire d'en continuer l'usage aussi long-temps.

On prescrit la cascarille comme légèrement astringente pour arrêter les lochies trop abondantes et le vomissement. Elle est, pour cette même vertu, recommandée dans les dyssenteries chroniques et les diarrhées rebelles; dans les affections muqueuses et les cachexies. Son usage est d'autant moins répugnant aux malades, qu'on peut donner à de tréspetites doses, l'extrait que M. Boulduc nous a appris à en retirer par l'alcohol.

On fait usage des feuilles du croton cascarille, en infusion théiforme ( ce qui a fait donnèr à la plante le nom de thé du Port-de-Paix); cette boisson augmente sensiblement la tonicité du système des voies digestives, flatte le goût et l'odorat, mais avant d'en faire usage il faut avoir la précaution de la filtrer pour retenir sur le blanchet, les petites chausses-trapes, dont la surface des feuilles est tapissée, et que M. Turpin y a reconnues.

C'est en raison de ses principes constituans, que la cascarille est un des meilleurs stimulans à prescrire dans les fièvres exanthématiques, dans les fièvres ataxiques compliquées de spasmes, de carus et de prostration; alors on lui associe des excitans plus diffusibles, tels que l'éther, le camphre, etc.

On imite fort bien les cigarres de la Havanne, en ajoutant aux feuilles de tabac à fumer une certaine quantité de poudre de eascarille. Cette préparation 


\section{(14)}

n'a d'autre inconvénient que de caúser des vertiges, si on en a mis un peu trop.

La cascarille est recherchée en teinture pour le bean noir qu'elle procure. La couleur en est solide, et pénètre parfaitement les étoffes qui en sont imprégnées. Les habitans du Mexique, dit ValmontBomare, doivent aux naturels de la Californie le secret de tirer la partie colorante de ce végétal.

Mode d'administration. La eascarille s'emploie en poudre, en essence, en extrait et en infusion, ả la dose de 30 ou 40 grains dans un vin généreux. On ordonne le sirop à la dose de quatre à six gros. Il sert pour la préparation des bols et des électuaires. Quand on veut la prendre en décoction on fait bouillir, pendant dix minutes, à vaisseau clos, quatre gros de l'écorce dans une livre d'eau, et on édulcore la colature avec deux onces de sirop de gingembre.

\section{Explication de IA pLANChe troisik̀me.}

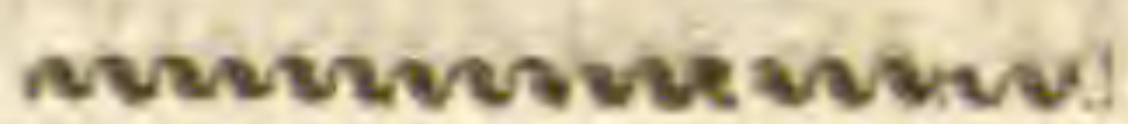

Plante réduite à moitié grandeur naturelle.

1. Feuille an trait, où sont exprimées les chaussestrapes qui en garnissent la surface entière. (Découverte de M. Turpin.)

2. Ecorce roulée d'un rameau de cascarille,

3. Fleur mâle.

4. Fleur femelle.

5. Fruit. 
$77: 4$

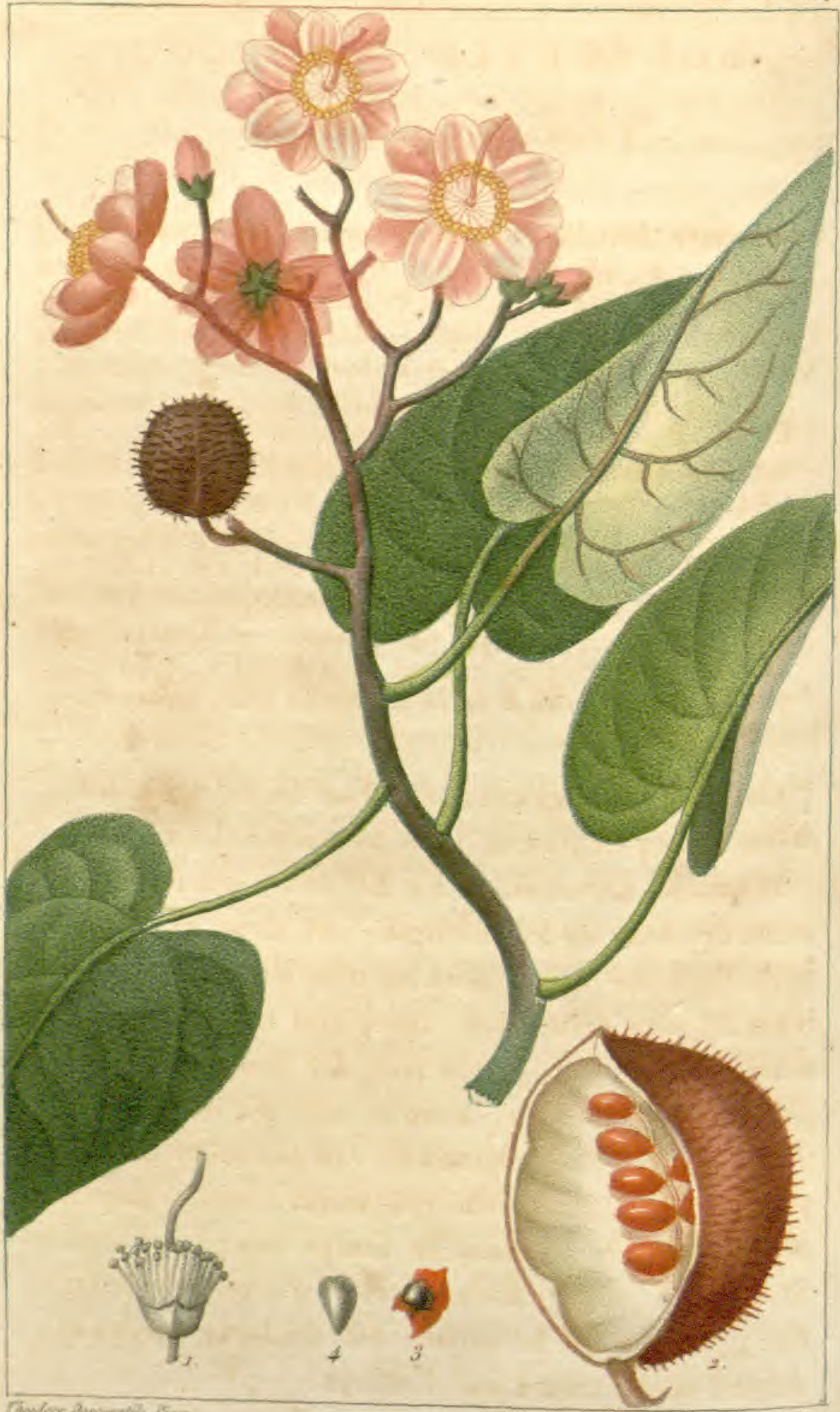

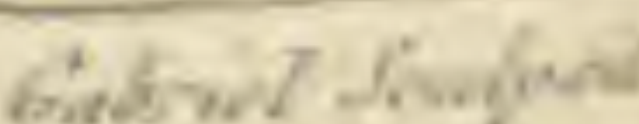




\section{(15)}

\section{ROUCOUYER OU ROUCOU.}

(Stomachique aromatique.)

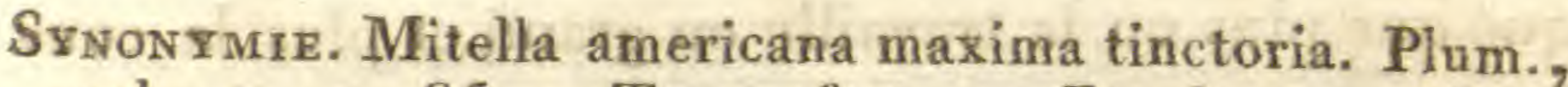
vol. 7, p. 85. - Tournefort. - Boerhave. - Bixa orellana. - Linn. Urucu de Pison. - Orellana folliculis Lapaccis. H. L. Bat. Herm.-Baburi, clus. - Achjot, hern. - Bixa, oviedo. - Arbor firium regundorum, Scalig. - Arnotto Dalech. - Arbor mexicana coccifera. C. B. Raj-Joust-Achiote, encatabi, cochehuc des sauvages Caraïbes mâles. Les femmes l'appellent Bichet (Valmont-Bomare), ord. , class. 6 , sect. 3 , genr. 7 , Tournefort, Rosacees. - Classe 13, polyandrie monogymie, Linn.-Fam. 48 les tilleuls, sect. $1^{\text {re }}$, Adanson. - Sect. $2^{\mathrm{e}}$., Jussieu, Fam. des saxifrages. - Achiotisen medecina tingendo apta, hern. - Tournefort a donné au Roucouyer le nom latin Mitella, qui signifie petite mitre, à cause de la forme du fruit de cet arbre.

Caractères botamieues. Corolle de dix pétales, calice à cinq dents ; capsule hérissée à deux valves.

Histoire naturelle. Ce bel arbre qui fait l'ornement des bois de l'Amérique, où il se rencontre, flatte l'œil par les nuances les plus douces et les couleurs les plus éclatantes. On y voit contraster d'une nhanière gracieuse, le ton rosé des fleurs et le violet purpurin des gousses, avec le vert gai du feuillage.

Propriétís particulierrs. On recueille deux fois par an, les gousses du roucouyer, savoir dans les secs vers Noël, et dans le temps des pluies vers la St.-Jean. Cette dernière récolte produit davantage. La maturité de la gousse est déclarée lorsqu'elle s'ouvre d'elle-même sur l'arbre. 


\section{( 16 )}

On retire de cette graine, par infusion ou macé. ration, une pâte ou extrait qu'on appelle Roucou, et dont on fait usage dans la teinture. Les Caräbes la dissolvaient dans l'huile, puis s'en barbouillaient le corps et en teignaient leurs hamacs ; on a remarqué que plus on la travaille en grand et plus la couleur est vive. Il en est de même lorsqu'on le fait sécher à l'ombre au lieu de l'exposer à l'action décolorante du soleil. Lorsqu'on évapore une petite quantité de solution, on n'obtient qu'un extrait noir; pour avoir une qualité parfaite, il faut que le roucou puisse se dissoudre entièrement dans l'eau; il faut aussi qu'il soit de couleur de feu, et plus vif au dedans qu'aú dehors, doux au toucher et d'une bonne consistance. On donne telle forme que l'on veut à la pâte, qu'on enveloppe de feuilles de balisier. Les ouvriers qui le travaillent, éprouvent des céphalalgies qu'on peut attribuer à l'odeur pénétrante de la graine du roucouyer qui exhale des émanations fétides pendant la macération, tandis que son parfum de violette ne se fait sentir qu'après.

Quelques insulaires en faisaient entrer dans la composition du chocolat, dit Bomare; et Barrère (Ess. 79) assure que le roucou, est le contrepoison du Manioc; mais cui fideas vide. Toutefois il fortifie l'estomac et arrête le cours de ventre; le linge en reçoit des taches, que le soleil seul peut effacer à la longue.

Il existe une espèce de roucouyer à fruits inermes.

Caractíres physiques. Le roucouyer s'élève à la hauteur de douze à quinze pieds, il est fort touffu; ses tiges sont droites, mais très garnies de feuilles; 


\section{(17)}

on a soin de l'étêter pour faciliter la récolte de ses gousses.

Son bois est blanc, cassant ; et susceptible de s'enflammer par le frottement. On fait des cordes arec son écorce.

Ses feưlles sont grandes, cordiformes, sans dentelures, minces, longuès de quatire à cing pouces sur trois de largeur, alternes, lisses, luisantes, d'un beau vert clair, et garnies en dessous de plusieurs nervures roussâtires; elles sont pétiolées.

Les jeunes rameaux produisent slenx fois par an, à leur extrémité, des groupes de fleurs rosacées, Farges, d'un rouge pâle, avèc les bords plus colorés. Elles sont inodores et insipides, pourvues de nombreuses étamines et d'un pistil. La corolle a dix pétales, veinés et đisposés sur deux rangs. Le calice a cinq dents; il leur suceéde des gousses arrondies, d'un à denx pouces de diamètre, d'un violet purpurin, et hérissées de pointes d'un rouge foncé. Ces gousses sont comprimées; elles rougissent en mûrissant, et s'ouspent evidenx parties égalés petites graines ridées, de fa grosseur de celles de eoriandre, couyertes diune pulpe yisqueuse, dun rouge de feu, et d'une odeur assez forte. Elles ont la forme d'un pepin de raisin, et sont fixées par des filets ou placentas oblongs; la graine séparée de la pulpe est noirâtre, et légèrement aromatique. Les Nègres l'emploient comme condiment.

Afralyse chimique. Je n'ai rien de positif à relater au sujet des parties constituantes du roucouyer.

Proprićxés ménicinales. La propriété aromatique 


\section{(18)}

du roucouyer, l'a probablement fait choisir pour la poudre aphrodisiaque de Wakaka des Indes, décrite ainsi dans le formulaire magistral de Cadet Gassicourt.

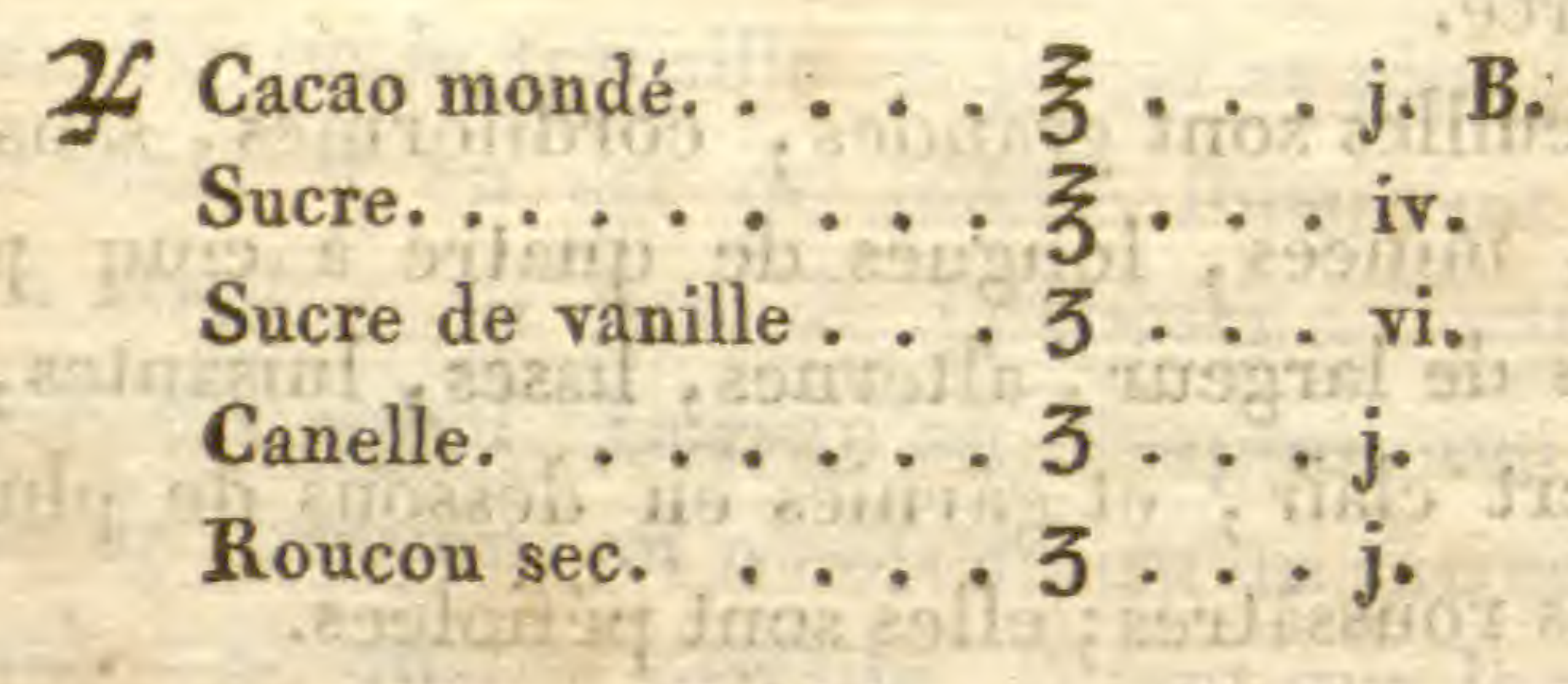

Faites une poudre selon l'art.

Nicolson regarde, au contraire, la pulpe des fruits du roucouyer comme rafraiehissante et astringente.

Explication dE IA PLANCHE QUATRLEME.

Le rameau de roucouyer est représenté au tier's de grandeur naturelle.

1. Parties sexuelles du roucouyer séparées des pétales qui les environnaient.

2. Moitié d'une capsule vue â l'intérieur.

3. Graine recouverte en partie, par 12 pulpe colorée qui l'entoure.

4. Graine nue. 


\section{(19)}

\section{Plantes stomachiques aromatiques}

Portées dans d'autres classes.

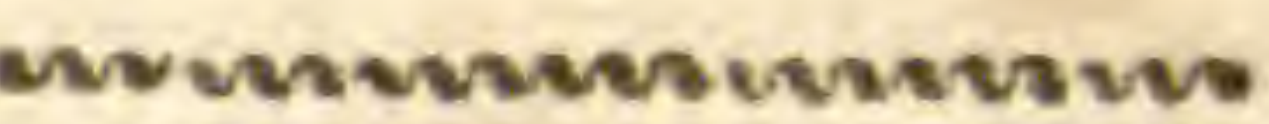

Canelle blanche. (Voyez antiscorbutiques.)

Absinthes. Absinthioîdes. Ambrosioides. (Voyez vermifuges.)

Myrthe poirre de la Jamaïque, Sariette américaine, Valériane, Epine blanche, Mélisse globuleuse, FauxRomarin, Sucrier de montagne. (Voyez alexitères.)

Capraire biflore ou thé des Antilles, Sauvagesia erecta ou thé de montagne, Basilics ou Franc-Bazins. Thym des savanes. Sauge, Franchipanier. (Voyez béchiques aromatiques.)

Oranges, Stachys, Camphrée, Courbaril, Valérianellehumble, Bois de laurier. (Voyez anti-spasmodiques aromatiques.)

Muscadier, Canellier, Gingembre, Vanille, Gingembre sauvage, Gérofle, Canelle noire, Giroflée, Costus, Zérumbeth. (Voyez aphrodisiaques.)

Grande Mélisse, Calamus aromaticus ( Voyez Enmenagogues.) 
P. $s$

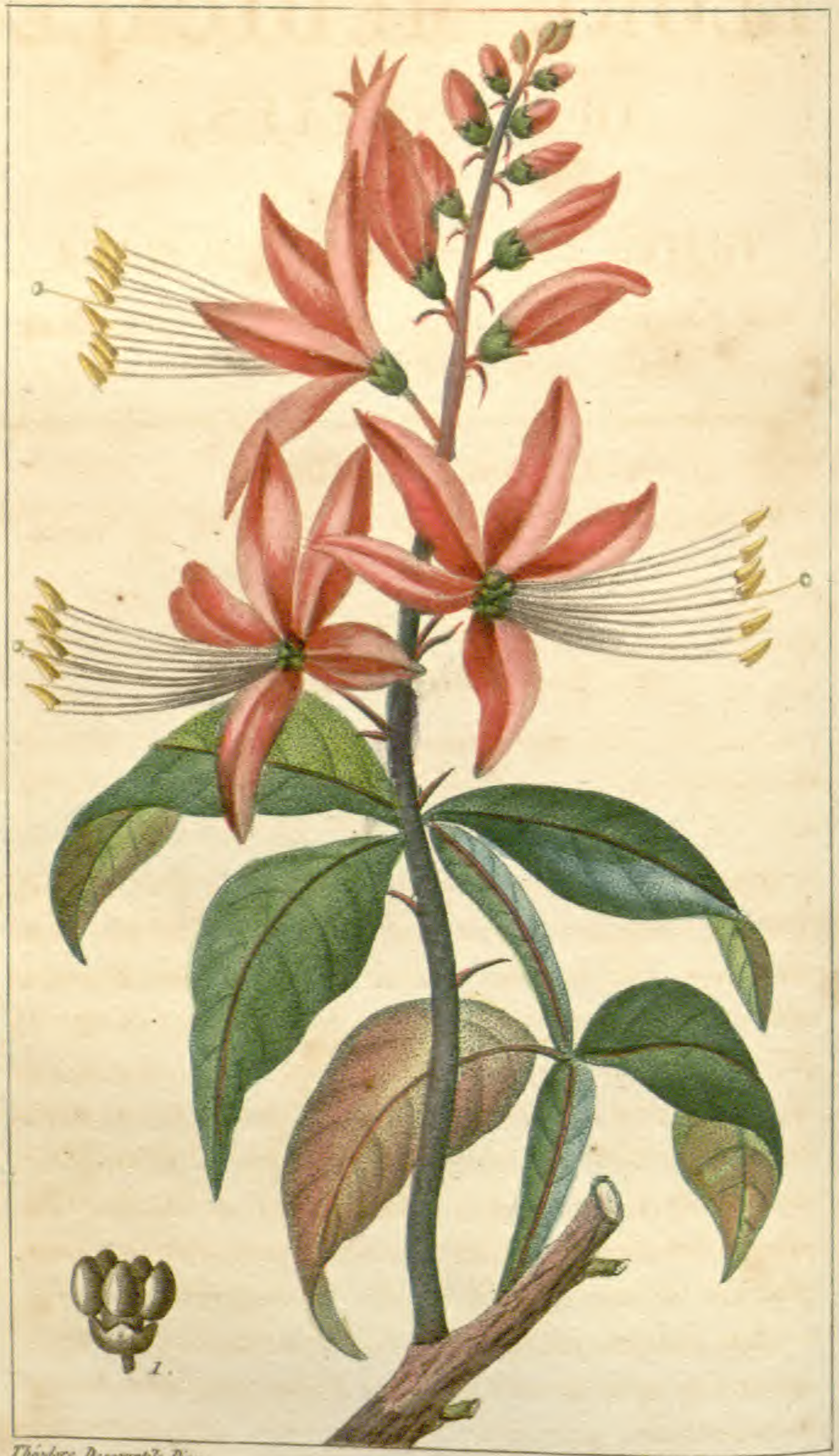

Thindure Dimworht: Arar. 


\title{
FLORE MÉDICALE
} DES ANTILLES,

\author{
o v
}

\section{TRAITÉ DES PLANTES USUELLES}

DES COLONIES FRANCAISES, ANGLAISES, ESPAGNOLES BT PORTUGAISES.

\section{CLASSE PREMIÈRE.}

Des plantes Qui excitent la tonicité des voIEs DIGESTIVÁS ET INTESTINALES.

$2^{\circ}$. Stomachiques FÉBrifuges.

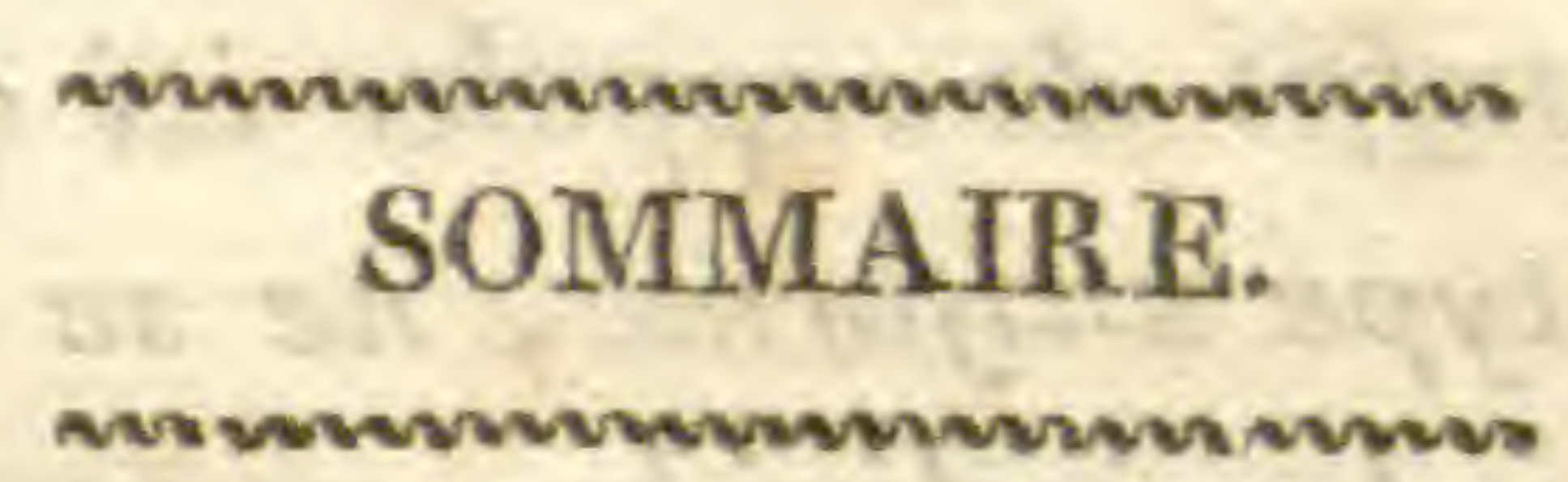

J'ai conservé à cette classe le titre de Fébrifuges, quoique vague, parce que l'usage l'a adopté pour désigner les plantes qu'on croyait spécialement douées du pouvoir de neutraliser le levain de la fièvre, comme les alcalis neutralisent les acides; ce qui n'est pas exact. Cependant l'action de ces plantes consistant à prévenir le retour des fièvres, ou maladies périodiques, et à régler, à rétablir l'énergie vitale troublée par les paroxysmes de la fièvre, $j$ 'ai cru devoir employer cette dénomination.

Les plantes fébrifuges sont excitantes, ou toniques, ou anti-spasmodiques. Elles ont une saveur aromatique, astringente ou amère. Ces demières $2^{e}$. Livraison. 


\section{(22)}

contiennent le plus souvent de l'acide kinique. Si ces plantes conviennent dans les fièvres, il faut savoir les identifier avec le malade, et suivant leur siége particulier; ne pas en prématurer l'ordonnance, avant d'avoir préalablement évacué les premières voies, source des maladies longues et contagieuses qui font le désespoir du médecin.

C'est pourquoi, d'après le type des fièrres, d'après les circonstances qui les ont produites, on doit conclure et juger de l'urgence de ces remèdes, et de leur continuation si l'état du malade en a été amé. lioré. Mais c'est plutót comme stomachiques, que comme neutralisantes du levain fébrile, qu'agissent los plantes fébrifuges. Enfin, pour mieux prouver que le mot Fébrifuge ne reçoit cette acception que par tolérance, il suffit de rappeler ici que les fièvres, quoique d'un type uniforme, ne se traitent pas de méme chez tous les individus, et que leur application doit être subordonnée à l'idiosincrasie du sujet; d'un autre côté, que les fièvres gastriques peuvent céder à l'administration de quelques purgatifs, tamdis que le quinquina, à haute dose, peut seul arréter les progrès alarmans des fièvres muqueuses, ataxi. ques et adynamiques; que ce méme quinquina devient contraire dans la fièvre angeiotónique, qui cède le plus ordinairement à l'emploi des bains, des saignées, ou des acides végétanx et autres moyens anti-phlogistiques; tandis que souvent les amers astringens et les anti-spasmodiquès, en cas de désordres nerveux, devront être préférés aut quinquina. 
$7 \% 6$

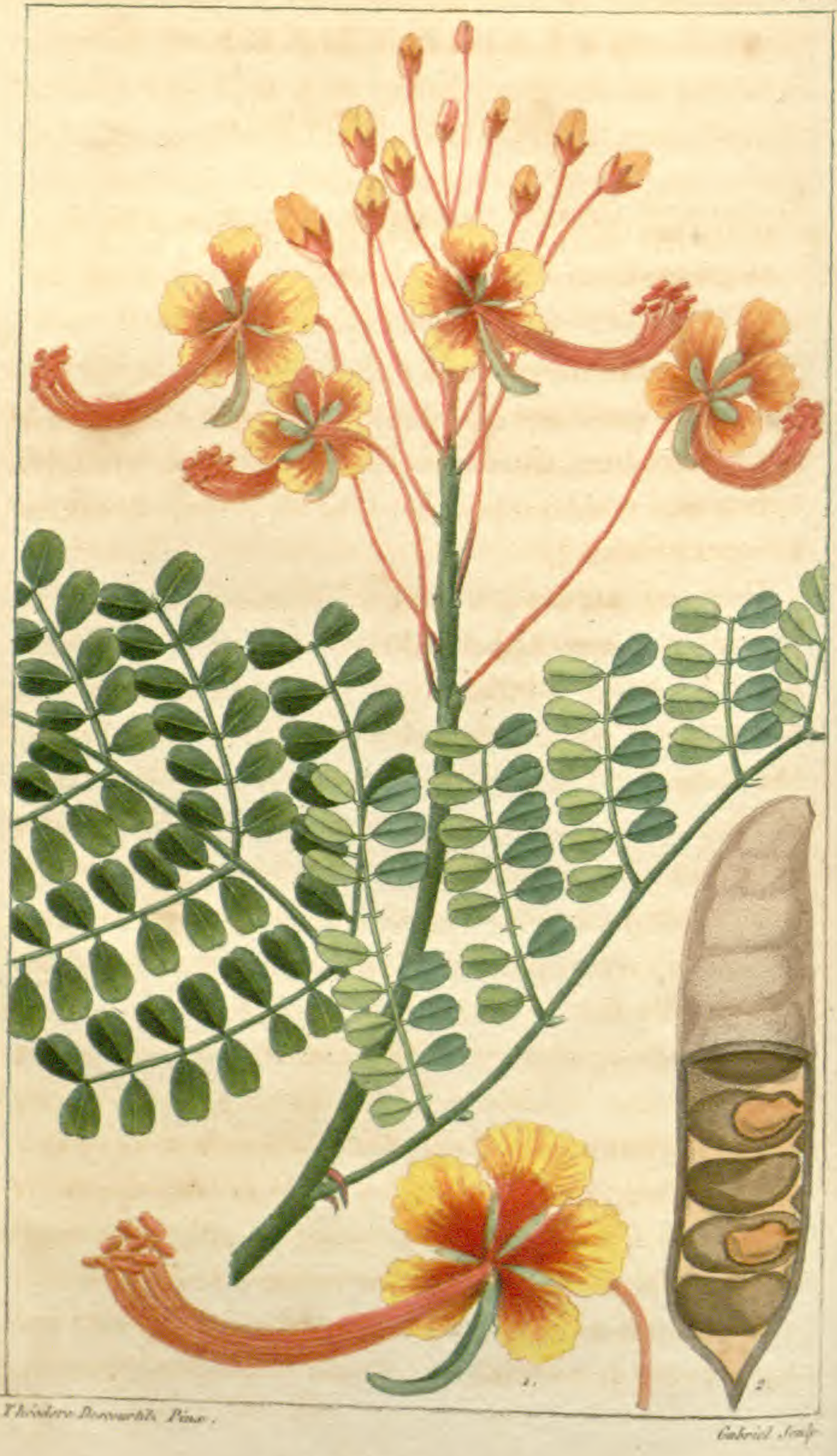




\section{(23) \\ QUASSIE A M E RE. \\ (Stomachique fébrifuge. )}

Sxnonyure. Quassia amara, Limn. Spec., pag. 553. Decandrie monogynie. - Quassia Jussieu, famille des Magnoliers.

Caractér es botaniques. Calice 5 Phylle; nectaire 5 Phylle; 5 péricarpes distans, monospermes; fleurs hermaphrodites, feuilles pinnées avec impaire, folioles opposées, sessiles, pétiole articulé, ailé, fleurs en grappes (vivace).

Histoire naturelle. Cet arbrisseau qui porte le nom d'un nègre appelé Quassi, qui en a découvert les propriétés, dit Bomarre, est commun dans les forêts de Surinam, d'où ila été transporté aux Antilles. On le trouve assez fréquemment dans les lieux frais et humides. Semée de graines sur le bord des rivières où ellese plâ̂t, dit le même auteur, la quassie amèra donne ses premières fleurs au bout de deux ou trois aus : je m'en suis procuré plusieurs fois dans les belles forêts de la baie de Saint-Jago de Cuba.

Caractìres physiQues. La racine de laquassie amére est pivotante, très grosse, l'écorce en est adhérente, mince, grisâtre au dehors, âpre au toucher et striée, jaunâtre au dedans, inodore, d'une amertume si énergique $q u^{2} a v e c$ une très petite quantité elle communique sa saveur à un grand volume de liquide.

Le bois de quassie est d'une moyenne hauteur; ses liges, avant de se ramifier, s'élèvent á cinq ou six pieds, 


\section{(24)}

et sont, dans leur longueur, garnies de feuilles qui se fanent et se détachent après que les branches sont formées. Les tiges sont cylindriques, de couleur cendrée ou grisâtre; les jeunes pousses ont l'écorce verte ponctuée de blanc; l'écorce des rameaux à leur naissance est d'un beau rouge brunissant, lisse dabord, puis recouverte de stries jaunâtres en vieillissant.

Les feuilles sont alternes, brusqquement pinnées a vec impaire, et de forme lancéolée; elles sont persistantes, et offrent le plus joli coup d'ceil par la dégradation des nuances et des tons, qui contrastent élégamment avec la couleur incarnate des bouquets.

Les fleurs, qui ont beaucoup de rapports avec celles de la fraxinelle, sont terminales, en grappe droite, d'un rouge vif, glacé de blanc; le calice trèscourt et à cinq divisions renferme les pétales égaux, alongés en fer de lance, larges à leur base, au nombre de cinq, roulés les uns sur les autres, et ne s'épanouissant que le soir.

Les filets des étamines ont deux fois la longueur des pétales; ils sont au nombre de dix, surmontés d'authères jaunes posées horizontalement.

Le pistil a un peu plus de longueur; il est terminé par un stygmate arrondi, et est remplacé, après la fécondation, par cinq capsules ovoïles.

Analyse chimiQue. Tronmsdorff et autres célèbres chimistes qui ont analysé l'écorce et les racines de la quassie amère, prétendent que, contenant beaucoup plus de parties gommeuses que de parties résineuses, son infusion à l'eau froide doit être la meilleure manière de l'employer comme médicament. 
Proprítés uédicales. On regarde la quassie amère; comme un trèspuissant anti-septique, en raison de son amertume balsamique, et comme propre à prévenir, retarder ou arrêter la corruption : c'est pourquoi les nègres l'emploient en lotion dans le pansement de leurs malingres et ulcères vermineux. Les médecins eux-mêmes, empressés de profiter des propriétés incontestables de cet arbrisseau, le prescrivent avec beancoup de confiance et de succès dans les fièvres de mauvais caractère, et dans celles intermittentes et qui ont quelquefois résisté à l'emploi du quinquina et de la fleur de poincillade. On emploie les fleurs de quassie dans certains bains fébrifuges, surtout à la suite des fièvres pétéchiales et exanthématiques. Alibert recommande l'usage de l'infusion de quassia amara dans les graves dispepsies accompagnées de vomissemens; soit que ces maladies soient essentielles, soit qu'elles succèdent à d'autres affections, particulièrement à des affections bilieuses. C'est en raison de son principe amer, que la quassie est adoptée an rétablissement des voies de l'estomac et des voies intestinales. Son usage convient aux personnes de cabinet, privées, pax leur état, d'un exercicesalutaire, et offre, suivant Alibert, un excellent vermifuge.

Mode d'administration. On prescrit peu le bois, mais les racines du quassia amara en infusion, à la dose d'un gros de sa poudre par pinte d'eau bouillante; en poudre, à celle d'un scrupule à un demigros, une heure avant l'accès; en teinture, depuis. dcmi-grosjusqu'à deux gros; en extrait, de demi-gros. ̀̀ 


\section{(26)}

un gros: on ordonne le vin, depuis une demi-once jusqu'à une once, avant le repas, contre la goutte, pour faciliter les digestions et fortifier l'estomac; un gros de la racine rapée, suffit pour un demi-litre de vin.

M. Planche, dit Alibert, a imaginé de faire construire des gobelets et des tasses avec le bois de quassie, qui sont d'un usage fort commode. On y fait infuser à froid, du vin ou de l'eau; il suffit de quelques minutes pour obtenir une potion convenable aux estamacs débilités.

Explication de ta planche cinquième.

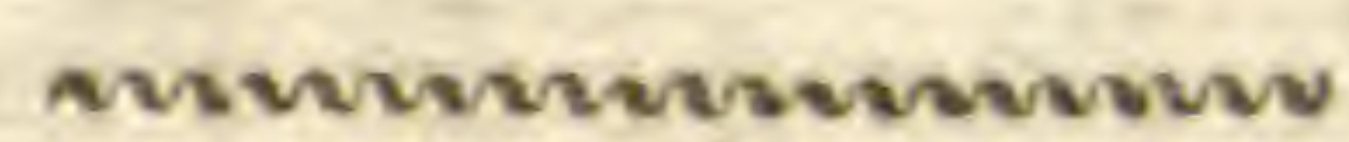

I a plante est représentée moitié grandeur naturelle.

1. Cinqq capsules renfermées dans le même calice. 


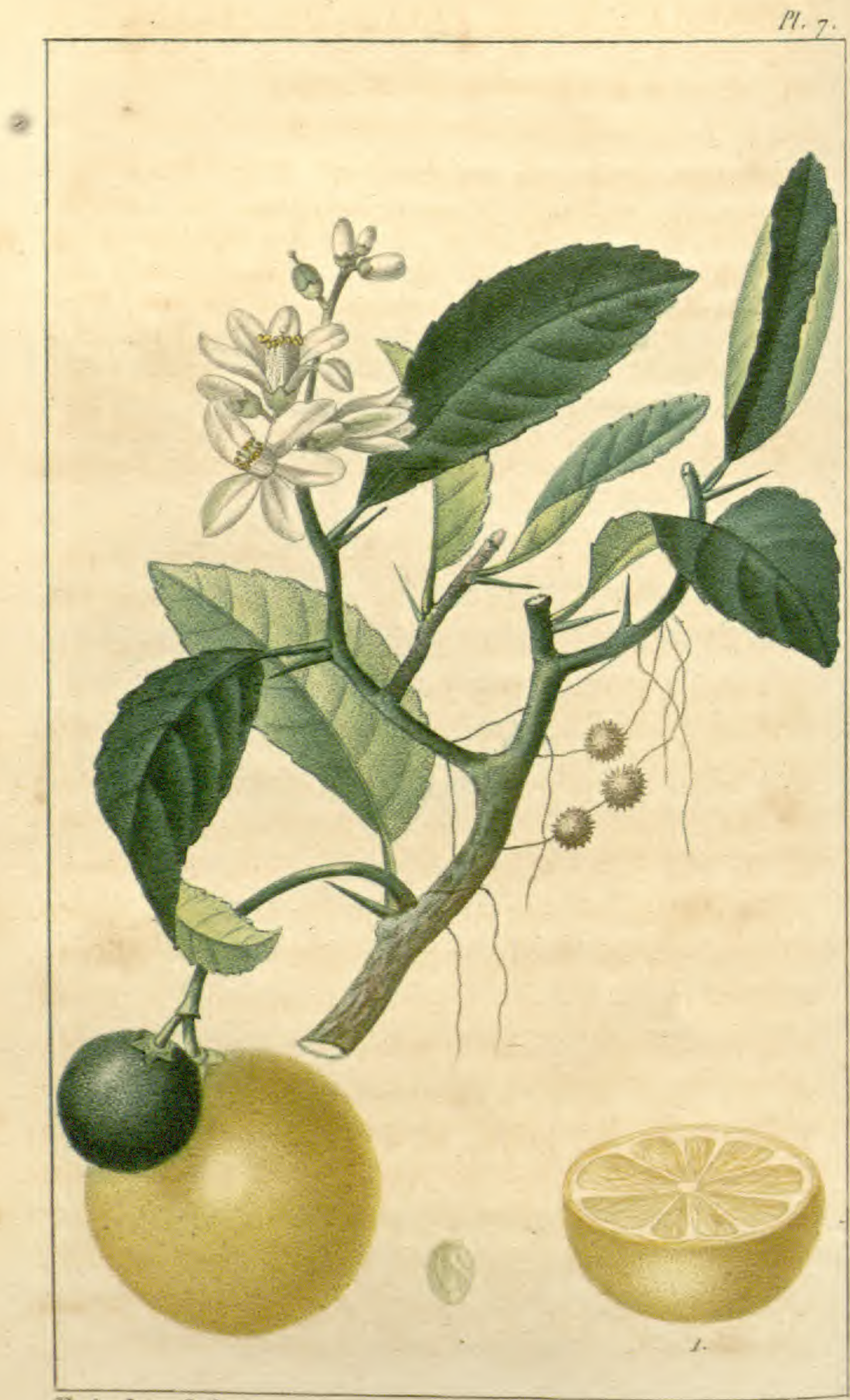

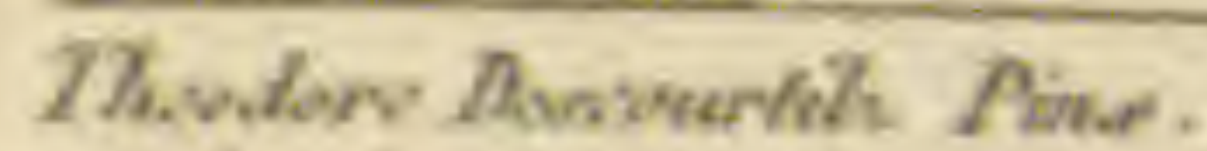




\section{POINCILLADE, OU FLEUR DE PARADIS.}

(Stomachique fébrifuge.)

Synonyme. Poinciana pulcherrima. Linn. Decandrie monogynie. - Cassia, Tournefort; class. 21, arbres rosacés, sect. 4.- Jussieu, famille des légumineuses, cl. 14 , ord. 2. - Senna spuria, Sloan.-Crista pavonis, Breyn. - Frutex pavonicus, flos pavonis, Mérian. - Tsietti mandara, Hort. Malab. - Fam. 43, les légumineuses, sect. 1, Adanson. - Acacia orbis. americani altera, flore pulcherrimo. H. R. P. - Poinciana flore pulcherrimo. Plum., vol. 7, pag. 129.Tsjetti mandarum. Mal. - Foula de Pavan. Portug.

Caractères botaniques. Calice 5 phylles, 5 pétales, dont le supérieur est le plus grand; étamines longues, toutes fécondes; légumes, arguillons géminés ( vivace). Linn. Par Joliclerc.

Histoire naturelle. La poincillade, l'une des plus belles légumineuses, doit son nom à M. de Poincy, gonverneur-général des îles Antilles, qui la fit venir de l'ile Saint-Martin. Ce magnifique arbrisseau, quoique épineux, est recherché par la beauté de sesfleurs et de son feuilage. On en fait de brillantes palissades. Chevalier recommande de recueillirles fleurs tous les matins, quand le soleil en a pompé la rosée, de les faire sécher à l'ombre avec soin, de les retourner tous les jours, et de les enfermer ensuite dans une boîte pour les conserver. Il fleurit en mai et août, et donne ses fruits en décembre et janvier.

Caractieres physiques. Ce bel arbrisseau épineux, equ'on est parvenu à cultiver dans quelques jardins: 


\section{( $2 \hat{b})$}

de l'Europe, croît naturellement aux Antilles, ou is étale pompensement son feuillage varié.

Il s'élève à la hauteur de douze pieds environ: les tiges sont grêles, tendres et cassantes; l'écorce d'un gris cendré, sillonnée de crevasses; les plus jeunes branches sont vertes, lisses et noueuses. De chaque noeud, dit Nicolson, qui l'a remarqué le premier, partent deux ramilles opposées, sur lesquelles sont placées les feuilles deux à deux, longues de quatre lignes sur deux de largeur, arrondies à l'extrémité, un peu en coin à la base; traversées dans leur longueur par une côte tendre, à bords entiers, d'un vert gai et diversement nuaucé. Chaque pétiole est garni à la base d'une épine crochue; il est toujours terminé par une paire de pétioles partiels, et ceux-ci le sont eux-mèmes par une paire de feuilles.

Les fleurs de la poincillade, qu'on a nommées fleurs de paon à cause de leur beauté, deleur élégance, et de leur éclat éblouissant, sont terminales en thyrse, dont l'extrémité est garnie de boutons gros en bas, et plus petits à mesure qu'ils s'approchent de la sommité dont les pédoncules s'alongent en proportion de la grosseur des bontons. Ces fleurs ont cinq pétales inégaux, crénelés dans leur contour, dont l'inférieur plus long est creusé en gouttière; jaunes sur les bords, de conleur de fen au milieu; d'un rouge plus pâle et mèlé de jaune et de vert au dehors; portés sur de longs pédoncules de la même couleur, et renfermés dans un calice découpé jusqu'à la base.

Les étamines partent du centre; elles sont aix nombre de dix; d'un ronge de feu, sétacées, un peu 


\section{(29)}

coupbées, plus grandes que les pétales, et à anthères oblongues.

Le pistil en forme d'alêne, de la longueur des étamines, devient une gousse plate, comprimée, et toujours solide, d'un violet lilas au dehors, blanchâtre en dedans; elles contiennent de six à neuf semences rougeâtres, larges, épaisses, d'une forme carrée et imitant celles du tamarinier; elles sont solitaires et suivant la largeur du légume, c'est-à-dire logées chacune dans une fosse cloisonnée.

Les fleurs de chaque thyrse s'épanouissent de trois à quatre par nuit, et il en renaît toujours pour remplacer celles qui fructifient: il en sort aussi d'axillaires; de sorte que l'arbrisseau, couvert de fleurs, offre la riante image d'un printemps continuel.

Analyse chimique. Les fleurs de la poincillade colorent en jaune foncé l'eau dans laquelle on les fait macérer; elles lui communiquent une saveur très amère, sa décoction n'est altérée ni par l'eau de chaux, ni par la dissolution de sulfate de fer.

Propriétés médicinales. Chevalier dit avoir guéri par leur secours trois personnes qui avaient un ulcère au poumon, et que M. Alais, médecin à la Rochelle, Ini en a confirmé les propriétés pour les mêmes circonstances. Je puis assurer, d'après ma propre expérience, que je les ai employées avec succès pour moimême, dans la convalescence d'un empoisonnement qui avait altéré mes fonctions digestives.

Je prescrivais souvent la poincillade comme pectorale dans les catarrhes pulmonaires; mais sa principale propriété est d'être fébrifuge par excellence. 


\section{(3o)}

Elle a sur le quinquina l'avantage d"être agréable an goût, et de ne point en répéter l'emploi; elle agit comme sudorifique dans les maladies de la peau, les fièvres milliaires et celles exanthématiques.

Mode d'administration. On prépare les fleurs de la poincillade en infusion théiforme, à la dose d'une petite poignée par pinte d'eau bouillante qu'on verse dessus, en couvrant le vase : on en donne au malade plusieurs tasses sucrées et bien chaudes, deux heures avant l'accès; le malade sue beaucoup, et ordinairement les accès ne reviennent pas.

Les fleurs réduites en poudre, et combinées avec la canelle, l'oxide de fer, le muriate d'ammoniaque et le sirop de gingembre, donnent un opiat qui combat puissamment les fièvres quartes les plus rebelles.

Ces mêmes fleurs, à forte dose, fournissent un emménagogue-très énergique, qu'on ne doit prescrire qu'avec prudence et une extrême circonspection. Les négresses mal intentionnées en font usage pour détruire les fruits de leurs coupables amours.

\section{Explication de la planche sixième.}

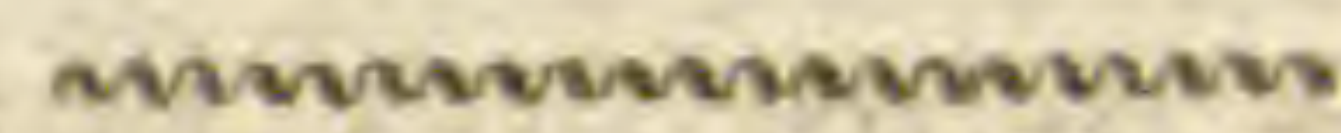

La plante est représentée moitié grandeur naturelle.

1. Fleur entière de grandeur naturelle.

2. Légume dont on a enlevé une partie d'une valve, afin de mettre à découvert les graines et les cavites qui les regoivent. 


\section{$(3 i)$}

\section{CITRONNIER DES HALLIERS.}

(Stomachique febrifuge.)

Synonymie. Citrus medica. Lin. Polyadelphie icosandrie.- Tournefort, citrus, cl. 21, arbres rosacés, genr. 2, sect. 6. - Jussieu, Citrus silvestris, fam. des orangers. - Inst. R. 4., Citrum vulgare acri medullâ. - Citrsm, Bergamottier. Cidromela, Lobel._-Medica malus, C. B. - Citrnm silvestre, fructu rotundo. (Desc.)

Caractères botanigues. Calice, 5 Phylle. 5 Pétales oblongs. Anthères à 20 filets connés en divers corps. Baie à 9 loges vésiculeuses. Pétioles légèrement ailés, et plus souvent linéaires.

Histoire naturelue. On connaît aux Antilles quatre espèces de citronniers : $1^{\circ}$ le citronnier de la Barbade ou Chadec; $2^{\circ}$ le citronnier de Portugal ; $3^{\circ}$ le citronnier doux; $4^{\circ}$ le citronnier sauvage ou des halliers, à fruits ronds. C'est de ce dernier dont il sera quetion dans cet article

Caractìres phrsiques. Le citronnier sauvage dont on forme des buissons de clôture, que ses épines aiguës et multipliées rendent impénétrables, est très touffu, médiocrement élevé. C'est l'image des quatre saisons, puisqu'en tout temps on le trouve chargé de boutons, de fleurs et de fruits de diverses grosseurs, d'après leur état d'accroissement.

L'écorçe du citronnier sauvage est d'un vert pâle, le cour dur, à fibres serrées et de couleur jaune. Ses branches ou rameaux, souvent en proie aux ravages 


\section{(32)}

de la cuscute, et servant de repaire aux couleuvrés et autres animaux venimeux, sont vertes. Les racines rameuses sont blanches au dedans et jaunes à l'extérieur. Les nouvelles pousses sont anguleuses, vertes et souvent violettes.

Les feuilles sont simples, oblongues, larges, d'un vert foncé luisant, et légèrement brodées par dessus; d'un vert glauque par dessous; souvent roulées sur elles-mêmes; d'une odeur forte, et contenant une huile aromatique essentielle. Le pétiole est rarement ailé, comme dans l'oranger, et la circonférence de la feuille est dentée.

La fleur naît au sommet des rameaux où elle forme une grappe droite. Elle est composée d'un calice monophylle à cinq dents, et se flétrissant; de cinq pétales disposés en rond, oblongs, planes, ouverts, de couleur blanche purpurine, d'une odeur agréable.

Les étamines presque toujours au nombre de vingt, sont subulées, souvent réunies. Les filets sont blancs, les anthères oblongues et jaunes.

Le pistil est de la longueur des étamines, le style cylindrique et terminé par un stygmate en tête, déprimé et verdâtre.

A ces fleurs succède un fruit rond, de la grosseur d'une balle à longue paume, revêtu d'une écorce lisse, peu épaisse, d'abord verdâtre, ensuite d'un jaune citrin, d'une odeur suave et fragante, contenant une huile éthérée très subtile qui s'échappe an moyen de la pression, d'une infinité de petites glandes dont cette peau est parsemée.

La pulpe est serrée, d'une acidité agréable, et lế- 


\section{$(33)$}

gèrement odorante; partagée intérieurement en nouf loges pleines d'un suc acide contenu dans des vésicules membraneuses. Les graines ou pépins oblongs sont âcres, amers; on les emploie en médeciue.

L'air embaumé qui règne autour des cases environnées de citronniers, décèle leur présence, et fait qu'on les met souvent à contribution pour divers besoins. Le cuisinier s'en fait apporter, chaque matin par ses négrillons, des macoutes pleines, pour en parfumer ses différens ragoûts, et ôter au Calalou sa vertu mucilagineuse. La créole voluptueuse fait composer ses bains avec les feuilles et les fleurs de cet arbrisseau odoriférant, tandis qu'avec son fruit, coupé par la moitié, on lui frotte le corps pour exciter et resserrer les organes cutanés. Le valet de chambre l'unit au sirop de batterie et à l'huile de riein, pour vernir avec ce cirage brillant et économique, les chaussures de son maître; et la négresse, dont la première qualité est l'extrême propreté, se sert des hémisphères du fruit pour décrasser le linge. On arrose de ee suc le poisson salé, et la viande fumée dont on fait une grande consommation aux colonies.

On confit au sucre les jeunes eitrons entiers, et simplement l'écorce des plus vieux. Cette écorce qui figure sur les tables somptueuses, facilite la digestion, et son candi offre à l'ceil des cristallisations diversement nuancées.

Aralyse chimique. Le zeste du citron contient une huile essentielle qu'on appelle Néroli, et un principe extractif amer. Le suc rougit les couleurs bleues végétales. Il se combine avec les bases salines et forme des citrates. 


\section{(3i)}

Propriétés médicinales. Le citromier sauvage, offre beaucoup de ressources à la pharmacie; son suc acide convient à beaucoup de maladies du pays; étant combiné avec le précieux jus de la canne à sucre, il procure une limonade agréable, qui fait bonne bouche, apaise la soif, réveille l'appétit, et aide la digestion; cette boisson salutaire qui se trouve en tous lieux de la colonie, non seulement tempére l'effervescence du sang, effet d'une chaleur excessive et énervante, mais devient aussi infiniment utile dans le traitement des fièvres angéioténiques, bilieuses et adynamiques, dans les dyssenteries putrides, les hémorragies actives, la rétention d'urine, et l'empoisonnement par les végétaux vénéneux.

Pax suite de principes hygiéniques, à la moindre indisposition, le colon fait usage de cette limonade comme moyen prophylactique d'accidens plus graves; prévient ainsi les maladies, et à l'aide d'une diète de vingt-quatre heures, il se trouve dispos, et comme dans une autre vie, débarrassé enfin de ces chaleurs d'entrailles, et des étourdissemens qui l'obsédaient, surtout s'il accompagne ce moyen de bains et de clystéres. Le même suc, uni au tamarin, fournit un évacuant laxatif, précieux à employer dans la fièvre janne.

L'écorce de sa racine et son extrait sont d'excellens fébrifuges, surtout si à la décoction on ajoute quelques gouttes d'acide muriatique dulcifié. Alors on l'emploie comme détersive dans la cure des ulcéres et des gonorrhées. Le jus de ce citron est tellement acide, qu'on fait avec une espèce d'onguent égyptiac, en le combinant avec la suie et le machefer. Il est ra- 


\section{(35)}

fraichissant, anti-putride, alexitère etanti-scorbutique, aussi les marins, au retour d'une longue navigation, en arrossent-ils leur viande fraiche, qu'ils font griller ensuite.

On fait mourir les vers des enfans en leur donnant, comme vomitif, une cuillerée d'huile d'olive, et deux de jus de citron; cette mixture est très efficace dans certaines convulsions du premier âge. Une cuillerée à café de ce suc, prise d'heure en heure, et que lon a mis en effervescence avec le carbonate de potasse, arrête le vomissement causé par une bile engorgée dans l'estomac, ou le duodénum; c'est la potion de Rivière. Les nègres vantent aussi un remède qu'ils emploient pour la cure du ténia : c'est un verre de jus de citron oú l'on a délayé deux pincées de cendre. Le ver meurt; mais on doit avoir recours aux purgatifs pour l'expulser. Un jus de citron, trois onces d'eau de rose, et le blanc d'un ceuf, donnent, au rapport de Chomel, une potion utile dans les gonorrhées.

Le sel essentiel de citron, se retire par l'évaporation de son suc jusqu'en consistance d'extrait.

L'huile essentielle est vermifuge et cordiale; on s'en sert pour aromatiser les potions nauséabondes: les graines sont vermifuges. Un citron lardé de clons de girofles porté sur soi, et souvent malaxé, est un bon préservatif dans les hôpitaux, pour neutraliser le méphytisme de l'air.

Le zeste réduit en poudre entre dans plusieurs préparations officinales: les feuilles sont généralement estimées toniques et anti-spasmodiques. 
Mode d'administration. L'écorce de citron en poudre entre dans la composition des opiats alexitíres et fébrifuges; on la prescrit aussi en infusion théiforme : la dose de l'huile volatile est de cinq à dix gouttes par once de véhicule. L'acide citrique absorbé par une suffisante quantité de sucre, fournit à l'aide d'un mucilage des pastilles très agréables, et qui rafrâchissent la bouche. L'infusion théiforme des feuilles, prise à jeun, détruit les levains d'une digestion viciée et interrompue. On donne avec succès entre les accès de fièvres intermittentes, le jus de deux citrons dans une tasse de fort café sans sucre et avec son mare.

On compose dans les hôpitaux des colonies une pommade contre les dartres, qui est une modification des préparations sulfureuses d'Alibert : la voici... Prenez suc de bois laiteux, de eitron, d'herbe à dartres, de chaque une once et demie; fleurs de soufre un gros; poudre à canon un scrupule; huile de gigiri, quantité suffisante ; mêlez.

Explication de ia pLANChe septik̀me.

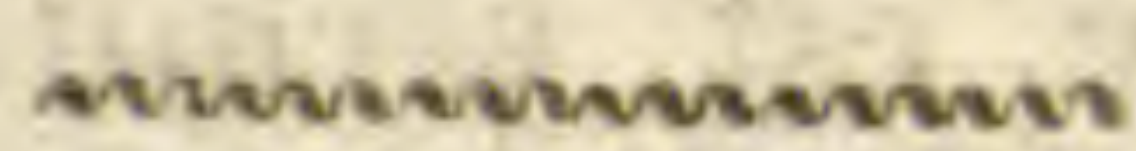

\section{Grandeur naturelle.}

1. Fruit coupé transversalement.

2. Graine. 
$7 \% .8$.

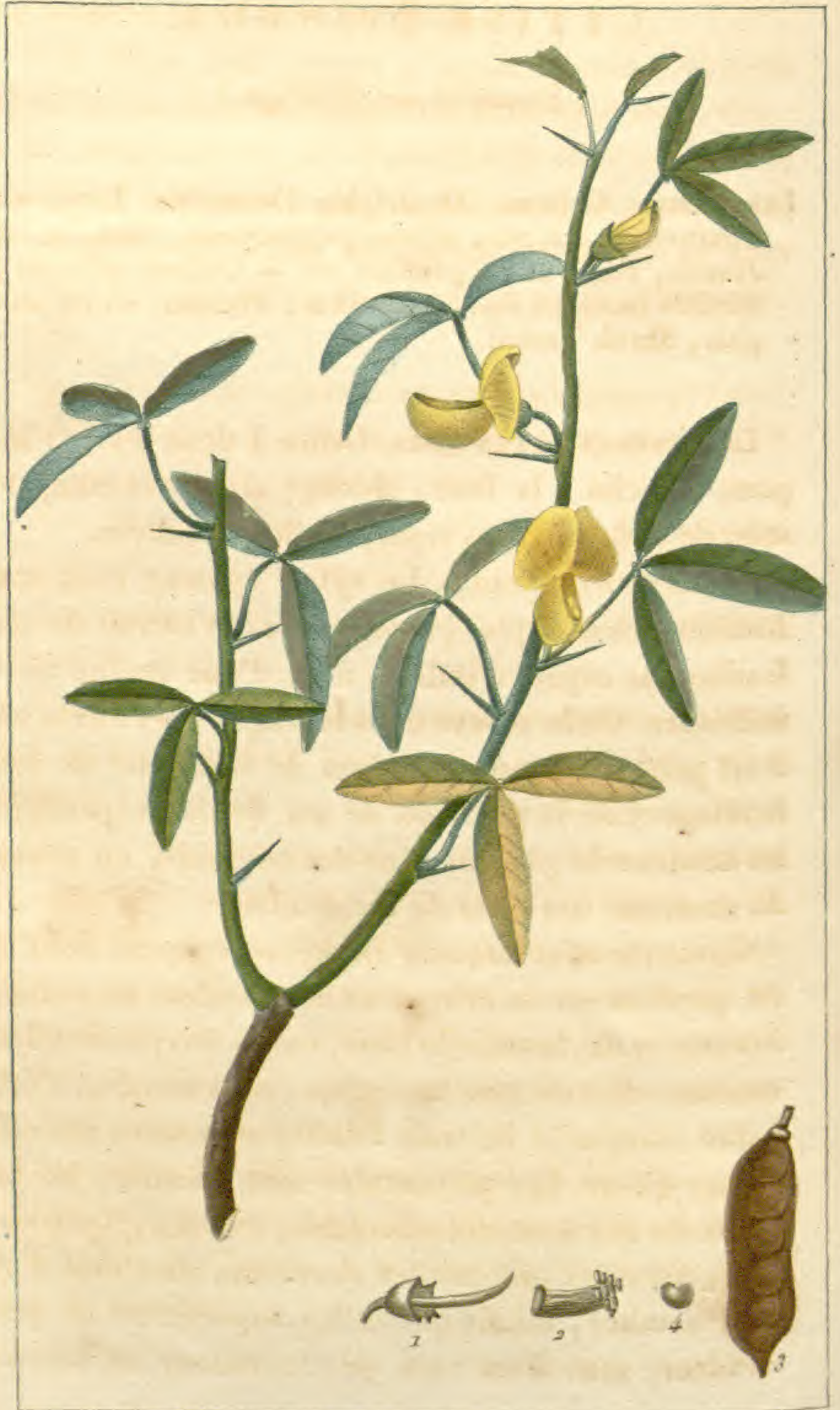




\section{( 37 ) \\ C Y T ISE ÉPIN E U X. \\ (Stomachique fébrifuge.)}

Synonymie. Cytisus. Diadelphie Decandrie. Linn. -

Tournefort, cl. 22 , arbres papillonacés, sect. 2. Jussieu, Fam. des légumineuses. - Cytisus spinosus, floribus luteis ad alas nascentibus, Plumier. - En anglais, Shrub Trefoïl.

Caractiones botaniotes. Calice à deux lèvres; légume attaché à la base, oblong; semences comprirurees de la forme d'un ricin; feuilles trifoliées.

Histörke natureliz. Le eytise épineux crốt aux Antilles, où quelques propriétaires ont extrait de ses feuilles une espèce d'indigo, mais d'une qualité trèsisférieưre. On le trouve dans la plupart des forêts où il esét peu remarqué, en raîson de la ténuité de son feunillage et de la petitesse de ses fleurrs; cependant lèsamateurs le placent dans des bosquets, en raison dà contrâste des verts de son feuillage.

Caractiones puryioges. Le cytise épineux dont if est quéstion est un arbrisseau dè grandeur moyenne, àeorcetverte, brodée de brun, en rêseaux; ses feuillès, comme celles de tous les eytises, sont ternées, c'està-dire composées de trois folioles sontenues sur une même queuè. Les pédoncules sont alternes, les folicles dü bas sont rhomboïdales, étroites, longues; lêrus nervures imitent des chevrons; elles sont d'urt vert sombre, tandis que celles supérieures et plus tendres; souti d'un vert gar ; le dessons est'argenté 


\section{( 38 )}

dans les unes et les autres; les feuilles acquièrent en se fanant une couleur de rouille.

Les fleurs sout jaunes, papillonacées, naissant dans les aisselles des feuilles, à l'insertion du pétiole; elles sont solitaires, ou au nombre de deux seulement, munies d'une épine aiguë : le pédoncule est très-petit; il supporte un calice campanulé et divisé en deux lèvres; la supérieure a deux pointes, et l'inférieure en a trois.

Les filamens des étamines sont diadelphes, recourbés, les anthères simples, le pistil est oblong, le style simple et montant.

Aux fleurs succèdent des siliques de la longueur. d'un pouce environ, renflées, d'abord vertes, puis de couleur de rouille en mûrissant; ces gousses ouvertes offrent de petites semences cordiformes.

Analyse chimique. Les fleurs du eytise épineux sont peu odorantes; leur saveur est amère; elles donnent à l'analyse une sabstance extractive inodore.

Propriétés médicinales. Les fleurs et les semences du cytise épineux sont réputées fébrifuges, ainsi que les autres amers; les fleurs surtout sontemployées lorsque les facultés digestives sont languissantes, et dans l'atonie des viscères abdominaux. On a souvent. recours aux fleurs du cytise épineux dans la curation des fièvres intermittentes.

Les feuilles de cet arbrisseau sont résolutives.

Mode d'administration. Les fleurs sont employées en infusion théiforme, à la dose de deux gros par. pinte de liquide.

Les graines, après avoir été torréfiées, servent à 


\section{(39)}

la confection des opiatsfébrifuges, depuis un scrupule jusqu'à un gros: on prend quelquefois cette poudre dans du vin.

On associe souvent aux fleurs celles de poincillade pour augmenter leur énergie.

On compose avec les feuilles, celles du convolvulus patate, et la liane molle, de fort bons cataplasmes résolutifs.

Expitcation de ta planche huitième.

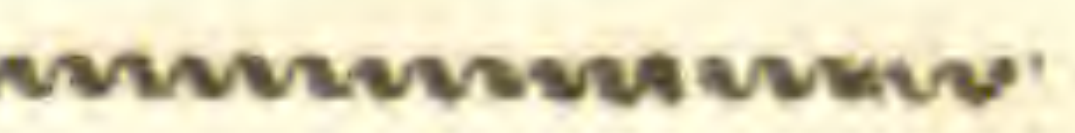

La plante est représentée presque de grandeur naturelle.

3. Calice et embryon.

2. Faisceau des étamines réunies à leur base。

3. Légume.

4. Graine. 


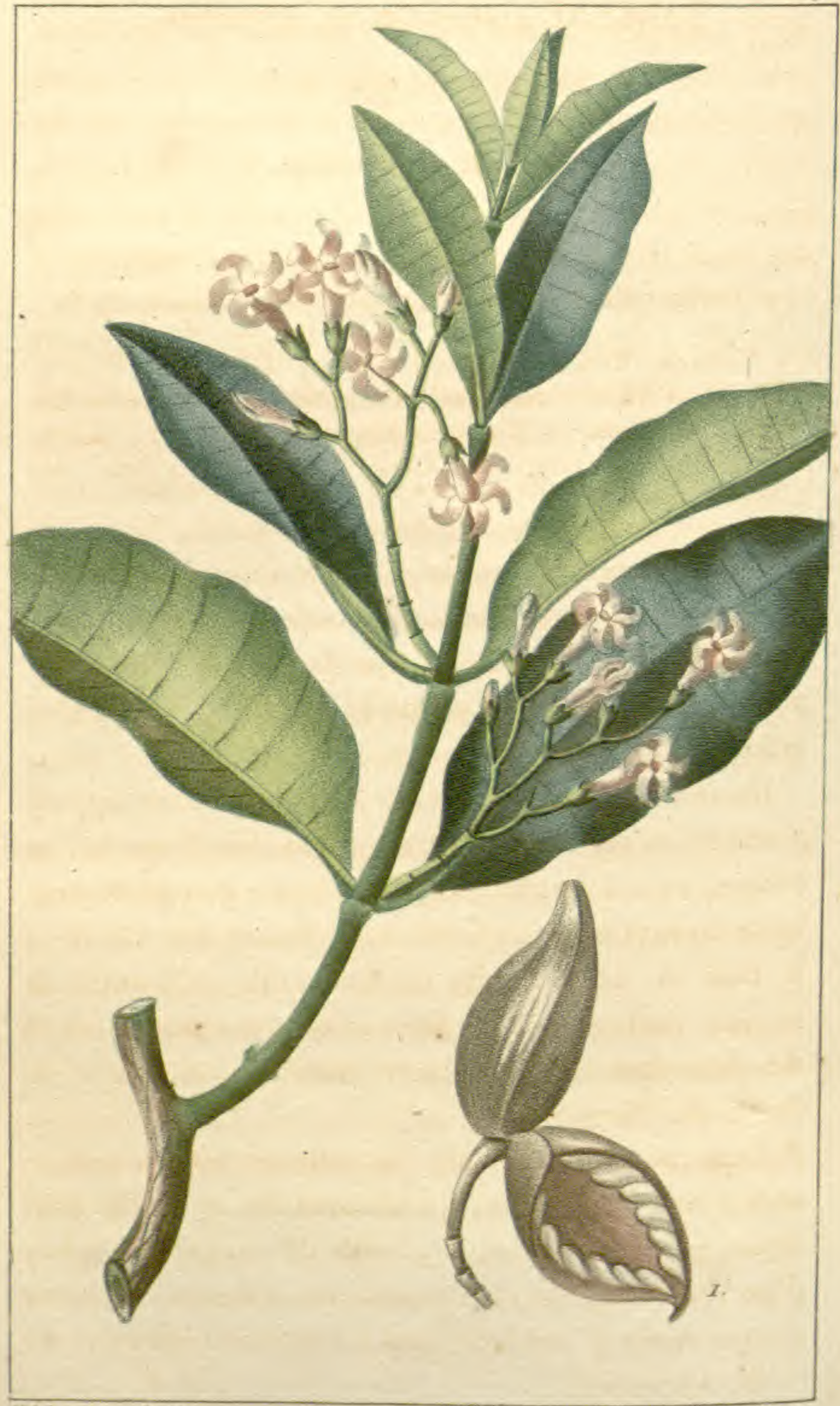

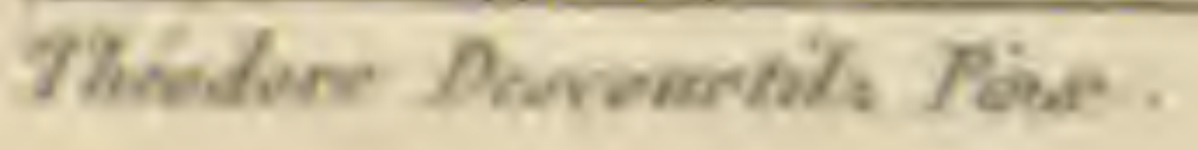

Coulnit Sinf

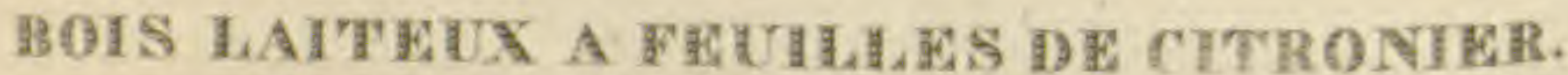


TABERNE a FEUILles de citrontek.

\section{Vulg. BOIS LAITEUX FRANC. \\ (Stomachique fébrifuge. )}

Synonymie. Tabernæmontana, lactescens, foliis citri undulatis ; Plum., vol. VI, pag. 62. - Rauwolfia lactescens (Nicolson). - Arbre laiteux des Antilles (Valmont-Bomarre). Bois laiteux fébrifuge (Chevalier ). - Taberne de quelques auteurs. - Ouronankle des Caräbes. - Tabernæmontana citrifolia, Linn. Pentandrie monogynie, Linn. - Jussieu, fam. des Apocynées.

Caractères génériques. Corolle infundibuliforme à limbe tors, deux follicules horizontales et divergentes; semences plongées dans la pulpe; feuilles opposées, ovales un peu obtuses; fleurs latérales, glomérées en ombelles; (vivace.)

Histoire naturelle. Cet arbre est ainsi appelé parce qu'on en retire, au moyen de l'incision de son écorce, un suc laiteux, âcre et amer : il se plaît danz les rochers et dans les forêts rocailleuses des Antilles; le bois en est si tendre et si cassant, qu'il suffit de secouer l'arbre pour en faire éclater des morceaux ct des branches. Le taberne se trouve dans toutes les forêts des Mornes.

Caractìres physiques. Le taberne est un arbrisseau à tige dichôtome, produisant de sa racine plusieurs jets grêles, cassans, hauts de cinq à six pieds ; d'un vert sombre à l'extrémité des rameaux, et d'uns écorce striée et cendrée dans les parties ligneuses.

$3^{4}$. Livraison. 


\section{( 42$)$}

Les feuilles, semblables à celles du citronnier, sont opposées, ondées sur les bords, luisantes, pointues, divisées en dessous par une côte saillante, à laquelle aboutissent des nervures transversales droites, d'un vert foncé en dessus, et d'un vert pâle en dessous. Ces feuilles sont longues de six pouces et larges d'un pouce et demi.

Les fleurs infundibuliformes et contournées sortent des aisselles des feuilles; elles sont portées sur de longs pédoncules, et forment des ombelles irrégulières; elles sont petites, blanches, ou d'un jaune d'or, peu odorantes, à limbe quinquéfide, dont les divisions étroites sont recourbées en divers sens; les pétales des jeunes boutons roulés les uns sur les autres; le périanthe 5-fides, connivent, est aigu et petit.

Les étamines ont cinq filamens, minces, renfermés dans le tube de la corolle; les anthères sont rapprochées.

Le pistyl est porté sur deux ovaires simples, le style est subulé, les stygmates peu apparens.

Les fruits offrent deux follicules divergentes, bom. bées, acuminées, uniloculaires et univalves; ils contienuent des semences nombreuses oblongues, obtuses à la partie ombilicale, imbriquées et entourées de pulpe.

Proprítés chimiQues. Le suc laiteux qui découle de toutes les parties du taberne, qu'il sufit de froisser pour en obtenir, est âcre et caustique; il donne une substance gommo-résineuse, soluble en partie dans l'eau, partie dans les spiritueux. Les acides agissent 


\section{(43)}

très-promptement sur cette substance, ce qui fait présumer qu'elle contient plus de gomme que de résine.

Propriétés médicinales. On se sert de ses feuilles pour composer des bains fébrifuges; on les emploie aussi en loiions comme vulnéraires. Le suc laiteux (dit Chevalier, pag. 150) arrète promptement, par sa vertu styptique, l'hémorragie d'une blessure.

Quelques nègres m'ont assuré avoir employé à l'intérieur, comme fébrifuge, le suc laiteux du taberne à ła dose d'un scrupule au commencement de l'accès, mais incorporé avec du beurre de cacao, pour en émousser la causticité : ils font boire ensuite au malade une infusion sudorifique, qui peut-être opére plus puissamment encore que l'agent principal; mais je n'ai pas éprouvé ce genre de traitement.

Mode d'administration. La dose des feuilles de taj berne, pour chaque bain, est de six poignées, et d'une poignée par pinte d'eau, lorsqu'on l'emploie à l'extérieur dans les décoctions vulnéraires.

On rencontre aux Antilles quatre autres espèces de ce genre qui sont, $1^{\circ}$. taberne à fleurs panachées ( $t a-$ bernœmontana discolor (Swartz Jamaïque); $2^{\circ} \cdot t a b$. à feuille de laurier (tab. laurifolia, Lin. Jamaíque); $3^{\circ}$. tab. ondulé (tab. undulata, Isle Trinité); $4^{\circ}$ tab. à feuilles de nérion ( $t a b$. nerifolia Porto-Rico.)

Ces plantes m'ont été indiquées par les nègres guérisseurs comme douées de propriétés fébrifuges; mais ne les ayant pas éprouvées moi-même, je ne les consigne point ici. 


\section{(44)}

Explication de la PLANChe NEUVIÈme.

La plante estréduite à moitié de grandeurnaturelle.

2 Follicules, dont une ouverte et laissant voir des graines imbriquées logées dans une pulpe.

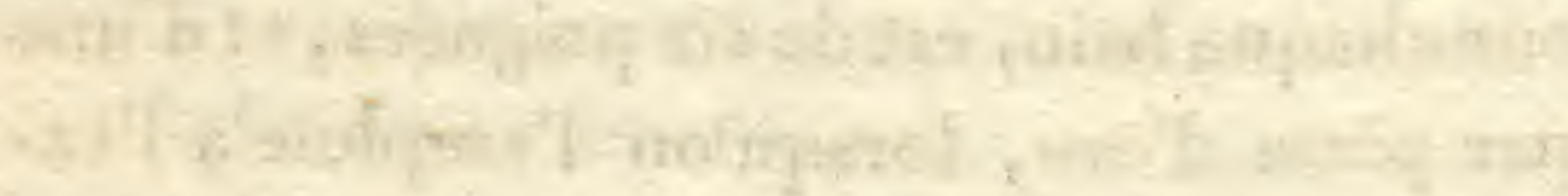

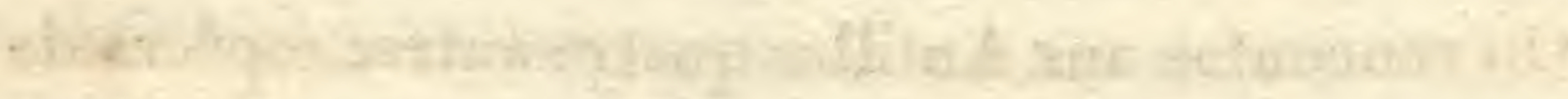

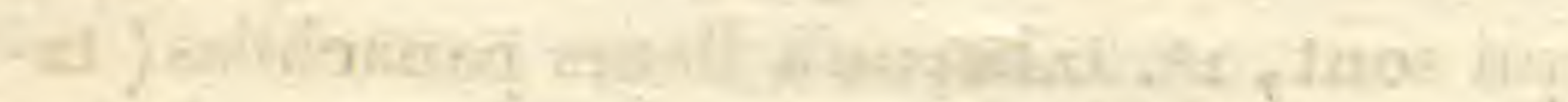


Pl 10 .

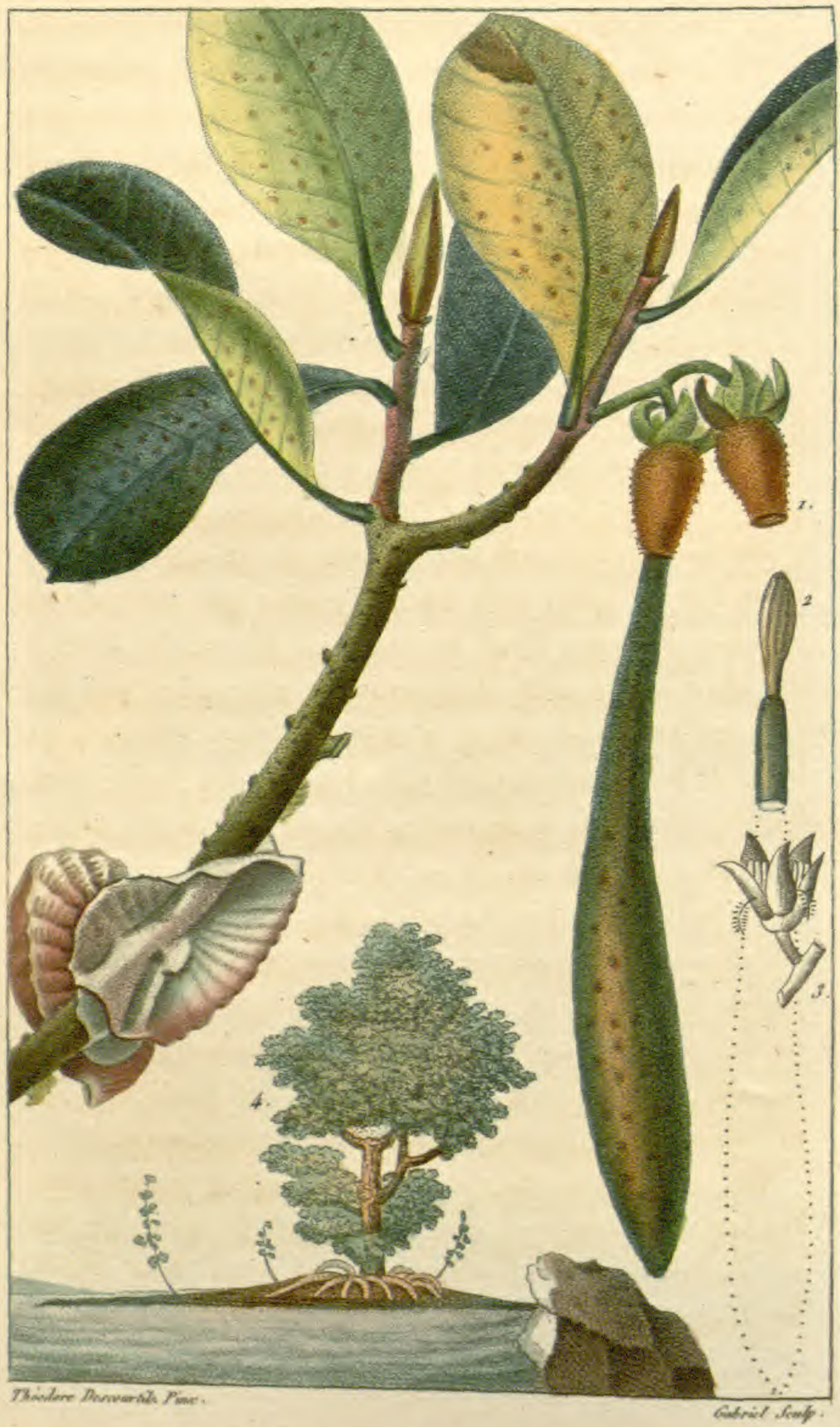

MANGHE CHANDWLL取。 


\title{
$(45)$
}

\section{RHIZOPHORE CHANDELLE.}

\author{
Vulg. manglier chandelle. \\ (Stomachique fébrifuge.)
}

Sxnonymre. Mangles aquatica, foliis subrotundis et punctatis. Plum. vol. 6, p. 8i, - Rhizophora candel. Lin. dodécandrie monogynie.-Candela americana.Nangue guaparaiba. Pison.- Famille des chèvrefeuilles de Jussien.--Manglier rouge de quelqnes auteurs.

Caracteres génériques. Calice et corolle en quatre parties, une semence très-longue, charnue ì sa base, feuilles obtuses; pédoncules bigéminés, plus longs que la feuille; fruits en alêne; (vivace).

Historbe Natunelle. Arbre de la solitude, ce manglier se plait aux Antilles, ainsi que ceux de sa famille, loin des lieux habités, sur les rivages déserts du bord de la mer. Les poissons poursuivis par les requins et les bêcunes, s'engagent avec vitesse, et bravent leur persécuteur sous les arcades multipliées que forment, hors de terre, les racines de cet arbre curieux; c'est-là qu'ils se dérobent également par cêtte ruse, à celles du pêcheur; ils se tranvent en s fireté, l'entrelacement de ces racines ne permettant point aux squales et auires poissons de la grosse. espèce d'y pénétrer, et rendant impratieable l'usage des filets, et l'abordage des barques des pêcheurs; les crabes et les cériques en font aussi leur repaire.

On rencontre également le manglier rouge dans les lagons saumâtres qui avoisinent la mer, où ils se multiplient à l'infini; c'est sous leur épais feuillage, que le nègre chasseur arrive en tapinois, 


\section{( 46 )}

marchant dans l'eau jusqu'à la ceinture, muni d'us double tanga pour y écarter les miriades de man ringouins moustiques et vareux qui l'assaillent et le piquent de mille dards, dans l'espoir d'y surprendre, au milieu de leur sommeil, les bandes nombreuses de ramiers dout il espère faire son butin: heureux, si son adresse répond à son désir, et si le premicr coup de feu le dédommage de ses peines, de sa prévoyance et de son incertitude! car, à cette explosion, touie la bande s'envole et disparaît jusqu'au lendemain.

Le manglier chazdelle s'élève à la hauteur de - 25 pieds; son écorce est d'un gris brunâtre, tachetée de byssus verdâtres; sa reproduction est curieuse. Le premier jet qui sort de terre, en produit d'antres qui, au lieu de s'élever, se reçourbent circulairement vers la terre, en cerceaux, s'y provignent d'eux. mêmes, y prennent racine, et représentent en cetétat une espèce de guéridon. A mesure que la première tige, qui est la principale et qui doit devenir arbre, s'élève, elle produit d'autres rejețons qui se recourbent comme les premiers, et prennent aussi racines: cette multiplication est telle qu'au bout de quelques années te même arbre offrel'aspect d'une forêt impénétrable, qui a servi plus d'une fois d'asile aux blancs inforiunés dont la tête était mise à prix dans les derniers massacres de Saint-Domingue. J'y ai passé bien des jours de douleur, en proie à la bigaille, aux horreurs de la faim, et privé d'un sommeil auquel les angoisses d'une mort prochaine ne me permettaient pas de me livrer.

Les branches de ce manglier sont chargées d'huítres. 


\section{(47)}

exquises, mais d'une petile espèce, qui s'y fixent et conforment leurs écailles, aux contours de la branche qu'elles ont adoptée; plusieurs écailles se groupent et forment de petits rochers autour d'elle; les huitres y déposent leur frai; la petite famille y persiste, grossit, et d'après les marées, se trouve, tour-à-tour, sous l'eau, ou suspendue en l'air.

On vend, dans les marchés, de ces rameaux de manglier chargés. d'huîtres; mais il est préférable, pour le gourmet, d'aller en canot sur les lieux, les ouvrir lui-même, et les savourer à l'ombre de ces forêts silencieuses.

Caractétres physiQußs. Le bois du manglier rouge est solide, pesant, à fibres longues et serrées, de couleur brune-rougeâtre, les feuilles sont obtuses, ayant quelques rapports de forme avec celles du poirier; d'un vert foncé en dessus, tachetées de points rouges: pâles en dessous; la racine est très-tendre.

Les fleurs sont très-petites, blanches; le périanthe a quatre divisions dressées, à dentelures profondes, aiguës et persistantes.

La corolle 4-fides, à pétales lancéolés, douze ếtamines à filamens droits, les alternes plus courts, les anthères petites.

Le réceptacle ovoïde, l'ovaire subulé, le style peu apparent, le stygmate aigu.

Le fruit est une gousse cylindrique semblable à une chandelle à baguette dont le réceptacle forme. l'éteignoir. Il s'y trouve fixé par sa partie supérieure qui est charnue, contournée en spirale, et qui, lors de sa parfaite maturité, diminuant de volume, ez 
est alors facilement détaché par le moindre vent, en sorte que ces baguettes se fichent d'elles-mêmes dans la vase. Ces gousses renferment une pulpe d'une saveur âcre et amère.

Propriétrés chimiques. La décoction de l'écorce de manglier teint en rouille, ce qui prouve qu'elle contient beaucoup de tannin. Elle précipite en vert la colle forte et le sulfate de fer, et en brun l'acétate de cuivre. Sa saveur amère et astringente lui donne d'ailleurs beaucoup de rapport avec le quinquina dont elle a les vertus.

Propriétés particulis̀res. Son bois est propre à fa construction des petits bâtimens de cabotage. La pulpe de ses gousses, quoiqu'un peu amère, et semblable pour la consistance à la moëlle des os, est recherchée par les nègres marons qui s'en contentent pour nourriture, faute d'une meilleure. La vertu astringente de son écorce la rend propre à faire du tan.

Propriḱtés imédictalless. L'écorce du Rhizophorechandelle est un excellent fébrifuge, qui, au besoin, peut être substituée au quinquina dont elle a tous les avantages. Les pêcheurs se servent des racines rapées contre la piqûre despoissons et des insectes venimeux.

Mode d'ADMiti tration. On ordonne la poudre de l'écorce én Rhizophore-chandelle, à la dose d'un gros. On lui associe avec succès, d'après l'observation de Chevalier, un demi-gros des tiges séchées du convolvulus catharticus (liane purgative à minguet) réduites en poudre; alors l'effet est sûr et prompt. Je puis le certifier d'après ma propre expérience. 


\section{(49)}

Nota. On connaît encore aux Antilles plusieurs végétaux habitant les mêmes plages, sous le nom de manglier : tels sont, $1^{\circ}$. le cereiba, manglier blanc, mangle bobo ou mangle fou (conocarpus procumbens, Lin. ), dont les feuilles sont couvertes de sel, lors des marées descendantes. Ses fleurs sont jaunâtres et d'une odeur de miel; $2^{\circ}$. le manglier gris (conocarpus erecta, Lin. ); $3^{\circ}$, le cereibuna ou mangle arbrisseau, dont la feuille est ronde et épaisse, d'un beau vert, la fleur blanche, le fruit de la grosseur d'une aveline et amer; $4^{\circ}$. le manglier noir ou salé, appelé quapareïba par les Indiens, et mangue verdadeiro par les Portugais. Ce dernier vient à trente pieds de hauteur ; son écorce est gris-brunâtre ; il se multiplie d'une manière aussi curieuse qu'étonnante. De ses rameaux flexibles élevés et étendus partent des paquets de filamens qui descendent jusqu'à terre dans la vase, s'y couchent, y prennent racine, et croissent de nouveau pour former des arbres aussi gros que ceux dont ils ont tiré leur existence, ce qui les multiplie à l'infini. Leurs branches sont aussi chargées d'huîtres. La fleur est de couleur de rouille, et il lui succède une gousse allongée contenant des graines dont les ramiers sont fort friands. L'écorce en infusion est recommandée dans l'anasarque. On en combine les effets avec ceux du quinquina, du sucrier et de l'amandier. 
Explication de ta planche dixième,

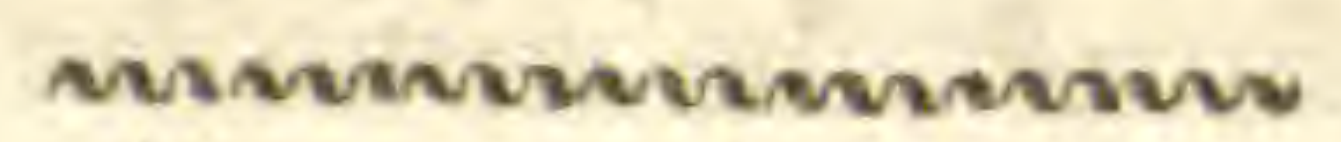

Le rameau est représenté de demi-grandeur naturelle. Il est garni à la partie inférieure d'une petite espèce d'huitre, dont les coquilles groupées sont exposées à l'air, à la marée descen. dante, et plongées sous l'onde au moment du. flux.

1. Calice.

2. Partie spongieuse et spirale du fruit au moment du desséchement qui permet à sa partie inférieure de quitter l'éteignoir ou calice, pour tomber perpendiculairement dans la vase, où la germination a lieu.

3. Fleur de grandeur naturelle.

4. Port de l'arbre dans l'éloignement. Les racines s'élevant hors de terre et s'y enfonçant une seconde fois pour laisser échapper de nouvelles tiges. 


\section{ACACIE A QUATRE FEUHLES.}

(Stomachique fébrifuge.)

Srnoxrmie. Mimosa unguis cati, Lin. - Acacia qua drifolia, siliquis circinatis, Plum. ic. 4. Pluk. tom. 1. fol. 6 .

Caractères génériques. Calice 4-fides. Fleurs globuleuses, disposées en grappes, légume gibbeux, allongé, contourné en spirale; pédoncules simples ; quatre feuilles larges, pinnées, sans impaire; stipule et pétiole en épine; feuilles insensibles au tact ; (vivace).

Histoire naturelle. L'acacie à quatre feuilles, distinguées par leur forme et leur disposition, se tronve dans plusieurs forêts de la Martinique, de la Jamaïque, de Saint-Jago-de-Cuba et de Saint-Domingue. On l'y remarque peu, en raison de la petitesse de ses fleurs; mais les animaux des hattes sont friands de ses siliques et de ses feuilles. La récolte des écorees qu'on emploie comme fébrifuges, se fait immédiatement avant la saison des pluies.

Caractìres physipues. Le bois de l'acacia à quatre feuilles est jaunâtre, l'écorce d'un brun violet, parsemée de points blancs; ses feuilles sont disposées par deux à l'extrémité d'un pétiole dichôtome qui lui-même est accompagné de deux épines à son insertion au tronc. La forme des feuilles se rapproche de celles du hêtre; c'est un trapèze irrégulier, marqué de nervures légères, et d'une côte 


\section{(52)}

peu saillante en dessous. Elles ont deux ponces de longueur sur un de largeur.

Les fleurs sont d'un blanc jaunâtre, monopétales, monadelphiques, polyandriques et ramassées par petites têtes pédonculées et en g̀rappes.

Le fruit est une silique longue, étroite, deux ou trois fois recourbée sur elle-même, applatie, renfermant des semences noires, irrégulières, saillantes an dehors. (Encycl. méth.)

Propriétés chimroues. Ces gousses, dans leur état de verdeur, contiennent un suc visqueux, astringent, extracto-résinenx qui noircit à l'air; les teinturiers savent en tirer parti. Son écorce a du rapport avec celle du quinquina, et précipite en vert la colle-forte et le sulfatede fer. Elle est amère et astringente.

Propriétés médicinales. La saveur de cette écorce l'a fait justement apprécier recommandable dans les fièvres intermittentes, où elle peut suppléer au quinquina. On la réduit en poudre, qu'on administre avec avantage dans les intervalles des accès. J’ai saisi l'oceasion de la prescrire à l'hôpital de Saint-Marc (ille Saint-Domingue), dans une fièvre ataxique, accompagnée d'anxiétés et de vomissemens qui se renouvelaient au retour de chaque paroxysmes; elle repondit à mon attente.

Cette écoree fait aussi partie des lavemens fébrifuges si en vogue dans les Colonies où les fonctions de l'abdomen sont souvent perverlies.

Mode d'administration. On fait unexcellent vin fébrifuge avec deux poignées de cette écorce, deux gros de racines de gingembre concassées, et un gros 


\section{$(53)$}

d'oxide de fer, au maximum, pour trois litres de vin de Bordeaux. On laisse infuser pendant la nuit, sur des cendres chaudes.

La dose du vin est de deux onces toutes les trois heures pendantl'apyrexie qui précède le paroxysme. Celle de l'écorce en poudre est d'un gros à demionce

Explication de La planche onzième.

La plante est représentée d'une dimension moindre que nature.

1. Portion d'une grappe garnie de ses fleurons.

2. Graine entière.

3. Graine coupée. 


\section{PARKINSONIE.}

\section{(Stomachique fébrifuge.)}

Srnonymie. Acacie grêle des Savanes.-Genet épineux ; Nicolson.-Parkinset. (Jolyclerc.) - Parkinsonia aculeata foliis minutis unicostæ adnexis; Plum. vol. 6, pag. 23. - Parkinsonia aculeata; Lin. decandrie monogynie..-Jussieu, famille des légumineuses.

Caractèrés génériques. Calice 5-fides, 5-pétales ovales, l'inférieur réniforme, style nul, légume en forme de collier de perles; deux aiguillons opposés aux côtés des pétioles, un intermédiaire trois fois plus long; ( vivace).

Hustorre naturelie. La parkinsonie ne se trouve ui sur les mornes frais et ombragés des Antilles, ni sur les bords des eaux; mais elle se plaît dans les terrains secs et arides de Hattes; dans les Savannes brû. lées par le soleil des tropiques : c'est-là, qu'elle découvre solitairement sa végétation singulière.

On ne reconnaît à la parkinsonie aucune propriété pour les arts, ou les besoins domestiques; les crocodiles trainent de leurs branches épineuses, pour recouvrir et cacher à la vue, le tertre sous lequel ils ont déposé leurs œufs, dont ils confient l'incubation au soleil, et à la concentration.

Caractìres physiques. Cet arbrisseau offre une tige peu rameuse et encore moins touffue ; les branches sont coudées en zigzag, et offrent à chaque articulation leurs feuilles singulières qui s'échappent, ainsi que les fleurs et les légumes longuement pédonculés, du milieu de trois épines, dont l'intermédiaire est la plus longue. 


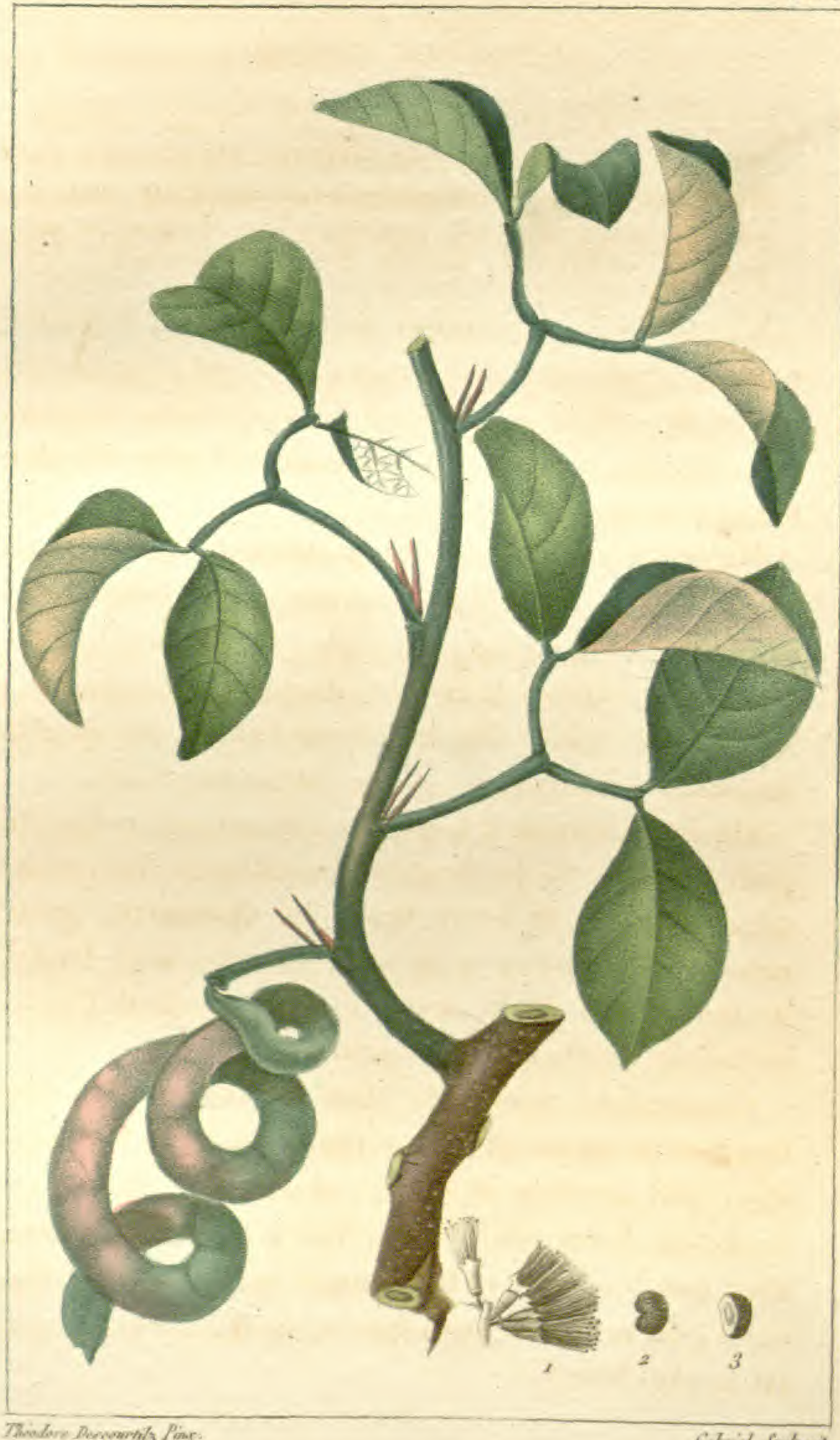

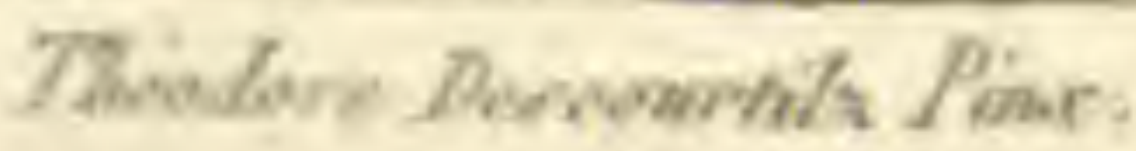




\section{(55)}

Les feuilles présentent une nervure làrge et fort longue, flanquée de deux rangs de folioles rondes, et de forme lenticulaire.

Le périanthe est monophylle, quinquéfide, ouvert, tombant avec la corolle, qui est composée de cinq pétales presque égaux; l'inférieur plus large est réniforme, arrondi, et ponctué de noir; tandis que les quatre supérieurs sont ovales.

Les filets des étamines sont au nombre de dix, déclinés, jaunâtres, les anthères oblongues, d'un rouge aurore.

L'ovaire inangulé un peu allongé, décliné; le siyle peu apparent, le stygmate obtus et redressé.

Le légume est très-long, eylindrique, relevé en bosse, e'est-à-dire alternativement renflé vis-à-vis les semences qu'il renferme, et retréci dans l'intervalle, ce qui lui donne la figure d'un collier de perles. Ce légume est aigu à son extrémité, et contient plusieurs graines noirâtres.

Propuítés chimieues. Les feuilles de la parkinsonie recèlent une partie extractive amère, et un peu de tannin; les fleurs colorent en jaune la décoction dans laquelle on les a fait bouillir. J'en avais suivi l'analyse avec M. Prampein, chimiste instruit attaché à l'agence du gouvernement à Saint-Domingue ; ce travail a été dévoré par les flammes, ainsi que tant d'autres, lors de l'incendie général.

Propriétés médicinales. On emploie peu souvent li: parkinsonie dans les hôpitaux des Colonies; mais les mulâtres guérisseurs en font beaucoup de cas. J'a eu moi-même l'occasion de vérifier les services que 


\section{(56)}

son usage peut rendre à l'humanité ; j'ai êu à me louer d'en avoir prescrit les fleurs en infusion théiforme, les feuilles et l'écorce en lavemens et en bains dans l'atrophie mésentérique, et dans les fièvres intermittentes, les graines torréfiées et préparées comme le café, pour le même usage.

L'expérience la plus chère à mon cour est celle que j'ai faite en faveur d'un père de famille atteint d'une fièvre exanthématique adynamique, qui offrait peu d'espoir par l'intensité de ses symptômes alarmans. L'estomac ne pouvant plus faire de fonctions, et le malade éprouvant une déglutition pénible, soit qu'il dût ce spasme à sa répugnance habituelle, soit à la constriction de l'cesophage, je le faisais frictionner, et j'enveloppais les parties couvertes d'exanthêmes et de pétéchies, avee des flanelles trempées dans une forte décoction de parkinsonie, saturée de muriate d'ammoniaque.

Mode d'administration. La poudre des graines torréfiées se preserit à la dose d'un scrupule à demigros par once de décoction des fleurs de la même plante. La dose des feuilles pour les bains et les lotions est de plusieurs poignées, et d'une senle par dystère.

\section{Bxplication de ta PLANCHE Douztk̀me.}

Ia plante y est représentée moitié grandeur natu-
relle. 
Pl. 32.

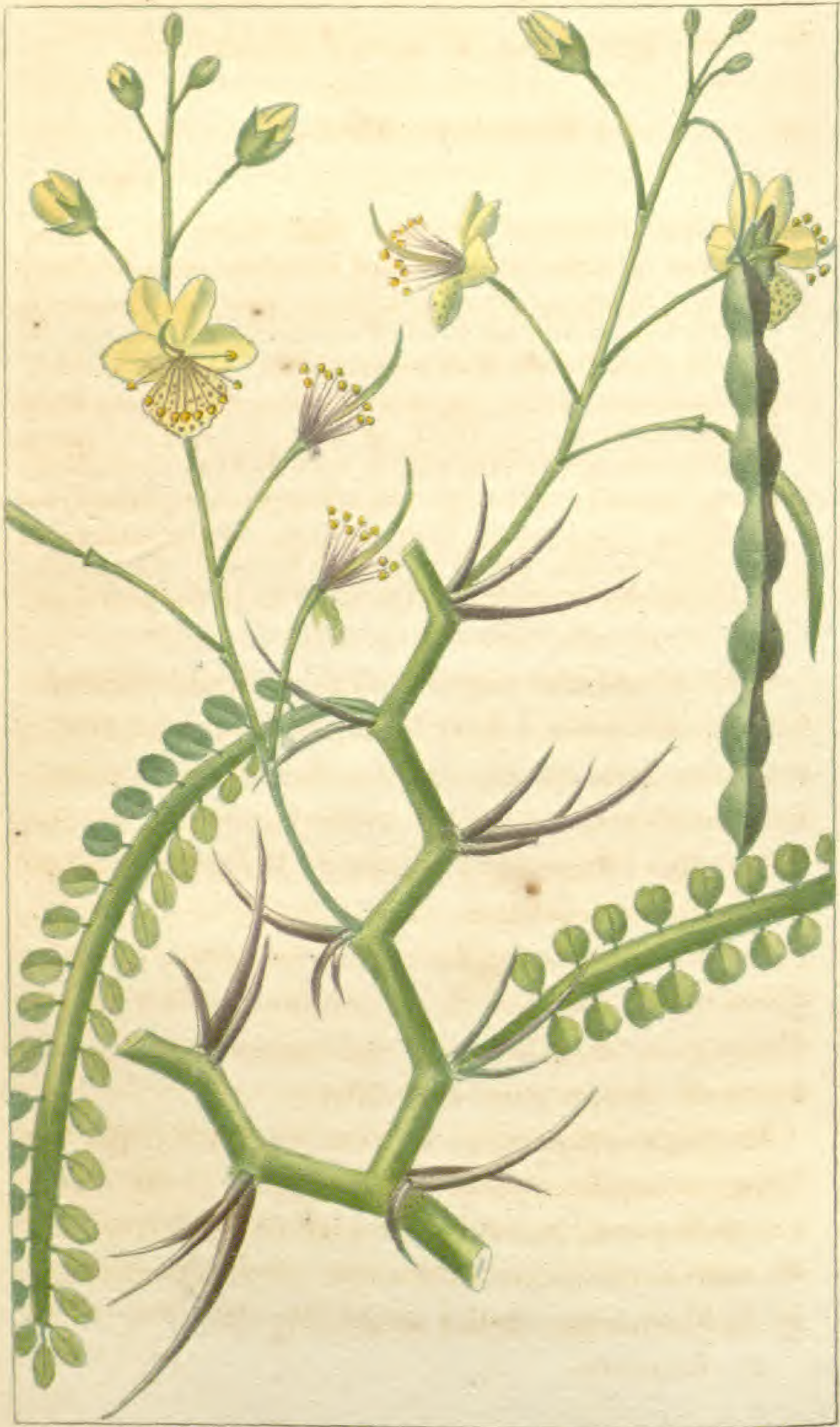

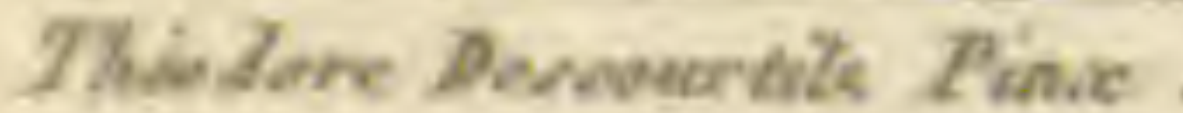




\section{$(57)$ \\ QUINQUINA PITON,}

ot QUINQUINA A FEEUTS NOMBREUSIS:

(Stomachique fébrifuge.)

SrNonymte. Cinchona montana, foliis oppositis, ovatis; utrinque glabris, stipulis basi connato-vaginantibus, corymbo terminali, corollis glabris (Valmont-Bomare): - Cinchona montana, Linn. Pentandrie monogynie. Jussieu, famille des Rubiacées: - Cinchona floribunda paniculâ terminali; capsulis turbinatis levibus; foliis elipticis acuminatis, $W$ alh et $S_{\text {wartz. }}$ - Trachelium arborescens montanum tini facie, floribus corymbosis albis, capsulis minùs crassis (Poupée-Desportes.) Cinchona montana de Badier, 1777. - Oulikaera des Caraïbes. - The Barck or Jesuits Powder, des anglais. - Quina des espagnols.-Quina de Losa des portugais.

Caractìnes botaniques. Corolle infundibuliforme; capsule inférieure à deux loges, la cloison parallèle, semences imbriquées; l'espècè cariboea a les pédoncules uniflores, les feuilles ovales lancéolées, les étamines plus longues que le tube de la corolle; l'odeur des fleurs est très-suave; (Jolyclerc.)

Caractere spécial. Le quinquina piton, ou quinquina de montagnes à fleurs nombreuses, est pourvu d'une gaine membraneuse qui embrasse la tige audessus de chaque paire de feuilles.

Histoire a aturelle. Le nom de piton, qui aux Colonies signifie sommet des montagnes, a été donné à ce quinquina, parce qu'il se plait de préférence sur les mornes du nouveau Mexique, de la Guadeloupe, de la Martinique et des autres iles Antilles, où la

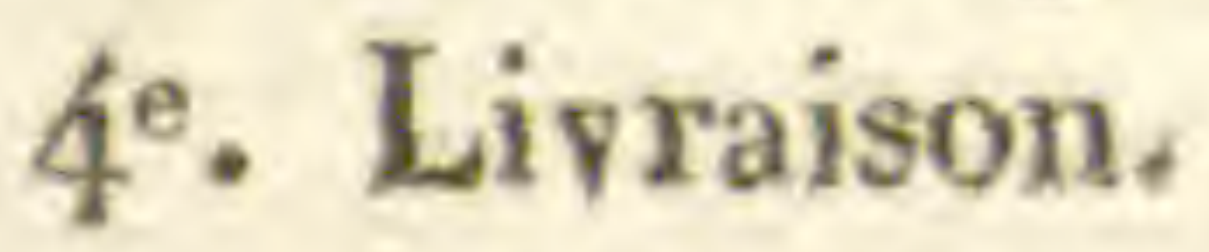




\section{( 58 )}

quantité de ses fleurs et leur odeur suave lui donnent un port agréable et le font remarquer.

On doit à Poupée-Despostes, la connaissance de cette espèce qu'il découvrit en 1742. “Quelques-uns 》 de ces arbres, dit-il, étaient tombés, dans un étang » où ils pourrissaient; personne ne pouvait boire de " celte eau, par rapport à la grande amertume qu'elle ग) avait contractée. Cependant un des habitans cir》) convoisins, attaqué d'une fièvre violente, et pressé " par l'ardeur de la soif, en but, et eut le bonheur 》 d'être délivré, et de la fièvre, et de la soif. "Cette écorce, introduite en France en 1779 par Radieu, est pesante, grise à l'extérieur, et d'un rouge fauve en dedans; elle est inodore, et contient un principe mucoso-amer; la poudre est grisâtre. On regarde cette espèce comme fébrifuge par excellence, au moyen de ses qualités amères, astringentes, émétiques et purgatives : on préfère en général l'écorce des jeunes branches, à celles des vieilles et du tronc, surtout si l'arbre végète dans un terrain qui lui convient, et sous l'influence de l'exposition qui lui est favorable.

Le quinquina est appelé en latin cinchona, du nom de Cinchon, vice-roi du Pérou, résidant à Lima, dont l'épouse fut guérie de fièvres rebelles par l'usage de cette plante jusqu'alors inconnue, et qu'indiqua un Indien au gouverneur de Loxa en 1640 ; il a pour cela porté le nom de poudre de la Comtesse, et tourà-tour celui de poudre des Pères, des Jésuites, parce que l'écorce péruvienne fut transportée en France, en 1649 , par le procureur-général des Jésuites de l'Amérique, qui revint en Europe pous se rendre à Rome. 


\section{(59)}

Le quinquina piton, nommé aussi bois-tabac-montagne, est beaucoup plus amer que celui du Pérou, et par conséquent plus actif, puisqu'à forte dose il excite le vomissement, et les déjections alvines. Il agit aussi plus promptement dans les fièvres muqueuses en raison de sa propriété plus excitante. Il offre un phénomène singulier : si on l'écorce dans un endroit, il est bientôt rongé par une espèce de cérambix à fortes michoires, qui, en peu de temps, le détruisent; ces insectes se réunissent par myriades.

Caractères physiques. Le quinquina piton, s'élève à 40 pieds de hauteur; son tronc a environ vingt pouces de diamètre; sa cime est très-touffue, rameuse, régulière ; son feuillage épais est vert et d'une teinte qui flatte la yue; les feuilles glabres sont pétiolées, opposées, ovales, lancéolées, rassemblées par touffes, longues de six à sept pouces, plus pâles en dessous qu'en dessus; ses jeunes branches sont légèrement anguleuses, lisses, de couleur pourpre foncée; l'écorce du tronc est d'un gris brunâtre, et très-amère.

Les fleurs terminales paraissent en juin et juillet : elles sont disposées en panicule élégant et gradué; dont les branches sont opposées; le calice, à cinc divisions subulées, porte le tube allongé de la corolle infundibuliforme; les divisions du limbe sont linéaires, très-longues, souvent réfléchies; les étamines filiformes sont saillantes; le stygmate ovale, régulier. Le fruit oblong est une capsule en massue, biloculaire, rétrécie à sa base, couronuée au sommet, et marquée de raies longitudinales; les semences sont comprimées, et ailées aux deux bouts. 


\section{(60)}

ÁrALYSE CHIMPUe. Le quinquína pilon, soumis à la ehimie, offre peu de différence dans l'analyse avec le quinquina péruvien, si ce n'est qu'il produit un principe extractif beaucoup plus amer, soluble dans f'eau et dans l'alcool, donnant une couleur verte aux sels ferrugineux, et un précipité avec la noix de galle. Cetfe substance, sui-generis, qui n'est ni gomme ni résine (d'après les remarques de Vauquelin et de Fourcroy), a la propriété spéciale de se saturer de l'oxigène contenu, soit dans l'eau, soit dans l'athmosphère, et de se convertir alors en une véritable résine. (On peut consulter ces détails intéressans, dans les soouveaux Élém. de Thérapentique, d'Alibert, t. i, pag. 38.) Le principe colorant est insipide, mais trèssoluble dans l'eau; combiné avec les sels métalliques, il fournit un précipité.

Propriépés médicrnales. Si fe quinquina pitor fait des merveilles en cas d'asthénie, et pour couper les fièvres intetmittentes, il perd tous ses avantages, si on veut l'employer dans les fièvres continues ou rémittentes, que le plus souvent il aggrave en augmentant Virritation et tous les désordres qui en sont la suite; c'ést pourquoi, si, après avoir administré ce quinquina, le malade éprouve des anxiétés, des vomissemens et des syncopes, on doit lui ordonner une infusion aromatique opiacée. Cet effet prouve que le quinquina piton est très-styptique et convenable dans le scorbut, les gangrènes, les fièvres adynamiques, les éeoufemens provenant du relâchement des membranes muqueuses: il est moins applicable dans un certain temps de la fiérre jaune, au moment 
de l'invasion, par exemple, où la prostration fallacieuse des forces et la fétidité des évacuations, annoncent une altération du prineípe vital, causée par une irritation violente de l'appareil digestif, que ce quinquina à haute dose pourrait argmenter. (Voyez mon Guide sanitaire des voyageurs aux Colonies, art. FIÈVRE JAUNE.) Toutefois l'emploi de ce quinquina est admissible, même au début de la maladie, si les symptômes de l'ataxie et de l'adynamie sans vomissemens présagent une issue funeste; alors on profite des rémissions, de l'état de faiblesse qui succède aux hémorragies, et ce quinquina, dansles mains d'un médecin prudent et instruit, devient le plus sûr moyen perturbateur, le prophylactique le plus puissant qu'on doive employer pour prévenir et détourner une irritation prochaine, violente et pernieieuse, qu'on ne peut plus domter après les deux ou trois premiers jours d'une stagnation perfide, qui est l'avant-coureur de l'irruption meurtrière de la fièvre. jaune.

C'est en vertu de cette propriété stimulante, que le quinquina piton est d'un grand secours dans l'éruption difficile d'une variole de mauvais caractère : lorss que le pouls est faible et les aréoles pâles, cette écorce salutaire modère la fièvre de suppuration, et prévient la gangrène.

Il y a plusieurs manières de preserire le quinquina piton : en poudre et à dose moyenne, il agit commo tonique, augmente la chaleur, et redouble les pulsations en accélérant la cireulation; il diminue, pas sa tonicité, les évacuations excessives. 
A haute dose, il occasionne, comme je l'ai dít plus haut, le vomissement et la diarrhée; e'est pourquoi il faut l'interdire aux jeunes gens sanguins, bilieux, secs et nerveux : il convient alors aux tempéramens lymphatiques, à fibre molle, et d'une sensibilité obtuse ; aux sujets pâles, pauvres, usant d'une nourriture malsaine, habitant des endroits marécageux, ou respirant l'air des prisons.

II convient aussi dans les maladies chroniques qui réclament des médicamens toniques et astringens; dans tous les cas d'atonie, dans les chloroses, dans les aménorrhées asthéniques, surtout dans les affections vermineuses où il agit comme moyen curatif et préservatif.

Veut - on réprimér une anomalie nerveuse? on l'emploiera avee succès dans l'hypocondrie, la coqueluche, l'épilepsie, etc., en observant de l'interdire en eas de pléthore, et de ne pas prolonger son usage. Je faisais toujours précéder l'emploi du quinquina piton par les évacuans, les apéritífs; et je ne le plaçais qu'après six ou sept accès de fièvres intermittentes: aussi m'a-t-il toujours réussi sans avoir jamais eu à regretter son usage prématuré. Avec ces précantions, je prévenais les infiltrations, lictère et les hydropisies.

A l'extérieur, le quinquina piton, soit en poudre, soit en embrocation, a parfaitement rempli mes vues dans le pansement des plaies gangréneuses, et des vlcères sordides dont le traitement m'était confié dans les hôpitaux que je desservais. La poudre de ce quinquina, ayant absorbé une certaine quantité d'eau de 


\section{(63)}

rabel, acquiert, par cette combinaison, une double propriété styptique qui la rend propré à arrêter certaines hémorragies.

Les phtisiques doivent s'abstenir de ce quinquina, à moins de lui associer le sirop de cacao, celui de gomme ou de karatas. (Voyez ces artieles.)

Mode d'admistration. La dose de ce quinquina en poudre est depuis un gros jusqu'à deux comme tonique; de deux à huit gros, comme fébrifuge, à des distances rapprochées. Une once à une once et demie suffit dans la fièvre jaune, en l'administrant au déclin des accès. On lúi associe des antispasmodiques et de l'opium, pour empêcher qu'il ne soit rejeté par le vomissement. On donne encore la poudre en suspension dans une certaine quantité de liquide; on la mêle à du miel ou à du sirop, pour en former, soit un électuaire, soit des pilules. Un gros de cette poudre, d'ap̣rès l'observation de Pugnet, a occasionné le vomissement, tandis que la même dose, administrée en trois prises, à une demi-heure d'intervalle l'une de l'autre, a déterminé des évacuations alvines. La même dose suffit pour les fièvres intermittentes; mais elle doit être distribuée en trois prises, à six heures d'intervalle l'une de l'autre: d'autres préfèrent la macération à froid, d'úne once par pinte d'eau pendant vingt-quatre heures, pour conserver à ce quinquina toutes ses propriétés, et le rendre d'un emploi moins désagréable. On le donne aussi en lavement dans la fièvre jaune, et on lui associe le camphre.

Sa teinture alcoolique, qu'on obtient par la ma- 
cération de dix parties de l'écorce, et de trente d'alcool à yingt degrés, sert, d'après la méthode de Parmentier, à former un vin fébrifuge, qui se compose avec une once et demie de cette teinture alcoolique par pinte de vin rouge ou blanc. La dose est de denx à quatre onces à jeun. La teinture s'emploje en frietions dans les fièvres de mauvais caractère.

L'extrait, par macération et évaporation, se donne de cinq à vingt-quatre grains. L'extrait mou, suivant le docteur Chaumeton, est préférable à l'extrait sec, qui est souvent brûlé, et perd une partie de ses propriétés médicinales.

On compose une bière tonique en mêlant ensemble une partie de quinquina en poudre dans cent parties d'eau et huit de sirop commun. Le vin et le sirop se donnent à deux ou trois onces par jour.

\section{Explication de ia planche treizlème.}

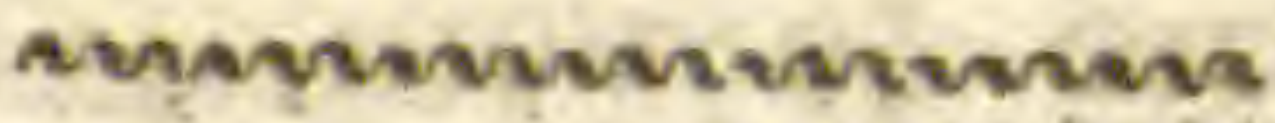

Nota. Le quinquina, moitié grandeur naturelle, a été rectifié d'après le dessin de M. Turpin, le mien ayant été avarié dans une tempête.

1. Parties sexuelles contenues dans le calice, 2. Fruit,

Nota. Poupée-Desportes, dans son catalogue des plantes médicinales, indique plusieurs autres espèces. de quinquina; savoir, $\mathbf{x}^{\circ}$, le quinquina arbrisseau, ou likaëra des Caraïbes, C'est le trachelium arborescens. et fluviatile, laurifoliis conjugatis, floribus racemosis seu corymbosis, albis, capsulis conicis nigris; 


\section{(65)}

$2^{\circ}$. le quinquina petit, trachelium frutescens et fluviatile, persico folio, floribus albis longissimis, siliqua crassiori; $3^{\circ}$. le quinquina faux, pseudo acacia fraxini folio rotundo minoriet lucido, (floribus racemosis violaceis. C'est le Oulébonhou des Caraïbes.

- Le quinquina des Caraïbes a été décrit par Swartz, sous le nom de Cinchona angustifolia, habitant les bords de la mer, et les versans des Mornes de ce côté; sa saveur est mucilaginense, amère et douceâtre ; on l'appelle dansle pays bois-chandelle, Marie-Galante, poirier de montagne, suivant Jaumes Saint-Hilaire, (Journal de Botan, de Devaux. ) 


\section{(66)}

\section{SIMAROUBA OU BOIS-AMER.}

\section{(Stomachique fébrifuge.)}

Srnontmie. Quassia simarouba floribus monoïcis, foliis abrupte-pinnatis, foliolis alternis, sub-petiolatis, petiolo nudo, floribus paniculatis, Linn. Decandrie monogynie.-Jussieu, famille des Magnoliers, class. 13, ord. 15. - Simarouba foliï conjugatis secundùm costam simplicem, H. R. P. - Evenymus fructu nigro tetragono vulgò Simarouba, Barr., ess., p. 5o. Les espagnols et les portugais le nomment Simaruba; ces derniers ajoutent Arbore de las camaras, arbre pour les dissenteries. Les Caraïbes l'appellent Chipion. - Les médecins Brachmanes Macre.

Caractíres gévériques. Calice 5-phylles; 5 pétales; nectaire 5 -phylles; 5 péricarpes distans, monospermes.

Caractéreg particuliers. Fleurs monö̈ques, feuilles pinnées sans impaire, folioles alternes comme péliolées; pétiole nue, fleurs en panicule. (Jamaïque vivace.)

Histoire naturelle. C'est en 1713 que, pour la première fois, on reçat, dans les ports d'Europe, de l'écorce de cet arbre, que les habitans de Cayenne et de la Guiane envoyèrent comme le spécifique des flux dyssentériques. Nous devons la confirmation de ces propriétés an célèbre Antoine de Jussieu, qui en retira de très-grands avantages dans l'épidémie qui se déclara au milieu des chaleurs excessives de l'été de 1718. C'est Aublet qui a donné le premier la description et l'histoire naturelle du simarouba. Deux 
yII

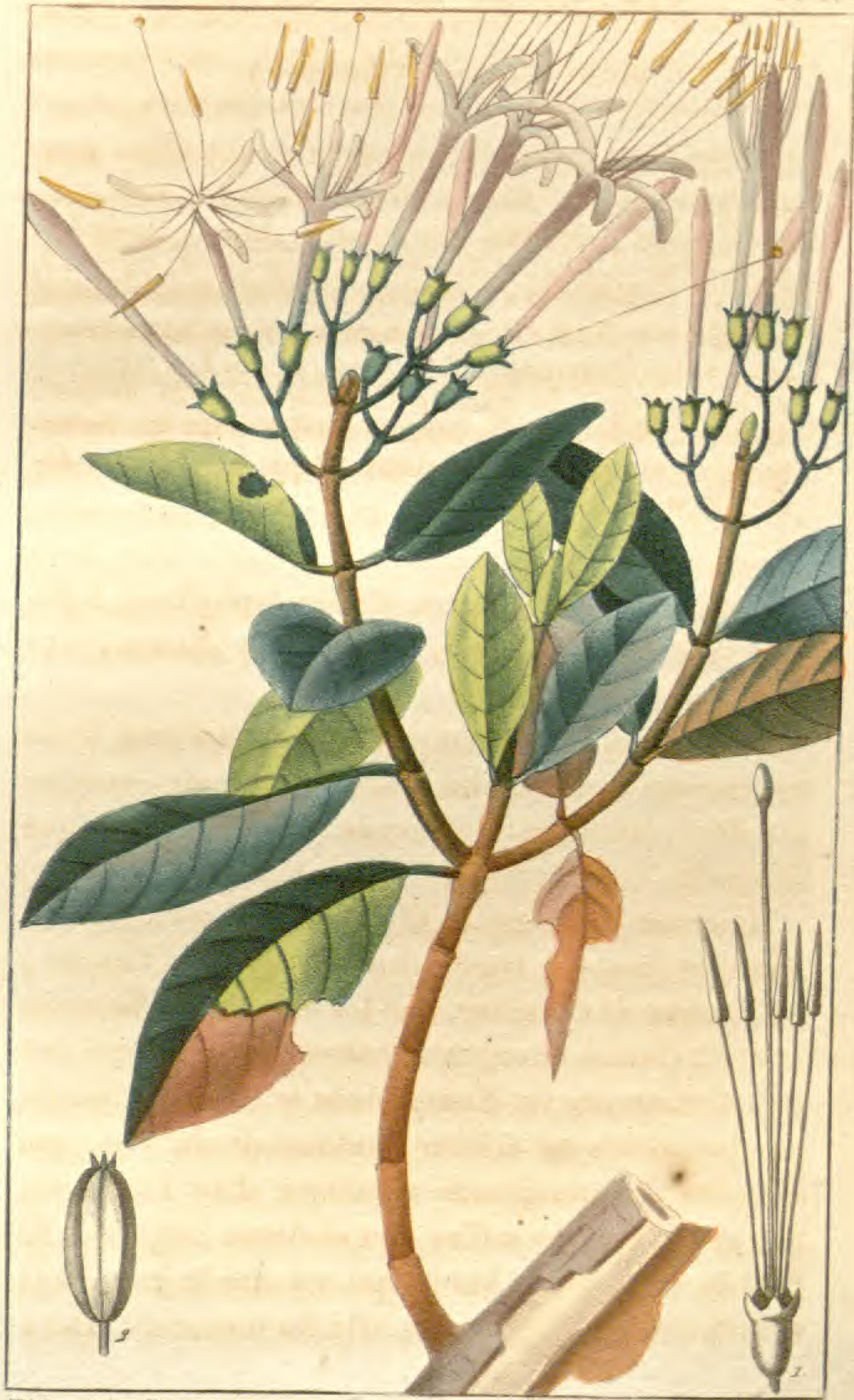

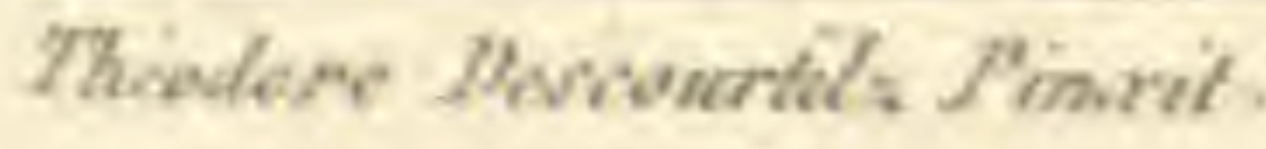

Gabriel wrulforit

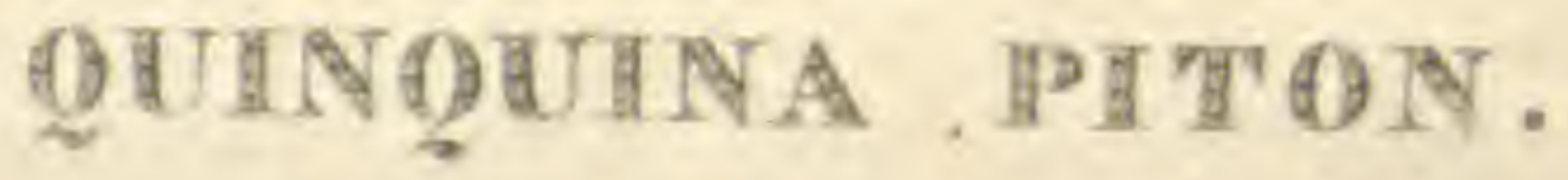




\section{(67)}

nègres, dit-il, sont employés à recueillir l'écorce de cette racine. L'un la coupe par tronçons, et l'autre la dépouille aisément en la battant en tous sens jusqu'à ce que l'écorce s'en détache. Ces nègres ont la précaution de se couvrir pendant ce travail, pour éviter de recevoir sur leur corps le suc âcre qui jaillit de la racine pendant l'opération, et qui, par sa causticité, occasionne un prurit insupportable, et des élevures urticaires à la peau. Quoique l'écorce des racines soit généralement la plus estimée, on se sert néanmoins de l'écorce de l'arbre et de son bois rapé, mais à double dose. Le simarouba se rencontre fréquemment aux Antilles.

Caractères physigues. L'arbre du simarouba est de moyenne taille ; son écorce est amère sans slypticité, rugueuse, inodore; celle des racines est d'un jaune pâle, cendrée au dehors et fauve en dedans. Elle est compacte, filandreuse ; il en découle un suc laiteux, jaunâtre, amer et un peu corrosif.

Son bois est blanc, léger, et les jeunes branches d'un brun violet. On l'offre dans le commerce en longs morceaux roulés, filandreux, d'un jaune pâle.

Les feuilles, d'un vert foncé, sont pinnées sans impaires, alternes, pétiolées ; leurs folioles, de neuf à quinze, sont alternes, presque sessiles, ovales, lancéolées, coriaces, glabres et sans dentehres.

Les fleurs monoïques sont axillaires, groupées en panicule écarté, dont chaque articulation est munie d'une stipule sessile. Le calice est un peu apparent, persistant, partagé en cinq divisions aiguës ; la corolle est blanche, formée de cinq pétales lan- 


\section{(68)}

céolés, aigus, fixés au fond du calice; dix étamines libres, un ovaire à cinq lobes, un style marqué de einq stries; le stygmate a cinq rayons disposés en étoile; le réceptacle épais, charnu, accompagné de dix écailles velues.

Le fruit offre cinq capsules conglomérées, et réunies à leur base, un peu charnues, ovoïdes, et de lagrosseur d'une cornouille, contenant une graine ovale.

Les fleurs mâles ( dit Poiret) ne diffèrent des femelles que par, l'avortement de leurs ovaires, prisés d'ailleurs de style et de stygmate. Les étamines manquent dans les fleurs femelles.

AnAIYse chimiQue. Le principe amer du simarouba est soluble dans l'eau et dans l'alcool; son infusion est inaltérable par la présence des sels ferrugineux et de la noix de Galle; mais, en raison de sa propriété gommo-résineuse, quoique légère, elle précipite en teinture laiteuse les nitrates d'argent et de plomb.

Propriérés mépicinales. L'écorce du simarouba est placée, par son extrême amertume, à la tête des toniques les plus actifs; mais il ne faut l'employer que dans le cas de faiblesse des systèmes, où elle produit des effets merveilleux, comme dans l'atonie mésentérique accompagnée de flatuosités, de colliques et de tranchées, dans les flux muqueux dys, sentériques, dans les affections vermineuses, dans Vanarsarque, les hémorragies passives, dans les diarrhées qui suivent le scorbut et les fièvres intermittentes, dans le catarrhe utérin, et ceux qui sont aecompagnés de prostration de force et de pâleur; dans 


\section{( 69$)$}

les scrophules, contre les fièvres d'accès rébulles, pourvu qu'il n'yait ni pléthore ni irritation gastrique, ni lésion organiques. On doit toutefois la preserire avec la ṕlus grande circonspection, et l'éviter même dans les fièvres adynamiques primitives, dans celles ataxiques nerveuses, et dans les hémorragies actives, si l'on n'a pas fait précéder son usage par des moyens antiphlogistiques et par des évacuans. Dans les flux dyssentériques même, où son emploi est préconisé avec emphase, on ne doit l'ordonner qu'après avoir satipfait aux moyens généraux, et détruit l'affection saburrale, si elle a lieu; car son action stimulante augmenterait les dangers d'une véritable phlegmasie qu'on doit au contraire combattre par les émolliens et les mucilagineux.

Les naturels des Antilles employèrent avec avantage, hors de la période d'irritation, l'écoree du simarouba jointe à celle du monbin et du gozyavier pour la composition d'un sirop qui eut de très-grands suecès dans l'épidémie de 1800 à Saint-Domingue, où je me trouvaisalors; car la vertu de cette écorce est incontestable lorsqu'on sait l'appliquer à propos. On en fait usage jusqu’ł la guérison qui s'annonce dans la dyssenterie, par la cessation des tranchées, le retour du sommeil, des urimes, et par conséquent la rareté des évacuations alvines, et leur passage à l'étak naturel; enfin celui de l'appétit et des forces. Son usage prolongé rend à la muqueuse intestinale le ve. louté que des évacuations excessives ont enlevé; ainsi, elle agit plutôt comme tonique antispasmodique que comme astringente. 


\section{( 70$)$}

Mode D'administration. On ordoune la décoctions de simarouba à la dose de deux gros de la racine divisée dans une pinte d'eau qu'on a fait bouillir jusqu'à réduction d'un tiers, et que l'on fait boire au malade en quatre doses, $\mathrm{e}^{\prime}$ est-à-dire de trois en trois heures, après l'avoir aromatisée avec un peu de cannelle. Cette écorce élastique, ténace et molle, se réduisant difficilement en poudre, on la rape, et on l'incorpore avec du sirop de gingembre, à la dose d'un scrupule, jusqu'à parfaite guérison.

D'autres personnes préfèrent l'emploidu simarouba à la dose de vingt grains en suspension, et macérés dans demi-once d'eau. Je recommande aux médecins des Colonies, d'après la formule du docteur RoQues, la préparation suivante:

35. Simarouba en poudre... ₹. B. Ipecacuana. ....... 3. B.

Extrait aqueux d'opium. .. 3. iv.

Conserve de gouyave. ... $\xi_{\text {. ij. }}$

Sirop d'écorce d'orange. ... Q. S. pourunélectuaire qu'on prend à la dose d'un gros quatre fois le jour.

Explication de ta planche quatorzième.

a)

Le Simarouba est représenté moitié grandeur naturelle.

1. Fleur hermaphrodite fertile.

2. Une des cinq capsules coupée transversalement,

3. La même coupée perpendiculairement.

4. Amande. 


\section{( 71 )}

Nota. Le simarouba de Saint-Domingue est l'evonymus armeniace folio et facie, ramulis et costis foliorum rufescentibus, fructu umbellato tetragono ex Insula Dominicana. (Poupée-Desportes.)

Le simarouba faux est le malpighia latifolia arborescens, cortice sanguineo, floribus luteis et racemosis. ( Du même.)

Le simarouba dit bois blanc est le malpighia arbor excelsa fraxini foliis crassis, ovatis subtùs incanis, extùs splendentibus, cortice levi albicante et amaro, floribus pyramidatis albis, baccis luteis. (Du même.) 


\section{$(72)$}

\section{GENTIANE A LONGS PÉDONCULES.}

Vulg. PETITE CENTAURÉ MARITIME:

(Stomachique fébrifuge.)

Sinonyme. Centaurium minus amplo flore ceruleo, Plum., vol. IV, p. 108. - Gentiana exaltata, Linn. Pentandrie digynie. - Tournefort, genre VIII, infundibuliformes. - Juss., fam. des Gentianes. - Loiseleur Deslonchamps. Gentianées, 226e genre, Chironie. - Gentiana eorollis quinquefidis eoronatis, crenatis, pedunculo longissimo terminali, Linn. Mill. Dict. , no. 12. - Aublet Guiane, pag. 283. - Yztac xihuitl. Hern. Mex., pag. 233, en anglais Gentian centaury.

Caractìres généuiques. Corolle 5-fides, campaniforme; style simple, bifurqué à l'extrémité, fruits biloculaires.

Histoire naturelle. Cette plante, appelée centaurée, est une gentiane dont toutes les parties sont visqueuses; elle se trouve sur les bords de la mer des îles de la Martinique, de la Jamaique, de la VéraCrux, de Saint-Yago-de-Cuba, de Saint-Domingue surtout, où on la rencontre fréquemment dans la partie appelée les anses de la béate. La centaurée d'Europe, dit Tournefort, tire son nom du centaure Chiron qui fut guéri par l'usage de cette herbe, d'une blessure qu'il avait au pied.

Par ses puissans secours la feuille de Chiron Souvent ravit sa proie à l'avide Achéron.

(Delille. Trois règhtes de la nature.) 


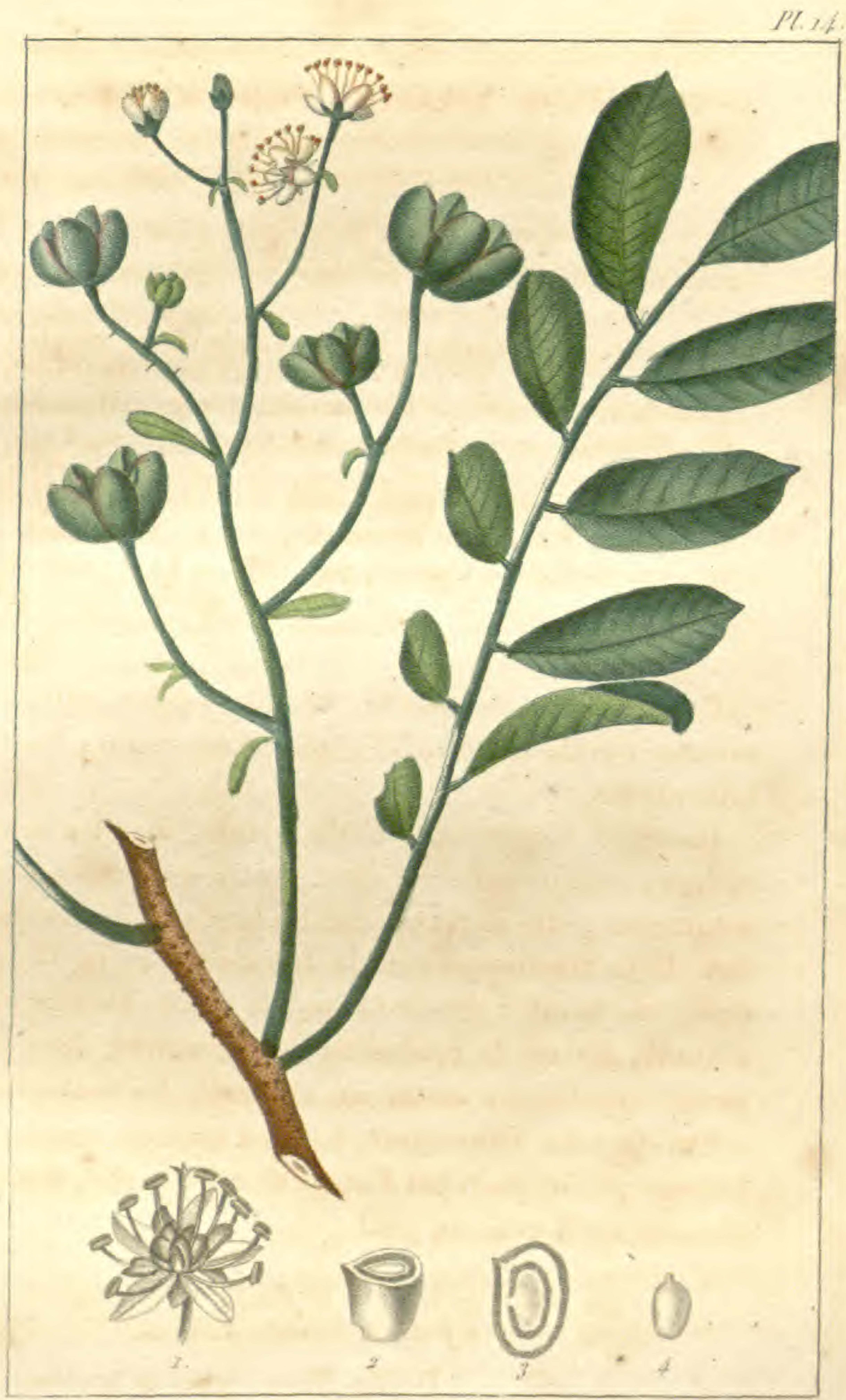

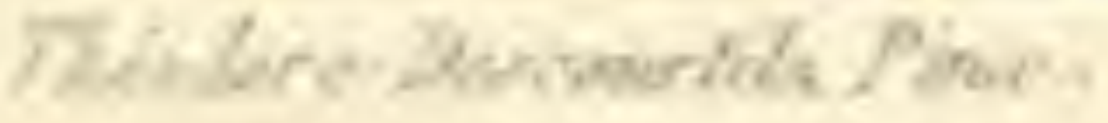




\section{$\left(7^{3}\right)$}

Caractires physroues. La racine de cette plante a la forme extérieure d'une petite rave rameuse, ligneuse, d'un blanc sale, et mamelonée, quelquefois donnant naissance à une seule tige, souvent à plusieurs rondes, presque ligneuses, de la grosseur d'une plume à écrire, garnies par intervalles de feuilles longues environ de deux pouces, amplexicaules, linguiformes, d'une saveur amère, et d'une couleur jaune verdâtre.

Au milieu des feuilles supérieures se prolonge une tige, simple d'abord, qui se bifurque ensuite avec articulations, pour offvir à chaque extrémité une fleur unique, de la grosseur du ponce, de conleur bleue; monopétale, campaniforme, ou infundibuliforme, divisée en cinq papties légèrement serrées, et profondément décoúpées.

Le calice, formé de lanières étroites, subulées, au nombre de cinq, renferme cinq étamines et un pistyl qui traverse les pétales de la corolle, et se transforme en un fruit ovoïde, semblable à une olive; il est membraneux, de couleur noirâtre, se partageant en deux parties, et offrant deux cellules garnies de petites graines noirâtres et glutineuses. Cette gentiane porte sés fleurs et ses semences mûrés au mois de septembre.

Analyse chimique. Toutes les parties de cette plante sont inodores; mais, douées d'une bienfaisante amertume, elles fournissent un principe extractif amer. On obtient aussi, par l'incinération de la plante, un sel qui peut remplacer le carbonate de potasse.

Propriétés médicinaizs. L'amertume de toutes les 


\section{( 74$)$}

parties de cette gentiane, la font estimer comme tonique, anti-vermineuse, et surtout fébrifuge. Son usage convient dans les cachexies, les anasarques, la diarrhée, si commune aux Colonies, et l'atonie des viscères abdominaux. Sa décoction procure un détersif anti-septique convenable dans la cure des ulcères malins et rebelles.

Mode d'administration. L'infusion théiforme se fait avec trois gros de la plante par pinte d'eau. On peut en préparer un extrait qui, à une dose plus forte que celui du quinquina, peut le remplacer, et être beaucoup plus économique. Je le donnais depuis un gros jusqu'à deux, à l'époque où, privé des ressources des pharmacies, j'étais forcé de mettre à contribution les plantes qui se rencontraient sous mes pas, aux environs des ambulances de l'armée noire, dont les généraux me retenaient prisonnier, et médecin en chef, afin de profiter de mes connaissances médicales.

L'infusion vineuse se prépare en mettant digérer à froid quatre gros de la tige dans deux pintes de vin de Bordeaux blanc. J'ai obtenu de très -grands succès d'une cuillerée de ce vin, édulcoré avec le sirop d'éther, dans les syncopes qui accompagnent la fièyre jaune. 
$\left(7^{5}\right)$

Explication de la planche quinztème.

Réduite aux 374 de grandeur naturelle. On a choisi un individu peu élevé.

1. Racine et partie inférieure de la tige.

2. Calice,

3. Capsule entière.

4. Capsule triloculaire coupée transversalement. 


\section{$\left(7^{6}\right)$}

\section{GENTIANE VERTICILLÉE}

Vulg. Petite centaurée a tige Quadrangulaire.

(Stomachique fébrifuge).

Srnonymie. Centaurium minus, ad alas floridum. Plum., vol. IV, pag. 107. - Gentiana verticillata, Linn. Gentiana corollis quinquefidis infundibuliformibus floribus verticillatis caule simplicissimo. Linn., hexandrie digynie. - Tournefort, genre 8 infundibuliformes. - Jussieu, fam. des gentianes. Loiseleur Deslonchamps, gentianées, 226e. genre. Chironie.

Caractères génériques. Corolle 5-fides. Infundibriforme, pistyl simple, terminé par un stygmate épais et tronqué. Capsule à deux loges formées par les bords roulés des valves.

Histoire naturelle. Cette petite gentiane qui se trouve, comme la précédente, sur les rivages de la mer, est estimée comme fébrifuge. Je l'ai souvent trouvée à Saint-Domingue, à Cuba; mais elle est plus fréquente à la Martinique, à Porto-Rico et à SaintVincent.

Ciractìnes physigues. La racine de cette plante est peu volumineuse, mais elle forme plusieurs branches rameuses : elle est dure, ligneuse, presque noire, ct d'une grande amertume. On en voit sortir des tiges un peu plus grosses qu'une plume à écrire, droites, quadrangulaires, ligneuses, d'un vert foncé. Ces tiges sont pourrues, à des distances très-rapprochées, de nceuds à chacun desquels adhèrent deux feuilles semblables à celles de la gentiane croisette d'Europe. 
Pl.X.

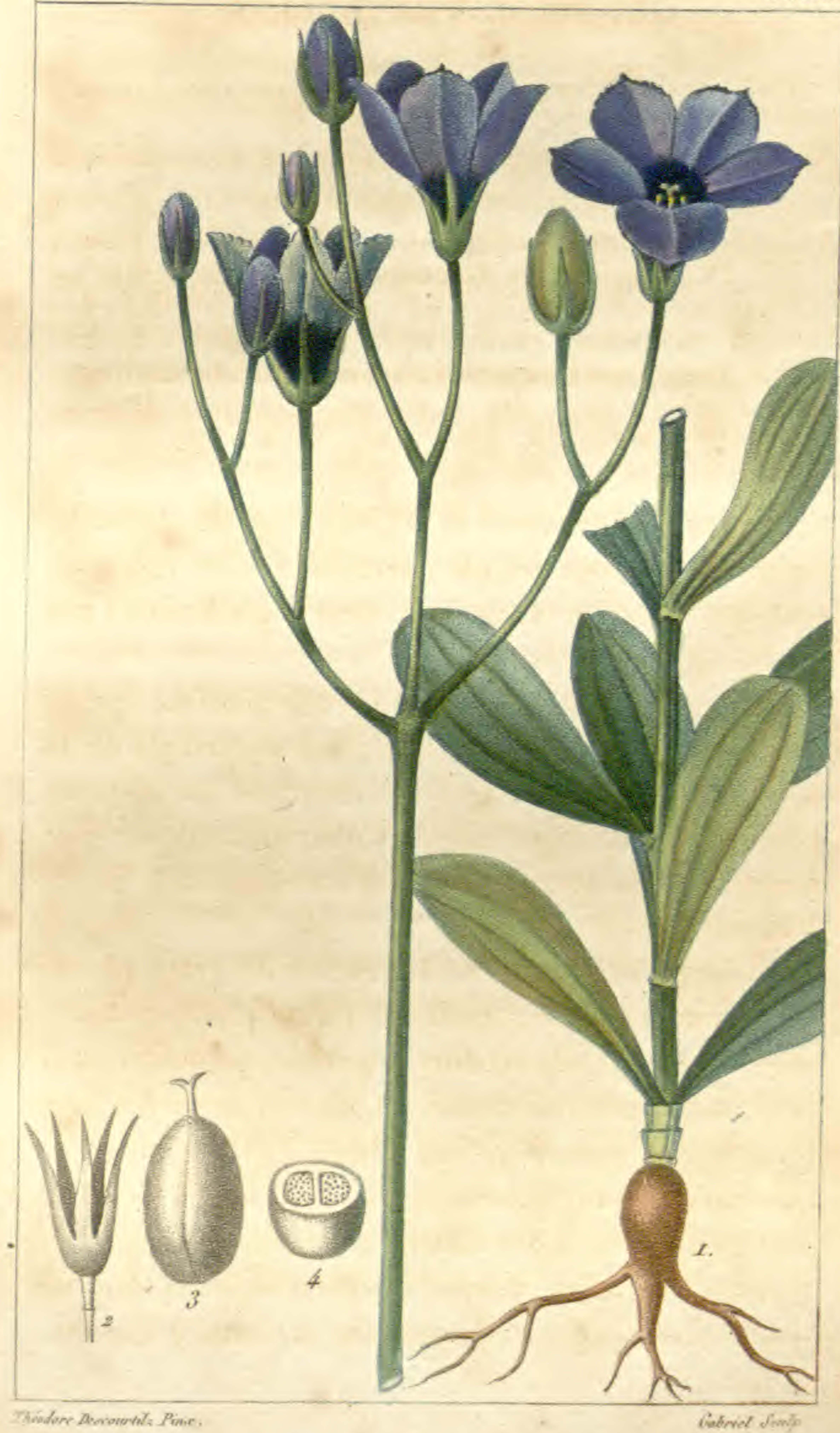

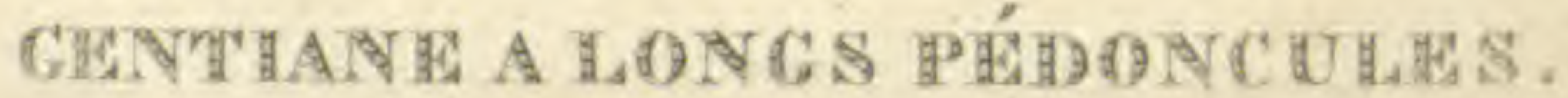




\section{( 77 )}

Elles sont opposées, tansdis que celles supérieures et inférieures, fixées dans un sens contraire, et sur les deux autres parties de la tige quadrilatère forment une croix. Ces feuilles portent trois nervures saillantes comme celles du plantain, et sont entourées d'une bordure d'un rouge brun, si étroite, qu'à peine elle est visible.

Les fleurs naissent par paquets axillaires, et sont disposées en verticilles autour de la tige. Elles sont très-petites, blanches, ou bleu d'azur, monopétales, infundibuliformes, divisées en cinq pétales allongés. Le calice verdâtre offre aussi cinq divisions, et porte le pistyl qui traverse la corolle, et forme un réceptacle ou fruit ovale qui se partage en deux, et fait voir deux divisions contenant de petites graines rondes et noires.

Avalyse chrmique. Toute la plante a l'amertume de notre centaurée d'Europe; elle précipite en vert la dissolution de sulfate de fer.

Propriétés médicinales. Cette gentiane est inodore, mais douée d'une amertume qui l'a toujours fait rechercher, et appliquer avec avantage dans les fièvres intermittentes : on ne se sert que des tiges garnies de fleurs.

Mode d'administration. On ordonne cette plante en infusion théiforme; en sirop, à la dose de deux onces; en teinture, à celle d'une once. On la fait entrer aussi dans la composition des bains fébrifuges et des lotions vulnéraires. 
EXPIICATION DE XA PLANCHE SEIZIK̀ME.

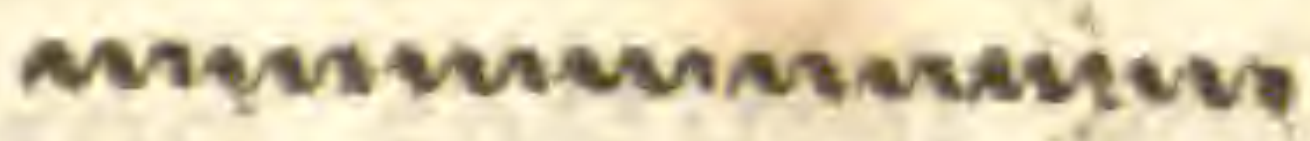

Elle est représentée moitié de grandeur naturelle.

2. Portion de la tige où on observe la disposition qu'affectent les feuilles inférieures.

2. Fleur.

3. Capsule entière.

4. Capsule coupée transversalement.

5. Graines. 


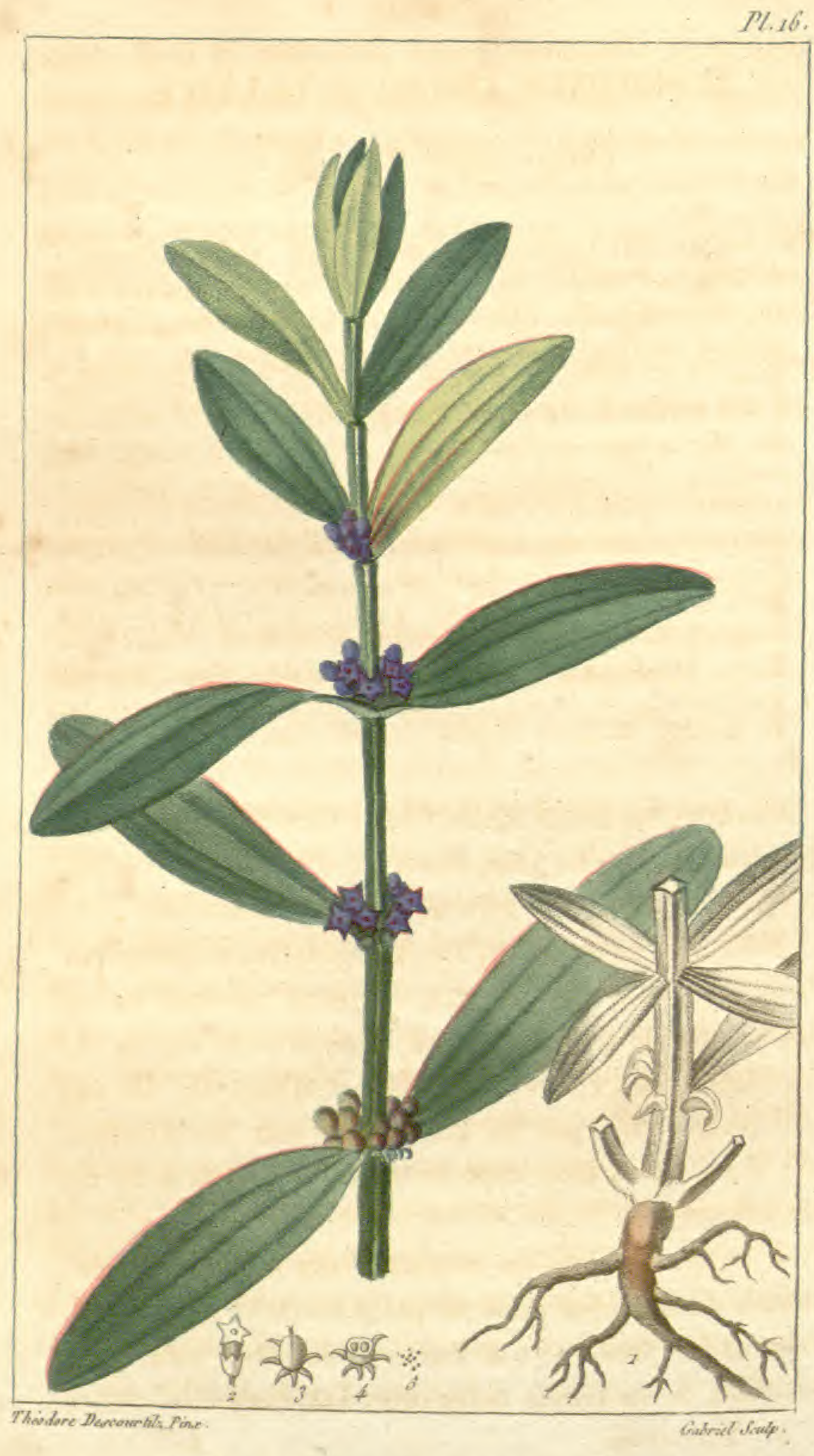

\section{GHNTHANE VERTICLLEEE.}




\section{(81) \\ INDIGOTIER FRANC OU CULTIVE.}

\section{(Stomachique fébrifuge,)}

Synonymie. Indigofera tinctoria. Anil. Foliis pinnatis, foliolis ovalibus, racemosis, brevibus, leguminibus incurra to falcatis, (Delamarck.) -Emerus americanus, siliquâ incurvatâ. Tournefort, 650 , class. 22 , sect. 3 , genr. 3. - Indigo vera, coluteæ foliis, utrinsque Indiæ (des savans de Londres.) - Hervas de anil, lusitanis de Marcgrave. - Xiuhquilith Pitzahac, sive anil tenuifolia, Hernandez. - Emerus, foliis latis, lucidis et teneris, siliquâ incurvâ, Flore rubro. Poupée - Desportes.-Emerus siliquâ incurvâ, ex quâ paratur indigo. Plum., cat., p. 19 et vol. 6, p. 37.-Colutea affinis fruticosa, floribus spicatis purpurascentibus, siliquis incurvis de Catesby. - Indigofera anil de Tussac. Linn. Diadelphie Décandrie. - Jussieu, fam. des légumineuses. - Isatis indica, rorismarini glasto affinis. C. Bauhin.-Ltin awaru, de Hermann.

Caractéres généripues. Calice ouvert monophylle, présque plane et à cinq dents ; carène des deux côtés à éperons en alène; légume linéaire en faucille.

Historre naturelle. Les indigotiers, connus par la belle fécule colorée que donnent presque toutes les espèces de ce genre, sont originaires du Japon, de la Chine, des Indes, d'Arabie et d'Egypte. Ils ont ćté transportés par les Européens aux îles Antilles, où il en eroît trois espéces que je désigne à la fin de cet article.

L'indigo est devenu trop utile aux arts et à T'économie domestique pour ne point retracer ici succinctement les procédés que l'on met en usage pour l'extraction de sa féeule colorante. On coupe la plaute 5e. Livraison. 


\section{( 82 )}

entre fleur et semence, chose essentielle pour être assuré de la maturité, qui doit décider de la qualité de la fécule. On met cette espèce de luzerne fermenter dans des cuves. Elles sont au nombre de trois et disposées les unes au dessus des autres, placées, s'il est possible, auprès d'un courant d'eau. Dans la première cuve, appelée trempoire, on dépose la plante qu'on y laisse fermenter sous quatre pouces d'eau; elle devient écumeuse et laisse échapper beaucoup de gaz hydrogène.'

Le talent de l'indigotier consiste à connaître le degré de fermentation nécessaire pour la séparation des parties colorantes. Il fait parvenir le liquide saturé dans la seconde cuve, appelée batterie, parce qu'on l'y agite au moyen d'instrumens appelés buquets. Quelquefois on précipite la partie colorante parl'eau de chaux, et on obtient plus de fécule; mais elle est d'une qualité inférieure. On agite le liquide tant qu'il conserve sa couleur verte, et qu'il n'a paś acquis la teinte bleue qui constitue et fait rechercher l'indigo. C'est alors qu'on décante le liquide de la deuxième cuve dans la troisième, appelée diablotin ou bassinot, d'où deux robinets, après un repos de quelques heures, laissent écouler l'eau comme inutile. Un troisième robinet placé plus bas donne issne à la fécule à demi-liquide, qui tombe dans des saç de toile placés près les uns des autres en forme de blanchets. Elle s'y desséche peu à peu par le suintement de l'eau qui l'a tenue en suspension; alors on l'étend par tablettes dans de petites caisses carrées de trois pouces de rebord. On l'y laisse sécher peu à peu en 


\section{(83)}

lexposant alternativement à l'ombre et à un solẹil gradué.

L'indigo léger, ou indiga Flore, ou indigo de Guatimala, est le plus estimé. Il surnage l'ean et est inflammable. Vient après cette espèce, appelée par Linnée indigofera dysperna; $\mathbf{2}^{\circ}$ l'indigofera tinctoria, qui est plus riche en coulenx, mais d'une qualité moins'estimée; $3^{\circ}$ l'indigofera argentea, Linn., espèce peu productive en fécule colorante et qu'on nous envoie de la Caroline.

On doit à M. Chevreul la connaissance d'un procédé simple et sûr pour extraire de l'indigo les parties hétérogènes qui lui sont associées. Il suffit de mettre de cette pâte bleue en poudre dans un creuset d'argent couvert et de l'exposer à une moyenne chaleur. On voit alors le plus pur indigo se sublimer sur les parois du vase.

L'indigo sert à teindre en bleu la soie et la laine; les peintres le mêlent à d'antres couleurs dans la peinture en détrempe, où il produit de beaux tons pour la verdure et pour les ciels. Les blanchisseuses donnent avec cette fécule une couleur bleue a linge.

Beaucoup de légumineuses, telles que les colutea, galega, robinia, sophora, coronilla, hedysarum, medicago, crotalaria, etc., fournissent aussi une fécule colorante bleue.

Caractères physiques. L'indigotier est une plante sous-ligneuse, à tige pleine, cylindrique, droite, dure, rameuse, feuillée, villeuse et blanchâtre dans sa partie supérieure, à écorce gercée et rayée de 


\section{(84)}

fibres. Les feuilles sont alternes, pinnées avec impaire, composées de neuf folioles ovales, obtuses, entières, d'un pouce de longueur. Elles sont lisses, douces au toucher, d'un vert foncé en dessus et argentées par dessous, attachées à un pétiole très-court. Moins la feuille est garnie, plus la foliole terminale est grande. Les stipules sont peu. apparentes et subulées.

Les grappes spiciformes qui naisssent dans les aisselles des feuilles sont plus courtes que ces dernières, et portant de petites fleurs papillonacées, d'un vert blanchâtre, parsemées de veines pourprées.L'étendard est le plus grand pétale; il est creusé en cuiller, et échancré en couur à son sommet; les ailes, d'après la remarque de Nicolson, sont les pétales les plus pointus, les plus étroits, et les plus colorés de tous.

Il sort du centre de la fleur un faisceau d'étamines, dont les filamens réunis à leur base, et divisés supérieurement en huit à dix lanières, portant des anthères d'un vert jaunâtre, environnent le pistyl; la fleur est portée sur un pédoneule très-court; les calices monophylles sont divisés en deux lèvres et cinq dents; ils sont très-courts, blanchâtres et pubescens; les bractées sétacées sont plus courtes que les fleurs.

A lcur chite, le pistyl devient une gousse linéaire de huit à dix lignes, courbée en montant en forme de faucille; ces gousses, terminées en pointe, sont presque glabres, brun-violet au dehors, blanchâtres en dedans, légèrement comprimées vers les sutures au dessous de chaque graine, qui, au nombre de cinq à sept, sont de forme carrée à quatre angles obtus et sếparés par des cloisons olivâtres. 


\section{(85)}

Les racines de l'indigotier sont dures, tortueuses, rameuses, chevelues et couvertes d'une éeorce blanchâtre qui est peu adhérente et qu'on enlève facilement.

AnaL yse Chrmeue. L'indigo est insoluble dansl'eau et dans l'éther; il est inaltérable à l'air; il se dissout dans l'aleool bouillant, et dans les acides sulfuriquo et nitrique. L'acide muriatique n'agit sur lui qu'à un certain degré de chaleur. L'acide muriatique oxigéné détruit sa couleür, tandis que les alcalisn'ont aucune action sur Jui. En lui ôtant son oxigène, il devient jaune, et reprend sa couleur bleue en l'exposant à l'air. Toutes ces observations appaitiennent à M. Loiseleur Deslongchamps.

Propriétés mépicinales: L'indigo franc dont la saveur est amère et piquante, est fébrifuge par excellence; mais il fant en user intérieurement avec réserve, en xaison de certaines propriétés délétères. Les médecins indiens l'ordonnent en bains, pour fortifier le système nerveux. Suivant Poupée-Desportes, c'est un excellent résolutif, qui est surtout applicable dans les érysipèles, où il agit comme sudorifique. Son sel, continue le même médecin américain, équivaut à celui d'absinthe. Contusé, on applique l'indigo en épithème frontal; tandis que sa poudre, dit encore Poupée-Desportes, déterge les anciennes plaies qu'ón lave ensuite avec la décoction de la plante.

L'indigo en fécule est employé dans la toilette des Nègres, et pour colorer leurs filets de pêche et leurs tangas. Il font usage des semences pilces ou des racines infusées dans le tafia, pour détruire leur ver- 
mine. On estime aussi les fleurs de l'indigo comme vulnéraires et céphaliques.

Mode D'administration. Les feuilles s'emploient dans les bains fébrifuges. La racine est estimée antiseptique; on l'administre en poudre à la dose d'un à deux gros, dans l'apyrexie des fièvres intermittentes, soit en opiat, soit dans un véhicule approprié à la maladie.

Nota.Poupée-Desportesindique trois autres espèces d'indigotiers : $1^{\circ}$. l'indigo bâtard emerus major, foliis rigidis, angustis et incanis, flore rubro-amorpha fructicosa. Lina barba Jovis americana pseudo-acadiae flosculis purpureis minimis. (Valm. de Bomare.) Voyez cl. XX, plantes résolutives. 20. L'indigo sauvage qu'il appelle de Guatimala emerus minimus montanus, foliis rarioribus, ineanis et rigidis siliquis, rectis pendulis; c'est l'emerus siliquis longissimis et angustissimis. (Plum. Bar. essais, p. 49.)

Explication de LA pLANChe dix-septrème.

La plante est représentée moitié grandeur naturelle.

3. Fleur grossie.

2. Légume de grosseur naturelle.

3. Graine. 


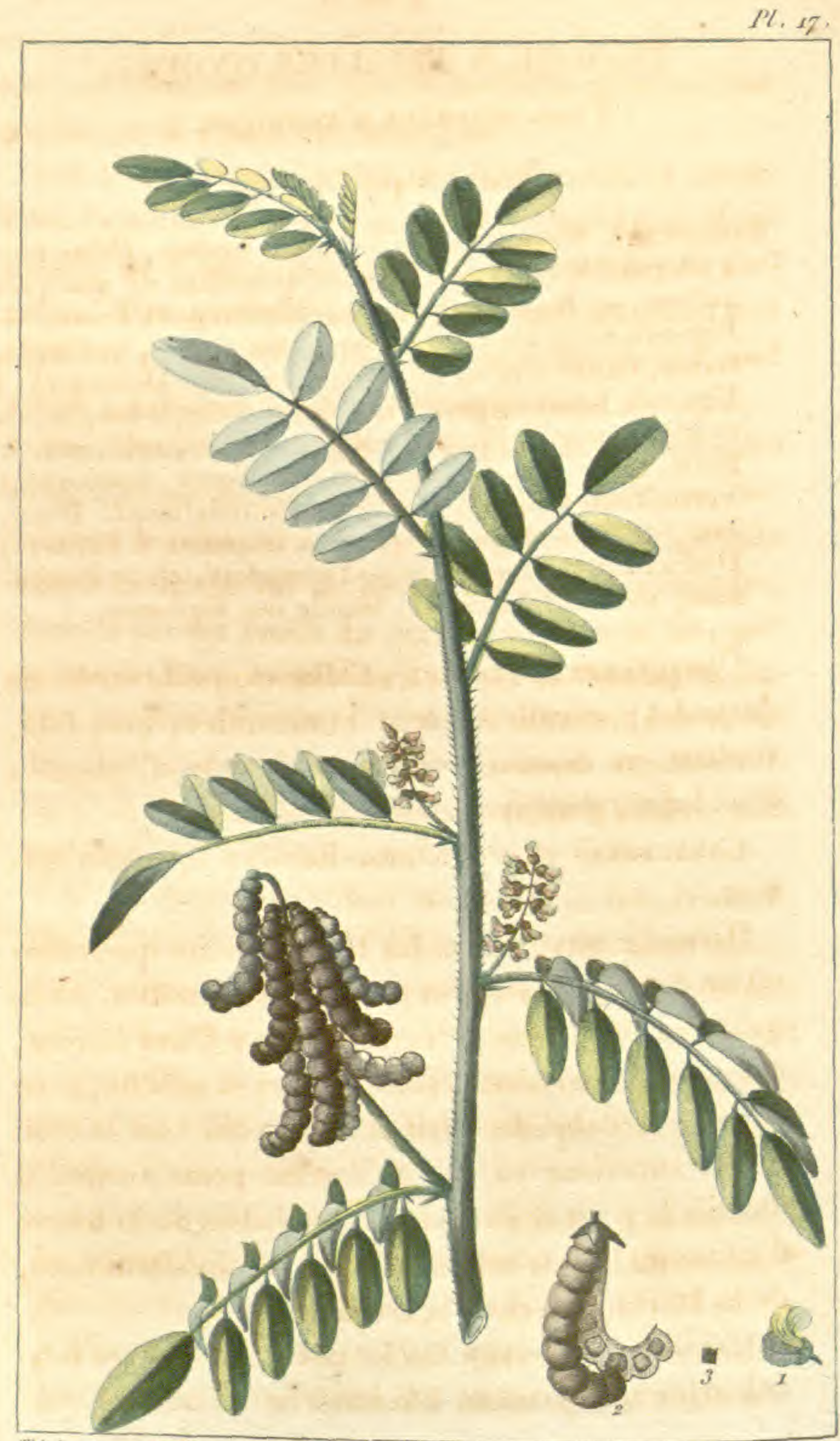

Thintore Dercourlite Pinx. 


\section{( 87 )}

\section{BIGNONE A FEUILLES ONDÉES,}

( BOIS DE CHÈNE D'AMÉRIQUE.)

(Stomachique fébrifuge.)

Synonymie. Bignone noire à feuilles ondées, chêne noir à silique (Vivace). - Bignone querciline de quelques auteurs. - Bignonia quercus, hort. reg. et Tussac. Bignonia foliis simplicibus, ovato lanceolatis, undulatis, ternis, Caule erecto, Floribus diandris, (Delamarck.) Bignonia foliio singulari undulato, siliquis longissimis et angustissimis. Plum., vol. 7 , pag. $9^{6}$, vel., gen. 5 . Burm. amer, tab. 57.- Bignonia arborea, foliis ovatis Verticillato-ternatis, siliquấ gracili longissimâ. Brwn. Jam. 264: - Bignonia (espèce inconnue à Linnée.) Dydinamie angio-spermie.-Tournefort, cl. 3. Personnées, sect. 3. - Jussieu, famille des Bignones.

Caractìres génériques. Calice cinqu-fide en forme de godet; corolle à gorge campanulée; cinq-fide, ventrue en dessous; silique ou capsule siliqueuse à deux loges, semences membraneuses, ailées.

Ciaracteres particuliers. Feuilles opposées ternées.

Histolre natutelLe. La bignone noire querciline est un des arbres les plus précieux des Antilles, en ce qu'il fournit du bois de construction à fibres serrées, comparable au chêne d'Europe pour sa solidité, si on le place à l'abri du soleil et de la pluie : on le croit même supérieur en ce qu'il n'est point assujéti à devenir la proie des vers et des pholades; on le trouve dans toutes les plaines et les forêts de Saint-Domingue, de la Martinique et de la Guadeloupe.

Caractènes raysreues. Le chêne noir est un trèsbel arbre qui parvient à la hauteur de trente à qua- 
rante pieds. Son tronc est droit et très-branchu, surtout aư sommet. Son écorce cannelée est d'un roux cendré, et le bois d'un jảune pâle.

Ses feuilles sont simples, ovales, lancéolées, pourvues de pétioles, ondulées vers leur bord; de deux pouces dé largeur sur quatre à cinq pouces de longueur. Elles sont glabres aux deux surfaces, d'un vert clair en dessus, blanchâtres en dessous; elles sont rangées par deux ou trois à chaque noud.

Les fleurs disposées en panicules à l'extrémité des rameaux sont monopétales, légèrement courbées, évasées par le haut, et gonflées à la partie inférieure du tube. Le limbe est divisé en cinq parties inégales, dentelé sur les bords. La corolle est blanchâtre, parsemée de filets rougeâtres, ce qui lui donne un aspect couleur de rose. Ces fleurs exhalent une odeur des plus suaves. Elles n'ont que deux étamines fertiles, et comme le B. catalpa trois filamens sans anthères.

A ces fleurs succèdent des siliques très-étroites, biloculaires, bivalves et pendantes; elles sont arrondies, vertes, puis brunâtres au dehors et blanchâtres au dedans; longues de plus d'un pied, et renfermant en quantité, de petites graines ailées, de la forme d'un ceeur, dout les ailes sont terminées par des poils, et placées en recouvrement.

Axalyse chimiqúg. L'écorce de cette bignone offre beaucoup de tannin qu'on obtient par la décoction, et dont les tanneurs-corroyeurs se servent.

Propriétés médicinales. On emploie l'écorce, les feuilles et les fleurs du ohêne noir d'Amérique, 


\section{$(89)$}

qui ont une vertu fébrifuge et évidemment astringente. On recommande l'usage du sirop fait avec l'écorce et ses fleurs dans toutes les cireonstances, où on prescrit celui de quinquina.

Mode d'idministration. L'écorce réduite én poudre, se donne en suspension, depuis deux gros jusqu'à quatre, dans un véhieule aqueux ou vineux, suivant le cas. On peut en composer aussi, avec du sirop, un électuaire qui répugne moins aux fébricitans que la poudre en substance. Les feuilles servent à composer des topiques astringens, ou des lotions du mếme genre. Les fleurs, réduites en poudre, sont regardées conme fébrifuges, et se prescrivent à moitié dose de la poudre: on donne des clystères avec la décoction de ses feuilles, à la fin des dyssenteries.

\section{Expitcation de la PLANCHE DIX-huitième.}

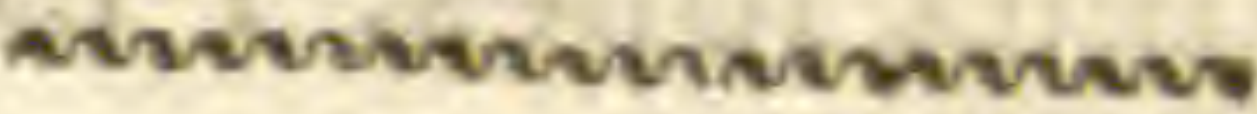

La plante est réduite aux deux tiers de sa gran. deur naturelle. 


\section{TROPHIS D'AMÉRIQUE, (BOIS RAMON.)}

(Stomachique fébrifuge.)

Synonyme. Arbor non excelsa foliis rigidis laté virentibus, Floribus in fasciculum congestis, ex luteo-albidis et suaveolentibus, fructu amygdalino parvo, cortice amarâ (Poupée-Desportes.) - Ramon-Bucephalon, fructu racemoso rubro. Plum., vol. VI, pl, 103. Micocoulier à petites feuilles. - Trophis americana, Celtis occidentalis. Tussac. - Trophis et alternativement savonnier aux Antilles, Bosc.- Micocoulier des Antilles. Celtis occidentalis. Linnée, cl. XXIII. Polygamie monoëcie. (Vivace), Tournefort, cl. 21, arbres rosacées. - Juss., sect, 2 , famille-des Amentacées. Mallam-Taddali. Mal. - Tarilla d'Agoa, Portug.

Caractéres gémériques. Fleurs diöques disposées en épi axillaire. Males, calice en quatre parties, corolle nulle, quatre étamines dont les filamens capillaires plus longs que les divisions du calice portent des anthères ovalaires à deux lobes. Femelles, calice monophylle très-petit fortement adhérent à l'ovaire, celuici très-petit, surmonté d'un style à deux divisions divergentes; feuilles obliquement ovales, aiguës.

Historre naturelle. Cet arbrisseau n'a rien de remarquable quant au port; mais on le recherche à cause de ses vertus médicinales; et il est fréquemment employé par les praticiens des pays où il se trouve. On le rencontre dans les bois humides, sur les bords des fleuves, et près des lieux habités.

Caractères physiques. Le trophis d'Amérique est un arbre dont les rameaux sont glabres, alternes, médiocrement étalés, revêtus d'une écorce d'un 


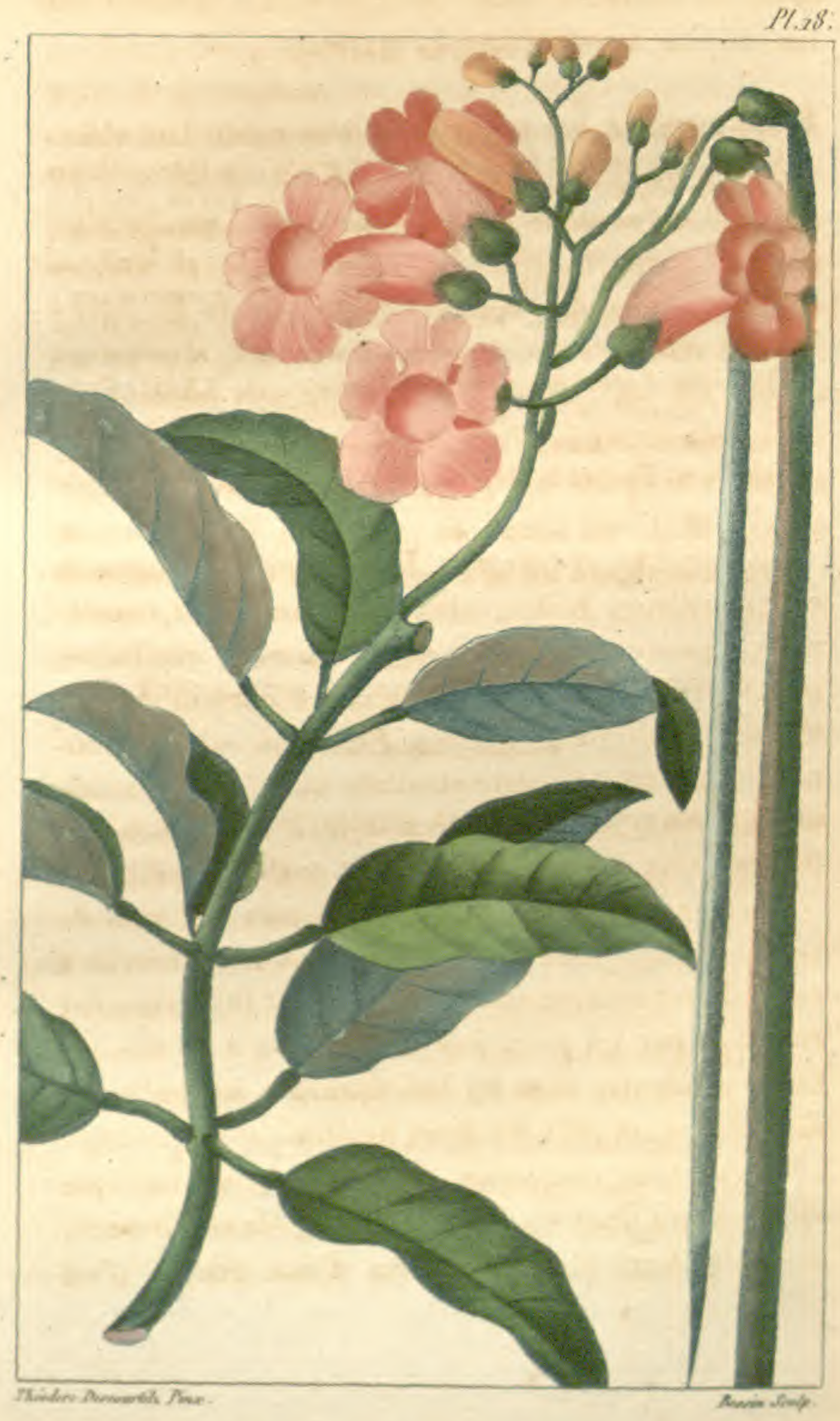

BIGNONA CHENA. 


\section{( 91$)$}

brun violet, parsemée de petites taches fauves; garnis de feuilles alternes, médiocrement pétiolées, ovales, lancéolées, longues de trois à quatre pouces et plus, larges d'environ deux pouces, glabres à leurs deux faces, très-entières à leurs bords, aiguës ou acuminées à leur sommet, veinées, supportées par un pétiole très court, un peu canaliculé.

Les fleurs sont diö̈ques; les mâles disposées dans l'aisselle des feuilles, en un épi de forme de chaton allongé, presque cylindrique, obtus, légèrement pédonculé, un peu grêle, chargé de fleurs sessiles et serrées, dont le calice, divisé en quatre parties obtuses, et, arrondies à leur sommet, environne quatre étamines sétacées du double de longueur du calice.

Les épis femelles un pei plus courts, axillaires, leur calice entier, adhèrent à l'ovaire; deux styles divergens aigus.

Le fruit est une baie globuleuse rougeâtre, couverte d'un léger duvet, à quatre côtés, à une seule loge, qui contient une semence unique. (Encycl., par o. d. m.)

Analyse chimique. L'écorce du bois ramon, contient beaucoup de tannin, et un principe extractif amer.

Propriétés particulières. Le feuillage du trophis est un très-bon aliment pour les chevaux, qui, lorsqu'ils en font usage, deviennent vifs comme s'ils mangeaient de l'avoine, et engraissent promptement.

Propriétés médicrales. Le bois ramon a la vertu de tous les amers, et pour cela, il est employé dans tous les cas où ces médicamens doivent être prescrits. 


\section{( 92$)$}

Poupée-Desportes s'en servait habituellement aves succès (1).

Mode d'administration. On fait usage du bois ramon en poudre ou en décoction : un gros de son écorce rapée, suffit pour une livre d'eau ou de vin.

Explicatron de IA pianche dix-NeUUizime.

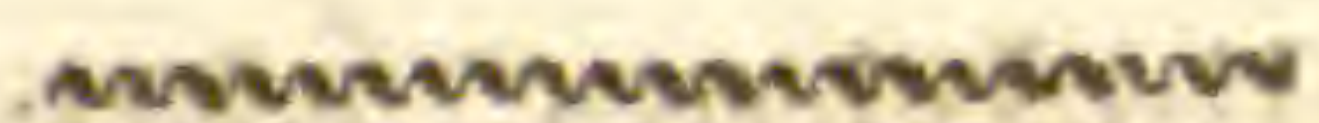

Le sujet est réduit à moitié de grandeur naturelle. It n'est chargé que d'un chaton femelle.

1 Fruit coupé transversalement et offrant à son milien le noyau qu'il contient.

2. Embryon femelle chargé de deux styles divergens en forme de cornes.

3. Fleur mâle pourvue de quatre étamines dont les filets sont adnés aux pétales.

(t) Selon Rhed, lés Malabarois Yindiquent comme convenable contre l'épilepsie, la phrénésie et les autres maladies du cerveau; mais la doctrine nouvelle réprouve ces assertiơns exagérées. 


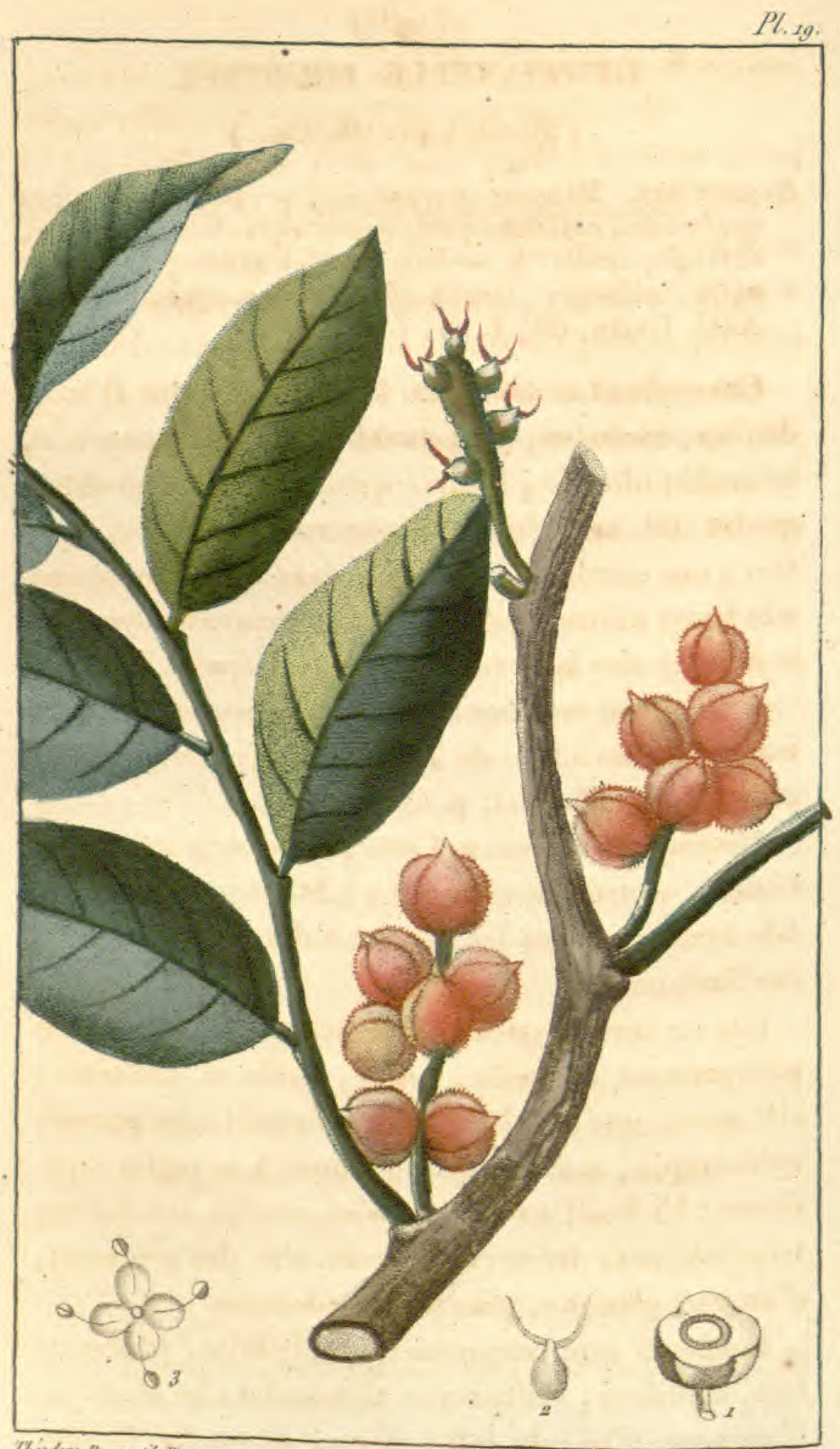

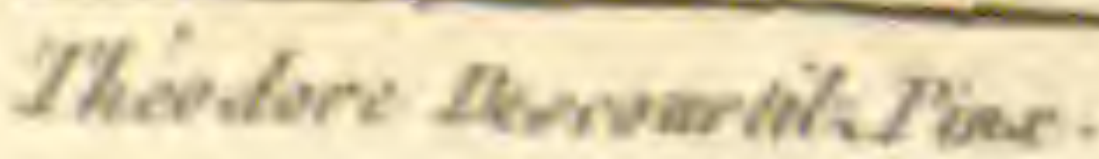

Bewion Siolf.

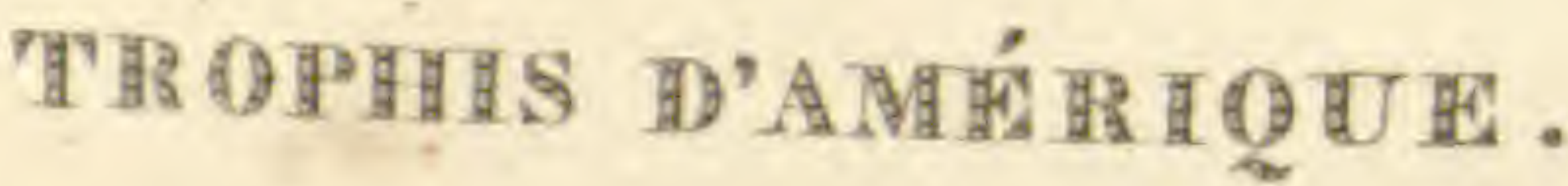




\section{( 930$)$}

\section{GENTIANELLE POURPRÉE.}

(Stomachique fébrifuge.)

Sxanymie. Exacum purpureum. - Exacum floribus quadrifidis, calicibus quadrangularibus, foliis sessilibus, oblongis, acutis. N. - Exacum (Guianense) foliis connatis, oblongis, acutis. Floribus purpurascentibus, Aubl. Guian. 68 , t. 26 , f. 1 .

Caractères génźr ipues. Calice de quatre folioles droites, carénées, persistantes, corolle monopétale, infundibuliforme, limbe à quatre divisions ouvertes, quatre étamines pérygines, pourvues d'anthères sagittées à une extrémité, et de trois écailles rudimentaires à la base ; ovaire supérieur ovale, surmonté d'un style aussi long que la corolle, à stigmate épais, bifide.

Le fruit est une capsule ovale, un pen comprimée, marquée d'un sillon de chaque côté ; biloculaire et polysperme. (Encycl. p. O. d. m).

Historre anaturel e. Cette plante, originaire de la Guiàne, se trouve néanmoins à St.-Jago de Cuba, et à la Jamaïque dans les bois humides, et sur le bord des fontaines.

Caractéres physpurs. La racine de la gentianelle pourprée est annuelle, jaune, grêle et tortueuse ; elle pousse une tige de la hauteur de huit à dix pouces, cylindrique, rameuse et dichôtome à sa partie supérieure; lès feuilles sont opposées, sessiles, lancéolées, très-pointues, tri-nervées, caractère des gentianes, d'un vert glauque, plus pâle en dessous.

Lesfleurs sont purpurines, quadrifides, pédonculées, solitaires, axillaires et terminales; les étamines d'un jaune d'or; le ealice formé de quatre folioles 


\section{(94)}

présente, pour angles dorsaux, une crête membraneuse et frangée : il est d'un vert bleu.

Les capsules de cette jolie plante servent d'étui pour préserver les semences des injures de l'air et de la terre, jusqu'à ce qu'elle soit invitée par un beau soleil à les disséminer; alors, à la première impression de la rosée, il se fait un départ des graines qui vont çà et là se reproduire, en se semant naturellement.

Analyse chumeue. Je ne me suis pas occupé particulièrement de l'analyse de la gentianelle pourprée; mais je pense qu'on peut lui attribuer les mêmes principes qu'aux plantes amères.

Propriétés médicinales. La gentianelle est stomachique, fébrifuge, emménagogue, anthelmintique et alexipharmaque; dans les fièvres intermittentes on l'associe au quinquigna, dont elle est l'nn des succédanés : elle convient par conséquent dans les atonies viscérales, et surtout dans les diarrhées chroniques produites par relâchement, et si fréquentes dans les climats chauds. On l'associe souvent aux plantes emménagogues; elle fait partie, ainsi que ses feuilles, des déeoctions détersives et anti-septiques.

Mode d'Administration. On l'emploie comme l'indigo cultivé. (Voyez article 17. .)

Explication de ta planche vingtième.

Individu peu élevé de grandeur naturelle.

1. Calice grossi revêtu à ses angles de crêtes membraneuses frangées.

2. Etamine sagittée garnie, à la base de son filet, de trois petites écailles.

3. Ovaire surmonté d'un pistyl bilobé. 


\section{$(95)$}

\section{PLANTES FÉBRIFUGES}

\section{Rapportées dans d'autres classes.}

Stomachipues aromatiques. Acacie de Farnèse, croton cascarille.

Stomachiques vermifuges. Presque toutes les espècès de cette classe sont fébrifuges.

Purgatives. Les espèces de ces classes, soit qu'elles agissent en débarrassant les premières voies, soit qu'elles procurent des évacuations alvines, sont les premiers moyens à employer pour combattre avec succès les fièvres gastriques et plusieurs d'un autre caractère.

Diurétiques excitantes. On a le choix, dans cette classe, de plantes dont les propriétés y sont indiquées et qui peuvent convenir à l'état de la maladie, surtout en les associant à d'autres espèces donées d'une. vertu directe et spéciale.

Rafraìchissantes, AQueuses et acides. L'usage de la plupart de ces plantes sont d'un puissant secours dans les fièvres angeioténiques et bilieuses; et le malade, consumé par un feu intérieur, voit arriver avec délices, une boisson propre à calmer et étancher la soif ardente et insupportable dont il est accablé.

Anti-spasmodiques. On trouve, dans les individus de cette classe, beaucoup de plantes dont le choix sage en rend l'usage précieux dans les fièvres ataxiques et adynamiques de mauvais caractère. 


\section{$\left(9^{6}\right)$}

Diaphorétipues et sudorifiques. D'après l'indication à remplir on use tour-à-tour des amers et des plantes de ces deux classes, lorsqu'il est utile d'aider les efforts de la nature par une diaphorèse ou des sueurs.

Epispastiques. Dans un pays où l'on cherche à utiliser en faveur de l'humanité tout ee qui s'offre à l'observation du médecin botaniste, les épispastiques végétaux indigènes remplacent les cantharides et les sinapismes. 
Pl. 20 .

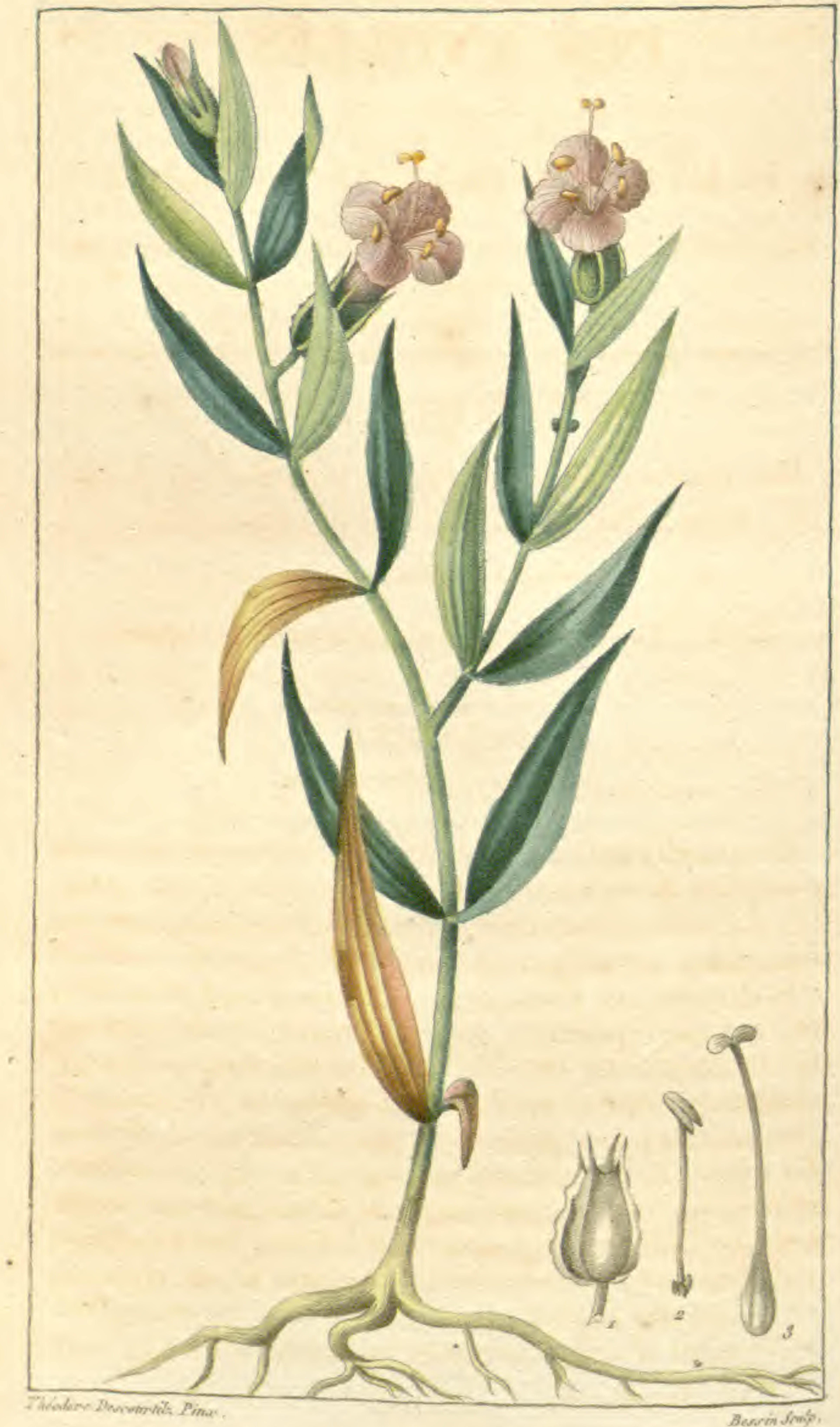

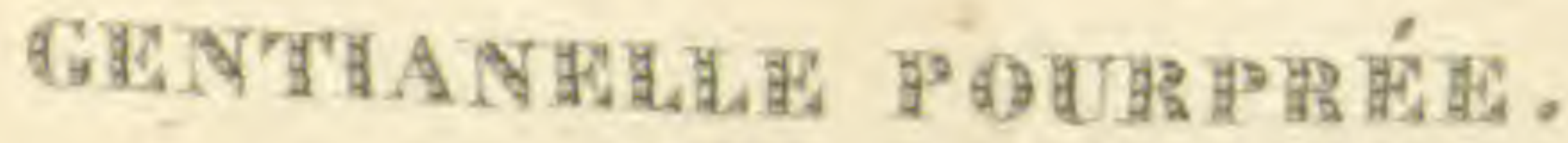




\section{FLORE MÉDICALE}

\section{DES ANTILLES,}

O U

\section{TRAITÉ DES PLANTES USUELLES}

DES COLONIES FRANCGATSES, ANGLAISES, ESPAGNOLES

ET PORTUGAISES.

\section{CLASSE PREMIËRE.}

DES PLANTES QUI EXCITENT LA TONICITÉ DES VOIEE DIGESTIVES ET DE L'APPAREIL FIBRILLAIRE.

Sect. 3. Stomachiques anti-scorbutipues.

\section{SOMMAIRE.}

On appelle anti-scorbutiques, les végétaux doués de principes acres ou aromatiques, soit fixes, soit volatils.Lavertu decesremèdes se manifeste, disait-on, en liquéfiant un sang trop épais dont la torpeurconduit à la dissolution. Dansce cas on associe aux premières les espèces apéritives comme propres à désobstruer les viscères, et à rétablir l'action des fluides. Cependant le scorbut se modifiant d'après la constitution du malade, son genre de vie, l'état où la fortune l'a placé, le traitement ne peut plus être le mếme, et il exige une grande sagacité de la part du médecin. Le matelot voguant sur les mers, par exemple, y éprouvant l'intempérie des saisons, et des climats, essuyant des privations de tout genre, les mauvaises influences d'une nourriture malsaine et de l'air con6e. Livraison. 


\section{$\left(9^{5}\right)$}

centré et infect des entreponts, exposé chaque jour à des suppressions de transpiration guérira plus difficilement sous des régions froides, que s'il vogue sur les mers de l'Amérique méridionale. Quelques jours de repos à terre, l'usage des fruits et de viandes fraîches, un exercice modéré au milieu d'un nouvel atmosphère, le rétabliront bientôt. Il n'en est pas de méme des vieillards dont le sang est déjà appauvri, et chez lesquels la nature fait peu d'efforts; de ces tempéramens lymphatiques, de ces scorbutiques mélancoliques que le défaut d'activité prive des sueurs, si précieuses et si convenables à la régénération du sang. C'est pour saisir ces divers caractères que le médecin doit joindre à l'expérience, une théorie sage et múrement combinée. Ainsi pour combattre cette affection chez les sujets a fibre molle et lymphatique, à paleur et bouffissure de la face, il prescrira les plantes de cette classe qui abondent en principes acres et volatils, irritans, comme propres à stimuler les organes, à accélérer la circulation, et à rappeler les forces vitales.

$A$-t-il à traiter des storbutiques mélancoliques? il associera aux anti-scorbutiques stimulantes, celles amères, telles que le quinquina, le menyanthe et autres toniques dont l'action est de fortifier la fibre en la resserrant. Le punch et autres diffusibles y conviennent également.

Mais il combattra avec avantage les symptômes inflammatoires, chez les bilieux et les bilioso-sanguins, avec les acides végétaux de l'orange, des ananas, des citrons, de l'oseille de Guinée, de l'oxalide. Ces mêmes acides, indiqués en cas de dissolution et d'hémorragies si fréquentes en cet état, contrc-indiquent les alcalis qui ne font qu'augmenter les accidens. Il en est de méme du lait qui deviènt salutaire ou pernicieux, suivent l'idiosyncrasie et le stade de la maladie. 


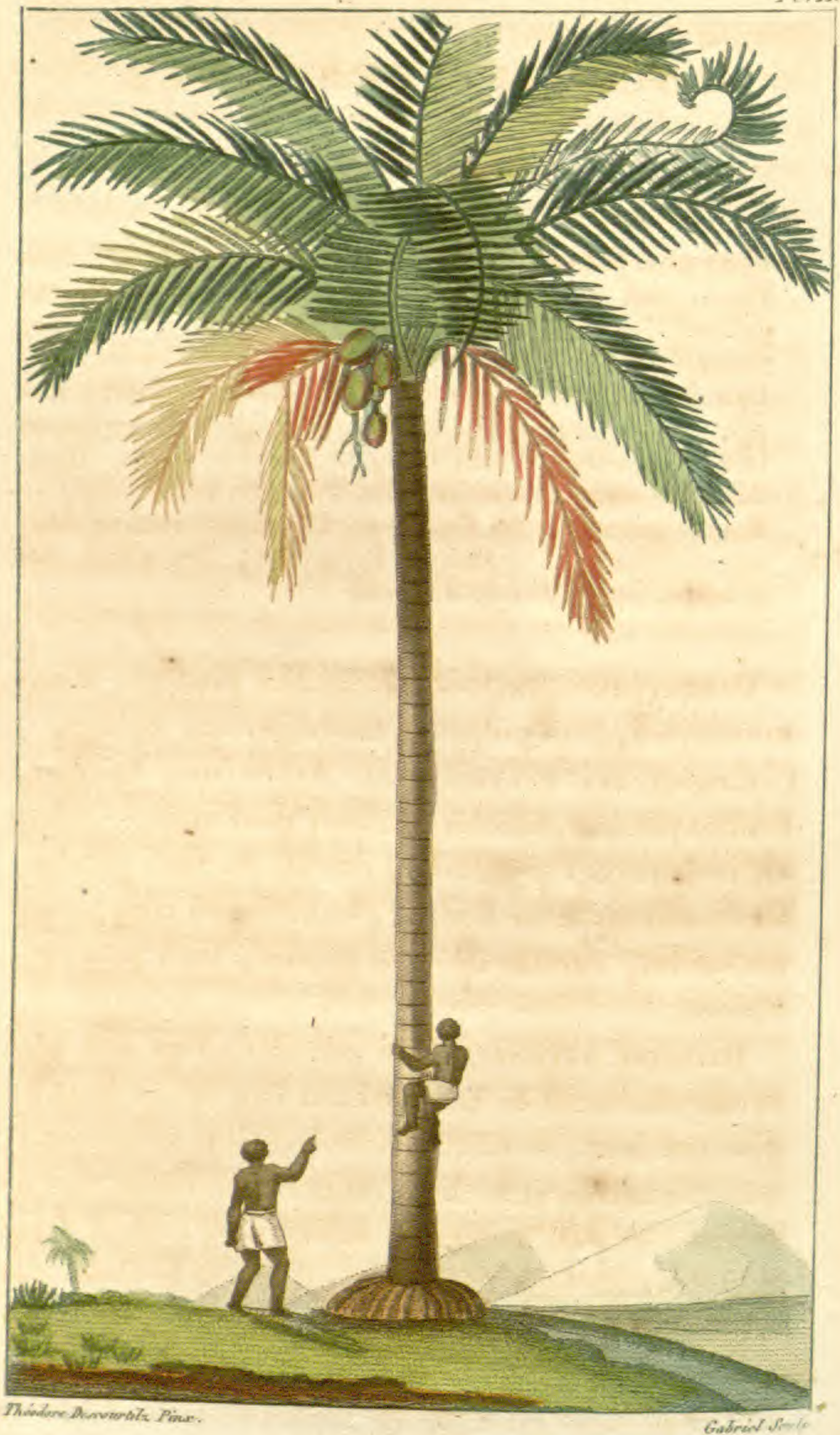




\section{(99) \\ COCOTIER DES IN DES。}

(Stomachique anti-scorbutique.)

Synon rmie. Palma coccifera, vaginis ventricosis et liratis. Plum., vol. 7, pag. 1re. - Palma indica, coccifera, an= gulosa. Bauh. Pin. 508. - Cocos inèrmis, frondibus pinnatis, foliolis replicatis ensiformibus, vel cocos nucifera. Lin. monoëcie hexandrie.- Cocos nucifer, nucleo dulci eduli. Jacq. Amer., 377, t. 168. - Palma indica coccifera. Plak. Calappa, rumph. tenda. Hort. Malab. - Ord., fam. 6, les Palmiers (Adanson).Inaya-guacuiba des Caraïbes, Pis. Pras. 130.-Monocotylédones, étamines Perigynes, 3 e. classe des familles naturelles de Jussieu.

Caractères générioues. Feuilles pinnées, fleurs monoïques, fruit pulpeux, monosperme, coriace.

Caractères particuliers. Arbre non épineux, feuilles pinnées, folioles repliées; fleur mâle, - calice en trois parties profondes, corolle de trois pétales, six étamines; fleur femelle, - calice en cinq parties profondes, corolle de trois pétales, fruit pulpeux, coriace.

Histoire naturelie. Le cocotier, l'un des plus beaux ornemens de la nature, et l'un de ses dons les plus précieux, se plait dans les terrains sablonneux, dans les marais et les lieux ombragés de l'Asie, de l'Afrique, et de l'Amérique méridionale, où il fructifie deux ou trois fois par an : il est de la classe de palmiers et de celle des plantes unilobées.

Ce beau palmier joint à la majesté du port une utilité presque générale de toutes les parties qui le 


\section{( 100$)$}

constituent; on peut donc lui adresser cet éloge avec l'académicien Dulard:

Toi dont s'enorgueillit la rive Américaine,

Viens, arbre merveilleux, et brille sur la scène.

Aux habitans grossiers de ces lointains climats

Quels utiles secours ne prodigues-tu pas?

De tom bois abattu par la hache acérée,

Ils construisent des toits que respecte Borée.

Par ton énorme tronc en esquif façonné

De l'humide élément le sein est sillonné.

Là, ta feuille est tissue et flotte au gré d'Éole:

Ici, souple, elle sert à peindre la parole.

De tes flancs incisés s'éconle une liqueur,

Dont s'abreuve à longs traits l'altéré voyageur.

Mais combieu de ton fruit la chair est saroureuse!

Que sa moëlle distille une eau délicieuse !

Cette eau, source de vie, en ces climats brûlans,

Sert de nectar au peuple, et de lait aux enfans.

(Poëme de la grandeur de Dieu dans les merveilles de la nature. Ch. IV , p. 178 , vers Ier. $^{\text {) }}$

Quoique M. Dulard ne parle point du cocotier en naturaliste et en voyageur, il fait connaître néanmoins une partie des propriétés de cet arbre merveilleux. En effet, il semble, dit Bernardin de Saint-Pierre (dans ses harmonies de la nature), que l'abondance ait épuisé ses eornes dans les champs de l'Amérique plantés de cocotiers; puisqu'on trouve dans ces arbres, des alimens, de la boisson, de la toile, des meubles, et un grand nombre d'ustensiles.

Le pieux cénobite, qui vit des plus légers bienfaits de la nature, n'a plus rien à désirer s'il peutrassembler près de son hermitage un bananier et un cocotier; tandis que l'un pourvoit aux besoins les plus pressans de son existence, par la nature substantielle de ses fruits, l'autre ajoute à cette nourriture des mets auspi 
sains qu'agréables, que le silencieux hermite sait trouver dans le chou et dans le fruit du cocotier. Cependant, comme la sensualité ne peut s'accorder avec la sobriété du pieux anachorète, il ne vent point, pour une fantaisie sacrifier l'arbre, qui meurt dès que le chou en a été enlevé. Les gens du monde, plus sensuels, mais respectant les cocotiers qu'ils possèdent, en font ehercher dans les forêts par leurs nègres, et n'ont pas à regreter autant la perte de l'arbre dont ils se servent d'ailleurs pour la construction de leurs maisons, de leurs bâtimens de cabotage, et des colonnes naturelles qui composent les galeries tournantes de leurs cases, auprès desquelles ils protégent au contraire la végétation de ces arbres qui font le charme de leurs habitations.

Le chasseur fatigué ou le nègre maron veulent-ils se procurer une boisson saine etrafraîchissante? ilscoupent l'extrémité des spathes encore vertes, et il en suinte un suc limpide et doux d'une saveur agréable ; c'est ce qu'on appelle vin de palmiste, et que les naturels du pays nomment sura ou soury. Pour en obtenir une certaine quantité, il faut lier lés spathes, afin de les empêeher de s'ouvrir et de laisser épancher le liquide, qui, ne jaillissant que de l'endroit coupé, tombe dans des vases attachés au bas de la spathe.

Le vin soury, doux d'abord, acquiert me saveur aigrelette et piquante au bout de quelques heures, et atteint sa perfection à la fin de la journée ; mais il s'aigrit au bout de vingt-quatre heures, et fournit alors un vinaigre asssez fort s'il a été exposé à la chaleur. En distilant ce vin de palmier dans sa plus 
grande forcé, et avant que la fermentation acéteuseait commencé, on obtient une liqueur alcoolique, ou espèce d'eau-de-vie, à laquelle on donne le nom d'arraka ou rach de palmiers.

Veut-on, lorsque le vin est récent, concentrer son principe mucoso-sucré? On le fait évaporer jusqu'à consistance sirupeuse, puis l'on procède, par les moyens connus, å la cristallisation de ce sucreque l'on reud plus blanc au moyen de l'addition de chaux vive. Il est cependant moins délicat que le sucre de cannes; mais on l'emploie à la cuisine pour les besoins domestiqués, et à l'office pour la confection de certaines confitures, on nomme ce sucre Jagra. (Suivant Valmont Bomare.)

Il est bon d'observer que le cocotier dont on a incisé les spathes, ne porte pas de fruits, puisqu'on a enlevé, par ce procédé, toute la substance qui les formait.

Lorsque le fruit du cocotier est arrivé à sa parfaite grosseur, il est ovoïde trigone et à angles arrondis ; il a à son sommet une cavité légère placée au milieu de trois saillies, obtuse où est attaché l'un dès pédoncules de la grappe.

Sous le brou très-épais ou caire, dont l'enveloppe extérieure est lisse et d'un gris verdâtre, on trouve une coque ovoíde très-dure, de la grosseur d'un ceuf d'autruche ou environ, marquée à sa base de trois trous, dont un seul est perforable au moyen d'une épine ou d'un clou. La ceque ligneuse du fruit contient une amande à chair blanche, et ferme comme celle de la noisette dont elle a la saveur : elle est 
creuse, sa surface intérieure mamelonnée et remplie d'une eau claire, agréable et aigrelette.

Ces fruits avee leurs trois trous, dit Bernardin de St.-Pierre, offrent une parfaite ressemblance avec la tête d'un nègre; ils semblent aussi, par leur forme carênée, avoir servi de modèle à l'architecture navale.

Lorsque l'amande u'est pas encore mûre, elle contient environ une chopine d'eau de cocos, qu'on estime anti-scorbutique, qui appaise promptement la soif, et soulage, ainsi que l'amande, dans le mal de mer. Mais si le fruit a acquis sa grosseur, la moëlle de la noix prend plus de consistance, et l'eau y diminue de manière à devenir partie intégrante de l'amande qui, ayant absorbé ce liquide, s'écrême à la cuiller, tandis que la base, adhérente aux parois ligneuses, a acquis une plusgrande compacité. Suivant l'expression de quelques auteurs, le fruit du cocotier renferme lait et beure, parce que son amande procure une émulsion laiteuse, etune huile comparable à celle de la noisette d'Europe.

On voit, par ce qui précède, combicncesfruits doivent exciter l'envie de ceux qui les déeouvrent: mais comment arriver à une hantenr si prodigieuse? Écontons l'ami de la nature, l'ohservateur exact Bernardin de St.-Pierre, et n'ajoutons rien à ses élégantes descriptions. "Chaque mois Junaire, dit l'aimable auteur 2) de Paul et Yirginie, le cocotier pousse une feuille

》) ou un régime de frnits, et sa tête s'élève d'un cran:

2) lorsque les nouvelles palmes se développent, les

》 inférieures, qui sont les plus anciennes, tombent

20 et laissent sur le trone des espèces de haches rabor 


\section{(104)}

刃 teuses et annulaires, qui servent ála fois de marques 》) chronologiques et de degrés pour monter à son som》met; et comme la circonférence des plus gros, n'a " pas plus d'amplitude que celle des bras d'un négre, ) lorsqu'il vent y grimper, il se fait, avee une des 》) palmes tombées, une ceinture dont il s'entoure avec ग le tronc, et en s'aidant des pieds et des mains, au 3) moyen des anneaux qui lui servent d'appui, il 》) s'élève jusqu'au sommet pour en tirer du vin ou 》) pour en cueillin les fruits. )

Le cocotier offre bien d'autres ressources : tantôt les nègres tressent, avec beaucoup d'adresse et de goût, les feuilles séchées pour en faire des macoutes ou paniers, des nates qui remplacent les tapis, et des coufles pour transporter le café; tantôt ilsencouvrent leurs maisons, en forment des parasols, des voiles de vaisseaux, tandis que les fibres en réseanx qui environnent la partie de l'arbre d'où sortent les branches, procurent des lamis pour filtrer les liquides. On peut écrire sur les spathes lorsqu'elles ont produit leurs fruits, et qu'elles se sont détachées de l'arbre. Les Caraibes en faisaient beaucoup d'usage.

L'écorce extérieure ou le brou, qu'on nomme aussi caire est formée d'un chevelu dont on fait des cordages pour les vaisseaux. Cette espèce de bourre est préférable aux étoupes pour calfeutrex les vaisseaux parce qu'elle ne pourrit pas si vite, et qu'étant spongieuse, elle pompe l'humidité.

La coque ligneuse du coco se travaille pour différens ouvrages. Les joailliers en font des poires à poudre, des tasses qui acquièrent le poli et la couleur 


\section{(105)}

da bois d'ébène, si on a eu la précaution de l'enfonir brute dans la vase pendant trois semaines. On la retire après ce temps, dégagée des fibres roussâtres, adhérentes aux sillons de la surface, qui en eussent empêché le poli parfait, qu'on obtient au moyen de l'huile des amandes du cocotier.

Le cocotier aime les climats exposés aux vents, et semble destiné à croître dans les sables et sur les rochers des rivages des mers Torridiennes, car il languit dans l'intérieur des terres. Ses feuilles rongissent au moment de leur chute.

“ Les lourds cocos sont suspendus aux palmiers 2) avec précaution, dit l'auteur des études de la

3 nature : is viennent en grappes, attachés à une " queue commune, plus forte qu'un cordage de 》) ehanvre de même grandeur; ils sortent du sommet 》) de leurs palmiers, et posent sur son tronc, qui les " préserve, en partie, des secousses des veñts. ग) Leur caire étant compact et élastique, ils ne se » rompent jamais en tombant ». Quelquefois on les voit flotter sur les mers, et ils annoncent aux marins les attérages; d'autres fois le flux les porte vers des rives opposées. C'est au moyen de ce fruit, dont ils avaient enlevé l'amande, que certains voyageurs ont fait connaître la hauteur des mers où ils se trouvaient, en abandonnant à leurs flots et à leurs courans des cocos, dans lesquels ils renfermaient les détails de leur navigation, et qui étaient ensuite recueillis avec empressement sur les rivages où ils venaient aborder.

Caractíres rhysiQues. Les cocotiers sont des arbres à colonnes nues et longues de plus de cent pieds ; sur- 


\section{(106)}

montés à leur sommet d'un bouquet de dix à douze feuilles ou palmes, les unes droites, les autres trèsétendues arquées ou pendantes, que le moindre vent agite et balance gracieusement en tous sens avee un bruissement particulier. Ces palmiers imposans paraissent au dessus des autres arbres, selon l'expression de Bernardin de St.-Pierre, comme une forêt plantée sur une autre forêt: il s'y joint des lianes de divers feuillages, et qui, en s'enlaçant d'un arbre à l'autre, forment iei des arcadés de fleurs, et là des courtines de verdure. Leur diamètre ne change jamais, à quelque hauteur que la tige s'élève. Cette tige est composée de paquets de fibres qui les rendent souples et capables de résister an choc impétueux des ouragans. Au centre du faisceau des longues feuilles, on trouve un bourgeon droit presque cylindrique, tendre, bon à manger, et qu'on nomme chou.

Le trone grêle, en raison de la hauteur de larbre, offre quelquefois une légère courbure, et est souvent moins gros dans son milieu qu'aux extrémités : il est nu, marqué de cicatrices semi-circulaires produites par la chute des anciennes feuilles. Ces feuilles sont pimnées, longues de douze á quinze pieds, larges de trois àquatre pieds environ, composées de folioles nombreuses, pétiolées, ensiformes, fixéessur un pétiole commun, nu à sa base qui est plus large d̀ son ix sertion près du tronc, et garnie de fllamens sur les bords: les folioles forment deux plans rapprochés. l'un de Pautre.

On voit sortir du milieu des palmes de grandes. sp thes univalves, oblongues, pointues, qui se 


\section{(107)}

fendent par le côté, et donnent issue à une panicule dont les rameaux sont chargés d'un grand nombre de fleurs sessiles et d'un jaune-paille. Les fleurs femelles ont trois pétales et leur calice cinq divisions profondes; elles se trouvent à la base de ces rameaux, tandis que les fleurs mâles, qui sont plus nombreuses, garnissent toute la partie supérieure; elles ont trois pétales ovés et aigus; les étamines sont pourvues d'anthères oblongues, incombantes, portées par des filets en nombre égal, simples ét de la longueur de la corolle. Le pistil offre à la base un ovaire rudimentaire; le style est court, grêle, le stigmate court et trifide, ses divisions réfléchies. Le périanthe est stérile. Aux fleurs femelles succèdent des fruits à peu près de la grosseur de la tête d'un homme, rassemblés en grappes, et dont le brou ou caire est très. lisse et trẻs-épais.

Ces fruits sont oblongs, à trois angles arrondis, et ont à leur sommet, comme je l'ai déjả dit, un enfoncementleger, placé entre trois petites saillies obtuses. Sous le brou très-fibreux se trouve une coque ovoïde, ligneuse, très-dure, marquée à sa partie supérieure de trois yeux inǵgaux, dont un seul est susceptible d'étre perforé avee le moindre instrument piģuant; les deux autres offrant trop de résistance, C'est par ce procédé qu'on peut se procurer l'eau ou lait de coco que renferme l'amande creuse du fruit dont lo chair a des rapports avec ceux du noisettiex. L'eau de coco est claire, odorante, acide: les cuisiniers l'emploient pour relever leurs sauces; elle sert anssi do boisson rafyaichissante aux chasseurs assez heapeux 


\section{$(\tau 08)$}

ponr rencontrer un cocotier, en poursuivant dans les mornes, la pintade ou le cabri marron.

Le cocotier pousse peu avant dans la terre sa principale racine qui est environnée d'une quantité d'autres plus petites, entrelacées les unes avec les autres, et qui servent à consolider l'arbre, à le piéter en l'amalgamant avec le terrain où il doit être exposé à la fureur des orages.

Analyse chimique. La pulpe amandée du coco, d'un blane éblouissant, d'une saveur douce et trèsagréable, miscible à l'eau, donne, par trituration, une émulsion ou espèce d'orgeat très-rafraîchissant. Elle contient beaucoup de mucilage et de fécule amilacée, et à peu près moitié de son poids d'une huile grasse, jaunâtre, claire, non-congelable, très-donce étant récente, mais qui rancit en vieillissant, et prend à la gorge ; elle ne sert plus alors que pour la peinture, l'éclairage et la fabrication des savons en la combinant avec les alcalis.

Le caire donne, par macération, beaucoup de tanmin et d'acide gallique, ce qui lui fait accorder des propriétés toniques et astringentes. L'enveloppe ligneuse et noire de l'amande, donne une huile empyreumatique particulière, qu'on obtient par la distillation, et qui est spécifique dans les odontalgies ; eette coque est très-usitée dans l'Inde, au ràpport de Sir Flemming; elle fournit également à la peinture, un charbon velouté préférable au noir de noyaux de pềches.

Propriétés Médicinales. Le fruit du palmiereoco peut remplacer, lorsqu'il est récent, les aman- 


\section{$(109)$}

des douces pour les locks. L'amande en est trèsnutritive, et lorsqu'elle est nouvelle, elle rafraichit, velâche, adoucit et modère les irritations générales ou locales; mais autant elle produit de bons effets étant fraîche, autant elle peut nuire étant rance, par une propriété contraire. Il en est de même de son huile, qui a les mêmes vertus que celles de l'amande douce, et qu'on emploie ntilement comme purgative et vermifuge.

Les amandes du coco, molles et abreuvées de leur eau, se servent au dessert, et sont, à ce point, d'une assez facile digestion; mais elles occasionnent le pyrosis et des rapports nidoreux, si on les mange sèches et privées depuis quelques jours de cette eau qui entretient leur fraîcheur.

Le décoctum du brou, qui acquiert une couleur noire, par sa combinaison avec le fer, procure un tonique apéritif, astringent, dont on obtient des succèsdansles hépatiques chroniques, et les diarrhées muqueuses, si fréquentes et si rebelles sous la Zône Torride.

On emploie ce même décoctum, aiguisé de muriate d'ammoniaque, comme gargarisme styptique dans les angines muqueuses et chroniques, contre les ulcérations indolentes de la bouche, contre le gonflement des gencives et le relâchement de la luette. Il agit comme détersif dans le pansement des ulcères atoniques.

Les nègres recommandent la poudre de la coque ligneuse rapée, à la dose d'un gros, tous les matins à jeun, dans un verre de vin de Madére (deux onces), 


\section{(110)}

pour rétablir les forces des valétudinaires. Cette pré. paration, disent-ils, accélère le mouvement du sang, et est favorable aux vieillards.

Mode d'adininistration. Le décoctum du caire se donne depuis deux jusqu'à quatre onces par jour ; sa teinture alcoolique est réputée stomachique, depuis quatre gros jusqu'à une once. L'amande récente procure une émulsion exquise, en en triturant une once ou deux par huit onces d'eau, ou une livre, suivant le besoin, et convenablement édulcorée. L'huile se prescrit depuis une once jusqu'à deux. La poưdre de la coque ligneuse, depuis un scrupule jusqu'à un gros.

L'eau de coco, comme anti-scorbutique, pent être bue, sans inconvénient, à la dose d'une livre par jour : elle convient principalement aux tempéramens pléthoriques sanguins.

Explication des pianches tixgt-UNième bT VINGTDEUXIÈME.

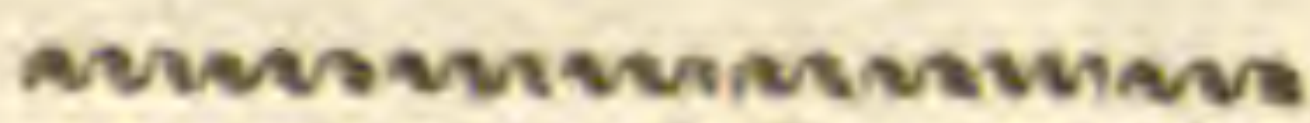

Pl. 21. Le cocotier est réduit environ à la soixantième partie de sa grandeur naturelle. Près de luí est placé un Nègre servant d'échelle de proportion; en observant qu'il ne peut en servir qu'à-peu-près jusqu'à la moitié de larbre, l'excédant ne peut étre mesuré que par approximation. Un autre Nègre $y$ grimpe pour faire voir comment les naturels parviennent au sommet, où se trouvent les fruits.

PI. 22 , fig. 1. Spathe ouverte; on aperçoit à l'intérieur le Spadice chargé à la base de fleurs femelles, à son 


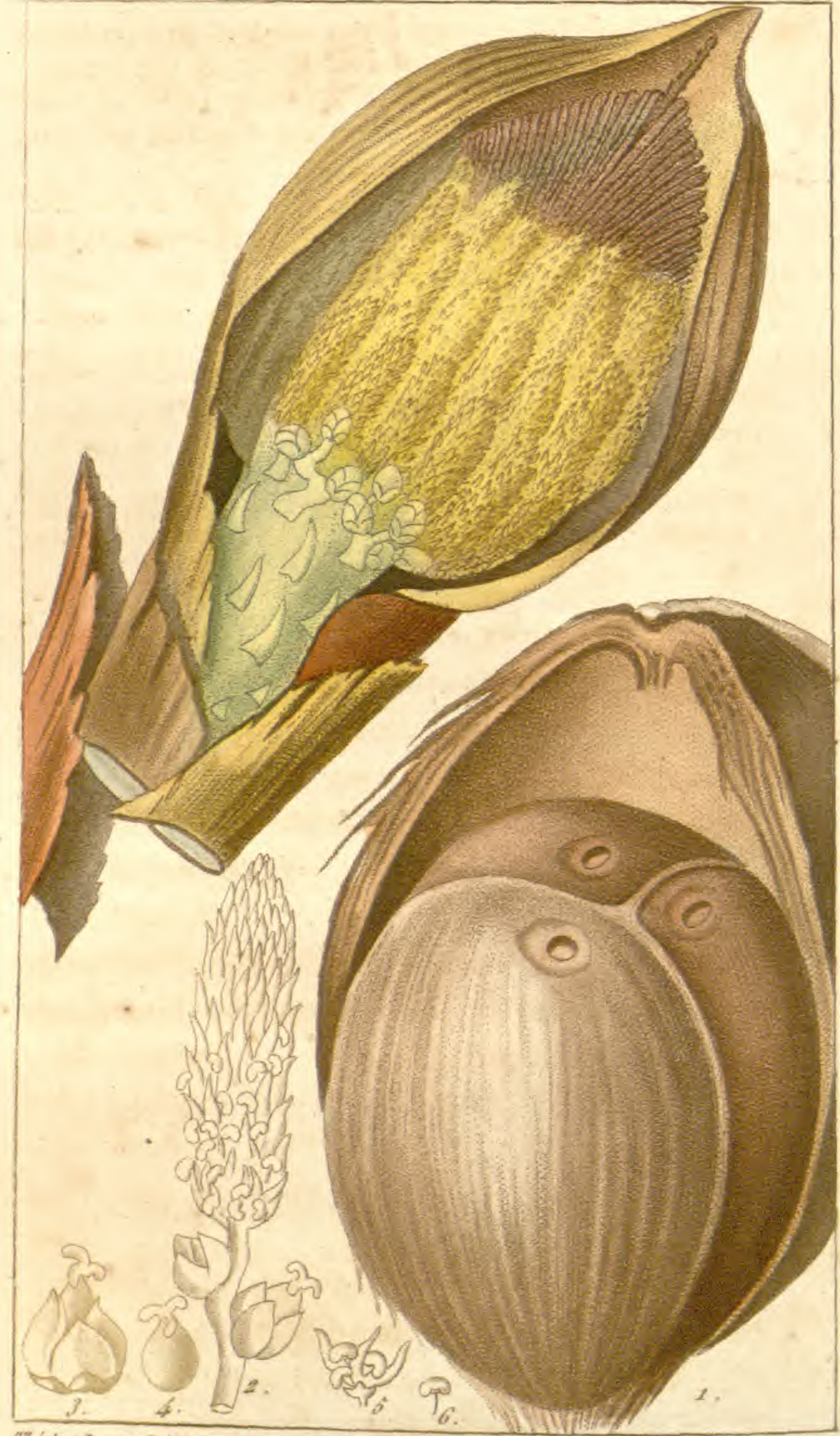

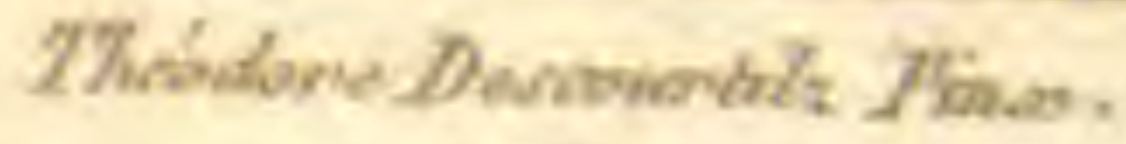

Anstid Be. 
milieu de fleurs mâles et à son sommet de l'extrémité. des rameaux des grappes dont les fleurs ont avorté.

2. Rameau du Spadice chargé de fleurs mâles au sommet, et inférieurement de fleurs femelles sur cette partie fléchie en zigzag.

3. Fleur femelle garnie de son calice et de sa corolle.

4. La même, dépouillée de ces parties et surmontée des trois divisions de son stigmate.

5. Fleur mâle.

6. Etamine d'une fleur mâle.

7. Fruit du cocotier réduit au quart, offrant supérieurement trois trous dont un seul est perforable et ouvert; l'extérieur dé la coque est ehargé de la base des fibres dont le reste a été excisé. Le fruit est à moitié sorti du brou ou caire filamenteux qui le renfermait.

Nota. Il y a deux autres espèces de cocotiers; $\mathbf{1}^{\circ}$. le cocos butyracea sans épines, feuilles pinnées, folioles simples, dont l'amande du noyau fournit, par l'expression, l'huile qu'on vend sous le nom d'huile de Palmiers. C'est le cocotier du Brésil. Cocos inermis, frondibus pinnatis, foliolis simplicibus. Lin., s. sup. 454 ;

$2^{\circ}$. Le cocotier de Guinée. Cocos aculeata tota, frondibus distantibus, radice repente. Lin. mant. 137. Se trouve d̀ la Jamaíque. 


\section{MÉ NIANTHE.}

(Stomachique anti-scorbutique.)

Srnonymie. Menyanthes, nymphea folio, Flore albo. Plum., vol. IV, p. 121.- Menyanthes indica. Linn. Pentandrie monogynie. - Tournefort, $\mathrm{cl} .2$, infundibuliformes.- Jussieu, fam. des Lisimachies.

Caractères génériques. Calice à cinq divisions, corolle hérissée infundibuliforme à cinq découpures profondes. Stigmate 2-fide, capsule oblongue à une loge et deux valves, contenant des graines nombreuses fixées aux réceptacles parallèles aux valves.

Caractères particulieks. Feuilles cordiformes, pétioles florifères; corolles intérieurement poilues. (Jolyclerc.)

Histoire naturelle. Le ménianthe se plaît dans les lagons et sur le bord des ruisseaux, où il étale son feuillage gracieux et diversement coloré. Théophraste, suivant Loiseleur-Deslonchamps, lui donne le nom de

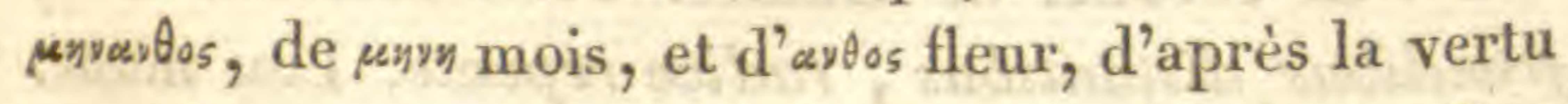
emménagogue qu'on attribuait à cette plante. Les bêtes à cornes le broutent, et on retire dans certains pays une assez mauvaise fécule de sa racine, dont les Nègres font du moussa, à défaut de farine de maïs.

Caractéres physiques. La racine du ménianthe des Antilles est fusiforme, de la grosseur du petit doigt, d'un blanc-verdâtre nuancé de rose, pivotante, géniculée, marquée dans toute sa longueur d'impres- 
Pl. 23.

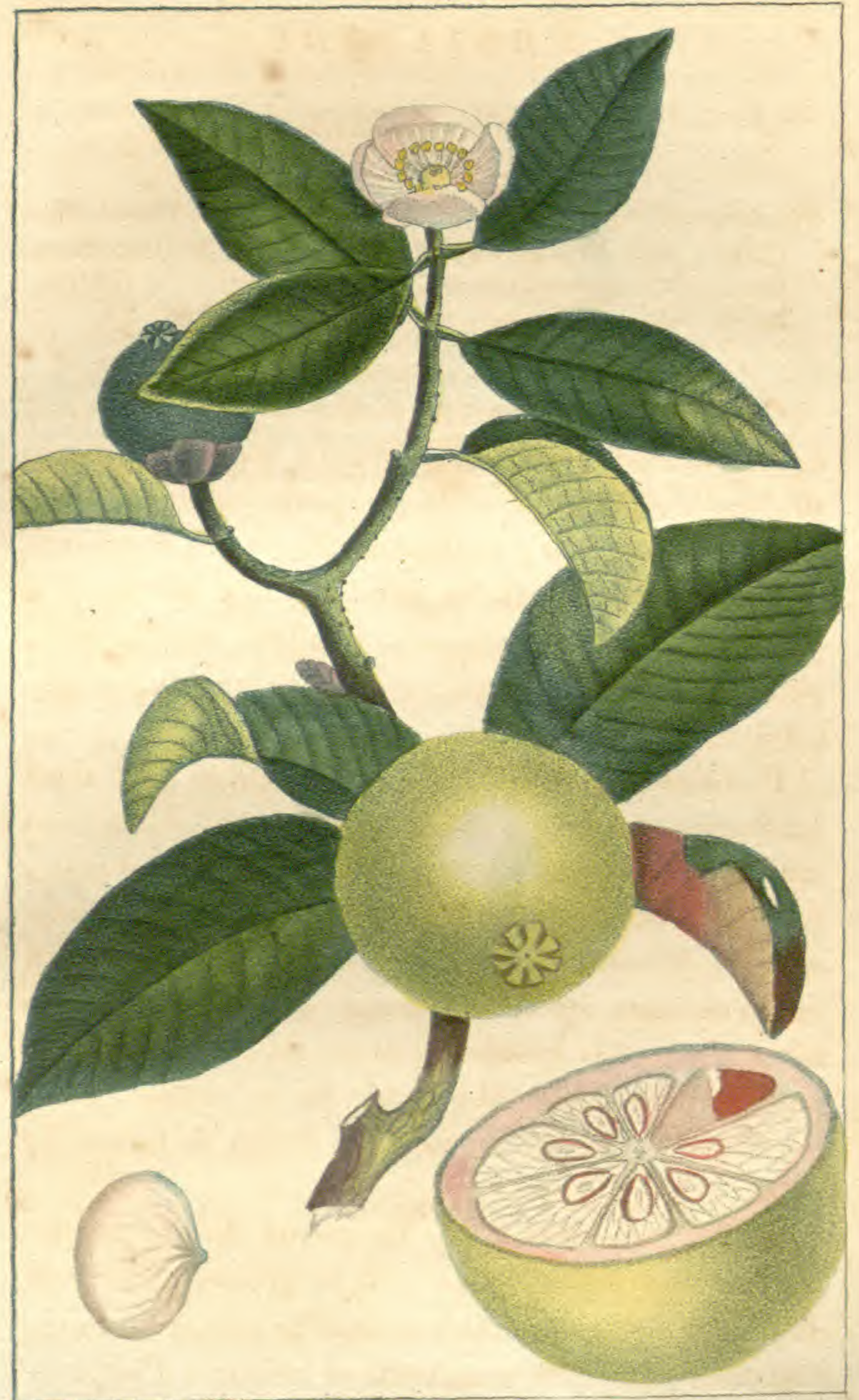

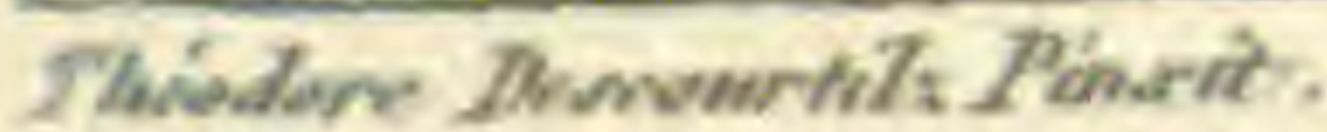

Giabriat fintpoid 


\section{(113)}

sions transversales excavées d'où partent des fibres. Ces excavations sont les cicatrices qu'ont laissées les feuilles du bas en se décomposant. Les feuilles sont radicales, cordiformes, horizontalement placées, ombiliquées à leur insertion sur leur long pétiole. Elles sont d'un beau vert luisant en dessus, d'un rouge d'Inde en dessous, garnies de nervures apparentes.

Les fleurs en étoile, qui éclosent en mai, naissent près des feuilles et sortent de leur pétiole : elles sont en corymbe; les boutons sont d'um rouge assez vif; les fleurs épanouies d'un rouge pourpré au dehors, d'un blanc pur à l'intérieur, couvertes, de ce côté et aux bords des pétales, de barbes de même couleur et sétacés.

Les étamines portent des anthères bifides; le calice est pourvu de cinq divisions; le style a le stygmate bilobé : le fruit, ainsi que je l'ai indiqué plus haut, renfermedes semences ovales, jaunâtres, d'un goût amer.

Analyse chimique. Le ménianthe a une odeur légèrement suave; mais il fournit un principe extrêmement amer qui se combine avec l'alcool et l'eau. Sa déeoction noircit la teinture de noix de galle; ce qui la fait estimer astringente. On en retire, par l'analyse, une substance gommo-résineuse fort amère.

Le ménianthe d'Europe a fourni les mêmes résul ł. tats à MM. Loiseleur-Deslongchamps et Marquis.

Propriétés médicinales. La saveur amère du ménianthe d'Amérique, qui a absolument les mêmes propriétés que le ménianthe trifolié d'Europe, le fait 


\section{(114)}

rechercher et employer avec avantage, comme prissant tonique, un fébrifuge éprouvé, et un anti-seorbutique supérieur à tous les autres. Toutes les fois qu'on a eu occasion d'appliquer le ménianthe, on a vu qu'il n'avait pas usurpé sa réputatión.

On a loué son usage dans les aménorrhées atoniques, dans les maladies arthritiques et les hydropisies; dans les rhumatismes et les hépatites chroniques ; contre les affections scrophuleuses et cutanées, contre les engorgemens abdominaux, la phthisie, l'hypocondrie et autres maladies nerveuses.

Sa propriété astringente le rend également recommandable dans les hémoptysies, dans les diarrhées chroniques, dans la cure des ulcères atoniques et scorbutiques: on l'applique, en ce cas, en topique, et on fait prendre son suc à l'intérieur.

Je lui ai aussi reconnu les propriétés vermifuges signalées par le docteur Alinert, à l'article Ménianthe de ses Élémens de Thérapeutique : dans ce cas on en fait continuer l'usage pendant une quinzaine de jours.

Il faut cependant n'administrer le ménianthe qu'avec prudence, et ex éviter l'usage, soit au dedans, soit au dehors, s'il y a irritation dans le premier cas, et phlogose de la partie affectée dans le second. Les sujets pléthoriques ou d'une grande susceptibilité nerveuse doivent s'en abstenir. On le confit dans le vinaigre, et on l'ordonne en gargarisme aux scorbutiques.

Mode d'administration. On ordonne les feuilles et les racines en décoction, à la dose de seize gram- 


\section{(115)}

mes (demi-once), par litre d'eau: le suc de la plante, à celle de trente-deux grammes (une once), plusieurs fois le jour, produit plus d'effet dans les affections goutteuses et autres maladies des articulations.

La poudre se donne depuis denx jusqu'à quatre grammes (demi-gros à un gros); en plus grande quantité elle irrite trop violemment la membrane muqueuse des yoies digestives, et provoque non-seulement le vomissement, mais même des déjections alvines.

L'extrait s'administre à la quantité de quatre grammes (un gros ). Le vin et la bierre peuvent servir de véhicule au menianthe, d'après le procédé du professeur Chaussier. Le docteur Alibert nous indique les moyens de se procurer un sirop avec le suc reposé et décanté du ménianthe, et suffisante quantité de sucre concassé. On soumet ce mélange dans un ballon, à la chaleur du bain-marie seulement. Il a remplacé à Saint-Domingue, daus ma pratique, le sirop antiscorbutique.

Les lotions et les fomentations faites avec cette plante dans les maladies cutanées, servent pour le traitement extérieur, et l'on prend à l'intérieur, le sirop, le suc, ou le vin de ménianthe.

Explication de la planche vingt-troistìme.

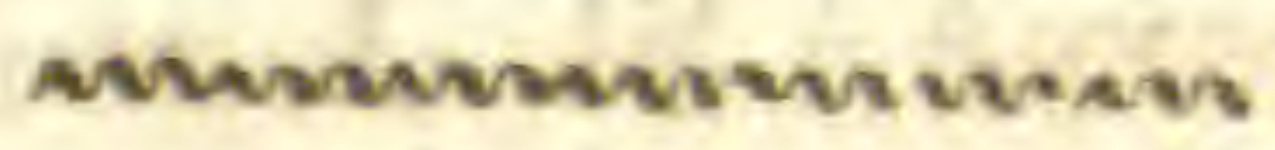

Le ménianthe est représenté à moitié de la grandeur naturelle.

i. Fleur de grandeur naturelle. 


\section{MA NGOUSTAN.}

(Stomachique anti-scorbutique.)

Srinonymte. Garcinia mangostana. Foliis ovatis, pedunculis unifloris. Linn., Sp., plant. no. 1.- Decandrie monogynie. - Laurifolia javanensis. Bauh. Pin., 461.Jussieu, fam. des Guttiers. Desrousseaux, famille des Cistes. Panitsjicamaram des Malabarois. (Valm. Bom.)

Caractères génériques. Calice tétraphylle inférieur, à folioles arrondies concaves, obtuses, ouvertes, persistantes; quatre pétales orbiculaires, concaves, évasés, un peu plus grands que le calice; seize étamines environ, à filets droits simples, et plus courts que le calice; anthères arrondies, baies à huit spermes couronnées par le stigmate persistant, clypéiforme, sessile, et à plusieurs lobes.

Caractères particuliers. Feuilles simples, opposées, fleurs solitaires et terminales, auxquelles succèdent de grosses baies d'une saveur exquise; l'écorce de la baie est épaisse et coriace; les loges dont les divisions du stigmate indiquent le nombre, contiennent une pulpe succulente, divisée par des cloisons très-minces et membraneuses.

Historke naturelle. Le mangoustan originaire de l'Asie paraît avoir été naturalisé dans plusieurs îles Antilles. Je l'ai observé à St.-Jago de Cuba, avec l'admiration que l'on doit à la richesse de son port, à la densité de son feuillage, et à la supériorité non contestée de ses fruits, qui, à une saveur d'une agréable acidité, réunissent les parfums les plus suaves. 


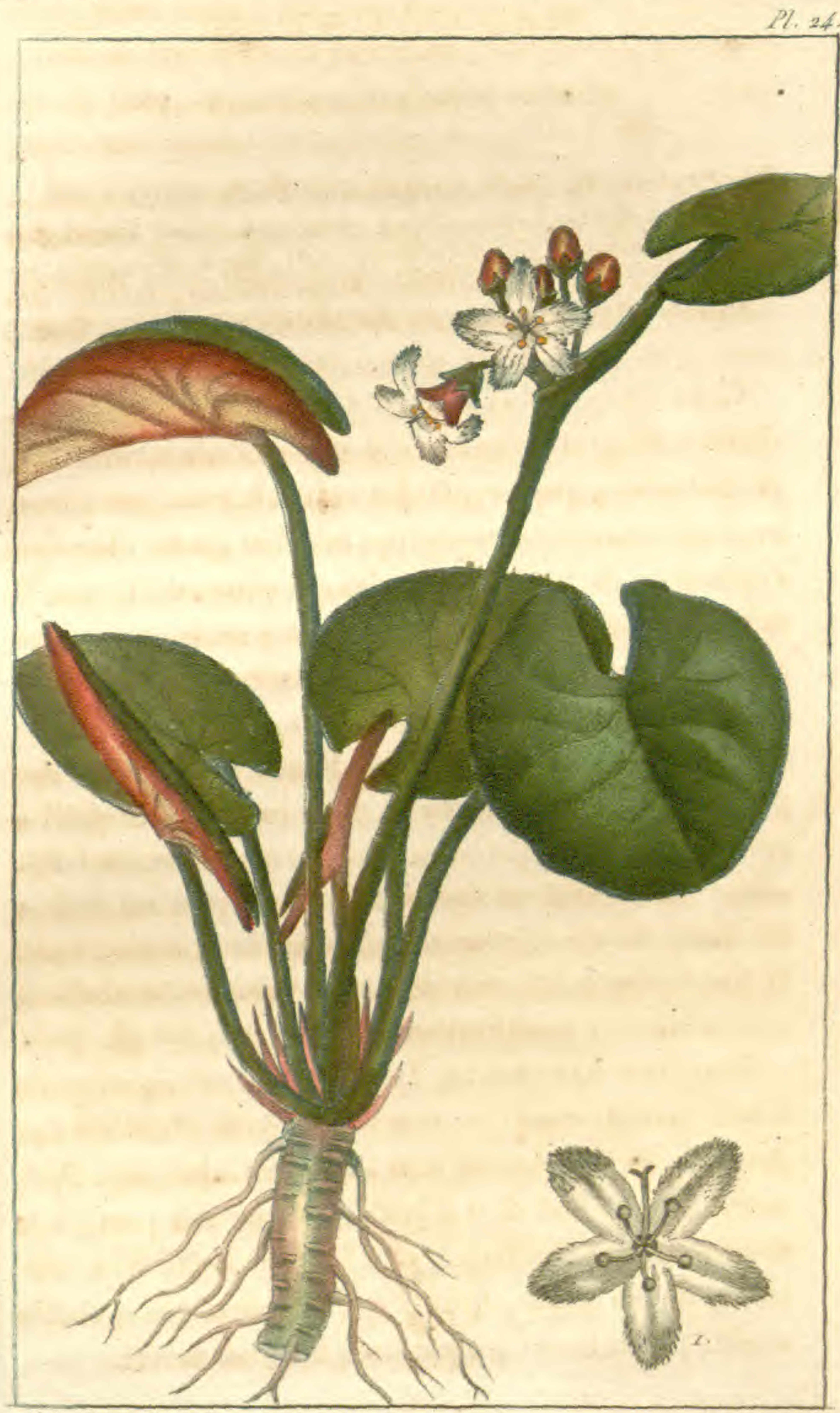

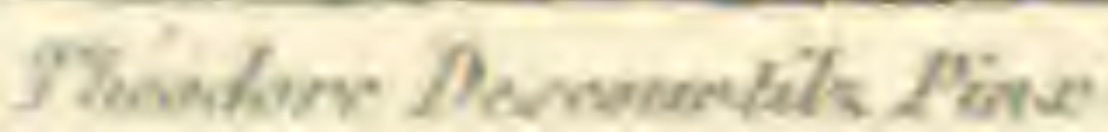

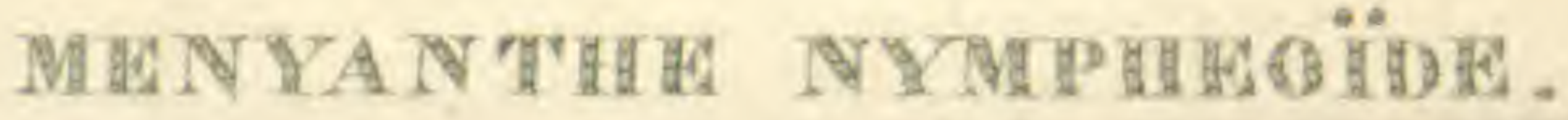




\section{(117)}

Le nom botanique de cet arbre a été consacré à la mémoire du D. Garcin; son bois abattu n'est bon qu'à brûler, et fait regretter aux voyageurs l'ombrage frais et salutaire qu'il leur procura.

Caractères physigues. Le mangoustan cultivé, nourri par le terrain qui lui convient, offre un arbre de moyenne taille qui aurait beaucoup de rapports avecles orangers, si la masse régulière de son feuillage ne l'élevait au-dessus par l'orbe ou plutôt le cône régulier et naturel qui le fait placer dans les avenues d'ornement.

Les feuilles opposées, pétiolées, ovales, pointues, sans dentelures, épaisses et cassantes, ont de six à sept pouces de longueur, sur une largeur de trois à quatre ; elles sontluisantes, d'un beau vert en dessus, olivâtres en dessous, et sillonnées de nervures latérales, réunies par des réseaux saillans; leur pétiole épais, est légèvement amplexicaule à sa base, et canaliculé en dessus.

Les fleurs, qui ont beaucoup de rapport avec celles du néflier d'Europe, sont aussi solitaires, terminales et portées sur des pédoncules courts et cylindriques. Elles sont d'une moyenne grandeur, ouvertes en rose, composées de quatre pétales égaux concaves, blanches ou souvent d'un rouge carminé, ou jaune et aurore.

Le calice composé de quatre folioles, est moins grand que les pétales dont il a la forme : il est à l'extérieur d'un vert gai et d'un rouge foncé au dedans.

Les étamines, surmontées d'anthères globuleuses et d'un beau jaune, environnent l'ovaire dont le pistil, composé d'un style presque nul, supporte un stigmate 


\section{( 118$)$}

divisé dans sa circonférence en lobes obtus dont le nombre indique celui des loges du fruit qui ont été fécondées.

Les fruits du mangoustan sont sphériques, renfermés dans une espèce de boîte, multiloculaires et de la grosseur d'une orange. Ces baies sont glabres, l'écorce en est épaisse, dure quoique fongueuse, et contenant un sue de couleur pourpre; d'un vert jaunâtre au dehors, et rouge à l'intérieur; elle se détache facilement de la pulpe qui est blanche, demi-transparente, succulente, et d'un goût exquis où les parfums de la fraise, de l'orange et de la framboise, se marient à l'agréable acidité de la cerise et du raisir; ce qui les rend très-rafraîchissans. La combinaison de l'arôme saccharin et de l'acide est telle, qu'on peut en manger en quantité sans êlre incommodé.

Anaryse chimiQue. Le suc concret et jaunâtre qui découle, par l'incision, des jeunes branches du mangoustan, donne une espèce de résine aromatique recherchée par les nègves guérisseurs. La pulpe des fruits avant leur maturité, contient un acide balszmique suigeneris, qui passe à la saveur sucrée au moyen de la cuisson.

L'écorce est astringente comme celle de la grenade avec laquelle le mangoustan a certains rapports.

Propríttés mrdicinales. Les fruits exquis et savoureux du mangoustan, procurent une fraîcheur douce et parfumée qui apaise la soif ardente des malades accablés par les accès renouvelés des fievres ataxiques et adynamiques. On les permet aux malades, suivant Garcin, comme on tolère en Europe l'usage du raisin, 
de la groseille, et l'on augure mal de l'etat des patiens qui en refusent la dégustation. lls sont très-utiles anx scorbutiques : l'usage prolongé de la pulpe lui donne une vertu laxative, qui approche de celle des tamarins, quoique beaucoup moins énergique.

A defaut de l'écorce de grenades, celle du fruit du mangoustan la remplace à la fin des dyssenteries. Cette même propriété astringente la rend propre aux gargarismes qu'on emploie contre les aphtes, le relâchement de la luette, et dans les angines catarrhales tousillaires. On estime l'usage des fruits du mangoustan dans les affections chroniques de la vessie.

L'écorce du tronc et des rameaux teint en noir.

Mode d'administration. On prescrit la pulpe dans les tisanes rafraîchissantes et laxatives. On en fait des marmelades et des confitures; l'écorce se donne en poudre à la dose d'un scrupule, et à celle d'une demi-once en décoction, dans les dyssenteries, les hémorragies, et les blénorragies.

Explication de la planche yingt-quatrième.

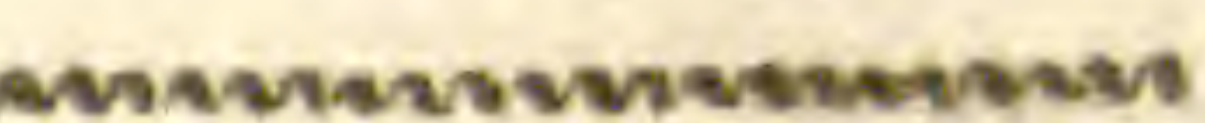

Branche de mangoustan avec fleur et fruit, réduite au tiers de grandeur.

3. Fruit ouvert, dont on a enlevé une partie de la pulpe afin de faire voir la couleur de l'intérieur.

2. Semence de grandeur naturelle. 
Pl. 25.

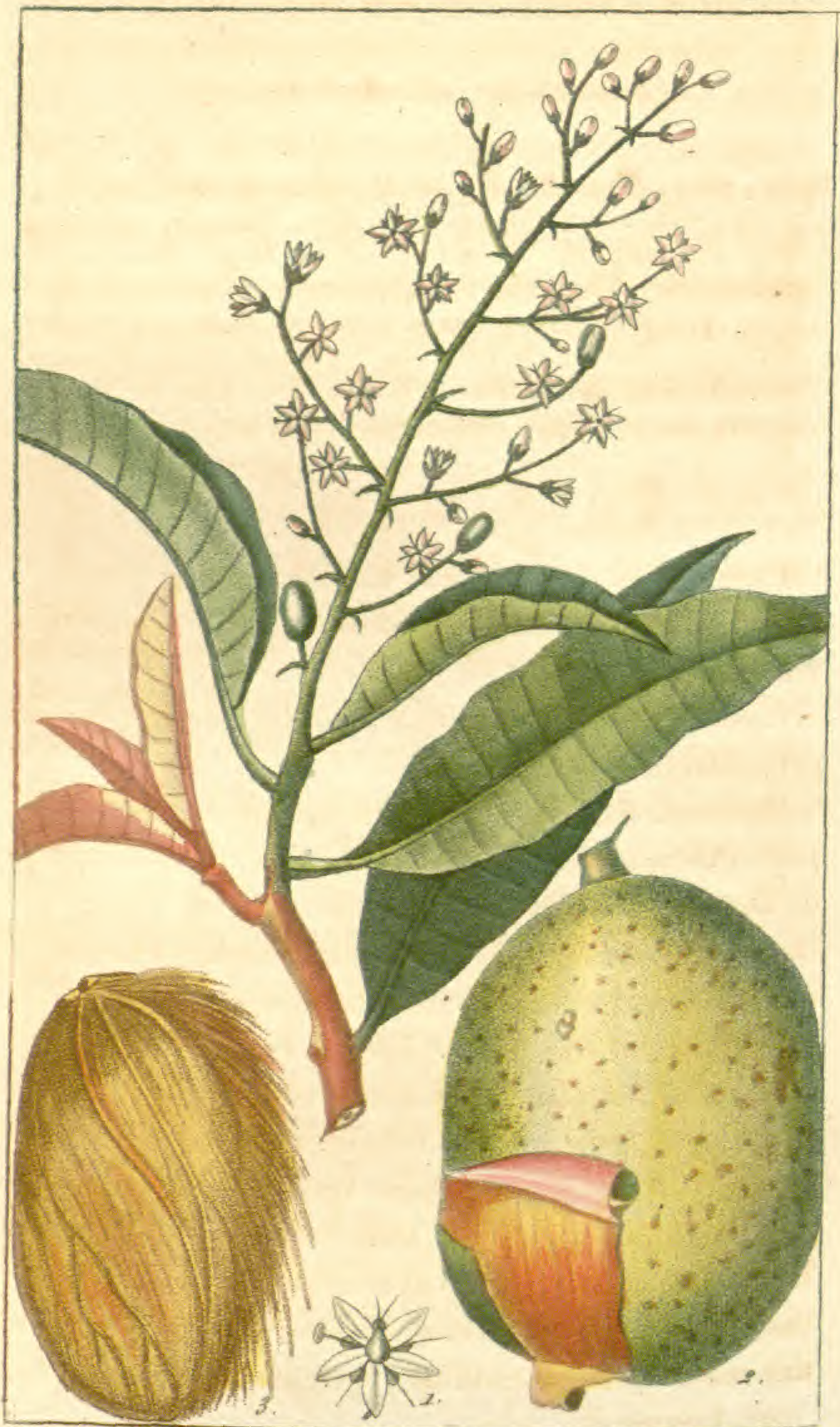

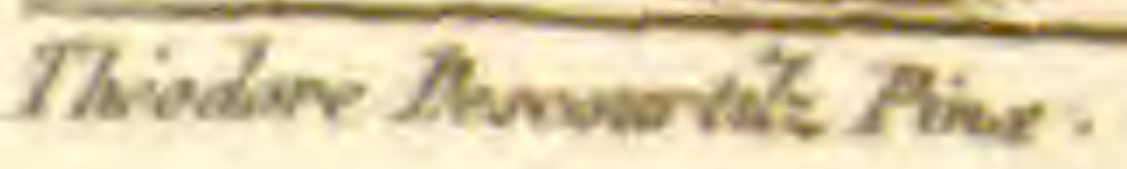

Gabial valy:

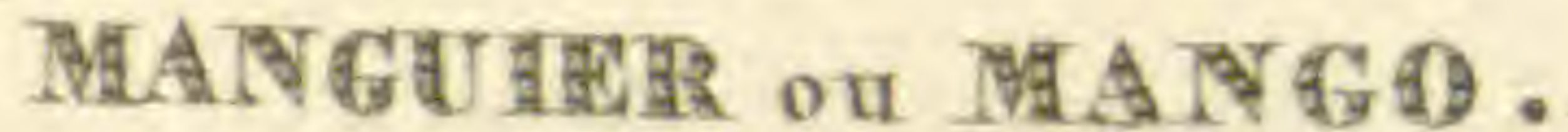




\section{(121) \\ MANGUIER oU MANGO.}

(Stomachique anti-scorbutique.)

Sxronyme. Maos-Mang. vel Manghos. Rheid. Mal. 4, p. 1, tab. 1, 2. Manga domestica. Rumph. amb. 1, pag. $9^{3}$, tab. 25. Mangifera indica. Linn. Pentandrie monogynie. Mangifera foliis oblongo.-Lanceolatis flo. ribus submonandris, drupa maxima reniforma (Desroches). Jussieu, famille des Térébinthacées. Persica similis putamine villoso, Bauh. Pin, 440. - Manga indica fructu magno reniformi, Raj., hist. 2, p. 1550 . Les anglais l'appellent Mango-Manga. Amba, ambo et ambe. Raj., suppl., Luz., page 55.-Mangas arab.

Caractères générieues. Corolle de cinq pétales, fruits à noyau ovoïde ou réniforme. Calice à cinq divisions lancéolées.

- Caractères particuliers. Feuilles simples, fleurs polyandriques.

Histoire naturelle. Le manguier, originaire des pays d'Ormus, de Malabar, de Goa, de Guzarare, de Bengale, de Pégu, de Malacca, a été débarqué en ${ }^{1} 7^{82}$ par le capitaine de vaisseau anglais Marshall, qui, au rapport du chevaliex de Tussác, prit une frégate française venant de l'île de France, et qui en transportait du plan, et de celui d'une infinité d'autres espèces précieuses, à St.-Domingue, où il a été naturalisé depuis dans certains quartiers de l'île. Ses fruits, dont les qualités sont inappréciables sous la Zône-Torride, sont sains et bienfaisans; ils flattent la vue, l'odorat et le goût; quelques-uns cependant ont nne odeur de térébenthine, qui, au premier abord, $7^{\mathrm{e}}$. Livraison. 


\section{(122)}

he plaît pas à tout le monde; mais on finit par s $s^{3}$ habituer, et on les trouve exquis : l'arbre crôt trèsvite, et fournit deux abondantes récoltes par annéej son bois est dur et très-cassant.

Il y a beaucoup de variétés de mangos, parmi lesquels on remarque, suivant Tussac (1), $x^{\circ}$. le mango vert de la plus grosse espèce; $2^{\circ}$. le mango-prune, très-petit, mais ayant le goût de la prune, le noyau petit et très-peu filandreux; $3^{\circ}$. le mango-pêche $; 4^{\circ}$. le mango-abricot, ainsi appelé par son rapport avec les abricots d'Europe.

Le fruit du manguier, lorsqu'on l'a dépouillé de son écorce, et conpé par tranches, se mange cru, ou macéré dans du vin sucré; on en fait d'excellentes marmelades, en lui associant le sucre, la canelle, le zeste de citrons et autres aromates; on le confit aussi dans le vinaigre avant qu'il ait atteint son degré de maturité; et on assaisonne ces atsjaurs ou acharts, comme l'observe Tussac, avec du poivre, de la moutarde, et du gingembre. Enfin, les Indiens, après avoir fait sécher les noyaux du manguier, les réduisent eu poudre, qu'ils mêlent à leurs alimens commè condiment. La pellicule du fruit infusée dansl'alcool, procure une liqueur aromatique très-agréable.

“ On se sert aussi, dit Tussac, du bois du man" guier avec celui du santal, pour faire brûler les 2) cadavres des personnes de distinetion, et l'on fait 3) avec ce bois des cercueils pour ensevelir cenx que ") l'on ne fait pas brûler. Quoique cet arbre soit con-

(1) Journal de Porthsmann, t. 2, pag. 180. 


\section{( 523$)$}

7) sacré aux funérailles, les Brachmanes sont ces 3) pendant dans l'usage d'orner leurs maisons avec 2) son feuillage, les grands jours de fêtes. »

Caractìres physiques. Le manguier s'élève à la hauteur de 40 pieds environ; il balance dans l'air une cime touffue portée par des tiges tri ou quadrichotômes, à écorce épaisse, rahoteuse ế cendrée; garnies aux sommités de grandes feuilles alternes, pétiolées, oblongues, lancéolées, entières, à nervares horizontales presqu'opposées, lisses, coriacēs, d'un rouge clair en se développant, puis d'un vert riche et foncé des deux côtés, lorsqu'elles ont acquis leur accroissement,

Les fleurs fixées sur de longues panicules terminales, sont de couleur rougeâtre; les pédoncules calorés sont accompagnés de bractées : le calice a cinq divisions, qui se détachent après la floraison, avec Ies cinq pétales lancéolées qu'il renferme, et qui les dépassent:

Les étamines, au nombre de cinq, offrent quatre filamens subulés, stériles; le cinquième seul porte une anthère qui féconde les germes de l'ovaire supérieur, arrondi, surmonté d'un style filiforme à stigmate simple.

Le fruit est oblong, renflé, un peu comprimé et de la grosseur d'un ouf. Ce drupe est nué des plus riches couleurs; on le voit trancher sur son lit de feuillage, et contraster agréablement par le jaune jonquille, teinte principale et universelle de sa robe, avec le beau rouge, le vert aigue-marine et le bistre, qui en sont les teintes accidentelles, et forment des 


\section{(124)}

taches sur la peau, qui s'enlève comme celle de la pêche et laisse apercevoir une pulpe fibreuse, de couleur aurore. Dans cette pulpe se trouverenfermée une noix de même forme, monosperme, couverte à l'extérieur du même tissu filandreux aurore comme la ehair du fruit.

Quoique, ainsi que je l'ai déjà dit, la saveur résineuse des fruits ne plaise pas aux voyageurs, la finesse de leur parfum la fait bientôt oublier : une amanide fort amère est renfermée dans la noix; ces fruits offrent des différences dans le coloris, la saveur, et le volume, que l'on doit attribuer à la culture.

Analyse chmpee. L'incision $d u$ fruit vert $d u$ mango, et l'excision de ses jeunes branches, fournit une résine liquide, odorante, caustique avant la maturité du fruit.

Propriétés. Ménicinales. Les fruits du manguier offrent de précieuses ressources dans les maladies exanthématiques, cutanées, scorbutiques et syphillitiques, où ils agissent comme dépurans et sudorifiques. Le marin accablé des longues fatigues d'une navigation où il a essuyé des privations, et fait usage d'alimens mal sains, recherche avec avidité, en mettant pied à terre, le mango qui doit le soulager dans le scorbut auquel il est en proie; et sa maladie fûtelle avancée, il trouvera dans le constant usage de ces fruits, dont il doit faire sa principale nourriture, un principe extracto-résineux qui lui assure une guérison certaine et constatée par de nombreuses expériences. L'effet de ces fruits est de faire éprouver aux malades, pendant leur traitement, des éruptions ou 


\section{(125)}

boutons accompagnés de démangeaisons excessives. Leur usage constant a guéri un jeune européen, auquel je les avais conseillés, du virus syphillitique dont il était douloureusement tourmenté.

Les feuilles sont odontalgiques, et servent à nétoyer les dents; elles raffermissent les geneives, par leur vertu astringente. Les jeunes tiges, comme masticatoire, remplacent au besoin le bétel. Les Indiens font grand cas de la poudre de l'écorce prise à la dose d'une once, dans une pinte de bouillon, ou de l'infusion d'une poignée de ses feuilles pour dissondre le sang coagulé à la suite des chutes et des contusions. Le suc de l'écorce verte du manguier mêléả la gomme arabique et à l'opium, remplace le cachou et la gomme kino dans les dyssenteries.

Le bois, les fleurs, les racines du manguier, s'administrent aussi intérieurement. L'amande du fruit, ayant subi la torréfaction, est un très-bon antelmintique, et est employée comme astringente dans les flyx de ventre et les gonorrhées.

Mode d'administration. La poudre de l'amande. torréfiée se donne à la dose d'un gros; - la résine en substance à celle d'un scrupule; - la teinture, obtenue par une once de résine dans une livre d'al. cool, à la dose de vingt-cing à trente gouttes. 


\section{(326)}

Expiontion de ia planche vingt-cinquieme. Ifs

La plante est réduite à moitié de sa grandeur naturelle:

1. La fleur.

2. Fruit dont une portion de la pellicule enlevée, laisse voir le tissu fibreux.

3. Noyau récemment sorti de la pulpe. 


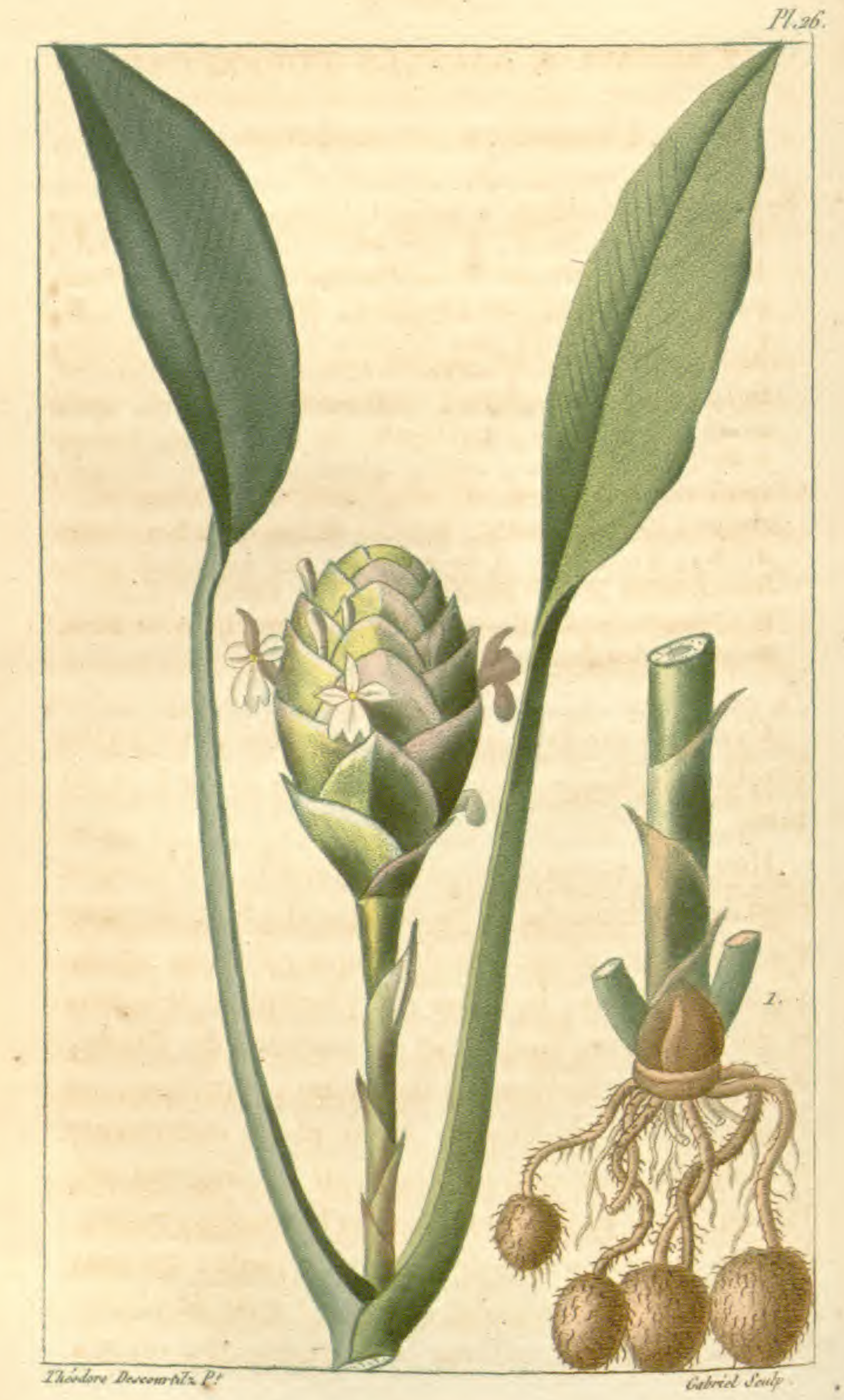

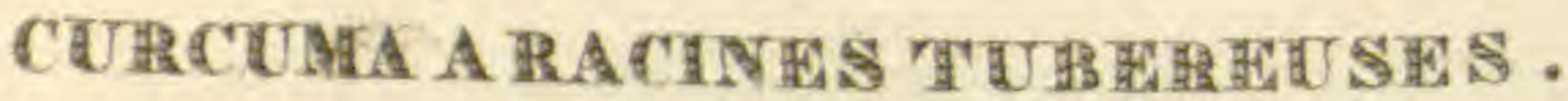




\section{(127)}

\section{CURCUMA A RACINES TUBÉREUSES:}

\section{(Stomachique anti-scorbutique.)}

Synonymie. Galanga à racines tubéreuses, tige simple feuillée au sommet, à épi oval imbriqué terminal : Diction, encycl., no. 3.- Pomme de terre, Nicolson. p. 297. - Alloya des Caraïbes, Plum., miss., t. 5; p. 35. - Alleluya des Créoles. - Maranta allouya Aublet. guyan, P. 3.-Curcuma americana caulescens, foliis ovato-lanceolatis, petiolatis, nervosis, spicá ovatâ pedunculatâ, terminali, N. - Maranta allouya radicibus tuberosis, culmo simplici, apice folioso, spicîa ovatâ, imbricatâ, terminali; vel curcuma americana, Encycl, méth., $n^{\circ}$. 3. Alloia radicibus stoloniferis, Tussac. - A la Jamaïque les anglais l'appellent Indian Arbw-Boot. - Toulola. Caraïbe, Labat., t. 1, pag. 477.-Monandrie monogynie, Linn.-Fam? naturelle des Balisiers, Juss.

Caractìres génériques. Calice supérieur triphylle, corolle irrégulière à six divisions, un drupe à noyau mou.

Historre maturelie. Le curcuma d'Amérique croît naturellement à la Martinique et à Saint-Domingue, et on le cultive à la Jamaiqque, d'où on en exporte à Londres, la farine qui y remplace le sagou, et qui peut remplacer aussi le maranta de l'Inde, dont on fait actuellement de belles plantations, au rapport de M. de Tussac. Cette plante intéressante se multiplie beaucoup à la faveur de ses drageons souterrains, qui produisent des tiges herbacées, rameuses, de la hauteur de deux ou trois pieds, qui sont znnuelles et se dessèchent après huit mois de végétation. Cette époque indique la perfection des racines 


\section{$(128)$}

chevelues et tubéreuses, succulentes et farineuses qui sont les rudimens de nouvelles tiges. Ourre que ces drageons sont très-agréables à manger bouillis, et assaisonnés comme les salsifix d'Europe, on en retire, au moyen de l'eau et d'une rape de fer-blanc ou grage, toute la fécule, qui ne le cède en rien au salep et au sagou. La fécule de curcuma d'Amérique procure une excellente bouillie aux enfans, et les cuisiniers l'associent au service des tables en y mélangeant du sucre et des aromates.

D'après l'assertion formelle de M. le chevalier de Tussac, « il paraît certain que la fameuse poudre 2) de Castillon, qui a eu tant de succès pour la guéri? son des diarrhées scorbutiques à Saint-Domingue, » el dont l'auteur a (dit-on) emporté le secret dans ") la tombe, n'était autre chose que la fécule du 3) maranta, à laquelle ce médecin ajoutait de la 3) gelée de corne de cerf, de la canelle, du piment et 3) un peu de gérofle. ")

Caractères physigues. Les racines du curcuma d'Amérique forment plusieurs filamens longs, tortueux, velus, qui se terminent chacun par une tu. bérosité ovoïde de la grosseur d'un ouf de perdrix ou environ. L'écorce pileuse est brun-violâtré, et la partie interne blanche et farineuse. - Les feuilles portées sur des pétioles fermes, roides, canaliculés, envaginans, ont deux pieds de longueur, sont radicales, grandes, lancéolées, semblables à celles du balisier, tantôt d'un vert sombre, et souvent d'un vert-gai tendre, pourvues de nerrures latérales courbes et nombreuses. 


\section{(129)}

Du collet de la racine, s'élève perpendiculairement et avec grâce, entre ces feuilles engaînantes, une tige cylindrique épaisse, de la hauteur de vingt pouces environ, offrant à son sommet une réunion de plusieurs feuilles semblables aux premières pour les couleurs et la forme, mais plus petites. Du centre de ces feuilles s'échappe un épi en massue, de la grosseur d'un œuf de poule, embriqué d'écailles spathacées dont le centre est vert, la partie supérieure blanche, et les bords rosés. De l'aisselle des écailles sort une fleur blanche ou légèrement colorée, monopétale, à corolle irrégulière et à six divisions; les trois supérieures détachées l'une de l'autre; les trois inférieures réunies et formant trois échancrures sur le même pétale. Elles renferment des étamines blanches, épaisses à anthẻres jaunes. Le fruit est une capsule ovée, à trois côtes, uniloculaire, monosperme ; l'embryon est petit et farineux.

Analyse cuimique. Le suc de la tige et des racines du maranta étant insipide et inodore, doit faire regarder comme chimériques les prétendues vertus alexitères de cette plante, contre les empoisonnemens internes ou externes. Ce suc n'est pas même doué de parties mucilagineuses, seules capables d'émousser et de modérer l'activité funeste et létifère des substances yénéneuses corrosives.

Propriétés médicinales. Le suc de curcuma d'Amérique que Labat nomma, d'après les Caraibes, Touloula, jouit bénévolement d'une réputation alexitère contre les blessures faites par des flèches empoisonnées des sauvages; d'où lui vient le nom anglais, 


\section{(130)}

qui veut dire Arbre utile de l'Inde : on le préconise encore pour combattre les influences délétères du mancenilier, mais cui fideas, vide. L'insipidité de ce suc ne permet pas de lui attribuer aucune vertu neutralisante, qu'on trouve plus sûrement dans l'usage de l'eau de la mer, ou de l'eau salée, dont l'efficacité, en pareil cas, ne peut être contestée.

La propriété la plus recommandable de ce curcuma est celle de son salep dansles affections scorbutiques.

Mone o'administration. On l'emploie comme la féeule de pomme de terre.

EXPLicatton de ra PLANChe vingt-sixtème.

La plante est réduite au tiers de grandeur naturelle?

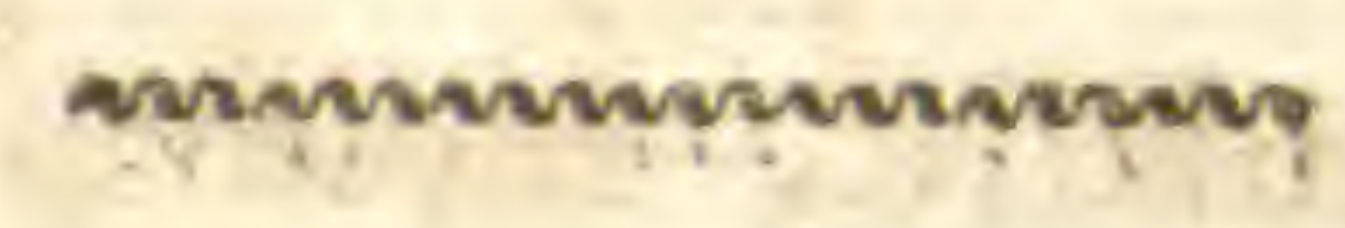

7. Partie inférieure de la tige, et tubercules qui sont fixés aux radicules. 


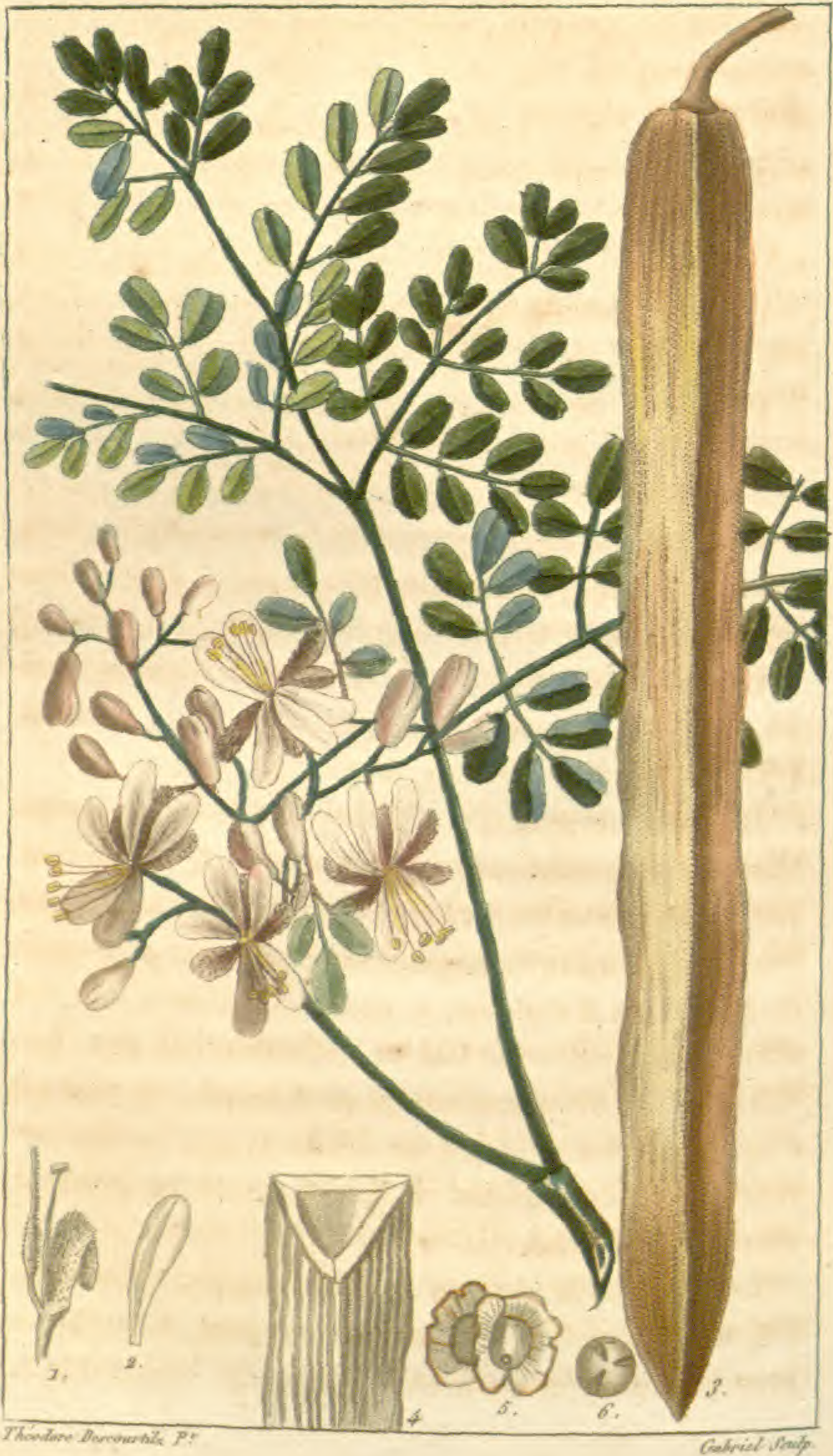




\section{$(\tau 3 x)$ \\ BEN OLÉIFÈRE:}

\section{(Stomachique anti-scorbutique.)}

Sfononruie. Guilandina moringa, inermis, foliis subpinnatis, foliolis inferioribus ternatis, Linn., classe $10_{3}$ pentandrie monogynie.-Moringa, Jussieu, classe 14, ord. 2, famille des Légumineuses.- Moringa oleifera, Lamarck. - Glans unguentaria, Bauhin wıy sect. 2, 402. - Moringa Zeylanica, folioram pinnis pinnatis, flore majore, fructu anguloso. Burm, Zeyl, 162, tab. 7.- Moringon, car., rhed., mal. 6, p. 19 , tab. II. Morunga, Rumph. - Balanus myrepsica, Blackw, t. 386.-Arbor del Béen en espagnol, Béenttrée ; Moringa-trée ; Bezad-trée, Knowles ( Flore du Dict. des Scienc.-médic. ) Mu'ringù, Malab.

Caractéres génériques. Calice monophylle, hyppocratériforme, pétioles insérés au col du calice comme égaux ; légume trivalve à graines ailées. (Jolyclerc.)

Caractères particuliers. Arbre sans épines; feuil les comme bipinnées, folioles inférieures ternées. (Vivace)

Histoire naturelie. Quoique, par la conformation de ses gousses et de ses graines ailées, le ben n'appartienne pas au genre bonduc, néanmoins Linné, par. une vénération méritée pour Guilandinus, professeur de botanique à Padoue, a consacré ce nom à ce bel arbre, originaire de Ceylan, et naturalisé aux Antilles, où on le rencontre fréquemment, et où il est employé à former des haies d'entourage, sur les terrains secs et sabloneux. Il porte ses fleurs pendant six mois de l'année.

Les noix ailées du ben procurent, par expression à froid, ou par le secours de plaques métalliques plus ou moins échauffées, une huile congelable á 


\section{(132)}

10 et 12 degrés au-dessous de zéro . Cette huile inodore et limpide ne rancit jamais, et, pour ces précieuses propriétés, elle est choisie par les parfumeurs comme étant la plus propre à se charger du parfüm des fleurs odorantes, et surtout des liliacées et autres, dont l'arome est si fugace; mais on lui substitue souvent l'huile de ooli, plante des Antilles également, qui se vend beaucoup moins cher. Pour obtenir l'arome des fleurs, on met à plusieurs reprises, sur chaque lit des fleurs dont on veut obtenir l'esprit recteur, du coton imbibé de cette huile, qui se charge du principe odorant qu'on rassemble au moyen d'une petite presse. Les dames créoles, très-sensuelles, mêlent aux fleurs du franchipanier celles du ben pour parfumer leur linge, et décorer les surtous des tables somptueuses. L'huile de ben est détersive et cosmétique.

Caractères phrsiques. Le ben est un très-bel arbre qui croît à la hauteur de quinze à vingt-cinq pièds. Son écorce blanchâtre en dedans, est noirâtre en dehors, d'une odeur et d'un goût de raifort sauvage. L'écorce des branches est verte, et celle des racines jaunâtre.

Les feuilles sont deux ou trois fois ailées et alternes, amples et composées de pinnules opposées qui portent chacune cinq à neuf folioles ovoïdes inégales, vertes, glabres, petites et pétiolées. Les fleurs qui paraissent en juin, ont un calice monophylle à profondesdécoupures; une corolle formée de cinq pétales, dix étamines, dont cinq stériles; les fécondes sont terminées par des filameras surmontés d'anthères jaunes, aro 


\section{(133)}

rondies; un ovaire supérieur, oblong, pubescent, surmonté d'un style filiforme à stigmate simple, sort en panicules éparses à l'extrémité des rameaux : elles sont blanchâtres, d'une odeur très-suave, et parfument l'air pur qui fait le charme des délicieuses soirées de nos colonies.

A ces fleurs succèdent des gousses longues environ d'un pied, légèrement canellées, à trois piẻces triangulaires, pleines, et à moëlle spongieuse, contenant 28 à 20 noix sphériques, sur un seul rang, ailées de trois membranes qui se trouvent cachées entre les divisions du fruit, le fruit au milieu. Ces capsules renferment des amandes blanchestrès-huileuses, desquelles on extrait une huile inaltérable, et qui ne rancit jamais.

Analyse chumìque. Les écorces du trone et de la racine du ben, analogues à celles du raifort, étant distillées avec l'alcool, donnent une teinture ammo- niacée, âcre et volatile, qui réunit la saveur et les vertus des anti-scorbutiques crucifères. Leur suc rougit le papier bleu.

Je n'ai point fait l'analyse de l'huile de noix, mais elle est âcre et occasionne des picotemens au gosier.

Proparétés médicinales. Les écorces du bois et des racines du ben ont l'odeur et la sayeur de celles du raifort et du cresson; ce qui les a fait employer comme condiment après les avoir rapées : c'est cette même vertu volatile qui en rend la teinture recommandable aux équipages affectés de scorbut et de cachexie. Les feuilles chauffées et appliquées sur les tumeurs, même syphilitiques, en opèrent, dit-on, la 


\section{(134)}

xuésolution. Leur suc est estimé parles Caraïbes, comme détersif et anti-scorbutique; sa racine, en suppositoire; est employée par les négresses mal intentionnées.

Les siliques, encore jeunes, du ben oleïfère se font cuire avec les alimens, dont elles relèvent la saveur: les semences ailées, et leur huile récente sont purgas tives; mais agissant à la manière des plus violens drastiques, on n'oserait les employer sans témérité.

On fait, avec l'huile de ben et les oxides de plomb; tun sparadrap dessicatif fort employé dans les hôpi taux des colonies. Les nègres estiment les feuilles, T'écorce de la racine et les fruits du ben, comme anti-spasmodiques, et préparent, avec, des pilules à cet usage. Le suc des feuilles en friction sur les tempes, soulage, dit-on, les enfans dans leurs convulsioas; aspiré par le nez, il apaise les vertiges; mêlé à Y'ail, il est alexitère.

Mode D'administration. La dose des racines est d'une once par pinte d'eau, comme tisane anti-seor ${ }^{4}$ butique : les feuilles s'ordonnent par poignées; mais elles n'ont que de faibles vertus; l'huile s'emploie plus volontiers dans la composition des onguens.

\section{Explication de ta planche vingt-septik̀me:}

La plante est réduite à moitié grandeur naturelle:

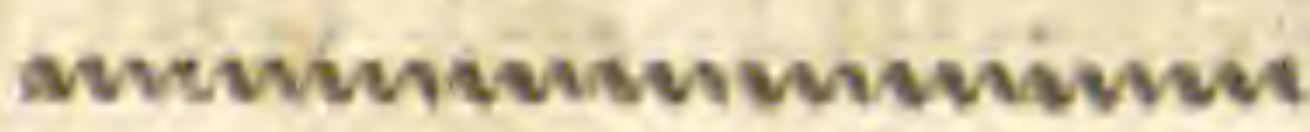

i. Un pétale, une étamine et le pistil, séparés di reste des parties constituantes de la fleur.

2. Forme d'un pétale.

3. Fruit entier.

4. Fruit coupé transversalement.

5. Deux graines ailées.

6. Graine séparée de ses ailesi 


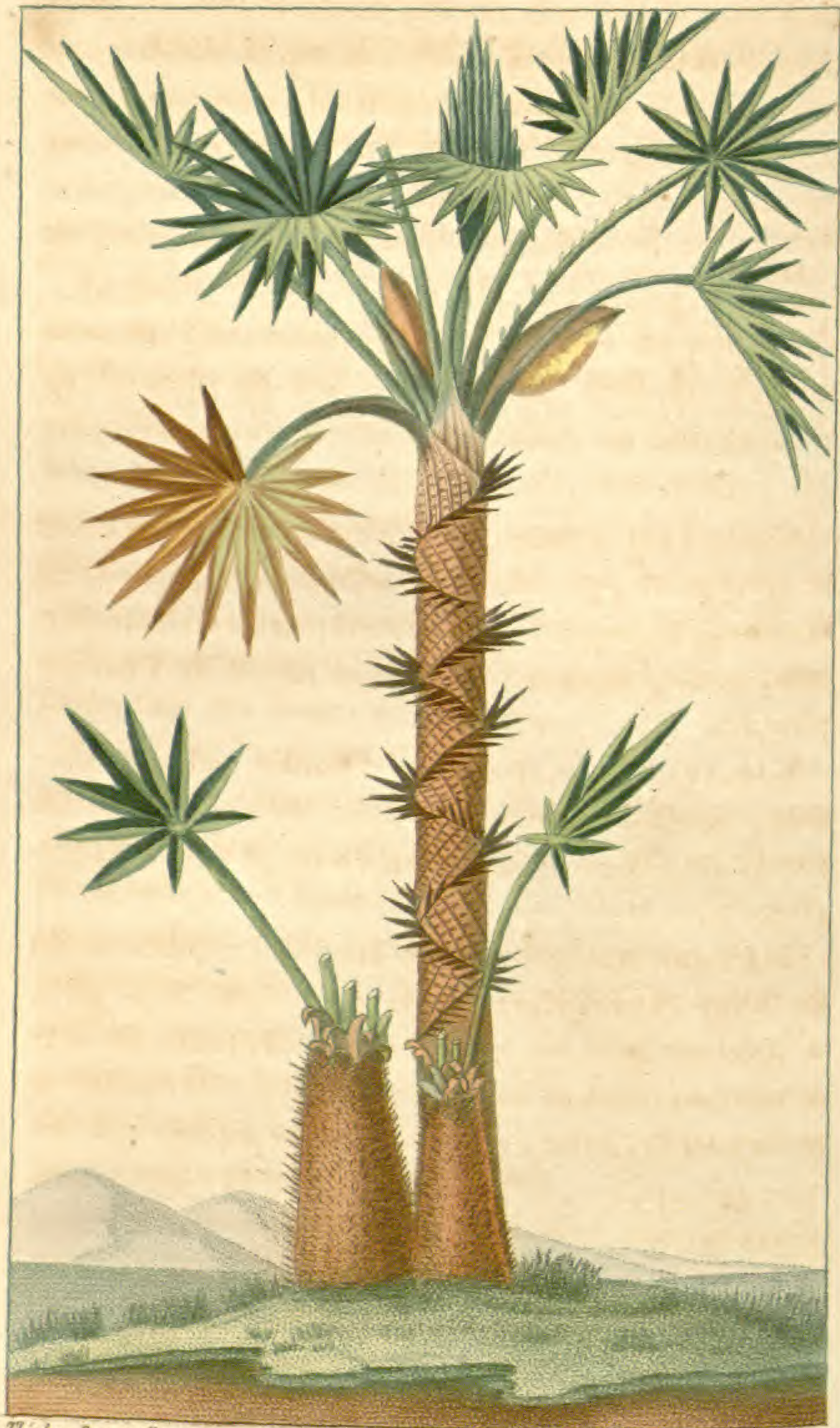




\section{( 135$)$}

\section{IATANIER ÉPINEUX oU HACHE:}

\section{(Stomachique anti-scorbutique.)}

Brnonimie. Chamoerops Antillarum, ou Palmier en éven tail de Linné, append., ordre des Palmiers. Hexandrie monogynie.- Palma dactylifera, radiata, spinosissima ; et thoracibus aculeatis munita. Plumier, vol. VII, p. 54 . - Palma prunifera folio plicatili, seu flabelliformi caulice et squammato, N.-Carnaïba. Pis. 1658 , p. 126. - Alattani des Caraibes.

Caractères gínériques. Hermaphrodite, calice en trois parties profondes, corolle detrois pétales, six étamines, trois pistils, trois fruits pulpeux, monospermes, male, diöque; les parties mâles de l'hermaphrodite. (Jolyclerc.)

Garactikres farticuliers. Feuilles palmées plisa sées, souches épineuses, trois baies uniloculaires roussâtres, semées de points élevés et pâles. (Jolyclexc.)

Histoire in aturelle. Le latanier, dit Bernardin de Saint-Pierre (Harm. de la nat., tom. 1. p. 98), « présente aux voyageurs des éventails sur ses rochers ) marins; il donne aux noirs, du vin, du vinaigre et ") du sucre, dans sa sève ». Ce n'est point le seul service qu'on puisse réclamer du latanier. Les nègres maxrons font, par disette, une farine avec l'amande de ses fruits, qu'ils pilent dans le silence de leurs retraites escarpées, et en obtiennent un pain grossier, ou plutôt une espèce de cassave, après l'avoir fait cuire entre deux plaques de fer, ou entourée de feuilles de bana- 
ther, ou sous la braise ardente des épis de maïs dont ils ont retiré les graines; mais les perroquets, friands de ces amandes, les disputent aux nègres qui ne sont point armés contre eux, et dont ils bravent l'impuissance, en trompant leur surveillance, et les devançant au point du jour dans leur maraude.

La partie digitée des feuilles du latanier, sert aussi à couvrir leurs cases, et en y laissant le pétiole ils en forment de très - bons balais. D'après d'autres préparations non moins ingénieuses, on voit sortir de leurs mains adroites, dếs parasols, des écrans, des éventails naturels destinés à se soustraire à l'action du soleil, et qui, jaunes dans leur état de nature, et sans apprêts, puis revêtus de couleurs brillantes et de figures grotesques, fixèrent il y a quelques années, l'attention des dames de l'Europe.

Le pétiole long, aplati, souple et ligneux de chaque feuille, sert aux nègres à radouber leurs pirogues et à border leurs canots, tandis que réduits en filasse, ils en composent leurs hamacs. La palme supérieure, moins solide, offre encore d'autres ressources; car, indépendamment des usages auxquels l'art ingénieux sait les approprier, les nègres en tressent des chàpeaux, et avec les plus épaisses ils en font des paniers, des macoutes à bras et à somme, pour porter et faire porter leurs provisions au marché.

Les nègres marrons font des lances avec la partie dure du tronc du latanier, et des épieux avec lesquels ils osent attaquer le crocodile: en vidant les troncs, ils peuvent, à la rigueur, procurer des tuyaux pour les aqueducs. 


\section{( 137$)$}

On trouve le latanier partout aux Antilles, sur le bord des ruisseaux, dans les ravines, dans les savanes les plus arides et les plus desséchées, et dans les cantons marécageux.

Caractères physiques. Ce palmier élégant qui se plait dans les terrains des hattes où il laisse échapper du sol, ses feuilles en éventail, au milieu d'une bourre épineuse, vient aux Antilles à la hauteur de 15 à 20 pieds sur vingt pouces de diamètre environ. Son tronc est hérissé de pointes produites pax les anciennes feuilles, qui, en se fanant et se consumant, laissent autour de la tige, des épines roides et longues, disposées en spirale contrariée, et indiquent la forme de la base des pétioles dont elles ne sont plus que les vestiges.

Les fibres corticales ou ligneuses du vrai bois du trone, sont noires et très-dures, susceptibles d'émousser les outils les mieux trempés, et de reeevoir un beau poli, ce que connaissent fort bien les ébénistes : mais cette partie externe et circulaire n'est épaisse que d'un à denx pouces; tandis que l'intérieur ou centre, offre un tissu spongieux et filamenteux que les nègres appellent moëlle. On voit souvent des objets curieux, tels que tabatières et étuis faits avec le bois de latanier, et qui paraissent comme variolés.

Ses feuilles qui, droites d'abord, se courbent en grandissant, sont placées à l'extrémité de longs pétioles plats, canaliculés légèrement, larges et semi-amplexicaules à leur base, épineux sur les bords chez certains individus. Elles sont plissées en éyentail, fermées avant leur développement, et représentent, lors- 


\section{( 138 )}

qu'elles sont épanouies, un éventail ouvert, dont chaque pli est terminé par une pointe qui les sépare les uns des autres à l'extrémité.

Le latanier des Antilles offre des fleurs hermaphrodites, dont on a vu ci-dessus la description: les fruits sortent en grappes d'une spathe, et forment un régime rameux; ils sont de la grosseur du citron des halliers, et de couleur rougeâtre; c'est une coque ovoïde, mince, lisse et luisante, marquée d'écailles légères, et ils contiennent une amande.

Aralyse chimique. Les amandes des fruits du latanier, contiennent tous les principes des amandes ordinaires, plus une espèce de fécule amilacée; sa sève un principe mucoso-sucré, susceptible de fermentation, et par conséquent de produire un acide.

Propriétés ménicinates. Ses amandes fournissent des émulsions utiles dans les affections scorbutiques; on emploie plus utilement dans ce cas le suc de la sève auquel les Caraibes attribuent de puissantes vertus; mais la saine médecine, n'en ayant pasencore fait une heureuse application, le sage observateur doit, dans cette incertitude, ne pas se prononcer. Il doit néanmoins, par intérêt pour la science et l'humanité, répéter les expériences cliniques, indiquées par les na? turels du pays, et qui sont seules capables de fixer son jugement sur des propriétés peut-être trop exagérées, mais qui ne sont point entièrement inefficaces. 


\section{$(139)$}

Explication de la planche vingt-huitik̀38:.

avereverut avos

La plante au douzième de grandeur naturelie, offre, près de sa base, deux autres troncs qki s'élèvent et qui offrent des feuilles digitées. 
Pl. 39 .

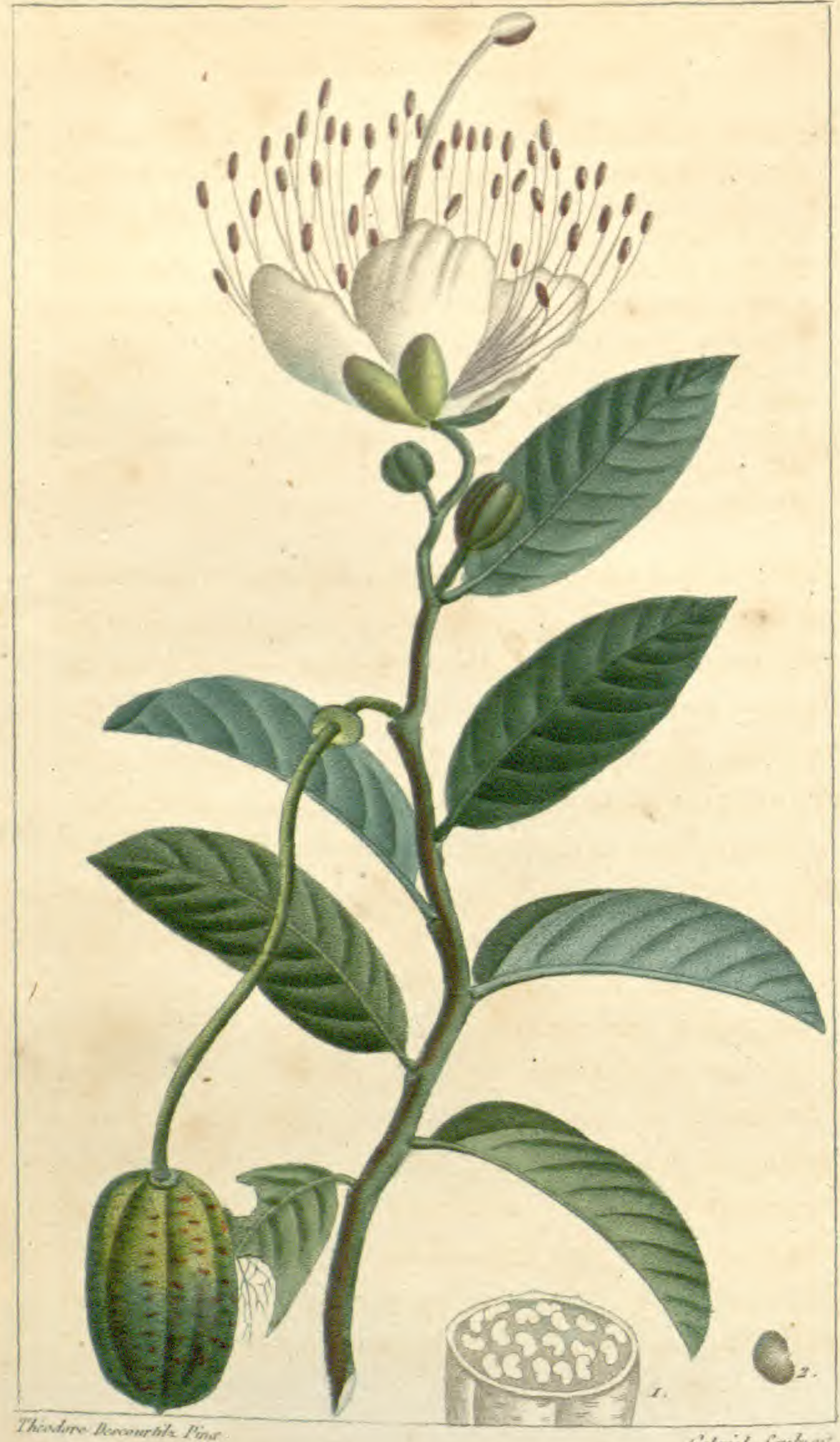

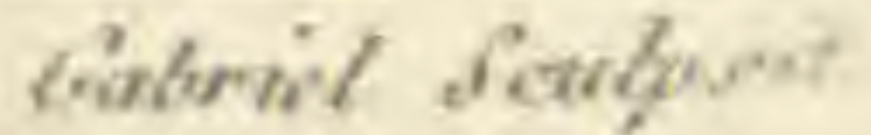

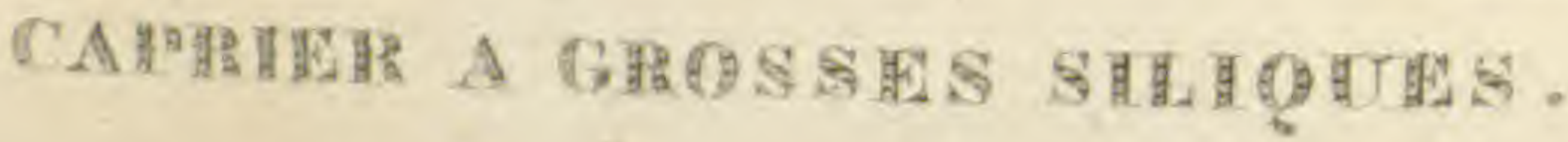




\section{( 141$)$ \\ CAPRIER A GROSSES SILIQUES.}

(Stomachique anti-scorbutique.)

Synonymite. Caprièr à grosses siliques, ordre, classe VI, sect. VI, genre I, Tournefort.-Classe XII, polyandrie monogynie, Linn.-Fam. 51, les capriers, Adanson.-Capparis inermis, foliis ovalibus, glabris, venosis, floribus solitariis axillaribus et terminatibus, staminibus corollâ longioribus, fractu ovato, N.-Capparis arborescens, amplissima fructu ovato. Plum., v. 7, p. 102. -Capparis alia arborescens, lauri foliis, fructu oblongo, ovato. Spec. 7, Burm. Amer., tab. 73, fig. 2.-En espagnol, Alcaparra, Alcaparro (Flor. du Dict. des Sc.-méd.) - En anglais, capet-Trée (Flor. du Dict. des Sc.-méd.)

Caractères génériques. Calice découpéen plusieurs parties. Corolle 4 à 5 pétales, ordinairement alternès avec les divisions du calice. Étamines définies ou indéfinies ; ovaire ordinairement porté sur un pédicelle; un style, un stigmate, une baie ou une capsule; graines attachées aux parois du fruit; feuilles alternes.

Caractères particuliers. Calice 4 feuilles concaves; corolle 4 pétales arrondis, ouverts; étamines nombreuses; ovaire en massue, porté sur un pédicelle, baie uniloculaire. (Lamarck.)

Histoire naturelie. On rencontre aux Antilles plusieurs espèces de capriers, dont les fleurs font l'ornement des bois où ils végètent; ils étendent élégamment leurs rameaux snr les murs et les buissons des terrainssecs et pierreux, ou parmi les fentes des rochers les plus exposés au soleil. Les principales espéces sont $1^{\circ}$. le caprier àgrosses siliques dont íl est parlé dans cet article; $2^{\circ}$. le caprier à feuilles ramas-

$$
\text { 28. Livraison. }
$$




\section{(142)}

sćes, capparis fiondosus, capparis Amencana arborescens lauri folio, fructu subrotundo, flore albo, Plum.; 3o. le caprier à siliques rouges ou pois mabouïa, fêve du Diable, des Caraïbes ; cap. paris synallophora, Linn.; capparis arborescens taurifolio, fru tu longissimo, Plum., spec. 7 ; $4^{\circ}$. le caprier luisant, capparis Breynia, Linn., Bieynia elaagni, foliis, Plum. gen. , 40; $5^{\circ}$. caprier à feuilles d'amandier, capparis amygdalina ferruginea, Linn.; $6^{\circ}$. le caprier à feuilles panachées de la Jamäque, capparis flexuosa Jamaïcensis.

Caractères phystques. Le caprier à grosses siliques, offre un arbre assez gros et assez élevé, dont l'écorce du trone est épaisse, noirâtre et ridée. Les branches sont garnies, à leur sommet, de feuilles nombreuses, alternes, ovales, lisses, veineuses, larges, d'un beau vert, semblables à celles du laurier, mais plus larges, plus épaises et plus arrondies; il sort de chaque aisselle des feuilles terminales, un pédoncule assez court, sur lequel repose une grande et belle fleur à quatre pétales blancs rosés, concaves et longs d'un pouce et demi environ; les filets des étamines sont blancs, légèrement teints de lilas, très-nombreux et beaucoup plus longs que les pétales, surmontés d'anthères oblongues, jaunes; ce faiscean imite bien une aigrette élégante dépassée par un style à stigmate oval.

Le fruit de ce caprier est oblong, arrondi, cannelé, et marqué de mouchetures transversales pendant à nur long pédicułe, pourvu d'une espéce de petite col- 


\section{( 143 )}

lerette indiquant la place du calice près de son insertion à la tige; l'écorce du fruit est coriace, ridée, d'un vert glacé de bistre et sa pulpe charnue.

Afalyse chimigue. La racine du caprier arbre ou à grosses siliques, offre un principe extractif amer et légèrement astringent; elle est âcre et piquante au goût.

Propriétés médicinales. L'indifférence des colons qui se créent des besoins au milieu de leurs propres ressources, leur fait négliger la culture des capriers dont ils achètent les fruits, à haut prix, des bâtimens qui viennent d'Europe, et cependant les jeunes boutons des capriers des Antilles sont tons suscepti. bles d'être mangés confits au vinaigre. Ils offrent un aliment sain, excitant, et surtout anti-scorbutique. L'écorce des racines s'enlève facilement; on la met sécher à l'ombre, où elle se roule d'elle-même. On l'estime apéritive, anthelmintique, et recommandable dans les affections de la rate, hystériques, et l'atrophie mésentérique. Les capres, estimées diurétiques, excitent indirectement les organes génitaux. Il ne faut cependant pas user avec excès de ce condiment digestif, qui convient plutôt aux tempérammens affaiblis muqueux ou lymphatiques, qu’à ceux sanguins et nerveux chez lesquels son tréquent usage occasionne trop d'irritabilité. Nicolson indique ses graines comme diurétiques, emménagogues, antiparalytiques, et propres à relever les ragoûts.

Mode d'administration. Plusieurs praticiens des Antilles recommandent dans les cas ci-dessus l'infusion de l'écoree des racines avec addition de sulfale 


\section{(144)}

de fer, surtout dans les splénites chroniques. La dose de l'écorce de la racine est d'un gros, en substance, ou d'une once par livre de liquide.

Les nègres détergent les vieux ulcères avec le vi: naigre dans lequel ont séjourné, pendant quelque temps, les boutons du caprier, et une once de suc de karatas par livre de véhicule.

EXPLication DE LA PLANCHE VINGT-NEUVIÈME.

La plante est réduite au tiers de grandeurnaturelle.

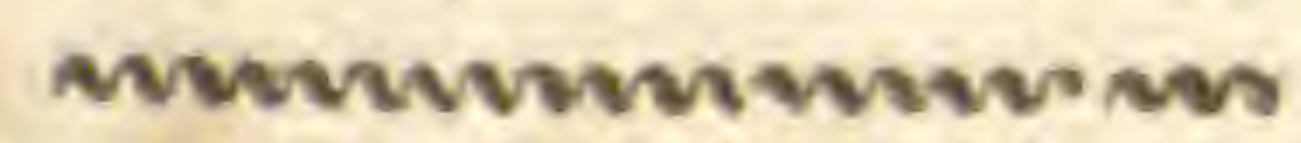

3. Fruit ouvert.

z. Graine. 
Pl.30,

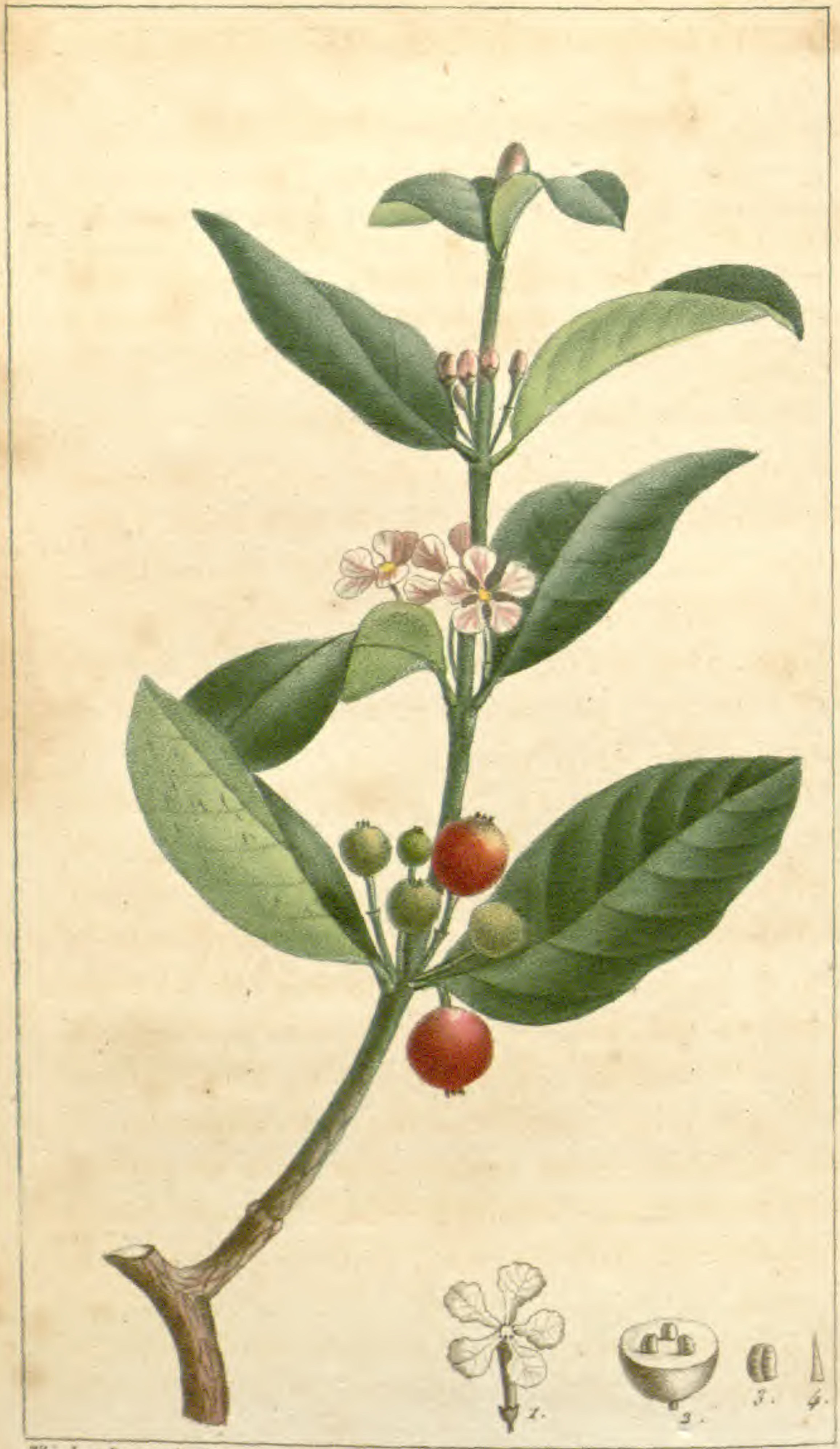

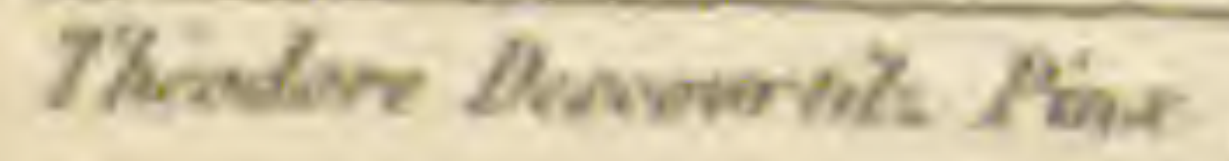




\section{MOURELLIER - CERISIER DES ANTILLES.}

(Stomachique anti-scorbutique.)

Srnonymie. Malpighia punicifolia, Linn,, classe $\mathbf{X}$. Décandrie trigynie-Fam. 49, les Géramines, Adanson. - Jussieu, fam. des Malpighies. - Malpighia mal punici facie (frucțu cerasiformi), Plumier, vol. 7 ,i p. 124. - Ibipitanga, Marg., Pis., Achyoulou des Caraïbes.

Caractìres génériques. Calice cinq-phille, garní extérieurement à la base des pores mellifères, cinqpétales comme ronds à onglets; baie uniloculaire, trois spermes.

Caractéres particuliers. Feuilles ovales, très-entières, glabres; pédoncules uniflores ou biflores et axillaires. (viv. Jolyclerc.)

Histoire naturelle. Le cerisier des Antilles se plaît également dans la plaine et dans les mornes, où il fructifie deux fois par année; son feuillage élégant est d'un beau vert, charme la vue, et fait ressortir le blane de ses fleurs multipliées et le rouge de ses fruits globuleux, qui, au premier abord, sont parfaitement semblables aux cerises d'Europe : on fait avec ces fruits des gelées aigxelettes très - rafraîchissantes et assez agréables; leur acidité néanmoins ne permet point de les manger cruds, à moins de les avoir roulés préalablement dans du sucre, et de les avoir exposés au soleil.

Caractimes physiques. Le cerisier des Antilles est un arbrisseau qui s'élève à la hauteư de douze à quinze 


\section{$=\quad(146)$}

pieds; ses tiges sont tortueuses, son écorce rugueuse et crevassée; le bois peu estimé est blanc, léger et cassant.

Ses feuilles sont assez semblables à celles du grenadier, mais plus grandes : elles sont longues de 16 à 20 lignes, et larges de 9 à 10 dans leur plus grande étendue; elles sont oblongues, lancéolées, minces, entières, luisantes, souples, d'un vert gai en dessus, et pâle en dessous, attachées par paires le long des rameaux, soutenues par un court pédicule, et d'une saveur amère.

Ses fleurs naissent par bouquets des aisselles des feuilles; elles sont en rose, à cinq pétales arrondis, blancs, nués de rose ; pourvues de dix étamines trèsfines, dont les anthères sont jaunes. Le style est surmonté de trois stigmates cylindriques, et porté sur l'ovaire qui devient une baie charnue sphérique, d'un rouge vif; marqué de trois stries vers l'ombilic, d'un goût aigrelet, même dans sa parfaite maturité; cette baie renferme trois noyaux striés, ailés, contenant des amandes oblongues; ce fruit très-petit est attaché à une queue grêle. (Nicolson.)

Analyse chumique. Le malpighiefournit de l'acide gallique, et une écorce abondante en tannin; l'écorce est rouge, mais elle prépare bien les peaux; on la nomme mouricie; la gomme qui suinte de l'arbre donne les mêmes produits : vingt livres de cerises donnent 2 livres 2 onces de rob rafraîchissant, dont l'usage tient le ventre libre.

Propriétés médicinales. Ces fruits muqueux, sucrés et acidules, sont très - salubres, dissipent les 


\section{(147)}

engorgemens des viscères, modèrent la soif des fébricitans, et leur usage est indiqué dans les maladies inr flammatoires, bilieuses et adynamiques; leur suc, à une forte dose, devient laxatif; le même suc étendu d'eau, procure une boisson rafraîchissante, précieuse dans le scorbut. L'écorce du cerisier des Antilles fournit une gomme pectorale, et qu'on emploie comme adoucissante, dans les catarrhes aigus de la vessie.

Mode d'administration. La dose du rob est d'un ̀े quatre gros à jeun, à la pointe du couteau.

Expltcation de la planche trentième.

La plante est représentée de grandeur naturelle. Le rameau offre des fleurs et des fruits approchant plus ou moins de leur maturité.

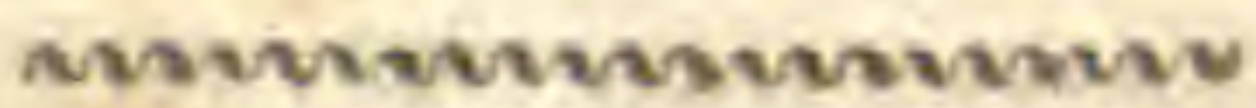

2. Fleur entiere.

2. Fruit coupé transversalement.

3. Graine cannelée séparée de la pulpe.

4. Epine du dessous de feuilles. 


\section{OSEILLE DE GUINÉE oU KETMIE ACIDF.}

(Stomachique anti-scorbutique.)

Srnonymre. Hibiscus Sabdariffă, L., monadelphie polyandrie.-Hibiscus caule herbaceo levi, foliis serratis: inferioribus ovatis, superioribus tripartitis vel quinquepartitis, floribus sessilibus, N.- Ketmia africana Hortensis rubra, acetoso sapore, Plum., vol. IV, p. 24.Ketmia indica acetosæ sapore, gossypii folio, Tourn., woo. Plum., cat. 2. - Althoca indica, gossypiifoliis, acetosæ sapore, Herm., lugdb. 25, Raj, hist. 1900. Alcea acetosa indica mitis, foliis superioribus gossypii in modum tripartito divisis, Plum., alm. 15, t. 6, t. 2 . -Quauhxocolt, seu Oxymalva, Hernaud., max. 216 (Encycl. méthod). Ketmie, Tournef., cl. 1, Camp., sect. 6. - Jussieu, famille des Malvacées.

Caractères génériques. Calice double, l'extérieur polyphylle. Style quinquéfide au sommet. Capsule à cinq loges, polysperme.

Caractìr es pam ticuliers. Feuilles dentées en scie, les inférieures ovales, entières, les supérieures septenées, partagées; tiges sans épines; fleurs seșsiles. (Annuelle. Jolyclerc.)

Historne naturelle. La saveur acide de cette plante fait qu'aux Antilles on la substitue à l'oseille, dont elle a d'ailleurs les propriétés. Les cuisiniers et les chefs d'office l'emploient, d'après la nature de leurs fenctions respectives, en lui associantdes coulis, du beurre; tirent un bon parti de ses calices et des feuilles pour les farces glacées sur lesquelles doivent paraître différentes viandes; les confiseurs réservent aux mêmes parties un emploi plus distingué, et en 
PZ, 37.

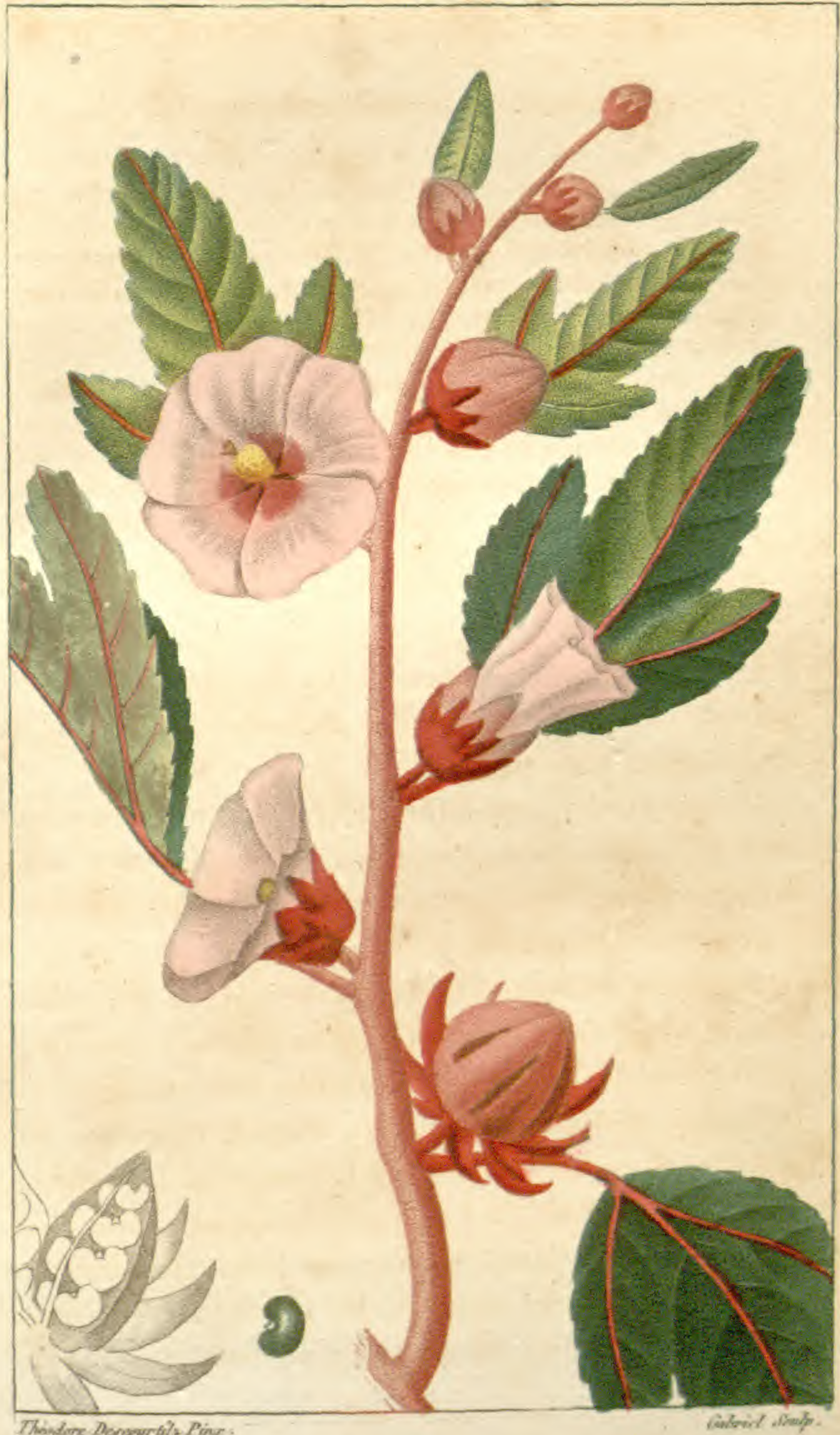

KETMIE ACIDE. 
font des conserves et des confitures d'une aciditê agréable et rafraîchissante. La ketmie acide croît naturellement en Guinée, dans les Antilles et dans toute l'Amérique méridionale.

Caractères physiques. L'oseille de Guinée rouge est annuelle, et s'élève à la hauteur de quatre à six pieds. Elle est souligneuse, quoiqu'herbacée, tortueuse, rameuse inférieurement, sans épines, flabre, couverte d'un épiderme rugueux, et carminée ainsi que les nervures des feuilles, les calices et les boutons des fleurs. Sa racine est chevelue, pivotante, coriace, grisâtre et inodore; la tige renferme une moëlle verdâtre, acide, inodore.

Les feuilles, vertes en dessus, et jaunâtres en des. sous, sont alternes, glabres, souples, d'une saveur acide et légèrement astringente; dentées, à nervures principales carminées, portées sur des pétioles assez longs, et ne s'inclinant vers la terre qu'après leur parfait développement. Les feuilles du bas de la tige sont plus petites, simples et ovales, tandis que celles de la partie supérieure sont composées de trois lobes ovales lancéolés, dont celui du milieu est beaucoup plus long; les pétioles sont pubescens à leur partie supérieure, et pourvus d'une glande à la naissance de la nervure dorsale. Les stipules sont filiformes.

Les fleurs sont axillaires, solitaires, presque sessiles; leurs calices sont rouges et presque glabres; l'extérieur est monophylle et découpé profondément en laniéres pointues, droites ou courbées, et comme spongieuses. L'intérieur est plus grand, sémi-quinquefide, jaune-poupré ou pourpre. 
La corolle, malvacée, est campanulée, ouverte ; rose ou jaune rouge, et offre aux onglets des pétales une tache d'un pourpre très-foncé, et qui donne cette couleur au fond de la fleur. De ce fond s'élève le tube columnifère qui soutient les nombreuses étamines, adhérentes à sa superficie et au sommet; à filamens libres vers leurs extrémités et portant des anthères réniformes.

L'ovaire supérieur, est oval, surmonté d'un style filiforme engainé dans le tube des étamines, quinquéfide au sommet, et à stigmates globuleux. La corolle flétrie est remplacée par le calice intérieur, qui s'allonge, devient épais, d'un rouge foncé, charnu et d'un goût acide. Le pistil se change en un fruit sec, oval, à cinq loges, composées chacune de trois lames minces oblongues, lisses en dedans et hérissés au dehors de poils fins et piquans. Chaque fruit renferme une vingtaine de graines noires et réniformes.

Analyse chimeue. L'oseille de Guinée fournit beaucoup d'acide oxalique solnble dans quatre parties d'eau froide ou deux d'eau bouillante. Il rougit les couleurs blenes végétales : en le combinant avec des substances salines, il forme des oxalates. C'est un excellent réactif pour reconnaitre la présence de la chaux dans les eaux minérales. Cet acide m'a servi pour l'analyse des eaux du Port-à-Piment. (Isle de Saint-Domingue.)

Propniétés médicinales. On fait avec la confiture ou le sirop de cette ketmie une boisson salutaire et tempérante que boivent avec délices les malades 


\section{( 151$)$}

atteintsde fièvres inflammatoires, adynarriques ou bilieuses. Hs demandent avec empressement un remède qui ne peut leur inspirer nul dégon̂t, et qui porte dans leur système un calme bienfaisant et réparateur. Les scorbuliques éprouvent un grand soulagement de l'usage de cette boisson. Dans ce cas, on édulcore avec son sirop les apozèmes de cresson de savanes etautres anti-scorbutiques d'où il résulte un sel neutre par la combinaison des parties volatiles de l'une avec les parties acides de l'autre. On mêle des feuilles entières dans leurs potages, et leurs autres alimens, auxquels on peut ajouter des préparations de mars, pour les rendre plus efficaces dans le scorbut et les autres maladies chroniques. Les feuilles sont employées extérieurement dans les cataplasmes comme émollientes et résolutives. On les ordonne aussi dans les clystères rafraîchissans et anti-putrides qu'on prescrit dans certaines diarrhées. Les racines amères indiquées comme apéritives et toniques s'emploient rarement.

Mode d'Administratiov. La dose du sirop et des confitures est de deux cuillerées par livre d'eau bouillante ; celle des feuilles, une poignée par pinte d'apozème; le suc se prescrit à la dose d'une à deux onces.

Il existe aussi une autre ketmie acide qu'on appelle oseille de Guinée blanche. ( $\mathrm{r}$ )

(1) Ketmia acida, africana, candida. Hibiscus digitatus (Plum.)-Cav., diss. $3, \mathrm{n}^{\circ} .215, \mathrm{t} .70$, fig. 2.

Ketmia africana, foliis et caulibus viridibus, fructu albo. (Desp.) 


\section{( 152$)$}

Sa racine est blanche au dehors, grisâtre intérieurement. L'épiderme de la tige est verte, les feuilles sont digitées, divisées en cinq parties allongées, d'un vert tendre ; les fleurs sont d'un jaune clair; le centre près des onglets d'un jaune foncé, le calice intérieur verdâtre, moins acerbe que dans l'espèce précédente. Le second calice est découpé en plusieurs segmens pointus, d'un vert foncé; les graines renfermées dans le fruit, sont plus petites, et leur nombre est d'environ quarante: du reste, cette plante est semblable à la précédente. (Nicolson.)

Explication de ra planche trente-Unième.

La plante est de demi-grandeur naturelle.

axาง

1. Branche garnie de fleurs et de fruits.

2. Portion du fruit ouvert.

3. Graine de grosseur naturelle. 


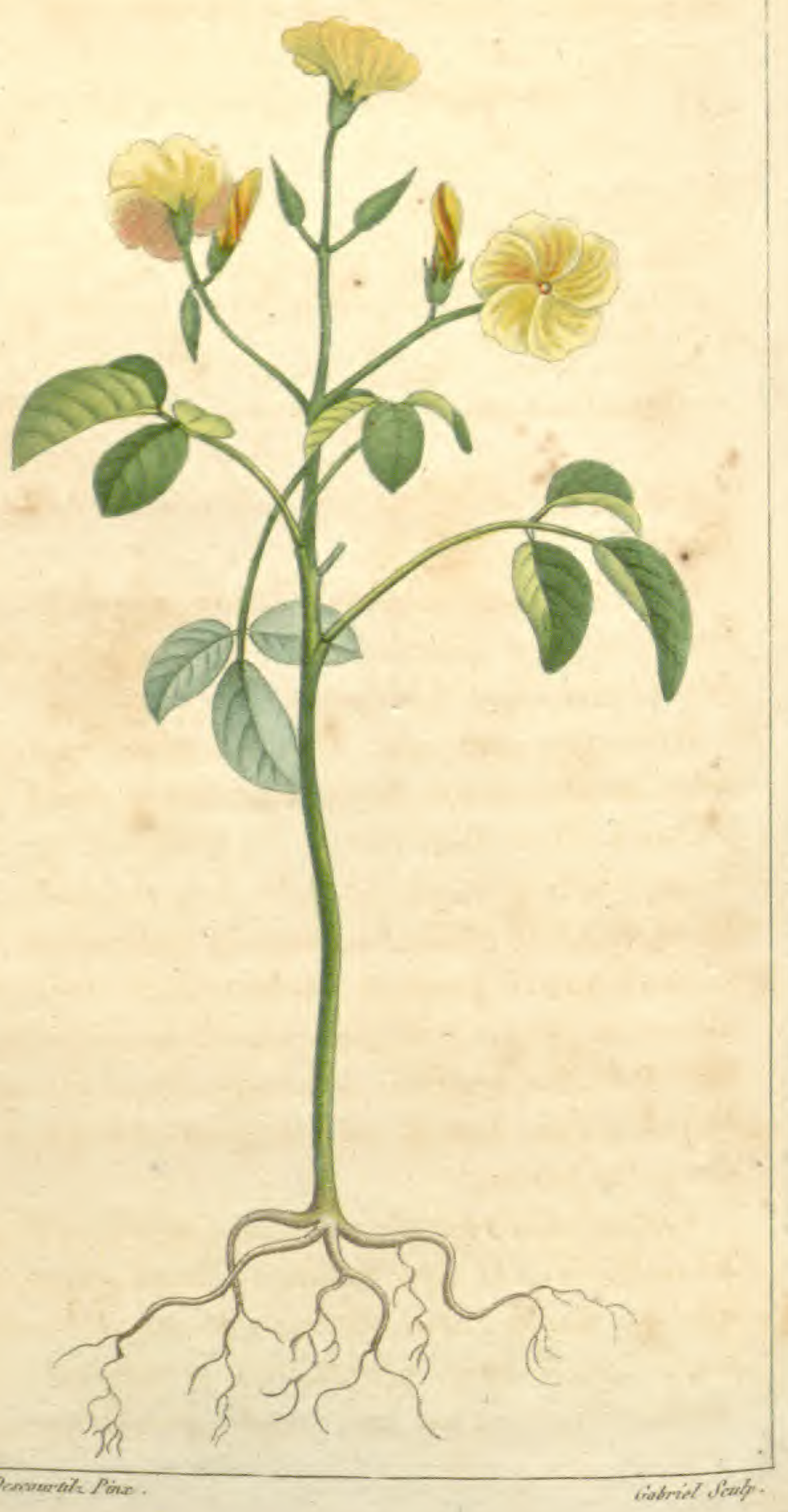

- OXALIE A FHEUS JAUNES. 
OXALIE oU ALLELUYA A FLEURS JAUNES.

(Stomachique anti-scorbutique.)

Srnonxmie. Oxys lutea, J.-B., 2 , 388. - Trifolium acetosum corniculatum, C. B. Pin. 33o.- Oxys lutea acetosæ sapore, trifolii bituminosi, foliis, Poup.-Desp., t.3, p. 233.-Tournef., Oxys, cl. 1, Campan., sect. 8. - Jussieu, fam. des Geraines.-Alleluya, oxalis frutescens, Linn., clas. X. Décandrie Pentagynie. - En espagnol, Alleluya. En anglais, Wood-Sorrel.

Caractères génériqués. Calice einq-phille; einq pétales.

Caractères particuliers. Pédoncules ombellifères, feuilles à longs pétioles, ternées, ovales, glabres ; fleurs redressées; tige droite.

Histoire naturelie. L'oseille maronne des Antilles, étant pourvue de cette acidité salutaire qui fait rechercher l'oseille d'Europe, on l'emploie aux mêmes usagès; on la rencontre dans les bois et dans les forêts humides. Cette plante inodore est recherchée par les nègres fumeurs, pour nétoyer leurs dents; mais comme elles sont agacées par ee moyen, ils ont recours, pour détruire cette impression désagréable, à l'usage de la liane à savon, dont ils portent sans cesse à la bouche des petits bâtons.

Caractères physiques. L'oxalide est une plante annuelle dont la tige s'élève de huit à onze pouces : elle est droite, rameuse vers lé sommet, diffuse'; ses feuilles à longs pétioles sont ternées; ses folioles ovales terminées par une impaire plus grande; la ra- 


\section{( 154 )}

cine est traçante, fibreuse, ef articulée. Elle donne naissance à une tige tortueuse, portant supérieurement environ quinze pétioles garnis chacun de trois folioles.

Les fleurs non épanouies ont les boutons roulés en spirale comme comme ceux du jasmin d'Europe, et en se développant laissent aperçevoir les pétales cachés à moitié l'un par l'autre; elles sont de couleur jaune soufré, glacées de jaune orangé, et comme veinées. Ces fleurs, au nombre de trois à cinq sur chaque rameau, sont accompagnées de boutons allongés, pointus et non développés.

Le calice persistant a cinq divisions aiguës; la corolle est deux fois plus grande; les styles et les étamines, de même grandeur, ne paraissent pas à l'extétieur.

A la fleur succède une capsnle à cinq loges polyspermes renfermant plusieurs semences striées transversalement, et munies d'un arille charnu, qui s'ouvre avec élasticité.

Analuse chrmreue. Cette oxalide fournit par excellence l'acide qui porte son nom, et qui dissout, comme on le sait, les oxides de fer. Il sert à enlever les taches d'encre; le sel rehausse le ton et donne de l'éclat à certaines couleurs; cette plante contient beaucoup d'eau, du mucilage, et de l'oxalate acidule de potasse.

Propriétés médicinales. L'oxalide a toutes les propriétés de l'oseille de Guinée ou ketmie acide. On l'emploie dans les tisanes anti-scorbutiques, apéritives, et on obtient du suc par évaporation, un sel qui procure une himonade rarement employée, cepen- 


\section{(155)}

dant, en raison de l'abondance des citrous qu'on reñcontre partout aux colonies. On obtient une tisane salutaire et tempérante, convenable dans les dissenteries et diarrhées adynamiques et scorbutiques, avec ane poignée de bourgeons d'oseille, une de cresson de savane par livre d'eau, édulcorée avec le sirop de nymphæa du pays qui remplace très-bien celui de diacode. Cette tisanne d'ailleurs appaise l'exacerbation de la fièvre, éteint la soif des malades, modèré l'ardeur des viscères du bas-ventre, et provoque la sortie des urines. L'usage de l'oxalide convient parconséquent dans les fièvres angéioténiques et antres maladies inflammatoires, dans les fièvres jaunes, gastriques ou bilieuses, ataxiques, adynamiques, etc., et dans les inflammations des reins, de la vessie, et du canal de l'urètre.

L'oxalide détruit l'amertume de la bouche, si désagréable dans certaines affeetions, et stimule l'ap= pétit.

Les malades affectés de calculs vésicaux à base d'oxalate de chaux ( disent les auteurs de l'article oxalide d'Europe) doivent s'abstenir d'en faire usage.

On ajoute aux potages des maladesles jeunes pousses ou les sommités d'oxalide.

On fait avec cette plante un sirop et des conserves.

Mode D'administration. L'oxalide s'emploie à la dose d'une poignée en décoction par deuxlivres d'eau; le sucà celle d'une once à deux; le sel peut se faire dissoudre à la dose d'un gros à deux par livre de véhisule: On édulcore avec le sirop de battexie. 
Explication de la planche trente-deUXièmę.

La plante est représentée réduite au tiers de granł deur naturelle. 
Pl. 33.

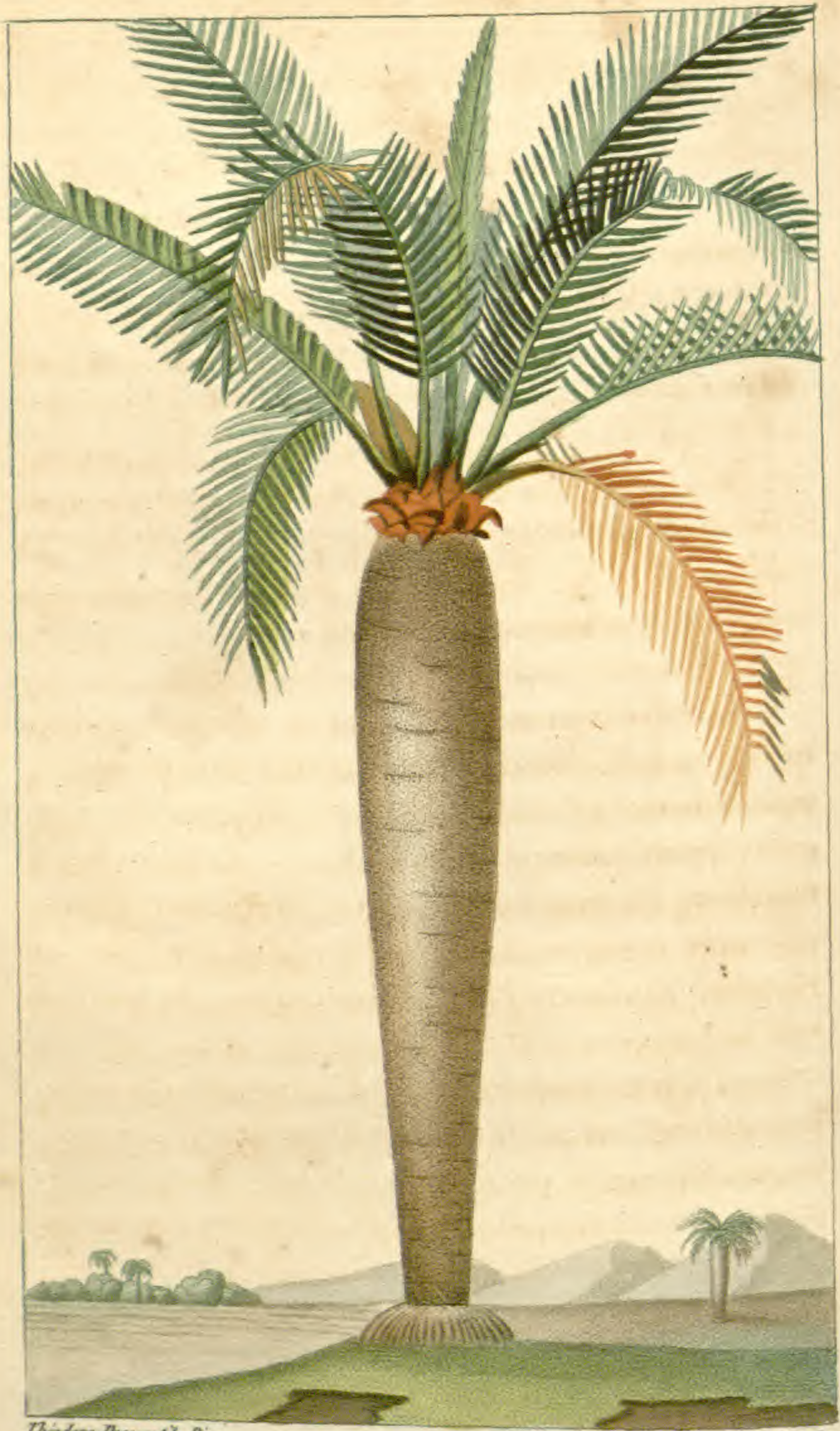

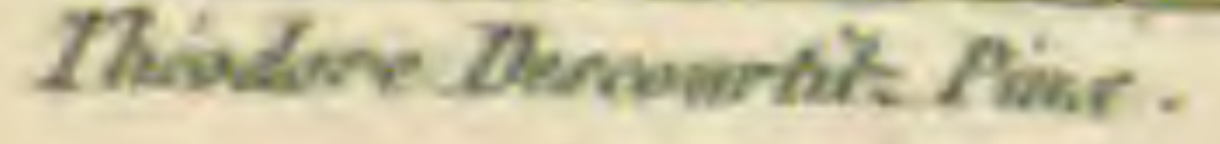
Giebrid stomlp.

BAPHIHE VITIFW 


\title{
RAPHIE VINIFÈRE。
}

\author{
$V u l g$. Palmier a Vin.
}

(Stomachique anti-scorbutique.)

Synorymie. Raphia vinistra. Palisot-Beaviois. (Flore d'Oware, tom. 1, pag. 75.) Calamus-Sagus, Jus-Sagus Palma-Pinus. Goertn; famílle des Palmiers. - Palma Pinus sive conifera. Lob. icon. - Palma Pinus Sylvestris, Dalech. - Peregrinus fructus squammosus. Clus. Exot. - Palma conifera ex Guineâ squamis ad pediculum conversis. Bauh., Pin. pag. 5 etc. - Sagouier vinifere. - SAgus R Aphia Encyc. p.o.d. X. M. - Sagus spadice ramosissimo, singulis floribus squamâ circulari cinctis, fronde Pinnatâ (N.) Yecott. Grevv. mus, pag. 200 , ce genre a de très-grands rapports avec le Rotang (Calamus ).

Caractère essentiet. Fleurs la plupart monoïques; un calice double, l'extérieur à trois divisions, squamiformes; l'intérieur à trois divisions plus longues; point de corolle; six étamines : dans les fleurs femelles, un ovaire ovale, un seul stygmate obtus, une noix presque globuleuse ou allongée (suivànt l'espèce), couverte d'écailles imbriquées du sommet vers la base.

\section{Garactìres particuliers. Fleurs mâles sessiles,} fruit oblong, stipe fusiforme surmonté d'une couronne élégante de palmes, dont la base embrasse circalairement la tige, et dont les inférieures, en se détachant, laissent la partie la plus solide du pétiole, entourée d'une bourre épaisse.

$9^{\mathrm{e}}$. Livraison. 
Historre naturelle. Ce Palmier, commun aur Isles Moluques et au Malabar, croît également aux Antilles. On l'y rencontre auprès des rivières, sur les mornes escarpés et silencieux, où son stipe matériel le fait distinguer des autres palmiers à taille svelte et très-élevée. Les régimes sont énormes et chargés d'une grande quantité de fruits couleur de bois d'acajou, comme vernissés, et semblables à ceux du sagouier, mais plus oblongs.

Le chasseur intrépide, le naturaliste impatient et curieux, attirés par le parfum et le riche aspect des lleurs de toute espèce, qui forment la végétation variée de ces collines, qui fuient, selon Bernardin de Saint-Pierre, les unes derrière les autres en amphithéâtre, trouvent la récompense de leurs fatigues dans les palmiers à vin dont la sève leur fournit à l'instant une liqueur agréable, tonique et rafraîchissante; il suffit, pour l'obtenir, de perforer l'arbre à deux pieds de terre, et de pénétrer jusqu'au canal médullaire. Cette sève, comparable à celle du cocotier, offre un liquide qui, ontre ses qualités précieuses dans l'état frais, donne da vinaigre par la fermentation, du sucre par le rapprochement, et enfin de l'alcool par la distillation. Le tronc de ce palmier sert à bâtir les ajoupas, et le fenillage sert à les couvrir. Les fruits dépouillés de leurs écailles contiennent une amande susceptible de fermentation, et dont on obtient une liqueur enivrante.

Caractêres physiques. Le slipe ou tronc de ce Palmier à vin s'élève peu. Il est droit, beaucoup plus 


\section{(159)}

gros au sommet qu'à la base; couronné à son sommet par une touffe de feuilles grandes, nombreuses, trèsamples, pinnées, pendantes, dont le pétiole commun est garni de petites épines presque dans toute sa longueur:

De la base de ses feuilles sortent et pendent de très-grands régimes ou spadices, trèsaramifiés, sousdivisés en un grand nombre d'autres rameaux serrés, rapprochés, inégaux, chacun d'eux environné de deux ou trois spathes partielles, courtes, cunéiformes, comprimées, tronquées, fendues longitudinalement à un de leurs côtés. Les fleurs sont sessiles et disposées alternativement sur chacune des divisions du spadice, enveloppées à leur base par une sorte d'écaille circulaire, dure, coriace, un peu jaunâtre, lisse, presque luisante : ces écailles sont imbriquées, et recouvrent les rameaux dans toute leur longueur.

Les fleurs mâles, situées sur les mêmes régimes que les fleurs femelles, en occupent la partie supérieure : elles sont très-nombreuses, persistent peridant quelque temps, et tombent enfin à la maturité des fruits, qui forment, par leur ensemble, leur rapprochement et leur nombre, une grosse touffe ovale, serrée, composée de baies sèches, presqu'ovales, luisantes, écailleuses, les écailles très-serrées, fortement imbriquées du sommet vers la base, ovales, obtuses. (Encycl. méth.)

Analyse chimique. La fécule amilacée du palmier à vin, n'offre rien de particulier à l'analyse. II 


\section{( 160$)$}

existe dans sa sève un principe mucoso-sucré susceptible d'acquérir une forte acidité par la fermentation. Cette même sève donne du sucre et de l'alcool, suivant les procédés chimiques auxquels on la sou. met.

Propriétés médicinales. Le Sagou du palmier à vin s'y rencontre en petite quantité, mais on l'emploie utilement comme analeptique, lorsqu'il s'agit de relever les forces des personnes épuisées. La sève jouit de toutes les propriétés de celle du cocotier. (Voy. cet article.)

Mode d'Administration. On prépare le Sagou au lait, ou au gras : son usage est salutaire, mais il est indispensable de l'aromatiser.

EXPLiCATION DE IA PLANCHE TRENTE-TROISIÈME.

Le Palmier à vin est représenté réduit au trentième de sa grandeur naturelle. On a choisi un moyen individu. On apercoit au-dessous de l'ample masse de feuillage qui couronne son tronc, des écailles environnées de bourre, formées par les vestiges persistans des pétioles. 


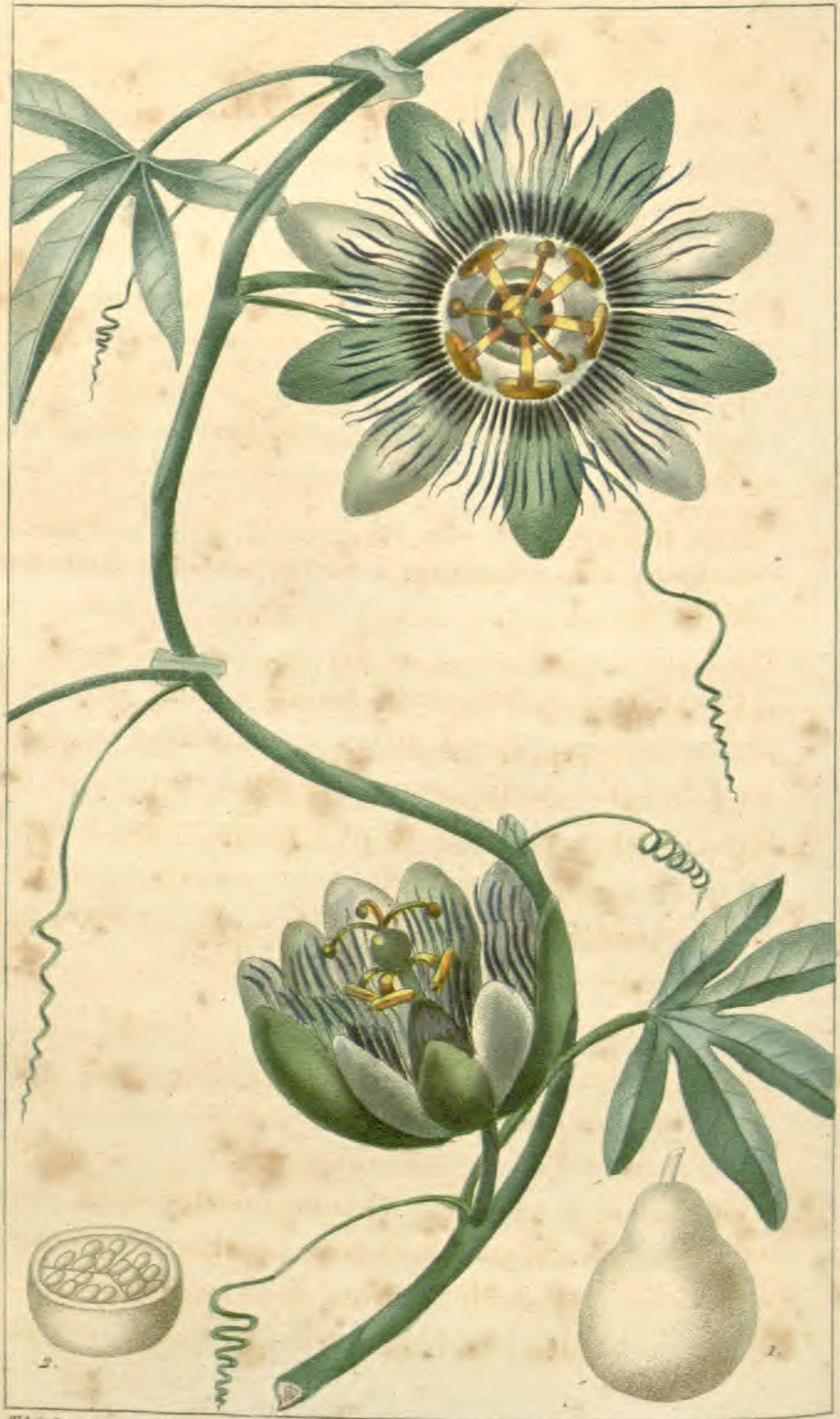

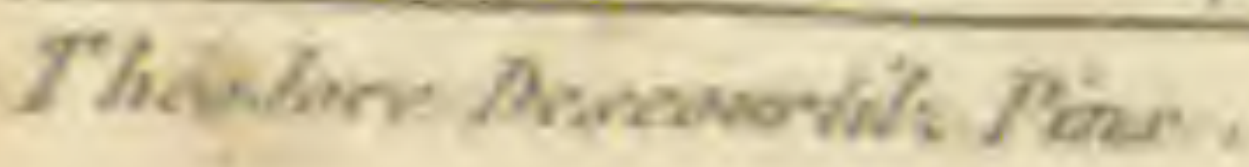




\section{GRENADILLE BLEUE.}

(Stomachique anti-scorbutique.)

Synonymie. Passiflora cærulea. Linn. - Passiflora folüs palmátis, lobis integerrimis, stipulis lunaribus integris aristatis, N.- Granadilla polyphyllos, fructu ovato. Tournef. 241. - Granadilla pentaphyllos, flore cæruleo magno. Boerh. Lugdb. 1, pag. 81. - Murucuia Pison, Bras. p. 247.- - Passiflora (Passionis flora) Lamarck. - Flos passionis major, pentaphillus. Sloan. Jam. Histoire 1, p. 229, Raj. suppl. 329: - Clematis quinque folia americana. S. flos passionis. Rob. ic. ex Linn.

Caractères génériques. Calice à cinq divisions profondes, cinq pétales planes alternes avec les divisions du calice, obtus, ouverts; nectaires en forme de filets disposés circulairement; cinq étamines dont les filets, réunis inférieurement en colonne, sont traversés par le style portant l'ovaire à son sommet, celui-ci couronné par trois stigma en tête.

Caractères particuliers. Feuilles palmées, trèsentières, les pétioles, glabres, pourvus de deux glandes. ( Viv.)

Histoire naturelie. Que de variétés de formes et de couleurs dans cette classe nombreuse qui fait, des nochers sombres et bruts, des amphithéatres où brille l'éclat des plus belles fleurs! Que de festons, 


\section{$(162)$}

de colonnes naturelles formées dans les forêts des Antilles, par ces belles plantes dont les fleurs (sur lesquelles se présentent tantôt l'azur le pllus tendre, le blanc de la neige, le rouge de la rose ou celui du feu, quelquefois même toutes ces couleurs réunies) pendent çà et là, balancées dans les airs par les brises du matin et du soir ! Qu'il est doux de pouvoir admirer ce spectacle enchanteur, sur le bord d'une rivière tranquille et profonde, qui comme un miroir, réfléchit ces masses élégantes de fleurs, de fruits et de feuillage tranchant sur un ciel sans nuage! Quelle preuve incontestable de l'immensité des ressources du Créateur, prouvées par la riche variété de couleurs et de formes de ces fleurs du nouveau monde! Les unes se font remarquer par leur coloris, d'autres par leur nombre, quelques-unes par la prodigieuse élévation à laquelle elles savent atteindre en embrassant l'arbre qui les supporte, et de la cime duquel leurs sarmens plongent encore jusques vers la. terre qui les nourrit. La forme des feuilles, la couleur et la saveur parfumée des fruits de cerlaines en rendent l'étude très-intéressante. Je donnexai l'histoire d'une partie dans les classes suivantes; ou je me contenterai de les indiquer lorsque leurs propriétés n'ont pas été suffisamment approuvées. Quis ut Deus? doit être le cri de ravissement au milieu de celte contemplation, un élan naturel du cour atteudri vers l'auteur de ces merveilles.

Caractìres pitrsigues. La Passiflore bleue origi 
naire du Brésil, se trouve aussi aux Antilles, et elle est même acclimatée en France. Ses sarmens sont ronds, glabres, verdâtres, grimpans, triangulaires ì leur partie supérieure. Elles sont pourvues de feuilles alternes assez grandes, vertes, glabres, palmées, à cinq divisions ovales oblongues très-entières sur les bords, et un peu obtuses à leur sommet. Les pétioles. sont glabres et chargés de deux glandes. Il sort de l'aisselle des feuilles, des vrilles qui protégent leur enlacement. Les stipules sont semi-lunaires, à bord extérieur arrondi et entier, mucronées inférieurement par un filet sétacé.

Les pédoncules sont axillaires solitaires, portent chacune une très-belle fleur de trois ou quatre pouces de diamètre, et garnie à sa base d'une collerette de trois follioles ovales, concaves, entières et d'un vert pâle. Le calice est à cinq divisions oblongues, mucronées, verdâtres en dehors, blanc-vert intérieu. rement.

Les pétales sont blancs, alternes avec les divisions du calice qu'ils égalent en grandeur. La couronne est composée de filets nombreux, disposés sur un rang; ils sont moins longs que les pétales; leur som. met jusques vers leur milieu est d'un bleu d'azur, le milieu est blanc, et la base purpurine.

Le fruit est ovoïde, pyriforme, de la grosseur d'une forte prune; l'extérieur est orangé, et l'intérieur contient des graines noirâtres nichées dans une pulpe aqueuse blanche et odorante, d'un goût acide trèsagréable. 


\section{(164)}

Analyse chimique. Le fruit de cette grenadille offre, à l'analyse, de l'acide malique et un principe sucré gommeux.

Propriétús médicinales. On fait avec le fruit de la passiflore bleue, une limonade que recherchent les scorbutiques ; mais il est tant d'autres fruits plus utiles et plus comunément employés, que je crois inutile d'énumérer les propriétés qu'on lui accorde gratuitement.

Mode d'administration. On emploie ce fruik comme celui du Grenadier. (Voy. ci-après.)

Exflication de LA pLANChe tRente-Quatrième*

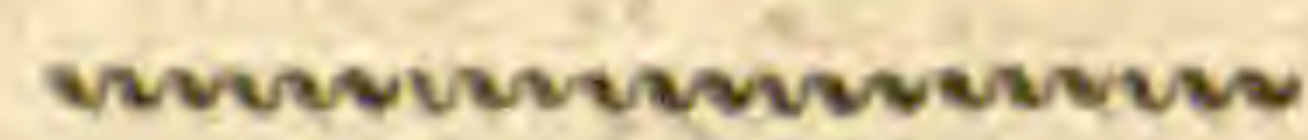

La plante est représentée presque de grandeur naturelle, et les détails à moitié de la leur. 


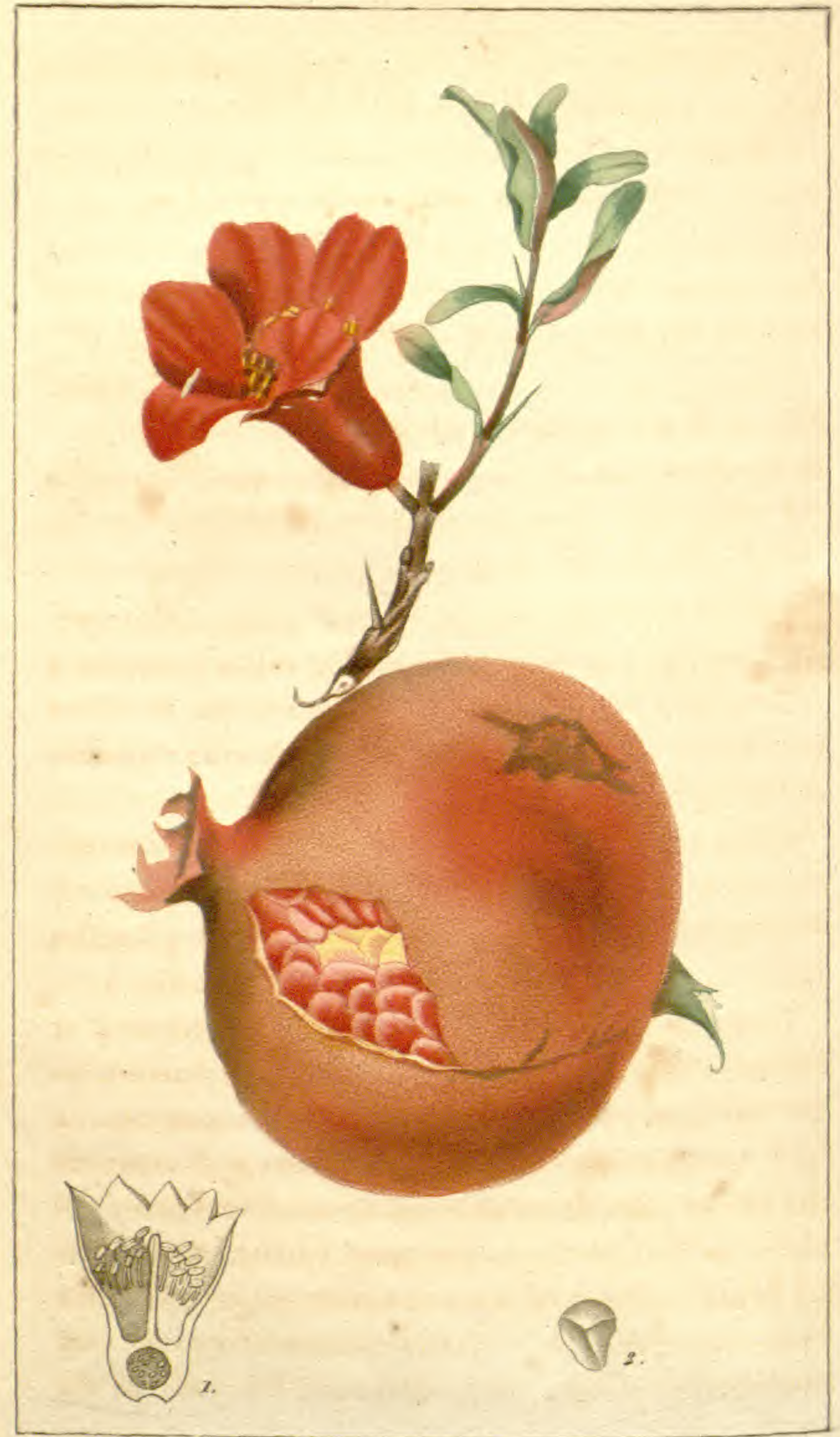

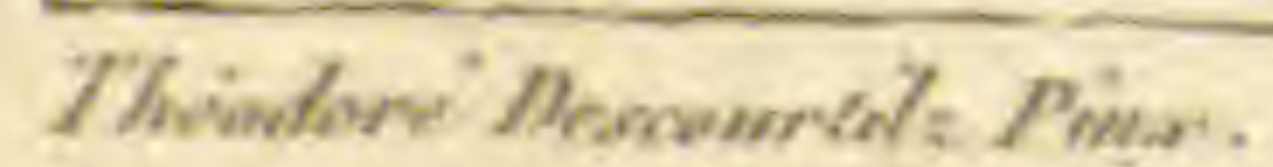




\section{$(165)$}

\section{GRENADIER SAUVAGE.}

(Stomachique anti-scorbutique.)

Sycontmie. Malus punica sylvestris, malus punica sativa, Bauh. awver 438. - Punica granatum, foliis lanceolatis caule arboreo, Lin. icosandrie monogynie. Punica sylvestris, Tournef. clas. 31 arbres rosacés 636. - Juss. sect, 8, fam. des myrthes.

En espagnol Granado, en portugais Romeira, en anglais Pomd-Granate-Tree, Granaat Boom en hollandais ( Fl. du $D$ des Sc, méd.)

Caractères génériques. Calice monophylle; pétal's dèfinis, attachés au sommetdu calice; étamines nombreuses, ovaire inférieur couronné par le calice persistant; fruit multiloculaire polysperme ; graines angüleuses, tiges ligneuses.

Caractères particuliers. Calice campaniforme coloré, à cinq divisions ; corolle à einq pétales crêpus ; étamines nombreuses; un style, un stigma ; feuilles linéaires; tige souligneuse. (Aux Antilles, viv.)

Histome naturelle. Originaire de l'Afrique, et commun aux environs de Carthage, d'où il paraît tirer son nom, le grenadier croît abondamment aux isles Antilles, où il ne fait pas seulement l'ornement des forêts, ses propriétés médicinales le faisant rechercher sous plusieurs rapports. Chargé de ses belles fleurs couleur de feu, cet arbuste offe le plus beau coup d'ceil, et contraste richement avec le vert diversement nuancé du fenillage, et les couleurs du 


\section{(166)}

fruit, qui revêt chaque jour une robe différente, suivant les progrès qu'il fait vers sa maturité; et cette transition graduée dure pendant toute une saison.

Le grenadier sauvage offre deux variétés à mêmes. propriétés, et qui ne diffèrent que par les fleurs plus. on moins grandes, et les fruits doux ou acides.

Le grenadier se multiplie par drageons; il perd ses. épines par la culture.

CAractìn es physiQues. Le grenadier, qui se plaît dans un terrain substantiel et à l'exposition du soleil, s'élève aux Antilles á la hauteur de 15 à 20 pieds. Ses. rameaux sont épineux, anguleux, très-grêles , recouverts, suikant l'âge, d'une écorce brune ou cendrée ; garnis de feuilles étroites, lancéolées, entières, contournéés, opposées, lisses-rouge dans leur jeunesse ; vert foncé ou même souvent brun après leur entier développement; les pétioles courts et rougéâtres.

Les fleurs, d'un rouge éclatant, brillent au sommet des rameaux. Elles sont presque sessiles, ordinairement solitaires, quelquefois cependant groupées en petit nombre.

Le calice est campaniforme, trèšs-coloré,-épais et à einq divisions. Il enveloppe une corbeille composée de cinq pétales ondés et comme chiffonnés, d'un rougede sang. Las étamines sont très-nombreuses, leurs filets sont pourprés et les anthères jaunes. Le style et le stigma sont d'un ronge vif.

Les fruits du grenadier sont sphérqquès, déprimés , ombiliqués, couronnés par le calice persistant, leur écorce coriace, d'un brun pourpré ou ferrugincus, 


\section{$(167)$}

contient une pulpe rosée ou améthyste, douce ou acidule, suivant la variété, et enveloppant, dens plusieurs loges formées par une membrane jaunâtré, des graines nombreuses anguleuses.

Analyse chimique. Les flears du gremadier, connues sous le nom de Balaustes, contiennetre di macilage, du tannin et un principe extractif. Liéconce et la membrane qui recèle les semences et qui est vexdue par les droguistes sous le nom de Malicorium, ont une saveur âcre, astringente, pcu ou point d'odeur, et donnent à l'analyse les mêmes résultats, plus un peu d'huile essentielle. Les unes et les autres colorent en noir, la dissolution de sulfate de fer. La pulpe éontient un peu de mucilage, un principe sucré, du tannin et un acide végétal particulięr.

Propriétés médichnales. Lorsqu'il s'agit d'exciter l'inertie des membranes muqueuses de liestomac ou du canal intestinal, on associe les fleurs ou l'écorce du grenadier aux tisannes astringentes qui conviennent dans les catarrhes ou les dyssenteries atoniques, les ménorrhagies. La pulpe, surtout celle qui est légèrement acidule, est rafraichissante, et sert à confectionner le sirop de grenade, qui est d'un usage trèsrépandu et très utile dans le typhus, la fièvre jaune, et dans toutes les maladies aiguës, inflammatoires des yoies urinaires et les sueurs colliquatives. Dans les mar ladies adynamiques et principalement dans tons les cas d'affection scorbutique, on préfére alors la variété de grenadier à fruit aigre. On peut l'unir a ceux du goyavier et du nonbin pour obtenir une boisson 


\section{(168)}

acide et légèrement astringente, utile à la fin des leucorrhées et des blénorrhagies. On obtient de la formule suivante, un gargarisme détersif très-utilement employé dans les angines muqueuses et les aphtes.

Prenez (dit Poupée-Desportes ) écorce de grenade et de citron, de chacune 3 gros; une demi-poiguée d'oxalide et de cresson; muriate d'ammoniaque, et sulfate d'alumine de chaque un gros; miel deux onces, eau huit onces. Faites infuser et passez avec expression. On ajoute du quinquina s'il y a gangrène.

Mode d'administration. Les fleurs et l'écorce da grenadier, se prescrivent en infusion ou en décoction, à la dose d'une once par livre de liquide, qu'on édulcore avec un sirop approprié. On compose, avec la poudre, des électuaires ou des pilules; et si l'on veut l'employer en substance, la dose est d'un scrupule à un gros dans deux onces de vin; celle du sirop est d'une once par livre d'eau; les graines, quoiqu'astringentes, se mêlent aux émulsions.

La limonade, faite avec une orange âcre, le suc de limon et celui de grenade, édulcorée de sirop de batterie est laxative et rafraîchissante.

La poudre do-l'écorce est aussi employée en topique dans le relâchement des organes génitaux, la chute du vagin ou du rectum.

Ledocteur Pollok assure que les racines sont anthelmintiques. (Gazette de santé, $\mathrm{n}^{\circ}$.34-1816.)

On prépare avec la pulpe de la grenade un vin aromatique et astringent auquel on a donné le nom de vin de Palladius. 


\section{(16́)}

La grenade bien mûre est un fruit sucré et acide dont on ne doit pas abuser, car son usage prolongé doit suspendre les digestions et épuiser, ou même détruire la force digestive. Les cuisiniers et les mầtres d'office en font des sorbets, des glaces, des confitures d'un goût agréable.

Un poëte a dit de la fleur du grenadier:

D'un pinceau lumineux l'astre de la lumière

Anime mes vives couleurs,

Et, régnant sur l'Olympe en sa vaste carrière,

Il me-fait régner sur les fleurs;

Ma pourpre est l'ornement de l'empire de Flore;

Autrefois je brillai sur la tếte des Rois,

Et le rivage More

Fut sujet à mes lois.

Nota. Il y a une autre espèce de grenadier qu'ou nomme grenadier nain, à petits fruits, dont les pommes sont de la grosseur d'une noix. Mais il ressemble tellement à celui-ci, qu'il n'en est pour ainsi dire qu'une variété de taille.

Explication de La planche tTENTE-CINQUì̀me.

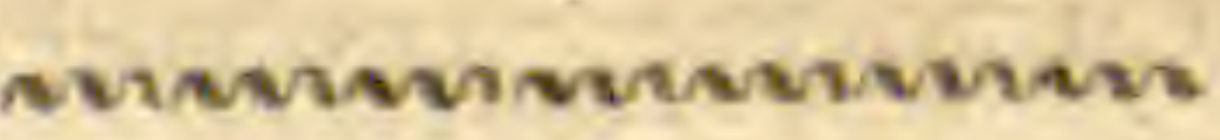

I. Fruit ouvert.

2. Fleur coupée perpendiculairement.

3. Graine. 


\section{$\left(17^{\circ}\right)$}

\section{ANANAS CONIQUE:}

(Stomachique anti-scorbutique.

Sranomyie. Ananas en pain de sucre. - Ananas à couronne de Jérémie ( St.-Dom, ) - Ananas aculeatus maximo fructu conico. Plum. - Bromelia ananas foliis ciliato spinosis, mucronatis, spicâ comosâ, Linn. ord. cl. 6, hexandrie monogynie. - Ananas aculeatus fructu conico, Tournef. appendix. - Class. 3 ord̉re V, fam. des ananas, Jussieu.- Famille 9 les gingembres, Adanson. - Archidops-Ǩ apà-tsjakka. Rheed hort. mal. V. XI, pag. 1 et 2.-Anznas, anana, fayama, pinas, Bout. - Carduus Brasilianus folís aloes, Bauh. pin. 384. - Boniama Car. - En espagnol ananas, pina. - En anglais ananas, pine. - Apple. -

Bromelia, tire son nom de Bromel, botaniste suédois auquel ce genre a été consacré. (Flor. du Dic. des Sc. méd. )

Caractìre générique. Calice persistant à six divisions, les trois internes plus longues; un nectaire au dessus de la base de chacune ; six étamines hastées , plus courtes que le calice; ovaire inférieur; un style filiforme ; un stigma trifide; baies agrégées.

Caractìres particuliers. Feuilles ciliées épineuses, mucronées; épi à chevelure vivace. Fruit conique à couleurs éclatantes. 


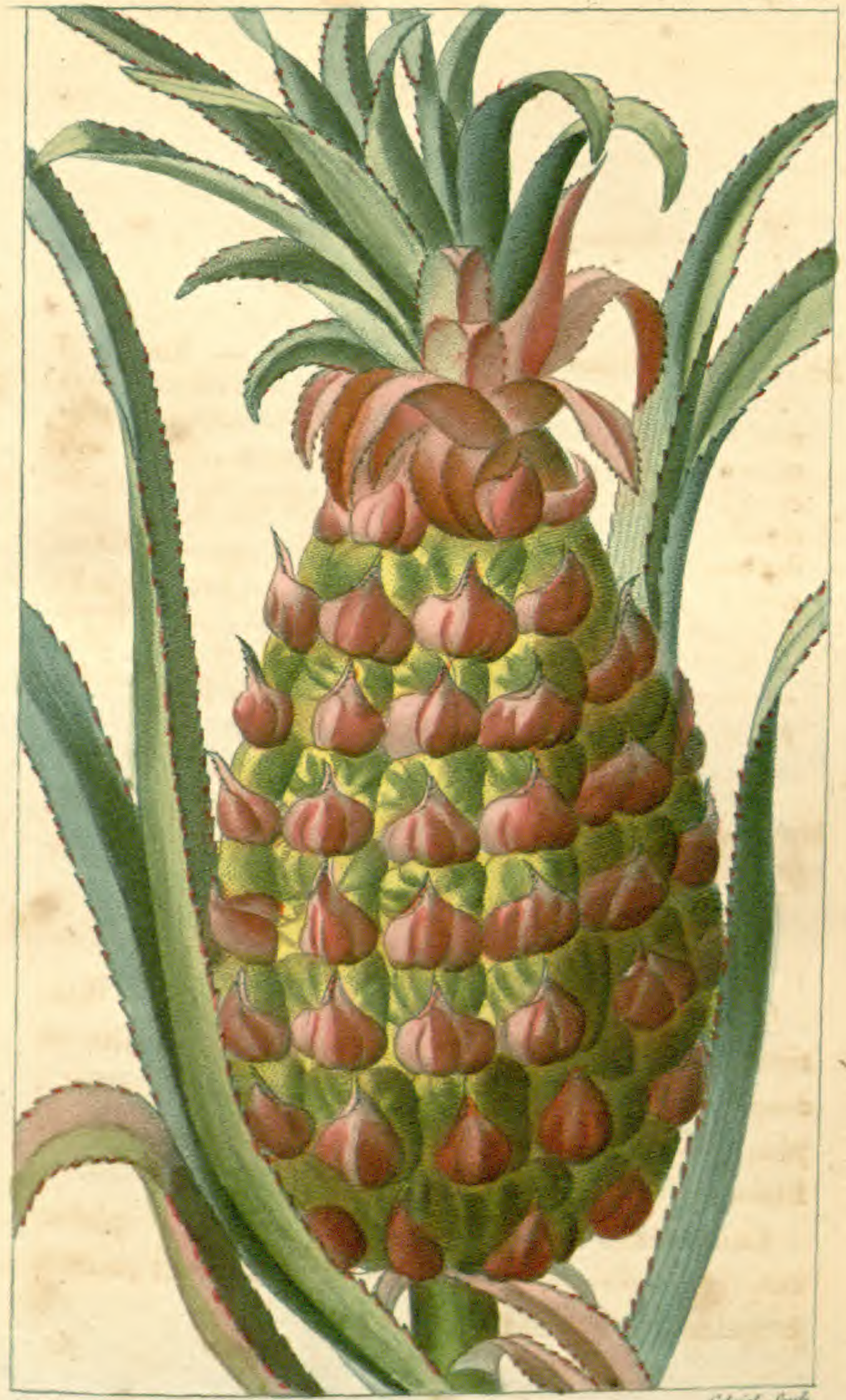

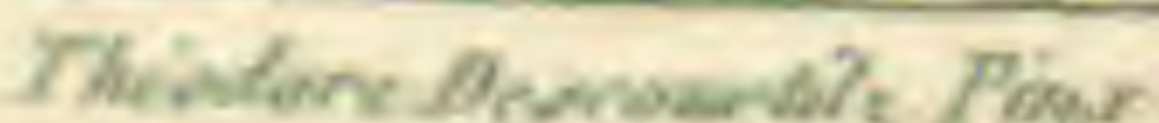

ANANAS CONIQUT. 


\section{(171.)}

Histotre naturelle. L'Ananas conique, vulgairement connu sous le nom d'Ananas-Pain-de-Sucre, en raison de sa forme, croît spontanément aux Antilles dans les savanes humides des bords de la mer; et plus particulièrement sur les mornes escarpés, près des sources ou des cascades ombragées par les hautes futaies que la hache y a respectées. Lequartier de Jérémie, à St.-Domingue, en produit une grande quantité; et leur récolte fournit aux caboteurs une petite branche de commerce avec les villes de l'intérieur de la colonie. Le voyageur fugitif ou égaré, en tranchant l'un de ses fruits, se désaltère, et peut ai-sément continuer sa route, s'il n'en a pas mangé en trop grande quantité, car leur abus trouble la digestion.

L'écorce de cet Ananas n'est point jaune comme celle de celui qui porte ce nom et qui est décrit plus loin. Lienveloppe de l'Ananas conique est verdâtre, nuancée de pourpre, d'orangé et de violet ; on reconnait sa maturité à la vivacité de ses couleurs et au parfum agréable dont s'imprègne l'atmosphère qui entoure le fruit.

Élève avec orgueil sa couronne brillante.

(PARNY.)

Pour manger l'Ananas, il faut le dépouiller de son, écorce et surtout enlever, sous chaque écusson, une pointe très-piquante, reste du style qui s'est desséché, et qui causerait une grande irritation à la gorge 


\section{( 172$)$}

si on ne s'en méfiait pas. On coupe ensuite le fruit part tranches que l'on saupoudre de sucre. On le met aussi macérer dans du vin. On fait avec le suc d' 'Snanas, des glaces, des sorbets, des confitures, des, marmelades, une limonade, un vin excellent; etsurtout des pastilles qui procurent à la bouche une frầcheur agréable et parfumée.

Caracteres physiques. Les feuilles qui partent des racines de la plante sont ouvertes en faisceau, longues de deux pieds environ, étroites, canaliculées, d'un vert glauque comme celles de l'aloës, et hérissées sur les bords d'épines courtes, brunes, aiguës, disposées en scie. Elles environnent une hampe cylindrique cannelée et colorée, feuillée à chaque articulation, courte et portant un épi glomérulé ou réceptacle commun garni de fleurs lilas, sessiles, en entonnoir, disposées au centre des compartimens, sur lesquels les ovaires paraissent à demi-enchassés dans leur pulpes Ces fleurs se fanent et tombent à mesure que le fruit grossit; elles sont quelquefois stériles et dounent alors une semence rouge et applatie.

Le fruit est un réceptacle charnu composé de beaucoup de baies symétriquement disposées, représentant une pomme de pin, et exhalant un parfum d'une odeur particulière. Ce fruit est surmonté d'un faisceau de feuilles courtes qui sert, ainsi que les cilletons, à propager la plante; ces fenilles sont ordiriairement vivement colorées.

La chair de l'Ananas-Pain-de-Sucre est blanche; la coupe transversale représente une étoile ou disque, 


\section{(173)}

dont les rayons déliês divergent du centre à la circonférence.

Si la robe de cet Ananas est colorée avec éclat, son parfnm est aussi plus agréable que celui des autres espèces. Son suc est cependant très-acide ; il agace les dents et fait saigner les gencives : cependant on le mange avec plaisir, car il réunit à la saveur vineuse de la pêche, celles des fraises, des framboises et des melons les plus exquis.

Analyse chimique. Le suc d'Ananas contient de l'acide acétique, de l'albumine, et un principe extractif gommoso-sucré.

Propriétés médicinales. Le sue de l'Ananas à demimûr, est un bon diurétique, et d'un très-grand secours contre les affections de la vessie et la gravelle. On l'emploie utilement en lui associant le fer contre l'ictère et l'hydropisie, et cette préparation remplace anx colonies le malate de fer dans le traitement des atrophies mésentériques.

Le vin que l'on'obtient des Ananas par la fermentation, est agréable et très-rafraîchissant. On coupe à cet effet le fruit par rouelles, et on le met macérer dans de l'eau; quelques - uns lui ajoutent du sucre, à fin de faire développer plus promptement la fermentation vineuse. On obtient alors une liqueur qui a beaucoup de rapport avec le vin de Malvoisie. Il est cordial, détruit les nauosées, et ranime la chaleur naturelle; mais on doit l'interdire aux femmes en ceintes. 


\section{(174)}

La limonade faite avec l'Ananas est très-rafrậehiš sante, et indiquée dans les maladies inflammatoires, bilieuses et adynamiques, dans le typhus et la fièvre jaune, où elle produit d'excellens effets; mais on doit en user avec modération, et la rendre vineuse ou al: coolique, afin d'éviter les inconvéniens que j’ai déjá fait connaître.

Le suc de l'Ananas procure, sans aucun apprêt' un gargarisme détersif, qu'on ne doit pas négliger dans les angines muqueuses, et compliquées de gangrène; il sert alors de véhicule.

Les nègres vantent beaucoup, pour la cure de leurs ulcères atoniques, le digestif suivant: - Prenez suc d'ananas, de feuilles d'agave-karatas, et de celles d'aloës, de chaque deux onces; baume de sucrier une once ; jaune d'œuf, $\mathrm{n}^{0} .1$; taffia, quantité suffisante ; mèlez pour l'usage.

Made d'aDministration. Le suc d'Ananas se donne depuis une once jusqu'à quatre, dans un véhicule aprproprié au genre de la maladie qu'on a à combattre. La dose du vin ne peut être indiquée précisément, puisqu'on en fait souvent usage sans prescription midicale.

\section{EXPLICATION DE IA PLANCHE TRENTE-SIXIÈME:}

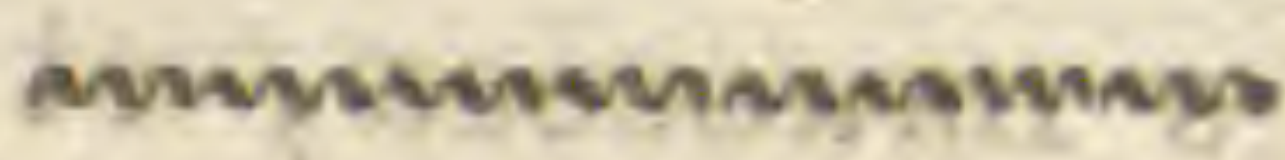

La plante est réduite au quart de sa grandeur? naturelle. 
PI. 37.

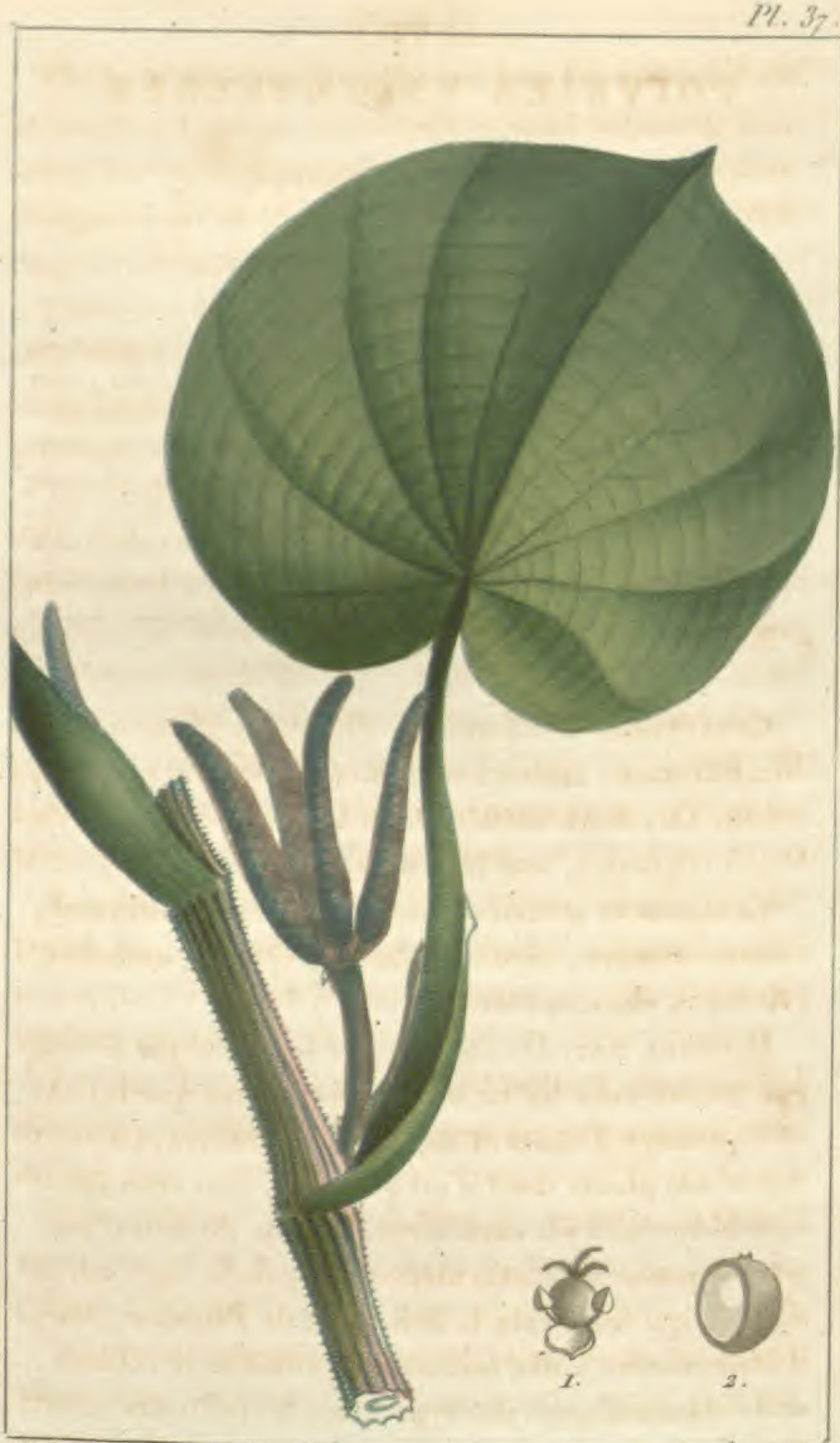

Thiodare Damonordit Pax.

Gixkriel seuthy

\section{POIVTIER A OMBELLES.}


POIVRIER EN OMBELLES:

Tulg. Bois D'A Nisettë.

(Stomachique anti-scorbutiqueb)

Synonxmie. Piper umbellatum. Lin, Diandrie Tryginie.Saururus frutescens foliis cordiformibus et latis, non umbilicatis, anethi odore. Plum. - Saururus foliis amplis orbiculato cordatis, sinu aperto, petiolis vaginantibus. Brwn., Jam., 203. - Piper longum racemosum Sloan., hist. 136.- P'iper fôlinis orbiculato cordatis, acuminatis, venosis, spicis umbellatis, daule ereeto, sulcato, pubescente, Wild. Spec, , plant, , vol, I, p. ${ }^{16} 6$, no. 43.- Jussieu, famille des Orties.-Joborandi, on Bihimitrou des Caraïbes.

Caractères gentériQues. Fleurs en châton, spadice filiforme, couvert de fleurs. Calice, 2 phylles, corolle $\mathrm{O}$, deux anthères à la base de lovaire, style O., 3 stigmates, une baie monosperme: (Lam:)

Ciaractìnes pariculiers. Fenilles cordiformes, commè rondes, aiguës, veinées; épis en ombetles. (Antilles, vivace, Jolycl.)

Histoire naturelle. Lorsque la botanique n'avait pas encore subi les heureux changemens que lui oht fait éprouver d'utiles et sages nomenclatures, on avait donné à la plante dont il est question, sans avoir égard à sa forme et à ses caractérés, le nom de bois d'antisette, parce que cet arbrisseau exhale une odeur d'aneth qui lui a valu la définition de Plumier. Mais. ib était réservé à des bolanistes profonds et éclairés, de le classer d'aprés son type, dans les poivriers, dont il a tous les caractères.

10e. Livraison. 


\section{( $\left.17^{8}\right)$}

On le trouve aux Antilles sur tous les mornes frais et touffus. L'odeur suave qu'il répand autour de lui, attire les regards complaisans qui aiment à admirer l'élégance de sa tige et de tout son ensemble, dont l'aspect est entièrement étranger à l'Européen.

Caractères pHysiQues. Les tiges de ce sous-arbrisseau sont verdâtres, de la hauteur d'un à deux pieds, droites, simples, genouillées, cannelées et légèrement pubescentes.

Les feuilles sont amples, distantes, pétiolées, cordiformes, entières, terminées en pointe, fortement échancrées à leur base, ou à deux lobes rapprochés, quelquefois velues en dessous, marquées de nervures qui s'étendent de la base jusque vers le milieu de la feuille où elles se ramifient. Les pétioles sont longs, glâbres, cylindriques, amplexicaules, et munis, à leur base, d'une gaine ou large membrane où l'épỉ se. trouve enfermé avant linflorescence.

Les épis sont axillaires, blanchâtres, au nombre de trois à six, disposés en ombelle, médiocrement pedi-) culés, portés sur un pédonculé commun, droit, et de couleur blanche.

Les écailles de chaque fleur (calice) sont arron-I dies, un peu ciliées, et paraissent un peu tomenteuses à l'œil nu.

Les anthères sont blanchâtres, l'ovaire oblong, surmonté de 3 stigmates épais, rétléchis, noirâtresse (Encycl. méth. T. V.p. 464.)

Analyse chimique. Toutes les parties de la planted: sont âcres et stimulantes, et il s'en développe in arôme, dont jusqu'ici l'utilité n'a point été appréciée. 
On retire de sés graines une huile essentielle qui a les propriétés de celle d'anis.

Propriétés médicinales. On prescrit l'huile essentielle des graines sur un morceau de sucre, dans les atonies de l'estomac qu'épronvent les scorbutiques à tempérament lymphatique; tandis que ce même moyen pourrait exciter les plus grands désordres dans les mêmes circonstances chez un individu robuste, pléthorique, et doué d'une sensibilité nerveuse irritable. Son usage inconsidéré occasionnerait des maladies inflammatoires. Le moyen le plus sûr est de l'employer en décoction ou en macération. vineuse. C'est de cette manière qu'on en retire beaucoup d'avantages, et que je le prescrivais dans les hôpitaux des colonies, d'après la formule de Poupée Desportes, à laquelle je faisais subir un léger changement. Par exemple, les scorbutiques éprouvaient du soulagement d'une tisanne composée avec gingembre, un gros; une orange sure coupée par rouelles, des bourgeons de bois d'anisette, une poignée; un gros de limaille de fer en nouet, pour deux pintes de vin.

Dans les douleurs pungitives qu'éprouvent les malades dans la péripneumonie, je faisais appliquer, au lieu de moutarde, de la poudre des graines du Poivrier à ombelles, incorporée avec du blanc d'ouf, qu'on étendait sur du coton pour en faire une espèce de cataplasme. Ce même topique procurait du soulagement dans les douleurs rhumatismales. Cette poudre dissipe le relâchement de la luette par atonie; elle est aussi odontalgique, sternutatoire et rubéfiante, comms tous les aromates de ce genre. 


\section{( 1880$)$}

Mone d'abminastrintion. La dose de lihuile essentielle est de 4 à 8 gouttes; celle de la poudre des graimes, d'un serupulé à un grøs; celle des feuilles et des bourgeons, d'une poignée par pinte de liquide.

EXPLICATION DE LA PIANCHE TRENTE-SEPTIÈME,

Ze Poiprier à Ombelle est représentél au tiers de sa grandeur naturelle.

Fig. I. Fleur eńtière grossié. On y distingue deux écailles calicinales, deux anthères supportees par des filets dont l'insertion est aux deux côtés opposés de l'ovaire. Cehuici, globuleux supporte trois stigmates réfléchỉs.

Fig. II. Graine grossie. Une partie de son enveleppe corticale a été enlevée afin de mettre à jour la sémence mique qu'elle contient.

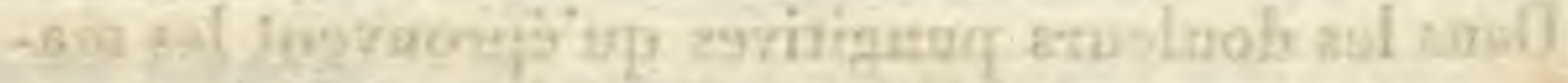

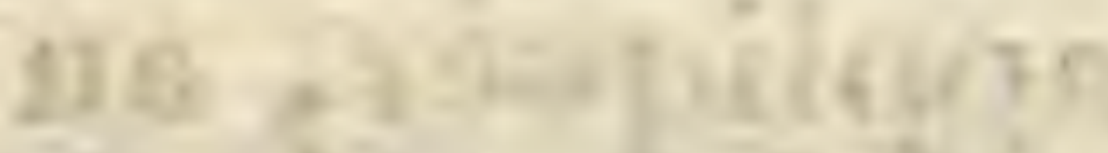

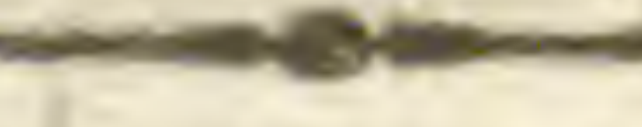

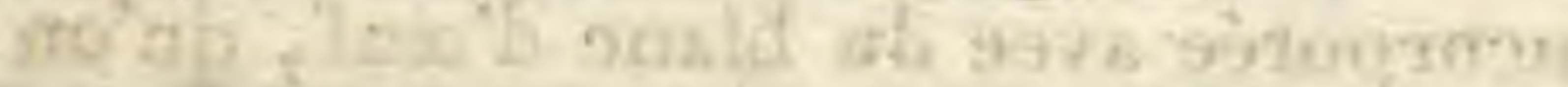

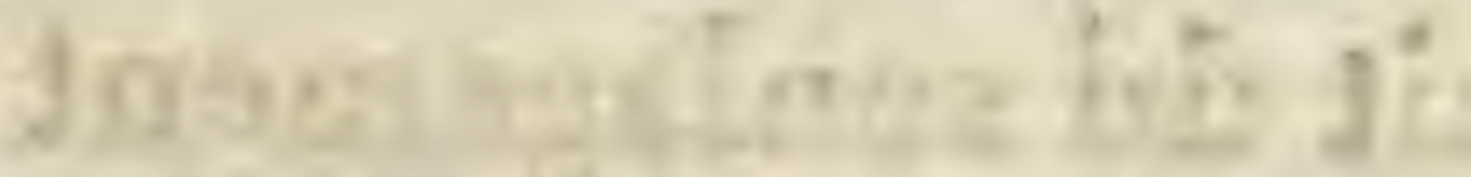

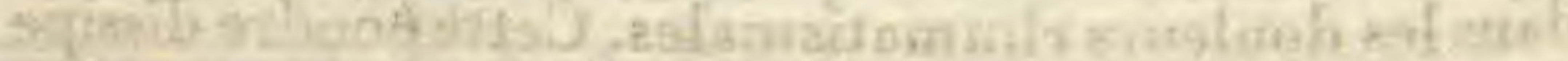

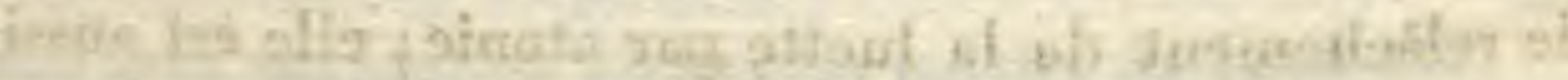

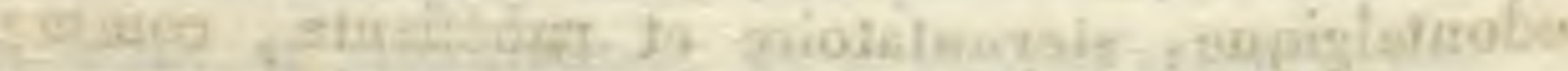


PI. 38 .

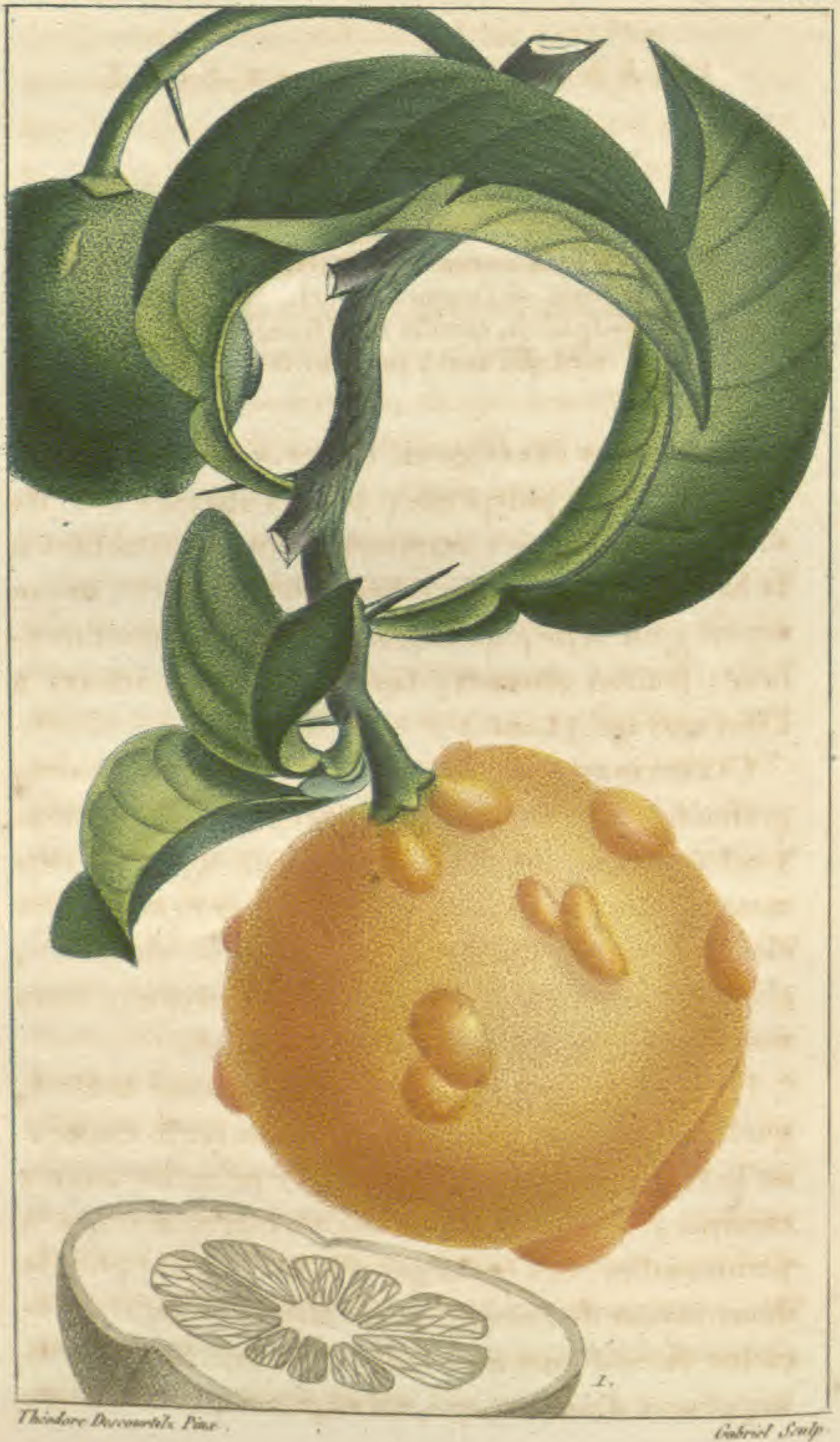

\section{ORAFGER ACHE.}




\section{ORANGER ÀCRE ov SURE。}

(Stomachique anti-scorbutique.)

Srnonyare. Citrus aurantium sylvestre. Lin. Polyadelphie icosandrie.-Tournefort, cl. 2l, arbres rosacès: sect. VI.-Jussieu, famille des Orangers. - Aurantium sylvestre, meduHâ acri, inst. k. tr.

Caractéres génériques. Calice monophylle multifide; corolle polypétale; pétalés alternes avee les. divisions du calice; étamines définies, attachées á Ta base des divisions du calice; flets distincts; ovaire supère; un style, un stigmate; une baie multifocnTaire; feuilles alternes, tiges ligneuses spinifères $\dot{a}$ Tétat sauvage-(Lam.)

Caractêres particulters. Galice à cinq divisions. profondes; corolles a cinq pétales elliptiques; environ vingt étamines ; filets comprimés; un style; un stigmate en tête; baie charnue, divisée par neuf ou onze cloisons, receuverte d'une écorce aurore chagrinée, glanduleuse et mamelonmée; graines ovoides; loges vésiculeuses; pétioles ailés; fenilles aiguës.

Histotre anterelle, Sous un ciel aussi brûlant, quelle surprise agréable doivent éprouver le chassent ou le botaniste, en escaladant avec peine les morres escarpés, s'ils découvient des Orangers sauvag̨es à pommes d'or. Ces fruits qui n'ont cependant point la douce saveur de P'orange de la Chine, étanchent néanmoins $4 a$ soif ardente; tempèrent les mouvemens. impétueux d'un sang qui, en augmentant Pexaltation. 


\section{$(182)$}

des forces vitales, porte le trouble dans tous les sens; donnent des palpitations, et occasionnent des syncopes que le changement subit de température doit faire présumer. Ils se repaissent avee délice de ces fruits acides et désaltérans; et le chasseur, oubliant sa cruautế pour contenter un besoin, environné de râmiers qui le guettent et veulent lui disputer leur nourriture, il les appaise en leur jetant les pépins dont ils sont très-friands, et qui rendent leur chair exquise. On trouve constamment ces oiseaux occupés à entamer les oranges à grands coups de bec, jusqu'à ce qu'ils soient parvenus au centre du fruit.

Les cuisiniers Américains ont toujours l'orange sure à la main pour en assaisonner leurs ragoûts, et surtout les gros houillons pimentés au poisson: et les nègres valets de chambre, coupant les fruits par moitié, et frottant avec, les chaussures de leur maître, puis recommençant ensuite à frotter avec une feuille de ricin légèrement chauffée, obtiennent avec la brosse un cirage du plus beau vernis.

Garactìres pirysigues. L'arbre toujours vert qui produit les oranges douces, à̀ peu près la même forme, et ne diffère que par celle des fruits. Je renvoie danc pour la description des parties de l'oranger à l'article oranger-doux (cl. des antispasmod.). Il me suffira d'observer seulement que les feuilles sont également à pétioles âllés, mais plus larges et souvent contournées; que les fruits ont une écorce (ou zeste) grossière, rougeátre, plus rude, et garnie de protubérances; quo ce zeste est très-épais, et la pulpe peu volumineuse, et d'une saveur très-acide. 


\section{( 183 )}

Anal yse chimique. Les feuilles de l'oranger à fruit: âcre, ont une saveur amère, et fournissent une huile volatile et un principe extractif. Les fleurs, d'une odeur plus suave, donnent une huile essentielle et un principe muqueux. La pulpe contient de l'acide citriqué. On obtient da zesté une huile vólatile jaune, et de l'extractif amer.

Proprítés médicinales. Les fleurs, justement réputées anti spasmodiques, conviennent dans les coliques nerveuses, dansl'hystérie, la cardialgie et les maladies convulsires. Les feuilles sont employées, comme tonique amer, dans certaines névroses, et dans l'atoniedu système digestif. Les fruits, coupés par tranches, réunis aux tamarins, fournissent un bon laxatif. La pulpe de ces fruits, roulée dans du sucre, et mangée à jeun, est utiłe aux tempéramens bilieux et sanguins, et surtout aux scorbutiques.

Mode o'administration. II serait superflu d'indiquer la manière de procéder aux préparations qu'on. fait avec les oranges sures, parce qu'étant journellement employées, elles sont toutes connues. Cependant en conseillant au jeune médecin qui se destine aux Antilles, d'y mettre à profit les ressources végétales. que la nature se plaît à lui offrir, je dois l'engager à préférer les móthodes les plus simples et les plus usitées, celles enfin, dont l'expérience couronne les succès, afin d'éviter, sous ce ciel brûlant, les abus d'un traitement perturbateur qui y contrarie les effets de la nature. Je répéterai seulement au bon habitant et propriétaire qui possédera ce lirre, que l'ean distillée des fleurs se donne à la dose d'une ou deuxcuille- 


\section{(184)}

rêes, et forme la base des potions antispasmodiques: L'écorce amère et aromatique s'emploie en infusion aqueuse, en teinture, en poudre ou en conserve, pour stimuler les fibres de l'estomac et des intestins. On voit, d'après l'anal yse des parties constituantęs des fleurs, feuilles et fruits, qu'ils doivent être d'une grande utilité dans les maladies scorbutiques.

Explication de IA PLANCHE TRENTE-HUITIÈME.

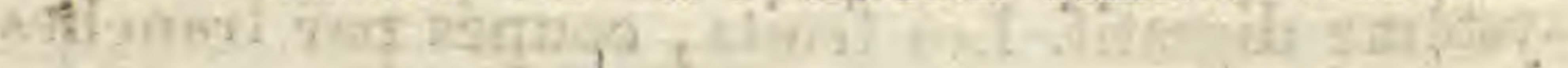

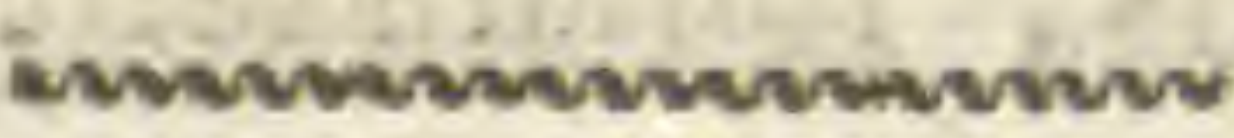

Le rameau d'oranger acre chargé d'un fruit mwr. est de demi-grandeur naturelle.

20 ' 1 . Fruit coppé transversalement. Inthereys

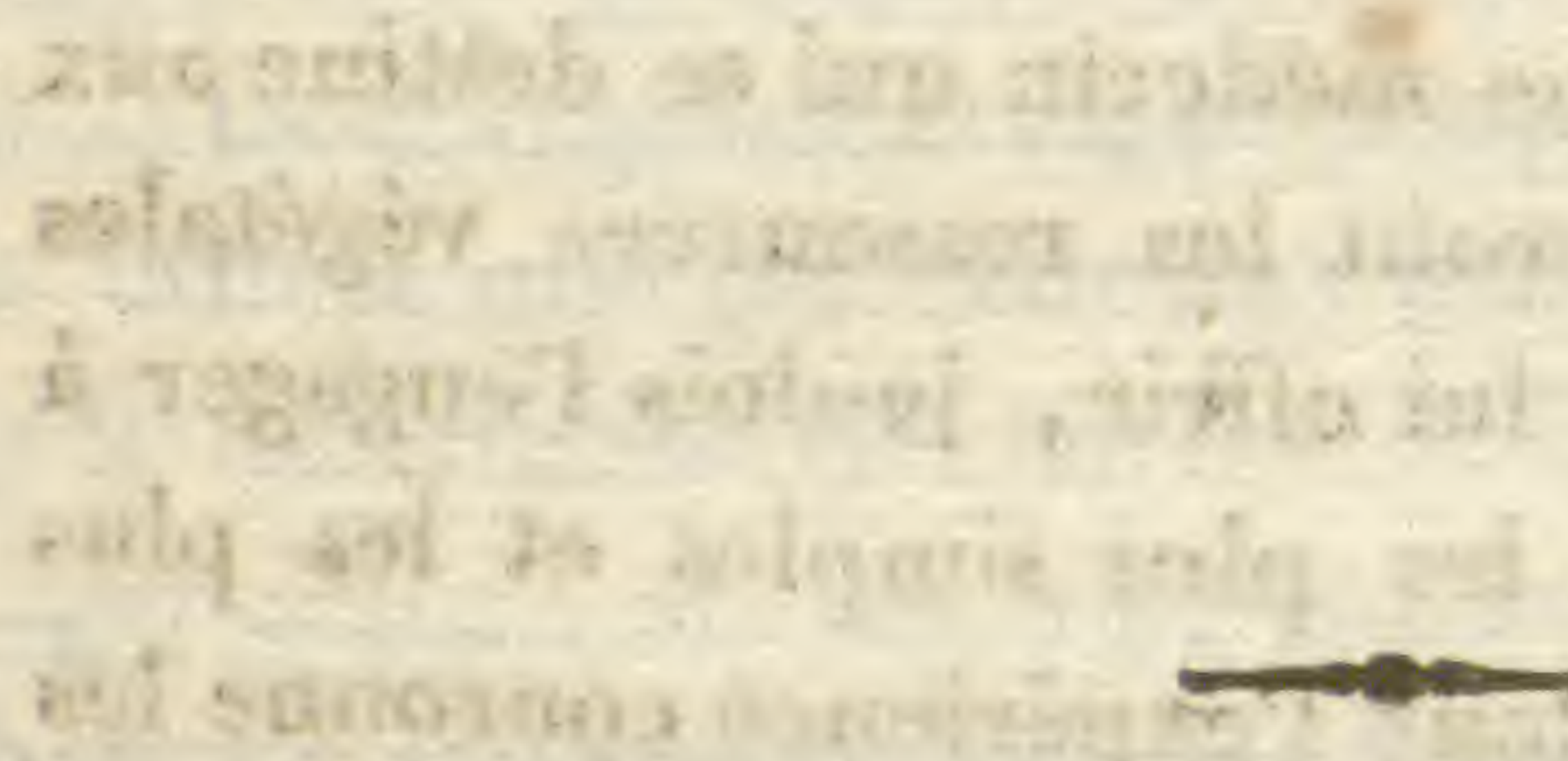

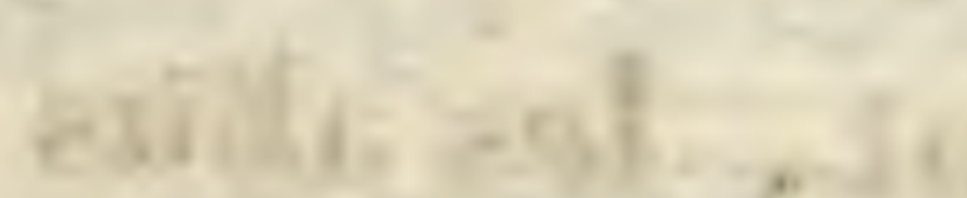




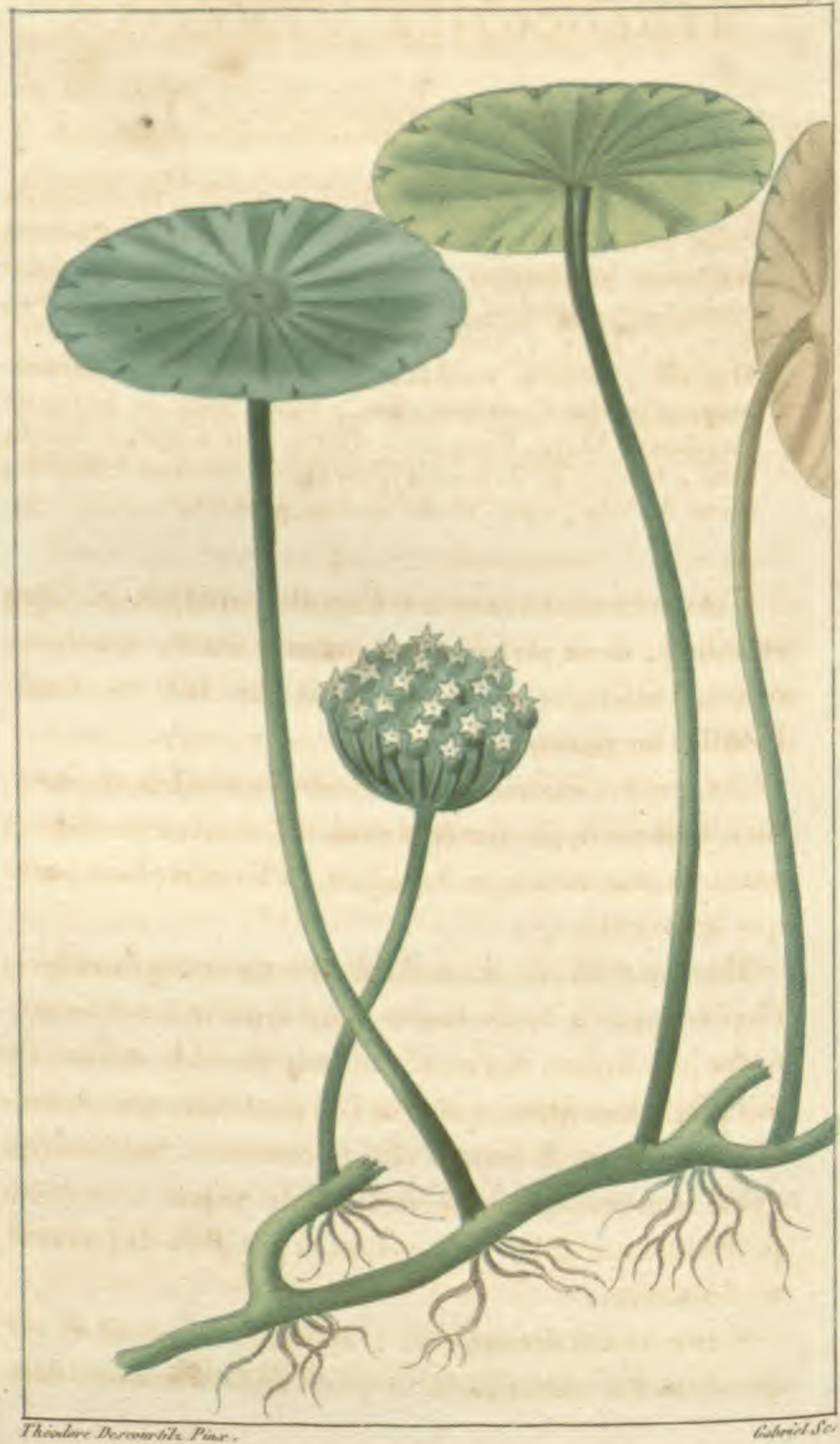

HYYT ROCOTILE OMBHELÉE. 
HYDROCOTILE A OMBELLE.

(Stomachique anti-scorbutique.)

SxNonymie. Hydrocotile umbellata, Lin.-Hydrocotile foliis peltatis, umbellarum radiis numerosis floseulis multoties longiorihus, , N.-Hydrocotile maxima, folio umbilicato, floribus in umbellam nascentibus. Plum., Spec. 7, Miss. 4, tom. 3. - Tournefort 328, cl. VII, Ombell., sect. 9. - Jussieu, fam. des ombellifêresacaricolia des Caraïbes. Pis., Bras. 260. - Erva de Capitaon. Marg. Bras. 27.-Cotyledon aquatica Sloan, fam., his. 1, p. 312.-Hydrocotile, suivant Lamark,

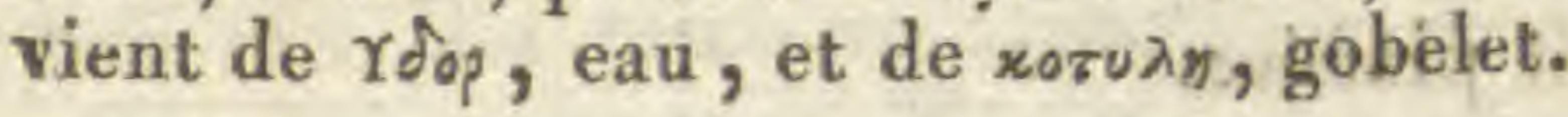

Caractèries génériques. Corolle pentapétale. Cinq étamines, deux styles, deux graines nues, accolées, ovoïdes inférieurement, souvent de bas en haut. Feuilles en parasol.

Caractíres pariticuliens، Ombelle multiflore, involucretrès-petit, gxainescompriméés; semi-orbiculaires; feuilles orbiculaires en bouclier, la hampe plus courte que les feuilles.

Histoire naturelle. Amie des savannes inondées, l'hydrocotile à ombelles se plait ainsi que ses congenères, au milien des eaux, où son humble stature l'y fait peu remarquer, quoique son port offre un ensemble intéressant de formes peu communes. Ses feuilles ayant une surface plane servent de repos à certains petits oiseaux qui y sont balancés, et d'où ils peuvent se désaltérer.

Caractieres physreurs. L'Hydrecotile dont il est question est une plante le plus ordinairement flot- 


\section{(186)}

tante, que ses feuilles rondes et petites font remarquér. On ne peut mieux les comparer qu'à celles de la eapucine.

Les tiges sont menues, rampantes, et poussent à chaque articulation de petites racines fibreuses.

Les feuilles sont orbiculaires, crénelées dans leur contours par de larges dents, coupées carrément à Jeur sommet, fixées à leur surface inférieure sur de Jongs petioles qui prennent leur insertion au centre, garnies de nervures qui s'étendent de l'insertion du petiole à la circonférence, et d'autres plus petites et obliquement placées.

Les hampes sont axillaires, plus courtes que les pétiołes, chaque hampe supporte à son sommet une onbelle composée d'une vingtaine de fleurs, enveloppées par des rayons beaucoup plus longs qu'elle; chaque fleur. est stelliforme, composée de cinq pétales d'un blanc pur; la corolle contient cinq étamines.

L'ovaire chargé de deux styles devient un fruit composé de deux maitiés accolées, comprimées s's s'ouvrant de bas en haut et renfermant deux graines nues.

Analyse chimeve. La racine de l'Hydrocotile à ombelle est aromatique, piquante et chaude à la dégustation. Elle fournit à Vanalyse une huile essentielle très-adorante, l'extrait aqueux est amer, et contient peu d'arôme, dont s'empare l'alcool lorsqu'on lés y met en digestion. Les tiges sont âcres et d'une odeur volatile.

Propriétés médicinales. Les racines qui ont l'adeur de celles du persil, sont apéritives et conviennent dans les obstructions des reins et du foie. On les. 


\section{$(187)$}

mêle aux tisanes anti-scorbutiques aromatiques. On fait confire les racines, et on les ordonne comme masticatoires; leur yertu cordiale et tonique les rend recommandables dans le catarrhe pulmonaire ave prédominance d'atonie. Les feuilles sont rarement employées; on leur préfère, sous tous les rapports, les tiges des cressons de savanes, dont il est question plus bas, et dont les propriétés sont incontestables. "

Mode d'administration. En raison des vertus héroiques de l'Hydrocotile, nous engageons les jeunes praticiens à n'employer cette plante qu'avec réserve et prudence. La teinture alcoolique se donne à la dose d'un gros par livre de véhicule, et d'une once en décoction, ou bien à celle d'un gros en poudre dans du vin.

Nota. On trouve aux Antilles deux autres espèces d'Hydrocotile, dont les vertus ne sont point éprouvées; je me contenterai de les indiquer ici:

1. Hydrocotile à épi. Hydrocotile spicata. (Commune à Saint-Domingue. Cuba,)

12. Hydrocotile droite. Hydrocotile erecta. (Jamaïque.)

Explication de la planche trente-Neuvième.

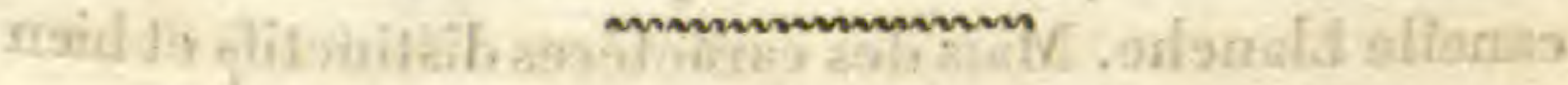

La plante est réduite à moitié de grandeur naturelle.

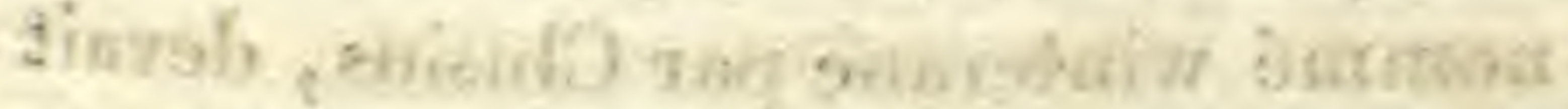




\section{DRY MIS AROMATIQUE. Vulg. ECORCE dE WiNTER.}

(Stomachique anti-scorbutique.)

Srnonymie. Ecorce de Caryocostin.-Drymis Winteri, L. F. Drymis peduneulis aggregatis, terminalibus, pistillis quatuor, L. F., suppl. 26\%.-Drymis Forsteri. Mutis. - Peryclimenum rectum, foliis laurinis, cortice aromatico acri. Sloan. Act. Angl. - Laurifolia magellanica cortice acri. Bauh., Pin. 461_-Cortex Winteranus. Olus, , eyot, 75 - Boigne cinnamomifera oliva fructu. Sloan. - Feuil. observ, vol. 3, p. 10, tab.6, fam. des Anones. Juss., Lamark.

Carractères génériques. Calice inférieur monophille à trois divisions. Six à douze pétales ouverts, étamines nombreuses à anthères didymes et épaissies. au sommet. Quatre à huit ovaires ovö̈des, point de style. Stigmate unique applati. Quatre à huit baies sessiles uniloculaires, contenant chacune quatre semences.

Caractères particuliers. Corolle à six pétales, étamines indéfinis. Quatre avaires sessiles. Stigmate épais situé sur le côté.

Histoire naturelie. On a pendant long-temps confondu le Drymis aromatique avec la winterane, canelle blanche. Mais des caractères distinctifs et bien tranchés ne permettent plus de s'y méprendre, en. confrontant les diverses parties de la plante.

Le Drymis, nommé winterane par Clusius, devait son nom au capitaine Winter, dont il consacrait le 
PL. 40.

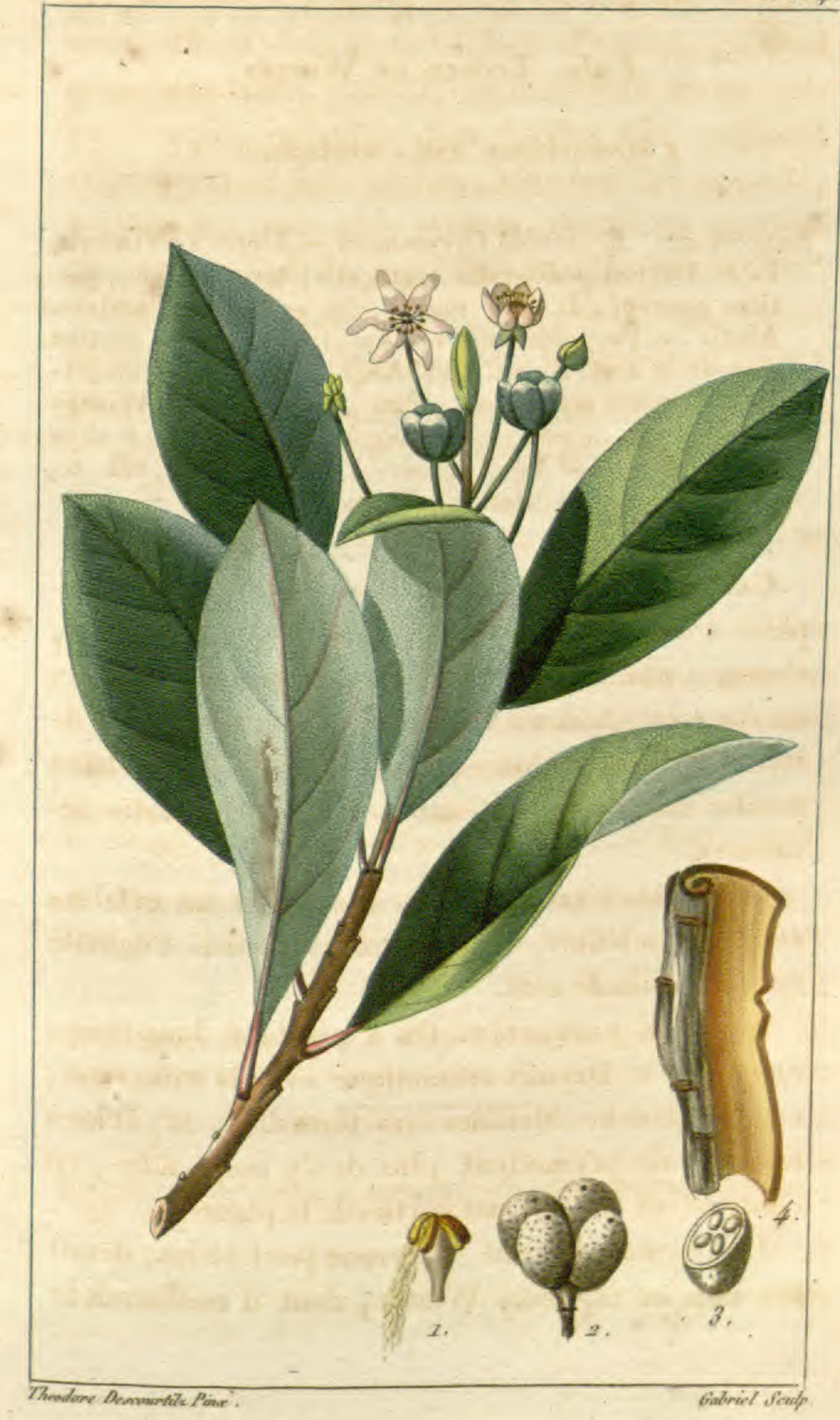

DRYMIS AROMATIOUE. 
souvenir, ef quile premier, le découvrit èn 4579 , au détroit de Magellan d'où il l'apporta en Angleterre.

L'étude de cet arbre curieux et intéressant a depuis fixé l'attention des Banks, dès Forster, Fothergill et autres célèbres médecins botanistes.

Caractères physiques. L'arbre conmu sous le nom de Drymis aromatique est d'une assez haute stature, d'un feuillage toujours vert, et se plaît particulièrement dans les lieux bas que le soleil éclaire.

Son écorce, connue dans le commerce, sous le nom de Caryocostin' s'y présente sous forme de fragmens roulés ou applatis, épais et spongieux, lisses, d'un jaune canelle au-dedans, et d'un gris de cendre à l'extérieur; cette dernièrề surface est inégale et rabotẹuse, ou , plutôt, couverte de stries vermiculaires longitudinales, et de saillies transversales et régulières? distantes.

Les feuilles sont nombreuses, éparses, quelquefoin alternes sur les jeunes raméanx, ovales laneéolées, très cntières et ayant de grands rapports aveo cellest du laurier.

Les fleurs viennent à l'extrémité des rameaux. Les pédoncules y naissent plusieurs ensemblè en faisceau; chacun porte une seule fleur dont la corolle offre six pétales d'un blanc pur, souvent teint de pourpre.

Lés étamines ont leurs filets épaissis àl'extrémité, et des anthères didymes à extrémité offrant la réunion des deux lobes qui les compósent; elles sonts nombreuses et jaunes.

A la ehûte de la corolle succède un frúit composé de quatre oyaires sèssiles, qui dans leur paxfait déke-b 


\section{$(190)$}

loppement, forment quatre baies ovoildes, brunâtres, pointillées au sommet, et un peu sur le côtế, où l'on aperçoit l'insertion du stigmate qui y paraît comme un point enfoncé.

Chaque baie contient dans une seule loge quatre semences ovoides noires et luisantes.

ANAlyse chymiene. Le Drymis aromatique se troues vant assez communément à St.-Domingue, j'ai eu occasion d'en soumettre à la distillation, et j'ai obtenu une eau aromatique, surmontée d'une très-petite quantité d'huile essentielle, d'une odeur très-suave et très-penétrante.

Propieiétés médiciantes. Le docteur Alibert nous confirme que dans le vaisseau du capitaine WV inter, et plus tard en 1600 , Jorsque la flotte commandée pavi l'amiral Van-Noort revint du détroit de Magellan, $b$ on eut souvent recours á cette écorcé pour assaisonner les mets et combatire les ravages du scorbut. Sil m'est permis de citer ma propre expérience, i'accor-: derai les plus grands éloges à ses propriétés, dans l'emploi que j'en ai fait au milieu des hôpitaux de St.-Marc et du Port-au-Prince ( ille St.-Domingne). Une poignée de cresson de Savannes, un gros d'écorcés de Drymis et une orarige sure par pinte d'eau, próetraient aux scorbutiques une tisanne salutaire dont ils éprouvaient les meilleurs effets. Quelques gonttes des son huile essentielle dans une limonade, composaient une boisson encore plus agréable.

Enfin cette écorcé convient dans tous les cas oùl'on doit recourir aux substanices aromatiques. 


\section{(191)}

Les habitans du détroit de Magellan, dit Valmonts Bomare, sont toujours munis de cette écorce sans pareille, dont ils font usage comme antidote lorsqu'il ont mangé de la chair du lion marin, qu'on regarde comme vénéneuse. Suivant Greoffroy elle est aussi sudorifique et employée avec succès dans la paralysie et les catharres.

Propriétés particulières. Cette écorce, essentiellement aromatique, a le parfum des clous de giroffle, et à la dégustation offre une saveur âcre et piquante qui se rapproche de celle du poivre. On la confit dans la verdeur, et elle sert alors de condiment dans les ragohts.

En Europe, où elle est fort rare, des droguistes peu assortis la remplacent ou la sophistiquent avec l'écorce du winterania, canelle blanche.

Mode d'administration. La dose de l'écorce de Drymis en poudre, est de deux grammes (ou demigros) en substance, ou malaxée avec le miel, sous forme d'électuaire. Celle de l'huile essentielle, de 3 à 8 gouttes sur un morcean de sucre, ou dans un véhicule approprié à la nature de la maladie. Les fleurs s'ordonnent par pincée dans une liyre d'eau bouillante. 


\section{Explication DE LA PLANCHE QUARANIIÈME.}

Q.

1. Ovaire surmonté des étamines.

siiz. Ovaires vus à la lonpe.

3. Ovaire coupé transversalement.

4. Ecorce du Drymis.

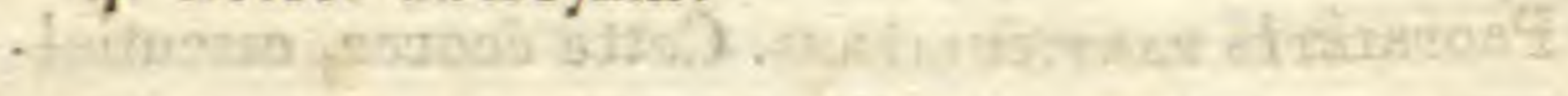

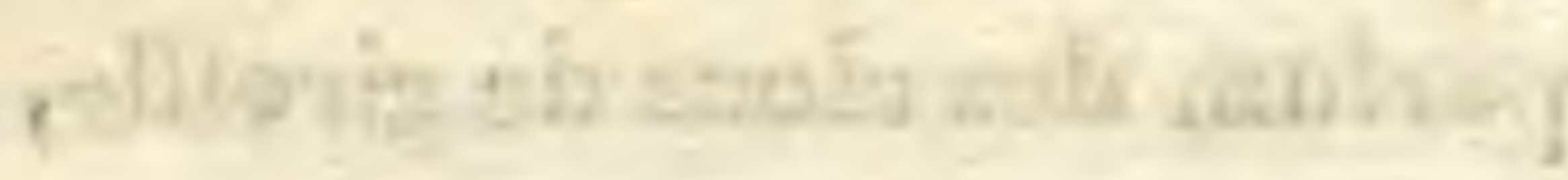

shoof

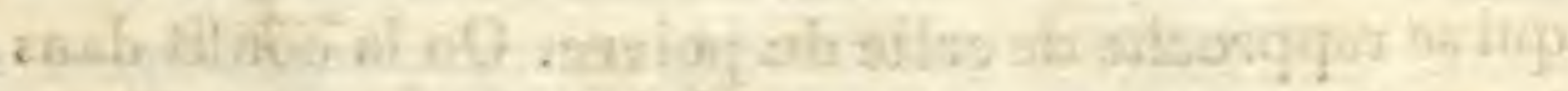

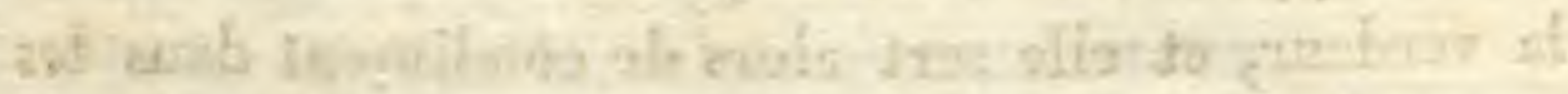

.elitgong

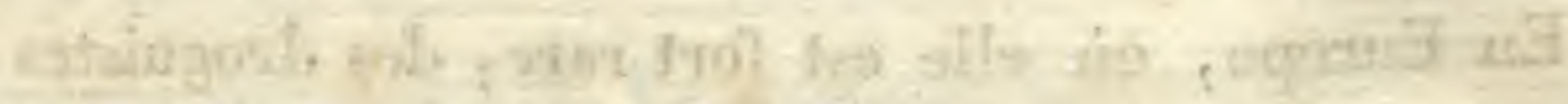

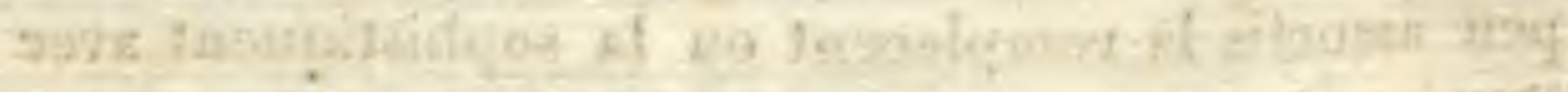

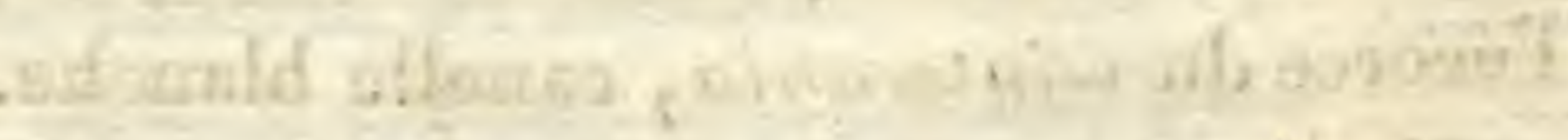

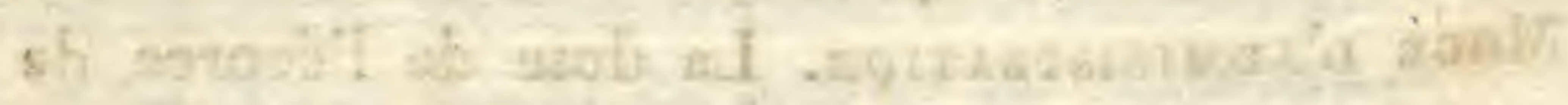

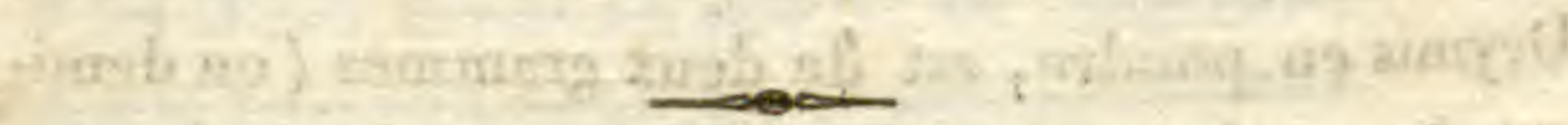

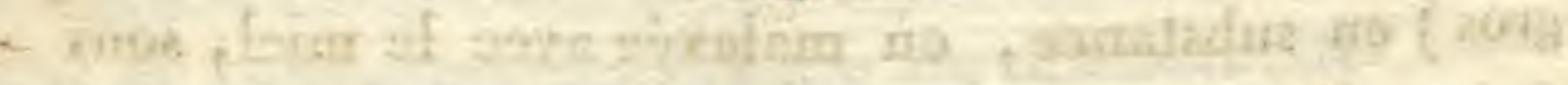

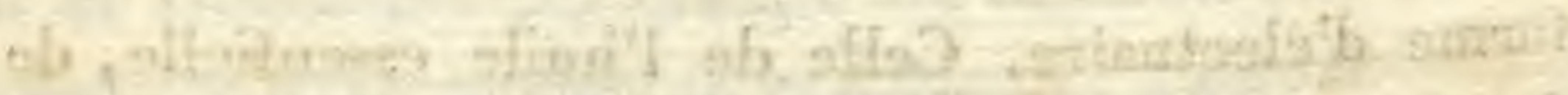

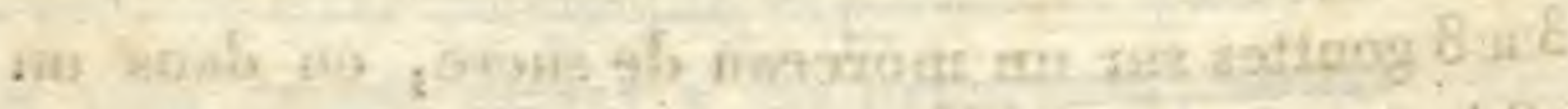

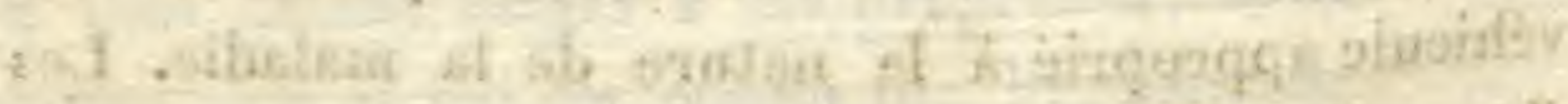

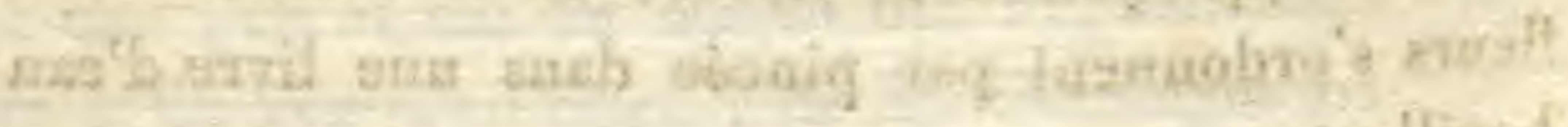



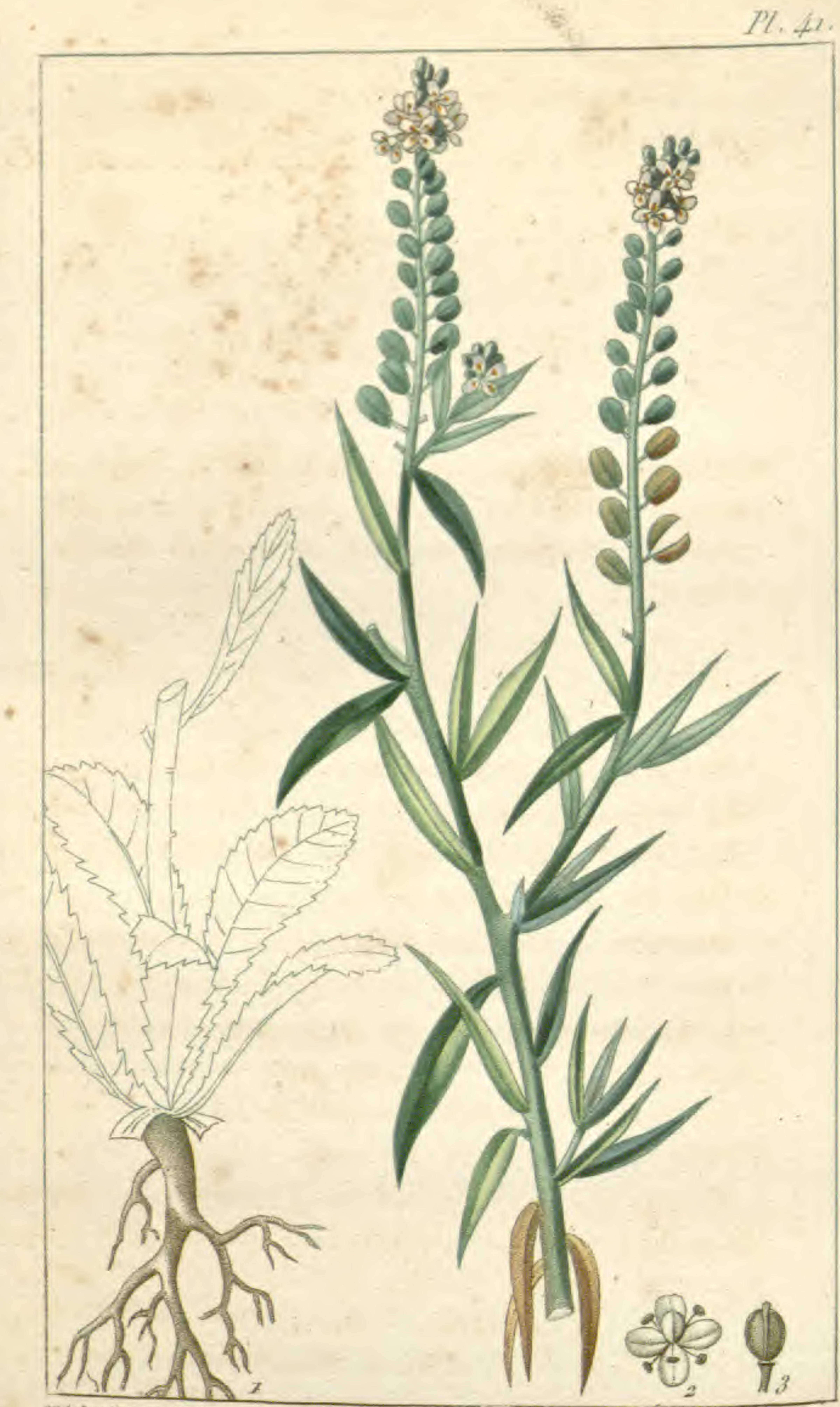

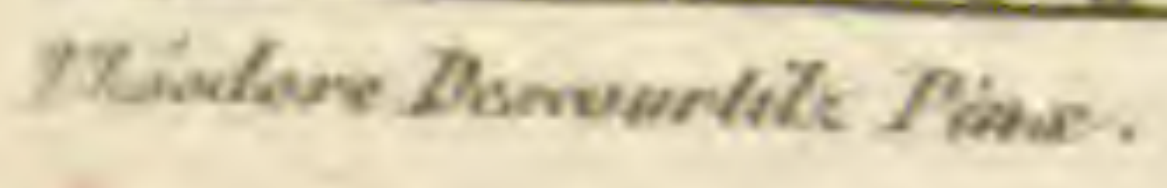

Gubriet foulport.

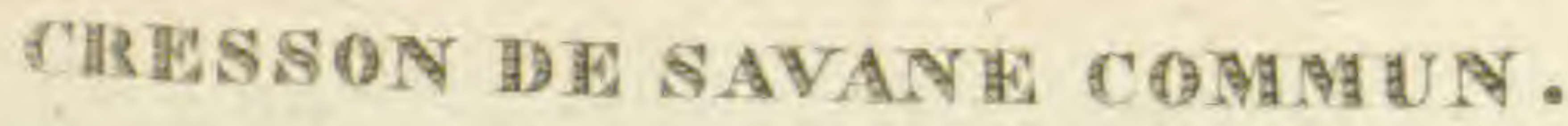




\section{$\left(10^{3}\right)$}

\section{GRESSON DE SAVANE GOMMUN.}

(Stomachique Anti-Scorbutique.)

Srrovyme Lepidium iberis, Lin. tetradynamie siliculeuse.Conysa linariæ folio, Poupée-Desportes.-Tournefort, clas. V, Crucifères, sect. II. - Jussieu, famille des Crucifères.

Caractères genériques. Silicule émarginée; cordiforme, polysperme, valvules carénées, contraires. .

Caragtimes particuliers. Fleurs diandriques, quatre pétales; feuilles inférieures lancéolées dentées en scie, les supérieures linéaires très-entières. (Ann. Jolycl. )

Histoire naturelle. Le cresson de savane commun croît aux Antilles, sur le bord des eaux, dans les savanes humides, et y sert de pâture aux canards de toute espèce dont on trouve une énorme quantité; toute la plante a une forte odeur de cresson et en a les propriélés.

Garactéres physigét. La racine du cresson de savane commun est pivotante, rameuse, sousligneuse. "

La tige est cylindrique, roide, droite, de la hauteur de deux pieds environ, rameuse à sa partie su périeure.

$11^{\mathrm{e}}$. Livraison. 


\section{( 194 )}

Les feuilles radicales sont spatulées, dentées dans tout leur contour, quelquefois en lyre : les feuilles de la tige sont linéaires, et les unes et les autres sont glabres.

Les fleurs sont jaunâtres, quelquefois d'un blanc pur : la corolle est composée de quatre pétales disposés en croix ; elles sont placées en grappes droites et terminales.

Les fleurs, à leur chûte, sont remplacées par des silicules courtes, ovales, divisées dans leur longueur, et s'ouvrant de haut en bas. Les valves, carénées sur le dos, contiennent plusieurs semences, ovales et trèsmenues. Ces silicules, d'abord d'un vert glauque, deviennent, par suite, jaune paille, et enfin rougeâtres.

Analyse chimeve. Le cresson de savane donne à l'analyse, ainsi que toutes les autres cruciferes, de l'ammoniaque, et une huile volatile. Sa racine offre les mêmes résultats, mais à un plus haut degré. Cinquante livres ont donné, à la presse, un suc, lequel traité au bain marie, a fourni huit livres deux onces d'extrait.

Propnilités médicinales. Le cresson de savane commun est généralement employé, aux Antilles, dans l'hydropisie et les affections scorbutiques compliquées d'anémie; dans les catharres pulmonaires muqueux ; dans les néphrites, dans les affections de la vessie, celles scrophuleuses, cutanées; dans les engorgemens des viscères, et la phthisie pulmonaire.

On l'estime lithontriptique; mais on sait à quoi s'en tenir sur celte prétendue vertu. 


\section{$\left(19^{5}\right)$}

La racine est incisive, durétique, vermifuge, et surtout stimulante et anti-scorbutique.

Mode d'administration. La racine de cette plante est d'une saveứ âcre, si brûlante et si piquante, qu'on ne peut l'employer en nature, mais à la dose d'une once ou deux pour un litre de liquide, aqueux ou vineux.

La propriété du bouillon fait avec la tortue, le cresson et les écrevisses, est tellement appréciée, qu'on l'offre dans les Cafés publics, où les marins, affectés du scorbut, se présentent en foule, pour en réclamer les bons effets. L'extrême volatilité de ce cresson ne permet pas de l'employer en décoction; mais on en donne le suc exprimé, à la dose de trois à quatre onces. Alors, il purge doucement. Le vin et l'alkool sont choisis pour en extraire les principes volatils et médicamenteux. La dose de l'extrait du suc exprimé, est de 12 grains à un demi-gros.

La teinture alkoolique de ce cresson étant trop pénétrante, on ne l'emploie qu'en gargarisme, ou contre les ulcères de la bouche, encore est-on obligé d'émousser sa trop grande force, par le moyen du miel.

Le lait préparé avec le cresson de savane est recommandé dans les affections cutanées, dans les embarras des reins et de la vessie, dans la phthisie et les maladies chroniques du poumon.

On fait un petit lait avec le cresson de savane. Cette préparation est très-estimée, et employée avec avantage par Poupée - Desportes, est purifiante et apéritive. Il se prépare ainsi : Prenez cresson, une poignée; faites infuser une demi-heure, dans petit lait , une pinte; exprimez l'infusion. 


\section{$(196)$}

La racine du eresson de savane, employée comme masticatoire, excite la salivation. La racine râpée, malaxée avec du vinaigre, procure un cataplasme révulsif, qui remplace celui de moutarde, dans les affections rhumatismales, les fièvres ataxiques, etc.

L'infusion de cette plante, à laquelle on ajoute du quinquina, se prescrit avec succès, avant le frisson des fièvres intermittentes.

EXPLICATION DE IA PLANGHE QUARANTE-UNLÈME.

La plante est de grandeur naturelle; on a peint un petit individu.

Fig. 1. Feuilles radicales au trait, racinẹs colorées.

2. Fleur grossie.

3. Semence de grosseur naturelle. 


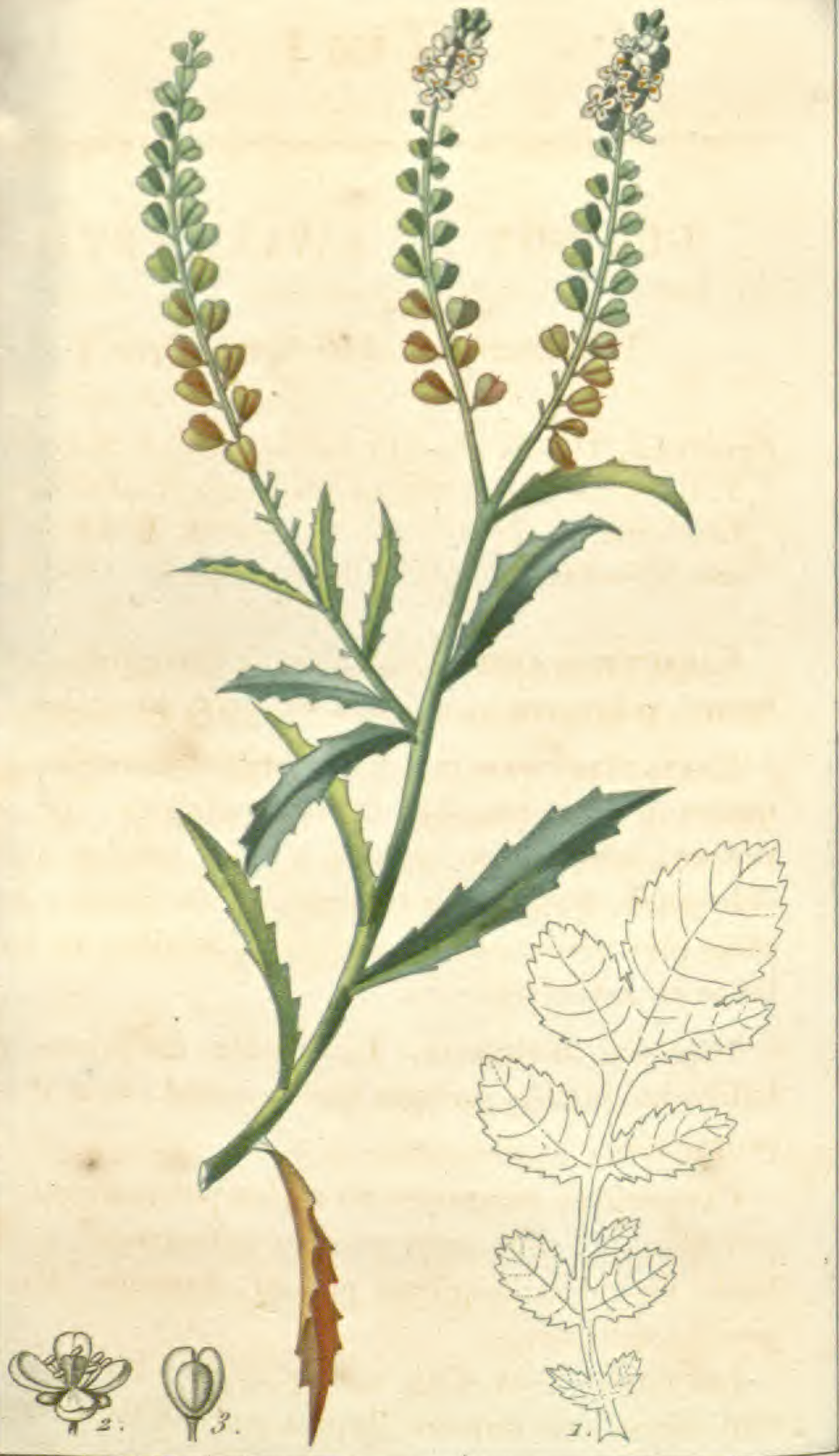

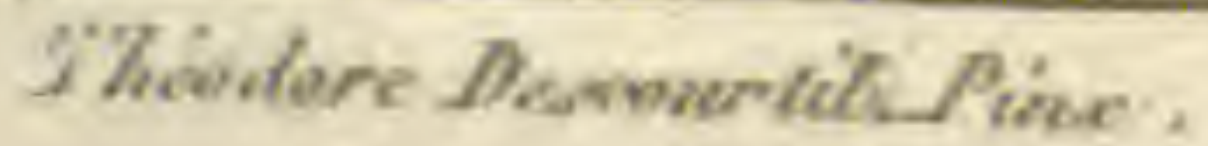




\section{$(197)$}

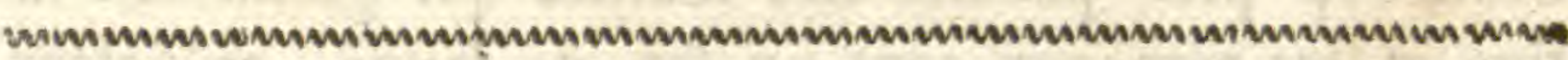

\section{CRESSON DE SAVANE PETIT.}

\section{(Stomachique Anti-Scorbutique.)}

Srronrmus. Thlaspi nasturtii sapore. Poupée-Desportes.T. Iberis humilior de Sloane. Passerage, Lepidium iberis, Lin. tetradyn. siliculeuse. - Tournefort, cl. 5 Cruciferes, sect. 2. - Jussieu, famille des Crucifères.

Caractìnes génériques. Silicule émarginée, cordiforme, polysperme, ralvules carénées contraires.

Caractimes particuliers. Fleurs diandriques, a quatre pétales cruciés; feuilles radicales, ou inférieures, 'ailées avec impaire à neuf folioles ovales, oblongues, quelquefois entremêlées de folioles beancoup plus petites. Les supérieures, sessiles, en fer de lance et crénelées.

Histoire natureliz. Le cresson de savane petit habite les mêmes parages que le grand, dont il a les propriétés.

Caractìres physiques. Sa racine pivotante est trèspeu fibreuse; elle pousse une tige cylindrique, glabre, haute de douze à quinze pouces, rameuse dans la partie supérieure.

Les feuilles sont d'un vert glauque; les radicales sont ailées, avec impaire, le plus souvent composées de neuf folioles, qui alternent quelquefois avec d'autres 16. 


\section{( $\left.19^{8}\right)$}

beaucoup plus petites. Les feuilles qui garnissent la tige et les rameaux sont en fer de lance, crénelées dans leur contour, et portées sur un pétiole rudimentaire.

Les fleurs sont blanches, petites, disposées en grappes à l'extrémité de la tige et des rameaux.

L'ovaire, après la floraison, se transforme en une silicule courte ovale, comprimée, cordiforme, garnie d'un rebord, et divisée en deux loges qui s'ouvrent par le sommet, en sens contraire de la carène dorsale des valves, et qui renferment chacune une seule graine.

Axalyse chimote. Ge cresson offrant, a l'analyse, les mêmes résultats que ceux du précédent, nous nous contenterons d'y renvoyer le lecteur.

Propriétés medicinales et hode $\mathbf{b}^{3} A$ DMinistration: Les vertus de cette plante étant également appliquées đạns les mêmes circonstances que célles où le cresson précédent procure tant d'avantages, il est inutile de nous répéter.

EXPLICATION DE LA PLANCHE QUARANTE-DEUXIEME.

La plante est représentée de grandeur naturelle.

1. Feuille radicale au trait.

2. Fleur grossie.

3. Graine de grosseur naturelle. 


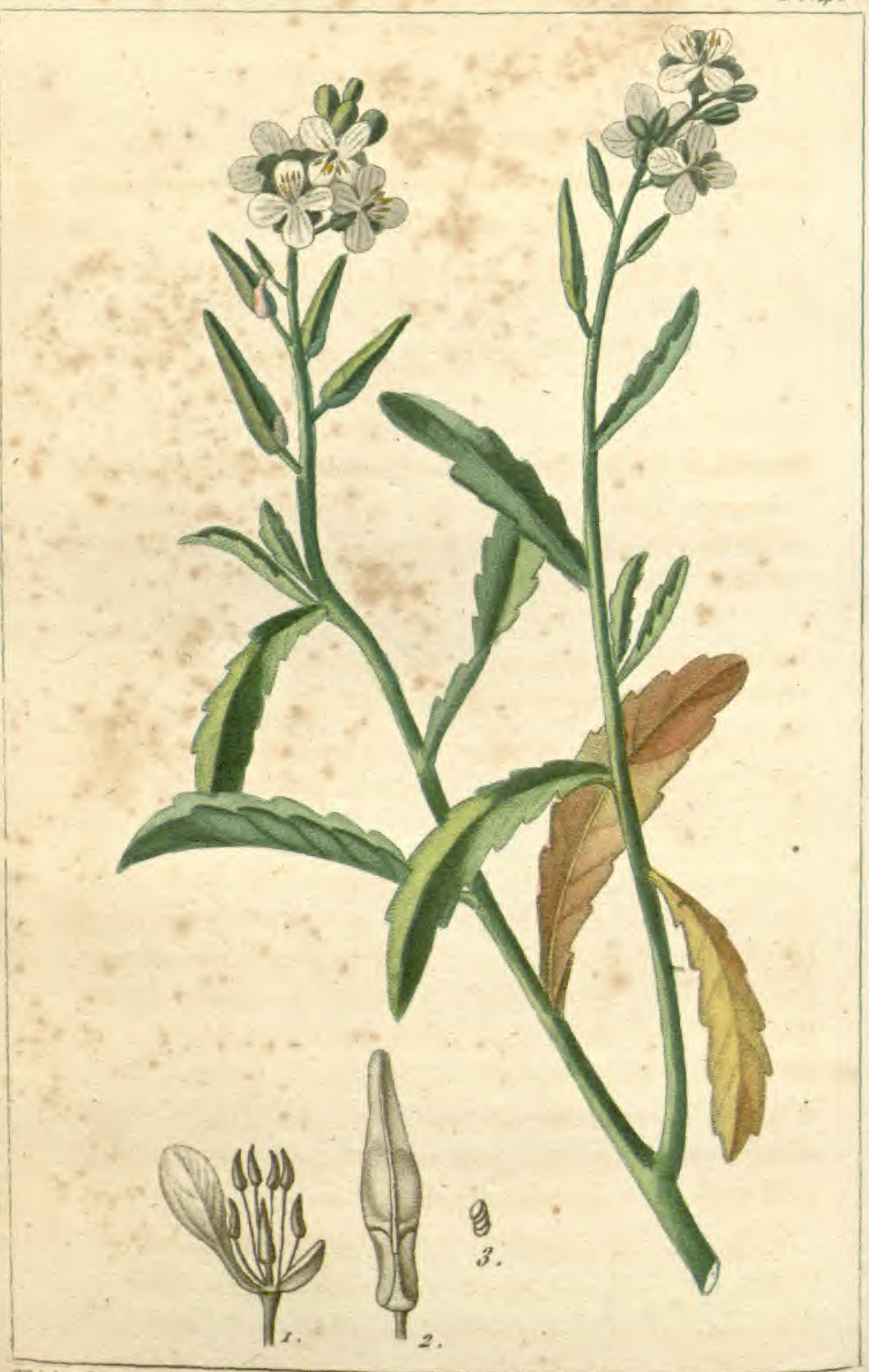

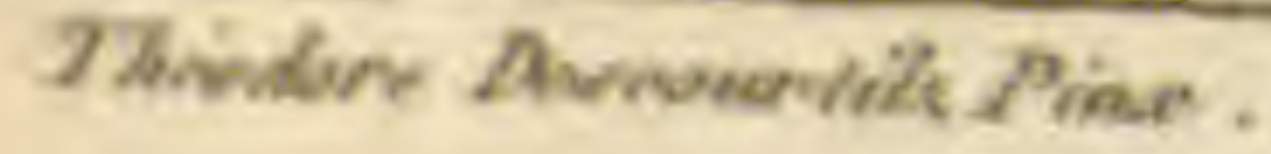

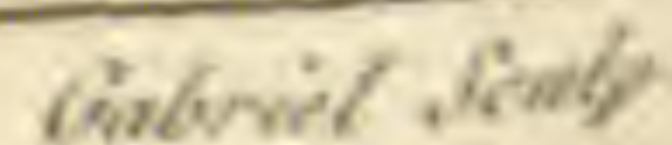

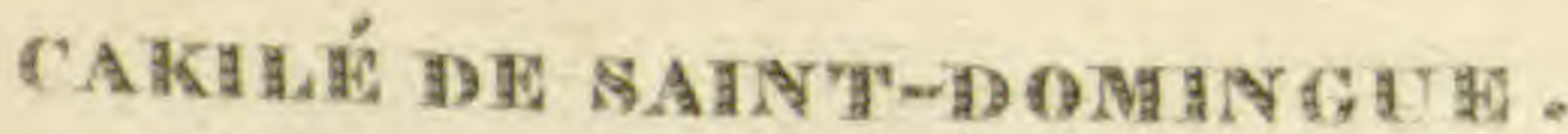




\section{(}

\section{GAKILÉ DE SAINT-DOMINGUE.}

\section{(Stomachique Anti-Scorbutique:)}

Sroomyme. Bunias Cakilé, Lin. Tetradynamie siliqueuse.Erucago Cakilé, Tourn. clas. V. Crucifères, sect. 7.Jussieu, famille des Crucifères. - Cakilé est un nom arabe:

Caractères glénérieves. Silique pulpeuse, caduque, à quatre angles inégaux, aigus; muriquée.

Caracteres particuliers. Siliques ovales lancéolées, lisses, composées de quatre pièces articulées les unes avec les autres.

Histoire naturelle. Le Cakilé se plaît sur le bord des ruisseaux, ou dans les lieux aquatiques, ainsi que la plupart des crucifères. Il y végète humblement comme elles, sans avoir à redouter que l'éclat de ses fleurs lui attire la main capricieuse des curieux qui ne lui trouvent rien de remarquable. Mais la nature a dédommagé le cakilé de són ensemble peu brillant, en le douant de propriétés anti-scorbutiques stimulantes , qu'il possède à un haut degré.

Caractenes physigues. Les tiges du cakilé sont cylindriques, peu rameuses, rarement droites, mais le plus souvent irrégulièrement fléchies.

Ses feuilles sont lancéolées, plus élroites à la base, 


\section{(200)}

obtuses au sommet; grossièrement dentées; d'un vert têrne supérieurement, glauque inférieurement; à mesure que la tige prend de l'accroissement, les anciennes feuilles jaunissent.

Les fleurs sont blanches, fouettées de jaune citrin très-pâle, disposées en grappes, peu garnies au sommet de la tige.

La corolle est composée de quatre pétales cruciés; leur sommet est large, et leur base terminée par un long onglet.

Les étamines offrent des filets $d^{\prime}$ un vert tendre, surmontées d'anthères sagitlées, jaunes. Elles sont au nombre de six, dont quatre plus grandes.

Le fruit est une silique composée de deux valves alongées, qui s'articulent inférieurement avec deux autres valves qui forment le tiers de la longueur du fruit. Elle contient plusieurs semences allongées, obtuses aux deux extrémités, et garnies de stries en spirale. Ces semences sont d'une couleur rougeâtre terne.

Analyse chimique. Le cakilé se fait remarquer par une saveur piquante et amère, il donne à l'analyse, de l'ammoniaque et une huile volatile, qui d'ailleurs existent en assez grande quantité dans toutes les crucifêres.

Propriétés médicinales. Toutes les préparations de cette plante conviennent dans certaines modifications du scorbut; dans l'hydropisie, dans les obstructions du foie, et des glandes mésentériques; dans tous les cas enfin où les anti-scorbutiques sont indiqués.

Mode d'administratiox. La racine du cakilé, infusée dans le vin blanc, se donne à la dose de deux onces par pinte de liquide; le suc de ses tiges, a celle de 


\section{(20I)}

deux onces. Les jeunes bourgeons en décoction, ou mangés en salade, sont très-utiles aux scorbutiques.

On obtient, par la distillation, l'esprit de cakilé , qui peut remplacer celui de cochléaria, et se prescrit depuis vingt jusqu'à trente six gouttes, dans une verrée de son infusion. Sa préparation la plus efficace se fait en combinant la plante pilée dans du vesou, ou jus de canne à sucre, qu'on a laissé fermenter, et qu'on soumet ensuite à la distillation; ce même esprit est encore plus pénétrant, en ajoutant au vesou moitié de Tafia.

\section{EXPLICATION DE LA PLANCHE QUARANTE-TROISIÈME.}

La plante est réduite à moitié de grandeur naturelle.

I. Parties sexuelles, de grandeur naturelle; une foliole du calice et un pétale, pour étudier leurs rapports.

2. Silique de grandeur naturelle.

3. Graine. 


\title{
CLÉ OME TRYPHILLE.
}

\author{
$V u l g$. Kaïa a trois feULles.
}

\section{(Stomachique Anti-Scorbutique.)}

Synoxyme. Sinapistrum d'Amérique, ligneux Tryphille à odeur de eresson alénois, Plum.-Sinapistrum frutescens, Triphillnm nasturtii sapore. Idem-S. Polygama, Lin. Tétradynamie siliqueuse. - Sinapistrum, Tournefort, cl. V, Crucifères, sect. V. - S. Juss., famille des Crucifères.

Caractìnes génériques. Trois glandes nectarifères, chacune à chaque sinus du calice, excepté le dernier; pétales, tous montant; silique portéesur un pédicelle uni-loculaire, à deux valves; semences réniformes; un placenta.

Caractimes particuliers. Fleurs supérieures tétrandiques mâles; feuilles ternies; follioles presque sessiles , comme aiguillonnées sur les bords; tige sous* ligneuse.

Histoire naturelle. Le Cléome d'Amérique diffère des plantes anti-scorbutiques précédentes par son port plus élevé, par sa tige sous-ligneuse, enfin, par ses feuilles trifides et pétiolées.

Il se plaît néanmoins, comme elles, dans les terrains bas et humides, sur le bord des ruisseaux, comme s'il semblait choisir ce lieu pour indiquer une propriété que confirme sa saveur, qui est semblable à 


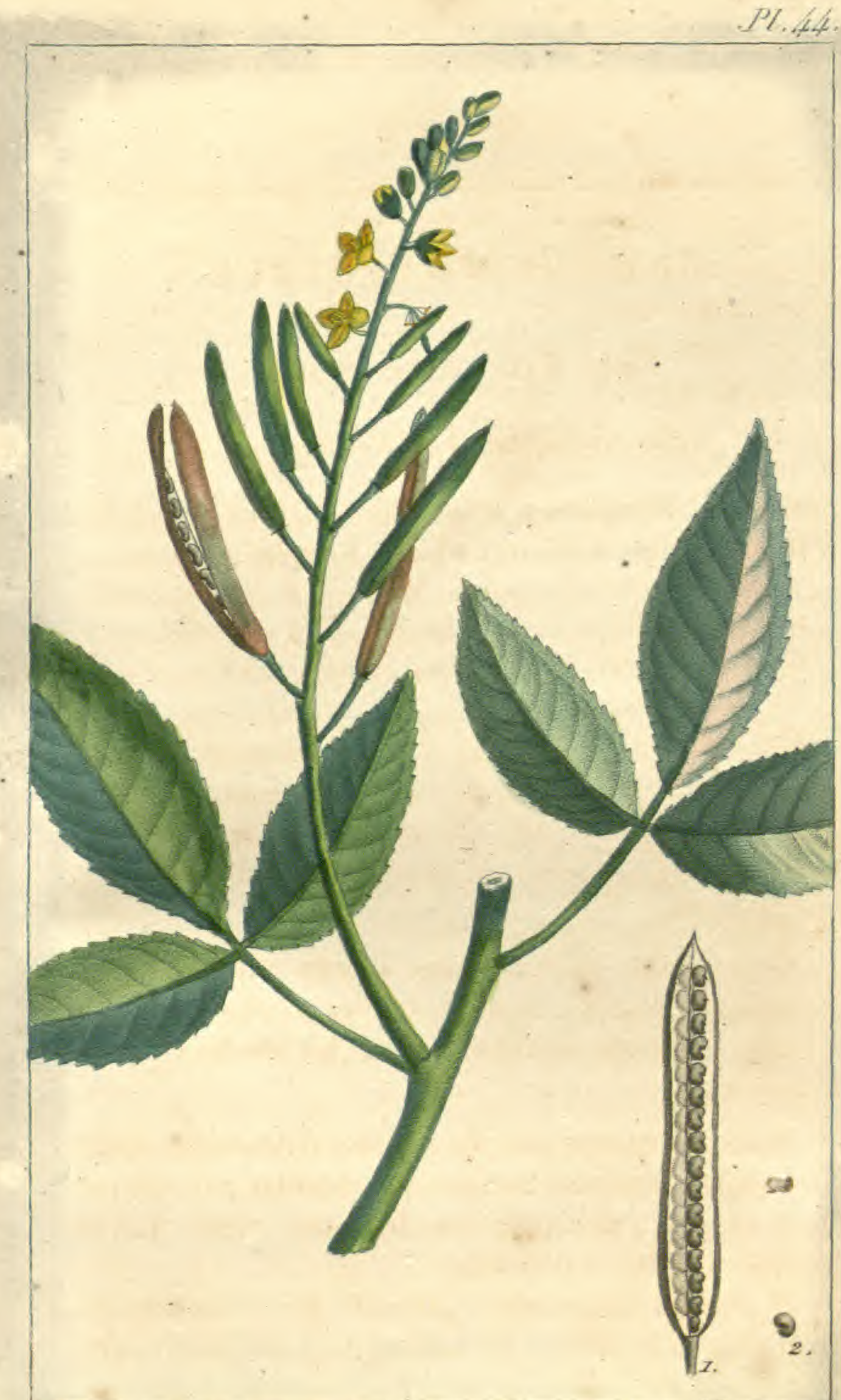

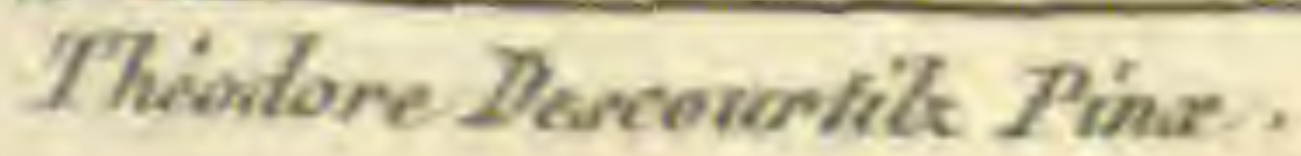




\section{(203)}

celle du cresson d'Europe. Les nègres l'emploient comme condiment.

Garactìnes physiques. La racine du cléome tryphille est pivotante, munie de fibres latérales, longues et menues. Elle donne naissance à une tige cylindrique, qui se subdivise au sommet en rameaux alternes. L'écorce de la tige est d'un vert cendré.

Les feuilles sont alternes, composées de trois follioles ovales, pointues, lancéolées, finement dentées sur les bords, à pétioles partiels, très-courts; mais à pétiole commun, de la longueur des follioles. Elles sont d'un beau vert en dessus, glauque en dessous; garnies d'un grand nombre de nervures obliques, à extrémité réfléchie vers la côte mroyenne.

Les fleurs, qui paraissent en juin, sont disposées alternativement en grappes terminales; elles sont jaunes, cruciformes, très-petites; leur calice est vert, et a quatre feuilles.

Il leur succède des siliques longues et étroites, portées sur un pédicelle; elles sont uniloculaires, contenant beaucoup de semences réniformes, séparées par un placenta transparent, de la longueur de la silique.

Analyse chimique. On retire de l'eau distillée et ammoniacale du cléome; plus une huile volatile et pénétrante qui, éprouvée par la langue, y imprime une causticité remarquable.

Paopnietes médicinales. Indépendamment de ses vertus anti-scorbutiques, le cléome est stimulant, incisif et diurélique : son écorce râpée, et appliquée à l'extérieur, agit comme rubéfiant; tandis que le suc 


\section{( 204$)$}

de toute la plante, édulcoré avec le sirop de batterie; convient dans l'asthme humide, et dans les maladies des reins et de la vessie, qui ont pour cause l'altération des membranes muqueuses, et la présence de la gravelle.

Mode d'administration. On fait, aux Antilles, avec toutes les parties de la plante, un vin et un sirop antiscorbutique, qui ne le cèdent en rien aux préparations de ce genre, qu'on exécute en Europe avec le cresson, le raifort et le cochléaria.

Nora. On trouve encore aux Antilles le Cléome procumbens de Saint-Domingue et de Cuba, à fleurs héxandriques, feuilles simples lancéolées, petiolées, tiges renversées, qui, assure-t-on, jouit des mèmes propriétés que le précédent.

EXPLICATION DE LA PLANCHE QUARANTE-QUATRIÈME.

La plante est représentée au tiers de grandeur naturelle.

1. Silique ouverte.

2. Graine. 


\section{(205)}

\section{T OME PREMIER.}

CLASSE PREMIÈRE.

Des plantes propres à remédier aux accidens dus à la présence des vers dans l'estomac ou le canal intestinal, soit qu'elles agissent directement sur eux, ou secondairement en provoquant une contraction violente et leur expulsion, puis la rectification des digestions.

\section{Stomachiques Anti-Helmintiques.}

\section{SOM M A I RE.}

D'Après la forme cylindrique, ou plate, ou vésiculeuse des vers qui portent le trouble et l'agitation dans notre économie, on peut réduire à trois classes leur divjsion méthodique; savoir : $1^{\circ}$ les ascarides et les lombries; $2^{\circ}$ les tania et les fascioles; $3^{\circ}$ les hydatides et les bicornes.

Les vers déterminant, par leur présence dans le le corps humain, une foule de maladies variées, dont ils sont la suite naturelle, ou plutôt la conséquence, avec quel empressement ne doit-on pas accueillir les moyens de détruire ces ennemis acharnés, qui causent sans cesse des désordres par les lésions profondes qu'ils impriment aux voies digestives?

On doit avoir pour but dans le traitement des affections vermineuses, de rectifier les digestions, en évacuant de l'estomac et des intestins, les matières muqueuses qui les rendent languissantes, et y servent au développement et à l'entretien des vers.

Dans la première vue, on emploie les émétiques et 120 Livraison. 


\section{( 206 )}

les purgatifs, auxquels on fait succéder les vermifuges, ou anthelmintiques proprement dits, comme doués d'une propriété particulière, délétère pour les animaux et prouvée tellepar l'engourdissement puis la mort que ces médicamens procurent à des vers rendus vivans, mais qui soumis à l'influence des vrais anti-helminliques, périssent de suite : on termine la cure par les amers.

Dans l'action des purgatifs, la contraction péristaltique est telle, que les vers froissés se détachent et sont entraînés en partie par les déjections.

L'emploi immédiat des anthelmintiques doit frapper de mort ceux qui ont résisté aux purgatifs. Parmi ces médicamens qui agissent directement sur les vers, on peut mettre au permier rang, les huiles, qui, en bouchant les trachées de ces animaux, les font périr en les privant de la respiration.

Viennent ensuite les anthelmintiques qui décomposent leur tissu, tels que le mercure et ses préparations; et parmi les végétaux, l'héroïqae cévadille, dont le dessin n'est pas encore connu, quoiqu'on fasse journellement usage de sa poudre, qui réunit les qualités purgatives, anthelmintiques et amères; mais qu'on ne doit prescrire qu'à une faible dose, et avec la plus grande prudence. On trouve dans cette classe beaucoup d' vidus qu'on peut lui substituer avec autant d'avantages, et moins de dangers.

On termine le traitement par un usage prolongé des amers, qui s'opposent à la formation des mucosités si favorablès au développement des germes. Les vers déjà formés ne trouvant plus à se nourrir, et à se soustraire à l'action des amers, périssent, et les malades les rendent décomposés ou desséchés. 
$P 40^{\circ}$

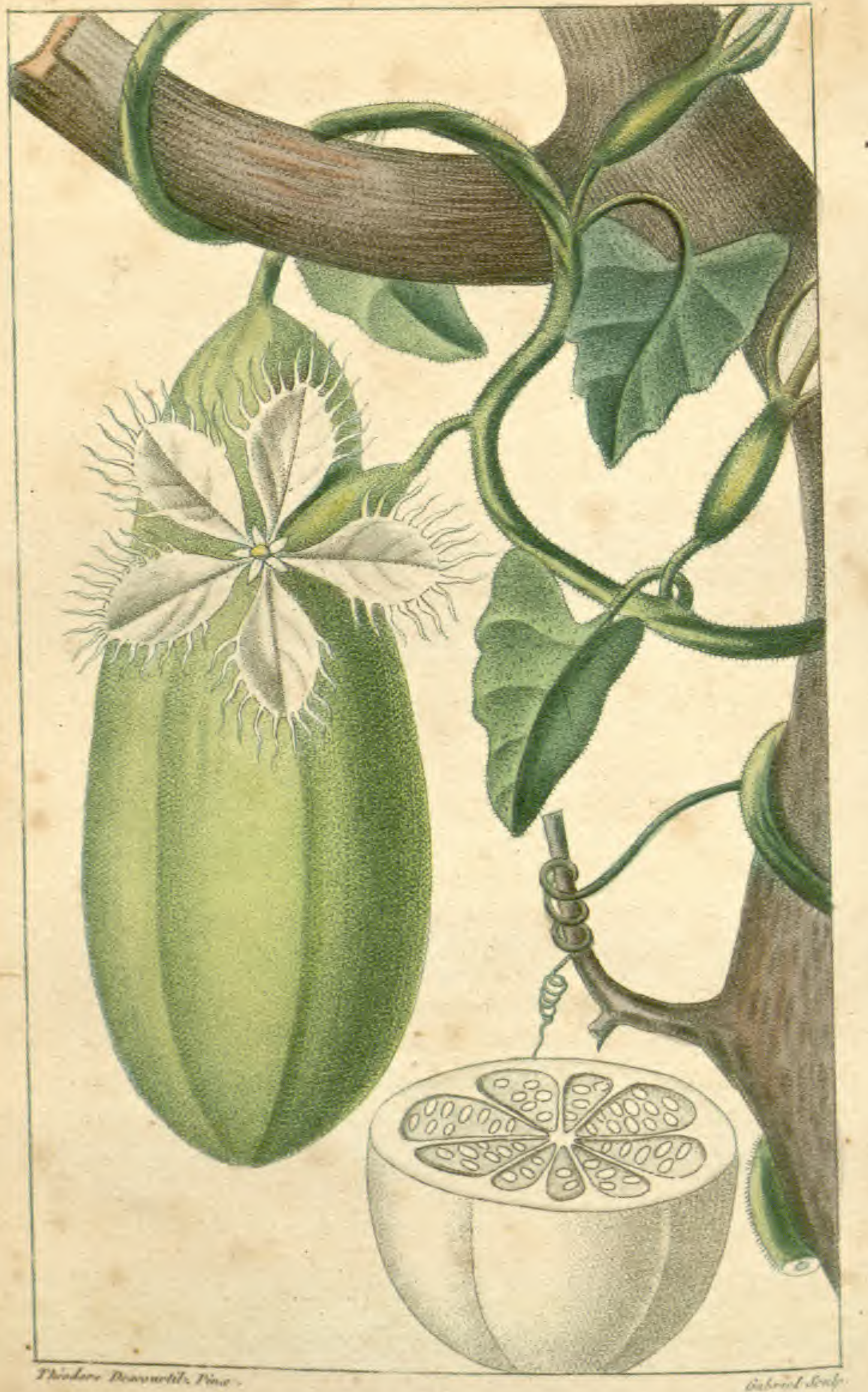




\section{$(207)$}

\section{ANGUINE AMÈRE.}

\section{(Stomachique Anti-Helmintique.)}

Srnonymiz, Coloquinte à fruit oblong, - Colocynthis flore albo fimbriato, fructu oblongo, Plum., tom. 2, pag. 35. -Amer. 86, tom. 101 ; Raj., suppl. 332.-Trichosantes pomis turbinato-ovatis. Lin. Anguine trichosantes amara, Lin. monoëcie syngenesie.- Tournefort, classe $\mathrm{I}^{\mathrm{ro}}$, campaniformes, sect. VII, - Jussieu, famille des Cucurbitacées, Caca-Palamo, $\mathrm{Mal}_{2}$ - Swalew Appel, Belg. Fruitte quisonte, Portug.

Caractìres géntriques. Mâle, calice à cinq dents, corolle en cinq parties; trois filets : femelle, calice à cinq dents; corolle en cinq parties, ciliée (type du genre); pistil trifide; semences de la pomme aigüe.

Caractieres particuliers. Feuilles triangulaires, sinuées, rudes au toucher; fleurs blanches, frangées; fruits turbinés, ovales, oblongs.

Histoire naturelle. L'anguine amère se plait aux Antilles, sous les voûtes silencieuses des forêts, ou sa fleur frangée s'épanouit en décembre; et son fruit arrive à sa perfection en avril. Embrassant étroitement les branches des arbres qui dui servent d'appui, ses tiges sarmenteuses se contournent avec élégance et supportent quantité de fruits que l'air balance mollement.

Caractìnes physiques. Cette plante fournit des tiges menues, anguleuses, vertes, glabres, où sont disposées, à des distances peu éloignées les unes des autres, des feuilles petites, triangulaires, sinuées, alternes, 


\section{( 208 )}

rudes au toucher, vertes, tachetées de points grisâtres, et soutenues par un pétiole de la longueur de la feuille.

Les tiges sont pourvues de vrilles simples, opposées aux feuilles.

Les fleurs sont grandes, d'un blanc de neige, teint de violet pâle, sur quelques individus. La corolle présente cinq divisions, dont la forme est ovale-obtuse. Le contour de chacun de ses pétales est garni d'une frange composée d'une multitude de filets capillaires, peu distans, assez longs, et de la couleur de la corolle. L'inflorescence a lieu en juillet.

Les fruits sont turbinés et ont beaucoup de rapports avec ceux de la mélongène; ils sont longs de quatre à six pouces, sur deux de largeur, d'un vert tendre tranché par des raies longitudinales jaunâtres. Ces fruits sont divisés à l'intérieur, en neuf loges contenant quantité de semences oblongues et un peu étroites, terminées aux deux bouts par une pointe. La pulpe du fruit est blanche et extrêmement amère.

Analyse cumreve. L'anguine amère contient une gomme résine, plus une huile très-âcre, douée de toutes les propriétés de celles du strychnos, et propre, comme elle, à agacer les nerfs et à les irriter violemment.

Propnítés mídicinales. L'anguine amère, en raison de ses principes gommo-résineux, offre un médicament héroîque, dont il faut user avec la plus gránde réserve; son abus peut causer les plus grands désordres dans l'appareil des fonctions digestives, ou son mode particulier agit sur le système nerveux, qu'elle ébranle et distend douloureusement, tandis qu'elle cause des 


\section{( 209 )}

érosions aux membranes muqueuses avec lesquello elle est en contact, si l'on n'a pas le soin d'enchainer, d'émousser sa vertu corrosive, au moyen des. mucilagineux.

Les nègres, qui ne doutent de rien, l'emploient dans. leur médication, pour purger abondamment, dans lescas d'atonie, d'hydropisie, d'apoplexie, et de carus. Mais, je le répète, je n'ai iamais osé l'administrer. qu'à très petites doses, dans les affections vermineuses, surtout dans celles où l'on reconnaît la présence du tœenia.

L'huile de l'anguine amère est si caustique, que j'ai vu son application sur un ulcère, produire, chez un nègre, une affection tétanique s et des convulsions que j'ai eu beaucoup de peine à réprimer.

Mode d'administration. On ne peut prescrire l'extrait de cette plante, que depuis deux grains jusqu'à six. On applique sur le bas-ventre le marc de sa pulpe écraste, dans les affections vermineuses, et on en fait entrer quelquefois dans les déeoctions destinées à composer les clystères anthelmintique.

Poupée-Desportes ordonnait deux gros de pulpe d'anguine, une once de celle de casse, quatre gros d'huile d'ooli ex trente gouttes de laudanum, par pinte d'eau de mer, pour les lavemens qu'on prescrit dans. la colique du Poitou.

EXPLICATION DE LA PLANCHE QUARANTE-CINQUIÈE,

Le dessin de la plante est exécuté de demingrandeun naturelle.

Fig. 1. Fruit coupé transversalement. 


\section{AZÉDARACH BIPINNÉ. $V$ ulg. LILAS DES INDES.}

\section{( Stomachique Anti-Helmintique. )}

Srrowrnrre. Melia azédarach, foliis bipinnatis, Lin., cl. X, décandrie monogynie.- Jussieu, classe XIII, ordre II, mêliacées. - Tournefort, classe XXI, arbres rosacés. Arbor Fraxini folio flore crevleo, Bauh., $\pi \omega$ c $\xi$, lib. II, sect. IV. - En français, azédarach, lilas des Indes, margousier, faux sycomore, arbre saint, arbre à chapelet; azédarach bipinné, Lamarck. - En espagnol, azédarach, cinamomo, ortega. - En anglais, Jazédarach, bead-trée, false sycamore. ( Flore du Dict.d. sc. med. ) - Aariabapou, en malabarois. - Amargoseira, en portugais ( $)$.

Caractènes géníriques. Calice à cinq divisions, corolle pentapétale; étamines, cinq ou dix filets réunis en cylindre; un style, une baie ou une capsule.

Caractìnes particuliers. Calice à cinq dents; corolle à cinq pétales ouverts; dix étamines, dont les filets réunis en cylindre supportent autant d'anthères, et environnent un style; drupe sphérique, jaune; noix sillonnée de cinq cannelures, et dont l'intérieur est divisé en cinq loges monospermes.

Histoire naturelle. Élégant dans sor port, l'azédarach, originaire des Indes orientales, et parfaitement acclimaté aux Antilles, y balance avec grâce, au moindre vent, ses panicules déliées, chargées de 
Pl. $46:$

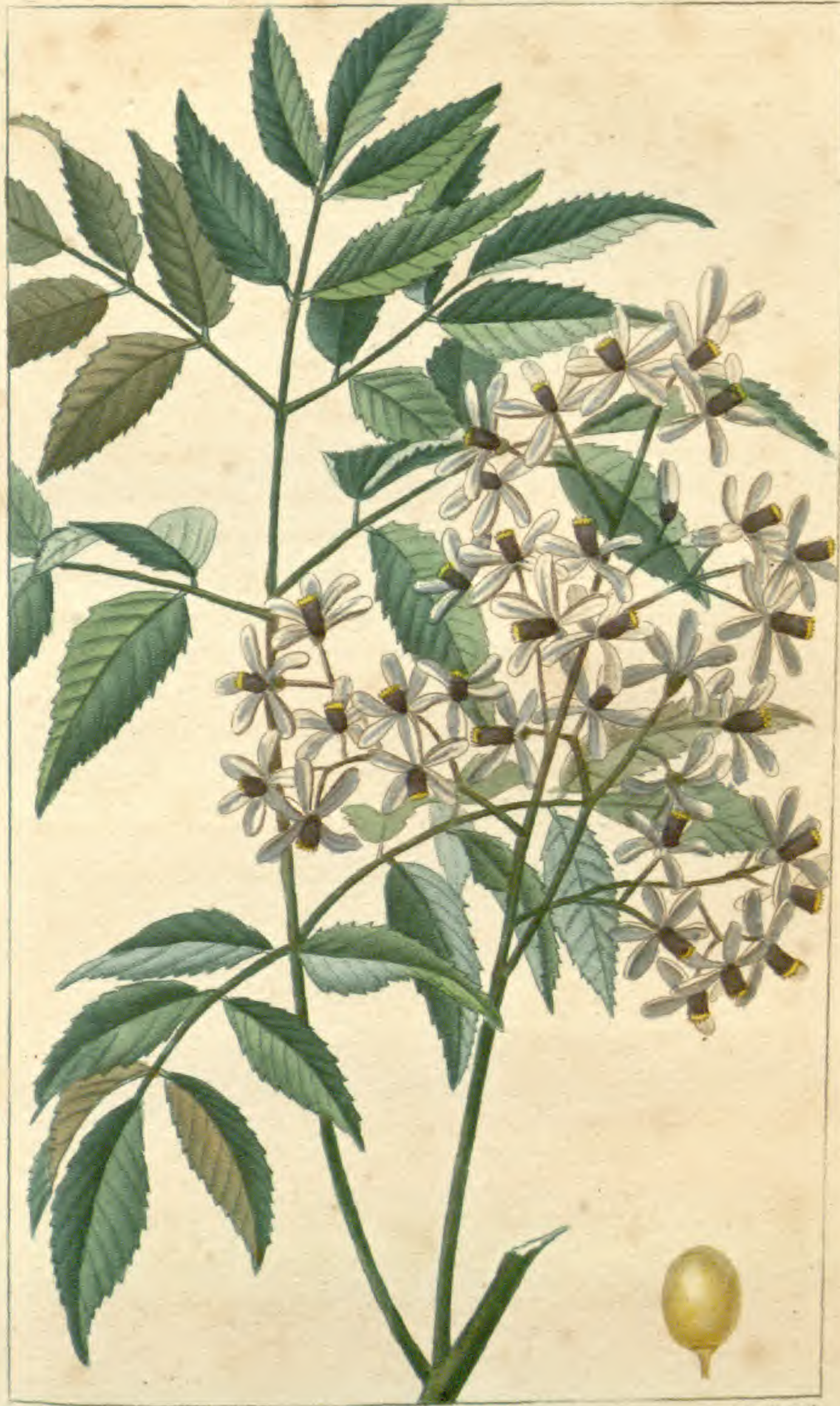




\section{(211)}

fleurs ou de baies dorées : il y marie a l'air do l'atmosphère ses suaves émanations, comparables à celles du lilas de France, dont il reproduit ainsi la couleur tendre et le parfum. C'est pour propager ce bel arbre, qu'aux Antilles, et dans tous les pays où il se plaît, on en fait planter devant beaucoup de maisons, dans l'espoir de respirer le soir, sous son ombrage, l'air aromatique qui s'en dégage en quantité à cette époque paisible de la journée. On y entend souvent, au milieu de la nuit, l'amant dire à sa belle :

Je te revois sous le dais de verdure

Que forment les lilas aux panaches fleuris. (Bírargers:)

Cependant, comme rien n'est parfait dans la nature, cet arbre, qui éveille et charme la plupart des sens, recèle, dans ses baies, une propriété délétère pour certains animaux, tandis que pour d'autres, elles n'offrent qu'un aliment sans danger. Les ramiers, par exemple, se repaissent avec avidité des baies de l'azédarach, et leur chair n'en contracte aucune qualité malfaisante.

Ces baies contiennent une huile concrète, dont on fait des bougies, en Perse et en Syrie, tandis qu'en Espagne et en Portugal, ses noyaux très-durs, convertis en chapelets, exercent la piété des fidèles de ces beaux climals. Cette huile sert aussi en peinture.

Caractìnes physiques. L'azédarach s'élève, au-delà du tropique, à la hauteur de soixante pieds. Le tronc est droit, surmonté de branches irrégulières, dont l'écorce est, ainsi que celle du corps, verte et lisse.

Les feuilles alternes, sont réunies par touffes à l'extrémité des rameaux; elles sopt deux fois ailées, a 


\section{( 212$)$}

Polioles larges, ovales, pointues, dentées, glabres, souvent incisées ou lobées, un peu luisantes et d'un vert agréable, quelquefois varié de teintes différentes.

Les fleurs naissent au sommet des branches, en danicules droites, moins longues que les feuilles. Les pétales, au nombre de cinq, sont obtus, assez allongés, d'un violet très-tendre, ou d'un blanc bleuâtre.

Le tube, formé par la réunion des filets des étamines, d'une couleur plus foncée, contraste agréablement par son violet pourpre, avec la légère teinte des pétales.

Le fruit est une noix globuleuse, charnue, de la grosseur d'une petite cerise, recouverte d'un brou assez épais qui, d'ahord vert, jaunit en mûrissant. Elle contient un noyau obrond, marqué de cinq sitlons, et divisé, à l'intérieur, en cinq loges, qui renferment chacune une graine oblongue.

ANAlYSe chimeve. Je ne puis donner aucun renseignement à cet égard, une parlie de mes manuscrits ayant été dévorée par les flammes.

Propriétés déletìnes. Parce que, sous un ciel tempéré, on aura fait manger à des animaux des baies d'azédarach, sans qu'ils en aient parus incommodés, il n'en faut pas conclure qu'elles n'agissent pas comme substance vénéneuse sous la zône torride: des expériences, trop nombreuses, ont constaté les vertus toxiques de la pulpe des baies de l'azẻdarach. Prises fraiches, et au nombre do six à huit, elles excitent des nausées, des convulsions, des grincemens de dents, et le rire sardonien. Bientôt le corps se courre d'une 
sueur froide; une soif ardente consume le malade. qu'une propension au sommeil ne peut appaiser; les vomissemens et les évacuations alvines, excessives, annoncent l'impression funeste de ce poison végétal sur les viscères; et si l'on n'administre promptement des secours, la malheureuse victime périt au milieu des tourmens.

On remédie à cet empoisonnement, par des boissons sucrées; et, au milieu du trouble alarmant qui l'accompagne, une limonade, donnée à grandes doses, peut encore conserver la vie.

Propriétés médicinales. En éloignant ce tableau désespérant des effets funestes du fruit de l'azédarach, nous dirons, à l'avan lage de cet arbre, que ses fruits, son écorce, son sue, ses racines jouissent d'une certaine réputation comme vermifuges; la pulpe des baies sert à composer un onguent qu'on emploie avec avantage dans les affections cutanées. Les fleurs et les feuilles sont estimées apéritives, anodines, et emménagogues, mais je ne puis rien affirmer à cet égard. Des bains de la déeoction des feuilles favorisent les éruptions et calment les douleurs arliculaires. Les feuilies séchées et pulvérisées, jointes à l'huile des fruits, forment un onguent contre les convulsions, spasmes, et douleurs nerveuses.

Mone d'administration. L'écorce et les racines se donnent en décoction, à la dose de huit grammes ( deux gros ), par chopine d'eau. Sa pulpe et son suc, à celle de quatre à huit grammes, selon l'âge. On administre, trois heures après, l'huile de ricin, pour expulser les vers morts. 


\section{(214)}

Nota. Il exisle aux Antilles une autre espèce d'azédarach, transporté des Indes : c'est l'azédarach toujours verd, mélia semper virens. Il s'élève à la hauteur de trente pieds, et porte des fruits olivaires, passant, à l'époque de leur maturité, d'une teinte jaune à la couleur purpurine. L'huile qu'on en retire est estimée vulnéraire.

EXPLICATION DE LA PLANCHE QUARANTE-SIXIL̀ME,

L'azédarach est représentée de grandeur naturelle.

Fig. 1. Fruit en maturité parfaite.

Nota. Mon dessin de l'azédarach ayant été la proie de l'incendie du cap (ile St.-Domingue), où je me trouvais, j’ai cru ne pas devoir choisir de plus parfait modèle que celui de M. Turpin, d'après lequel j'ai fait copier celui-ci qui rend la nature même parée de toutes ses grâces. 
PL. AT.

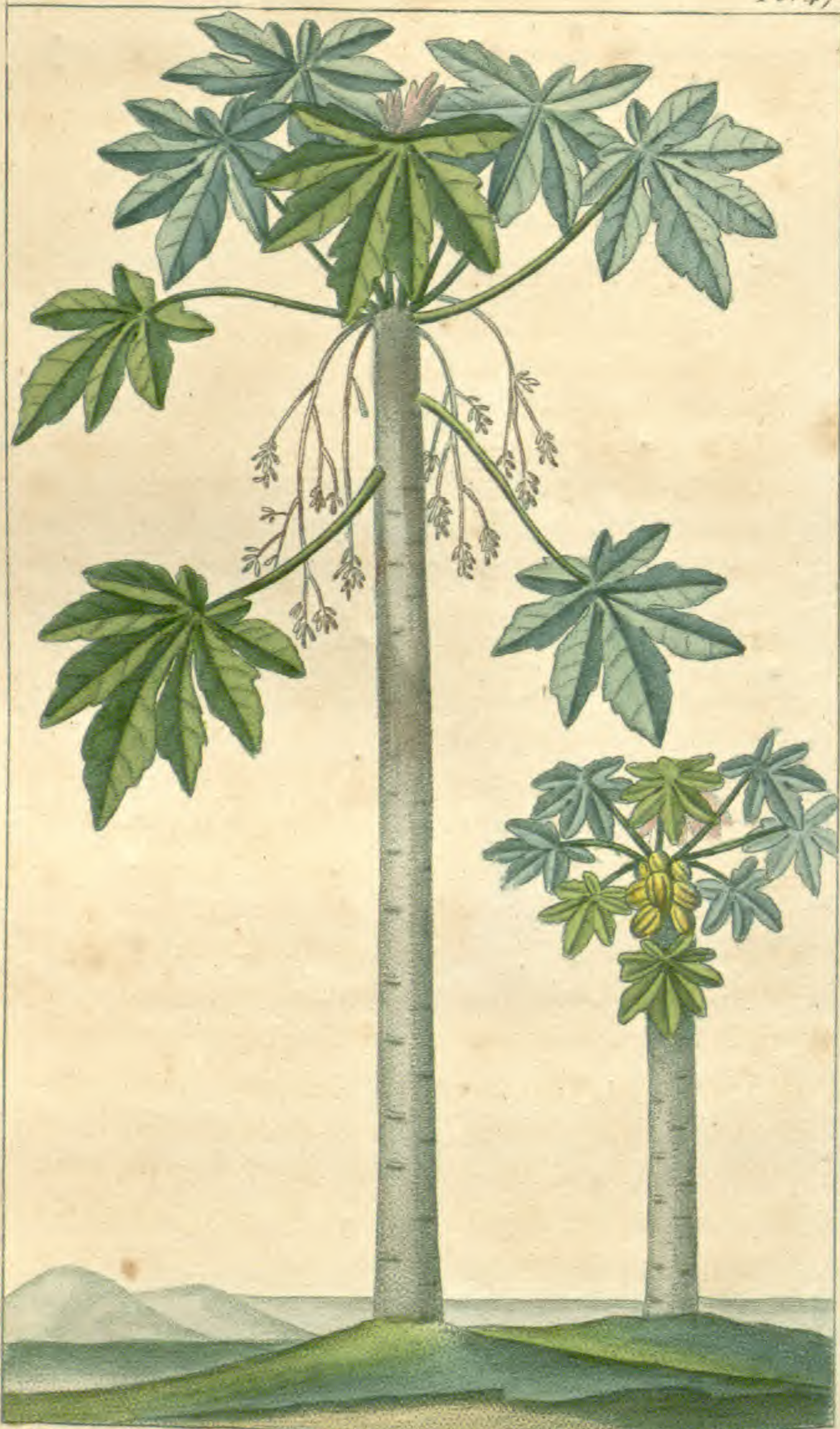




\section{$(215)$}

\section{PAPAYER COMMUN. \\ (Stomachique Anti-Helmintique. )}

Synonymie. Papaya vulgaris; papaya foliorum lobis sinuatis, Lin., diæcie decandrie. - Carica papaya Brown Jam.36o.Arbor platani folio etc. Bauh. pin. 131. - Papaya fructu maximo melonis Effigie, Plum., vol. VII, pag. 115, vel caract. spec., pag. 20, Ess., pag. 91. - Papaya maram., rheed.-malab., pag. 23 , tab. 15 , f. 1 .-Ambapaya rheed.malab., pag. 21, tab. 15, fig. 3.-Papaye Boom. Valent., pag. 169.-Arbor melonifera, Bout. 96. - Pino-guam., pis. 159. - Carica seu papaya, digitatis foliis, floribu's suaveolentibus, melonis fructu.-Pino-guam., hort. malab. - Abapaye, en Caraibe. - Aleulé, alélé, en Caraïbe, petite papaye.

Caractimes génlerioves. Fleurs mâles : calice trèspetit, corolle en entonnoir; tube très-long, grêle; limbe à cinq divisions contournées en spirale ; dix étamines au sommet du tube.

Fleurs femelles : calice très-petit; corolle à cinq pétales très-longs, réfléchis; un style très-court; cinq stigmales; baie sillonnée; une loge; giaines nombreuses.

Canactìnes particuliens. Bois de l'arbre, spengieux, laissant transuder un suc laiteux-glutineux; tronc hérissé par les vestiges des feuilles précédentes, qui sont comme circulaires; les feuilles pétiolées, et nombreuses au sommet de la tige; entremêlées de fleurs; les mâles portées sur de longues grappes pendantes; les femelles, en petit nombre, sur un pédicule court, épais et pendant. On rencontre souvent des fleurs hermaphrodites sur les arbres mâles, ou femelles: 


\section{$(216)$}

les feuilles des mâles sont moins grandes que celles des femelles,

Histoire naturelle. Cet arbre curieux du nouveau Monde, le papayer (1), dont le tronc sans branches, formé en colonne, hérissé de melons verts, porte un chapiteau de larges feuilles semblables à celles du figuier, offre, le plus souvent, des fleurs mâles et des fleurs femelles sur des individus différens. Cet arbre se plait dans des terrains légers, mais il porle peu de fruits; s'il végète au milieu d'un sol sabloneux. Le papayer croît promptement, et s'élève, en un an, à la hauleur de dix à douze pieds; il donne des fruits presque toute l'année.

Les fruits du papayer, très-fades, se mangent rarement cruds, mais souvent cuits, en compote ou en conserve; alors on leur associe des aromates et du sucre. Le suc de la pulpe est employé comme cosmétique pour effacer les taches de la peau, causées par le soleil. Dans quelques colonies, les nègres économes savonnent leur linge avec les feuilles du papayer.

La végétalion de cet arbre est si prompte, qu'une de ses graines mise en terre, offre, au bout de deux ans, un sujet portant fruits; mais sa durée n'est que de quatre à cinq ans : passé ce temps, le feuillage se fane, pourrit, et sa chûte ne précède que de peu la mort du tronc.

Caractìres physiques. La racine du papayer est blanchâtre, perpendiculaire, tendre et odorante; sa tige nue, et d'environ un pied de diamètre, s'élève

(i) Etudes de la nature, par Bernardin de Saint-Pierre, - Paul et Virginie. 


\section{(217)}

jusqu'à vingt pieds; elle est pleine et solide vers la base; tendre et spongieuse au sommet; divisée intérieurement par des cloisons charnues et blanchâtres; son écorce moyenne est épaisse, verdâtre, revêtue d'une pellicule cendrée; la surface est hérissée de vestiges pétiolaires des anciennes feuilles.

Les feuilles sont portées sur des pédoncules creux, longs de près de deux pieds; éparses, mais rassembléos en couronne à la cîme des arbres, dont elles protègent les fleurs. Elles sont grandes, divisées trèsprofondement en sept, neuf, ou onze lobes, dont chacun est plus ou moins sinué et incisé, surtout dans les pieds mâles. Ces feuilles, d'un vert tendre en dessus, sont glauques en dessous.

Les fleurs naissent au sommet de la tige, entremêlées arec les feuilles.

Les fleurs mâles, portées sur des pédoncules grêles, pendans, longs de deux ou trois pieds, sont composées d'un calice monophylle, divisé en cinq parlies oblongues et d'un vert soyeux.

La corolle est monopétale; le tube qui la forme, est long, légèrement courbé, divisé en six pétales, qui s'étendent jusqu'au tiers de la longueur totale de la fleur; avant l'épanouissement, ils sont roulés en spirale, les uns sur les autres.

Les étamines, au nombre de dix, sont placées au centre du tube; elles supportent des anthères oblongues et jaunâtres.

Le pistil manque.

Les grappes sont formées d'environ soixante de ces nleurs, dont la couleur est d'un blanc teint de citrin ; elles exhalent une odeur extrêmement suave.

Lorsque ces fleurs ont répandu leur poussière fécon. 


\section{$(218)$}

dante, elles se flétrissent, se détachent de la grappe , et ne laissent aucun fruit.

Les fleurs femelles, très-nombreuses, sont portées sur des pédoncules courts, simples, et pendans.

La corolle est composée de cinq pétales très-longs, réfléchis depuis le milieu de leur longueur: d'un blanc de neige, d'une consistance épaisse.

L'ovaire occupe le milieu de la corolle; il porte un style terminé par cinq stigmates, et devient un fruit qu'on nomme papaye. Ce fruit est suspendu au haut de la tige, près de l'endroit ou les pétioles des feuilles prennent naissance. Ce fruit, dit Valmont-Bomare, a le plus souvent la grosseur et la figure d'un melon; son extérieur est marqué de plusieurs côtes; la pellicule qui le revêt, est d'abord d'un vert foncé, il s'éclaircit, se mélange de jaune, à mesure que le fruit avance vers la maturité. Dans ce dernier état, la papaye est d'un jaune aurore. Ce fruit, creux à l'intérieur, renferme une pulpe fongueuse, douceâtre, et peu aromatique; les parois sont tapissées çà et là de graines brunâtres, noires, oblongues, ridées, bosselées, enveloppées séparément dans une membrane transparente grosses comme des grains de coriandre, et d'un goût aigrelet.

Axalyse cirmueue. D'après l'analyse du suc du papayer, faite par M. Vauquelin, " dit M. le docteur " Alibert, cette substance mise sur des charbons ardens, " exhale une odeur de corne brûlée. Ce suc donne, - à la distillation, $1^{\circ}$ une huile concrète, colorée, - très-désagréable, et tout-à-fait semblable à l'huile - animale de Dippel; $2^{\circ}$ du carbonate d'ammoniaque, - en quantité; $3^{\circ}$ de l'eau, de l'acide carbonique, et - de l'hydrogèine carboné. Réduite en poudre, elle se 


\section{(219)}

n dissout très-facilement dans l'eau. Si on expose cette * dissolution à la chaleur, elle se prend en gelée, n cơmme le blanc d'œuf, et se précipite par l'infusion " de noix de galle, par l'acide muriatique oxigéné, et " par tous les acides minéraux. Le charbon est composé " d'alumine, de magnésie, et de phosphate de chaux. „

Proprí́tés médicinales. Toutes les parties du papayer offrent des moyens sûrs à administrer dans les maladies vermineuses; et le succès ne peut être incertain, si on en faitl'applicaion d'après les rèğles de l'art.

Les graines ont un léger goût de poivre; elles sont estimées stomachiqnes: on les donne quelquefois dans les affections scorbutiques, hystériques et cystiques. Réduites en poudre, et prises intérieurement, pendant plusieurs jours, à la dose d'un scrupule, elles font mourir les vers.

Mais tel est l'avantage du suc de papayer, employé comme vermifuge, e'est que, d'après les expériences réitérées de MM. Charpentier et sir Fleming, une seule dose suffit pour tuer tous les vers, quelque grande qu'en soit la quantité.

Poupée-Desportes recommande l'usage de la poudre des semences de papayer, à la dose de son suc.

Mode d'administration. Pour masquer la saveur âcre et amère du suc de papayer, on lui associe un poids de lait de vache, ou d'une infusion aromatique, mais non sucrée, afin de lui conserver toute sa vertu. La dose du suc est, d'un à deux gros pour les enfans. et de deux à quatre, pour les adultes, dans le trai . tement du tœnia.

On se procure, sur les lieux, le suc laiteux du papayer, en incisant ses fruits verts; alors cette subs- 


\section{(220)}

tance, employée sur-le-champ, produit toujours un effet sûr, tandis qu'il est incertain en Europe, où on ne peut se le procurer que concret, ou dans un état d'altération qui le rend peu efficace.

On emploie aussi les décoctions des racines du papayer, qui sont également douées de vertus anthelmintiques. La dose est d'une once des racines, par livre d'eau, à prendre enquatre fois, à une heure de distance.

Lorsqu'on ne peut se procurer que du suc de papayer concret, on le fait dissoudre dans de l'eau bouillante, en l'agitant.

On fait cas, aux Colonies, d'un lavement vermifuge, composé avec une poignée de feuilles de papayer, une onced'huile de ricin, et suffisante quantité d'eau de mer.

Nota. On trouve aux Antilles, une autre espèce de papayer, appelée par les Nègres, papayer sauvage ou épineux. Papaya foliis digitatis, foliis integerrimis caule spinis inermibus instructo... Carica spinosa, syst. veget. Gmel., gen.

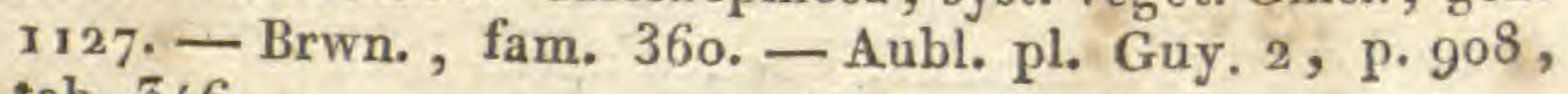
tab. 346 .

explication de LA PLANGHe QUARANTE-SEPTIÈme.

Papayermâle, sur l'avant-scène, il est chargé de fleurs. Dans le lointain, on distingue un papayer femelle chargé de fruits.

Les deux arbres sont réduits environ au $50^{\circ}$ de grandeur.

EXPLICATION DE LA PLANCHE QUARANTE-HUITIÈME. x. Portion d'un tronc de papayer femelle, portant fleurs
et fruits.

2. Fruit du papayer femelle ouvert.

Ces deux figures sont réduites au 8 e de grandeur naturelle.

3. Grappe pendante de fleurs mâles, réduite au quart. 
PI $\neq 8$.

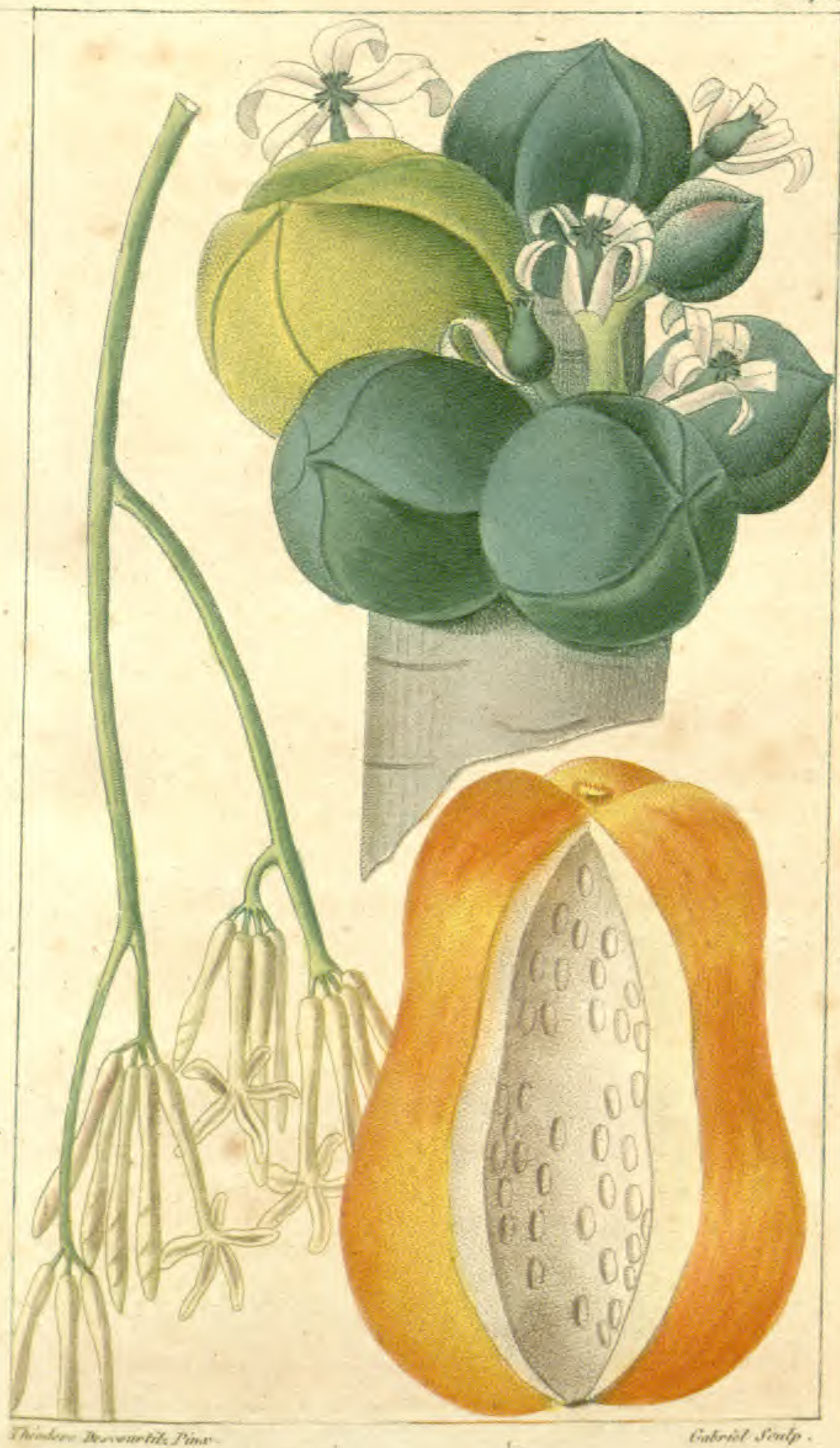

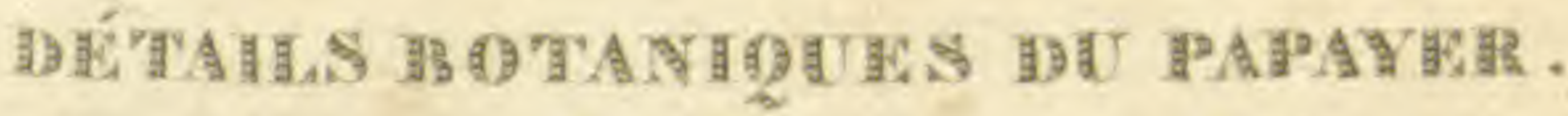


19.49.

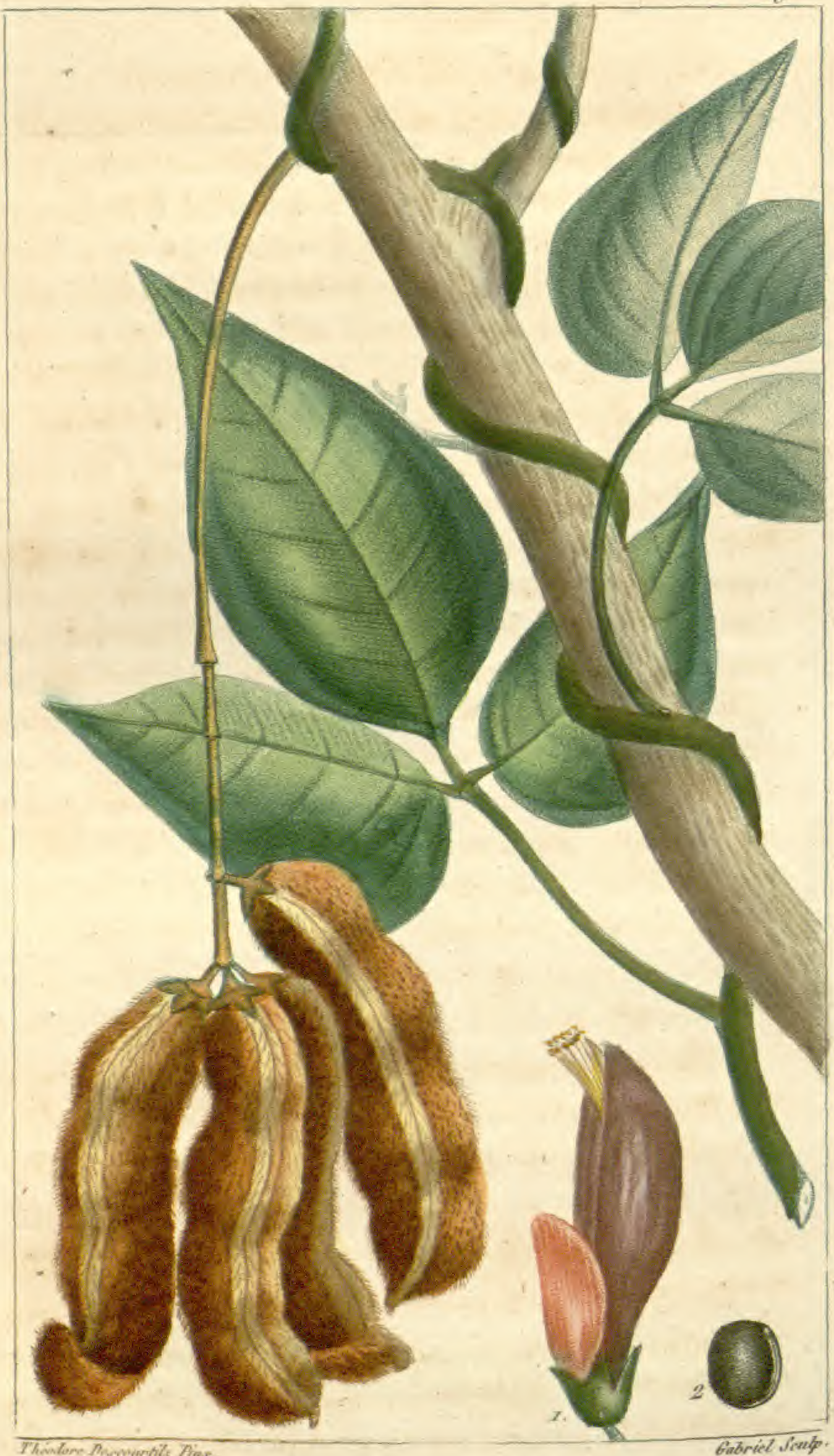

GDOHAC A HOHLS GUHSANS. 


\section{omol. DOLIC A POILS GUISANS.}

oras Jnay

\section{(Stomachique vermifuge.)}

Syronymre. Vulg. Pois Pouilleux ou Pois à gratter. - Dolichos pruriens Lin. Diadelphie décaudrie Dolichos volum bolis, leguminibus racemosis; valvulis sub-carinatis, hirtis, pedunculis ternis. Iin. - Jacquin. amer. 2oI, tab. 122, et Pict. 99, táb. 188, mill. Dict. n 3 . Phaseolus hirsutus, virgatus, prurigineus floribus racemosis magnis atro-purpureis, et, fœtidissimis Pum. spec. 8 , miss a , tab. $9^{2} ;-$ Phaseolus utriusque india lobis vilJosis pungentibus minor 'slopan; jam. hist. a, pag. 37. Phasẹtus americanus; folio molli lanugine obsito, siliquis pungentibus, semine fusco, punctato. Pluk, tab. 214 , fig. 1 , - Nai-corona. rheed molab. 8 , pag. 61, tab, 354 Raj. suppl. 444. - Fabas cuseira. Lusit. maagde Krugt. Belg. cacarad. pruritus. rumph. amb. 5 , pag. $39^{3}$, tab. 142. - Strizolobium Brwn. jam. 290. - Mantia Kaira des Carailbes. - Tournefort, class. 10. papillonacées. - Juss. fam. des léguminenses.

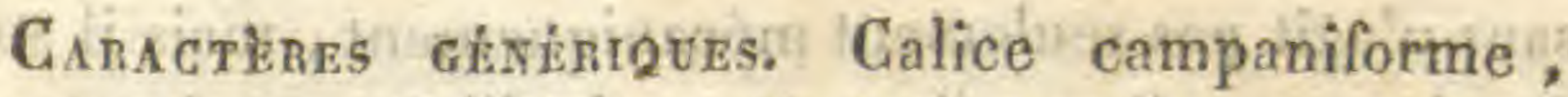
étendard arrondì; deux callesilés a sa base; gousse allongée (Dolichos, $\Delta$ orvoxos, long)'; grainés elliptiques, comprimées; un ombilic sur l'un des còtés (Lam.).

Caractènes particulinas. Tige volubile, légumes en grappe; valvules comme carrênées, hérissées; pédoncules ternés. Etendard de la corolle, ovale; trois fois plus petit que les autres pétales. 


\section{(2x2)}

Historne Natonblue. Malheur au hardi botaniste qui. veut moissonner des fleurs auprès du dolic à poils cuisans; ne fit-il que secouer légèrement l'arbre qui donne appui à la tige sarmenteuse et grimpante de cette liane, qui s'étend èt 's'attache jusqu'aux sommet des habitans séculaires des forêts, il sera puni de son inexpérience; la moindre agitation de l'air soufle et dirige vers lui un duvet court et brun trés-brillant, tellement pénétrant que les pores de la peáu ne peuvent lui refuser passagè. Il en résulte une démangeaison excessive, cuisante, et d'autant plus incommode , que plus on frotte la partie, et plus on enforice ce corps étranger dont la présence devient alors insupportable. Be mauvais plaisans, dit Valmont-Bomare, metteht quelquefois de ce duvet dans le lit des nouveaux mariés pour tes empêcher de dormir, et les en faire sortî̀. J'ai été témoin d'une plaisanterie de ce gente au Gros Moine (Ale Saint-Domingue), chez un habitant qu'un ñègre délivra bientôt de ses souffrances, en le fásant frictionner avec un mélange de beurre, de cacao et de cendres chaudes. Cette plante se reneontre dans les bois et sur les terrains incultes. Le dolic à poils cuisans n'agit pas seulement mécaniquement, mais il sort de chaque poil une liqueur particulière caustique que la pointe du duvet inocule.

Caractibaes physiques. Les tiges de ce dolic, sont cylindriques, légèrement velues, grises, volubiles et grimpantes.

Les feuilles amples, sont composées de trois folioles ovales pointues; les deux latérales ont leur côté extérieur plus grand, plus large et à coude arrondi; ceł 


\section{$(2.23)$}

folioles sont d'un vert gai et presque glabres en dessus, couvertes en dessous de poils fins, luisans et couchés, et sont presque sayeuses des deux côtés dans la jeunesse.

Les fleurs viennent sur des grappes axillaires, solitaires, pendantes, lậches, longues d'un pied et plus, et garnies de dix à trente fleucs, suivant les terrains.

Les pédoncules propres sont courts et disposés trois à trois par étage. Ges fleurs légumineuses ont le calice rougeậtre velu; leur étendard couleur de chair et beaucoup plus court que les autres pétales; les ailes oblongues, obtuses, d'un violet pourpre, et leur ca rêne linéaire, pointue, à pointe courbe et montante, d'une couleur vert-blanchâtre.

Les gousses sont longues de trois pouces, presque de l’épaisseur du doigt, médiocrement comprimées, courbées en $\mathrm{S}$, munies sur le côté et au milieu de chaque valve, d'une cộte tranchante et longitudinale, et abondamment chargées de poils rousseâtres, brillans; ces gousses contiennent trois ou quatre semences ovales, lisses brunes avec un ombilie blanc (encycl. méth. )

ANalyse chimique. " La démangeaison atroce que font éprouver les poils du dolic dont nous partons se guérit de suite par l'application de la cendre chaude; ce qui paraîtrait annoncer une combinaison et un prodúit du poil analogue à l'acide oxalique observé dans les pois chiches par M. Deyeux. 2

Propriétés mípicales, le docleur Gilbert, dans son exercice à Saint-Domingue, a reconnu les propriétés. anthelmintiques du dolic à poils cuisans; mais il faut * 


\section{(22f)}

dit-il, adoucir l'action mécanique irritante du duvet, en l'écrasant, le mêlant ensuite à un sirop simple, ou le prescrivant dans de la bouillie de farine de maîs.

Le duvet de ce dolic est employé par les nègres comme vomitif. Selon Rhéed, les graines du pois à gratter sont aphrodisiaques ; il recommande la décoction de la racine dans le catharre vésical, comme diurétique.

Mode D'administration. M. $\mathrm{X}^{\star \star \star}$, se méfiant des propriétés suspectes, quioique non contestées da dolic à poils cuisans, qu'il croit peut-être trop souvent preseritdans les affections vermineuses, indique le procédé suivant comme capable d'en émousser l'activité.

"On prend, dil-il, dix a douze légumes garnis de n leurs poils, on les jette dans une bouteille ordinaire, - et on rerse par dessus un quart de syrop (eau mère - du sucre) et le reste d'eau. On agile fortement, et $\Rightarrow$ on laisse infuser du soir au lendemain; on l'admix nistre par cuillerées pendaut trois jours, suivant $\rightarrow$ l'âge, ayant l'attention de faire manger de suite a - Y'enfạnt, une cuillerée de farine de manioc sèche " (ou de tout autre poudre absorbante). Ce moyen - fait toujours rendre des vers; on purge après cela D avec l'huile de riein. "

EXPLICATION DE LA PLANCHE QUARANTE-NEUVIKME.

La plante est réduile à moiltúe de grandeur naturelte.

Fig, x. Flenr.

Fig. 2. Graine,

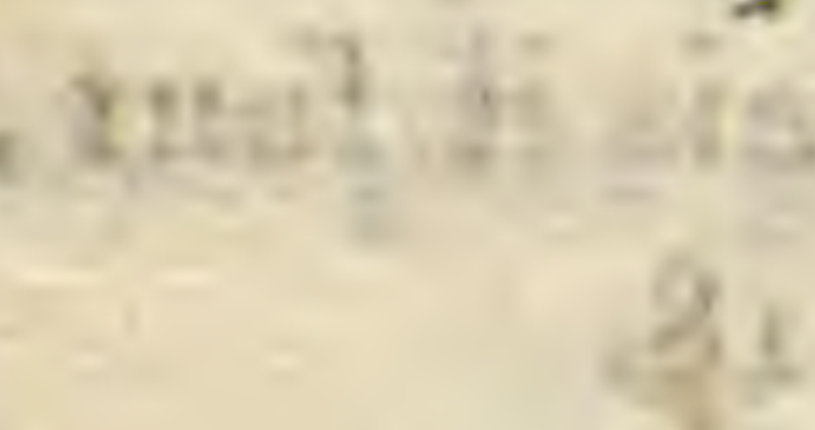


PL. оั.

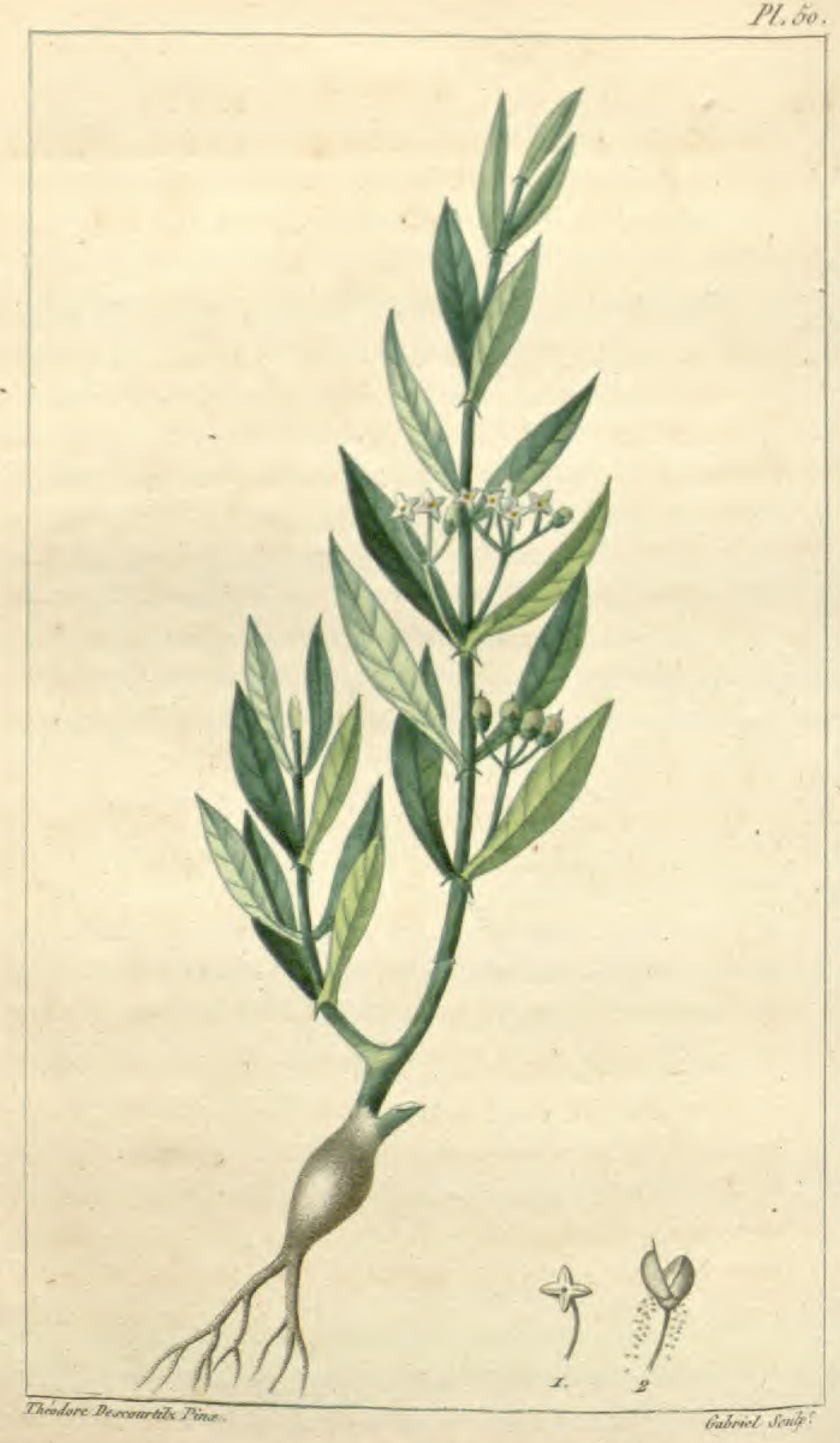

0H 


\section{$(225)$}

\section{OLDENLANDE A CORYMBES.}

(Stomachique anthelmintigue.)

Sysoxyure. Vulg. mille graine à feuilles d'hysope, Oldenlandia corymbosa. Lin, tétrandrie monogyrie. - Jussieu, famille des rubiacées. - Oldenlandia foliis lineari lanceolatis pedunculis multifloris, axillaribus; umbellis laxis, sub-quadrifloris; Lamarck. illust. genr, n. 1428, tab. 61 . - Oldenlandia pedunculis multifloris, foliis-lineari lanceolatis. Lin. syst. plant. 2, pag. 338. - Oldenlandia caule tenerrimo foliis lineari oppositis, ramulis minimis floriferis pedunculis ramosis et simplicibus. Brwn. jam. 146. - Oldenlandia humilis hysopifolia. Plum. gen. 42, icon. 212 , fig. 1. - Eheret. pict. tom. 2 , fig. 1.

Caractères genérieves. Corolle à quatre divisions; calice supérieur à quatre dents; quatre étamines, un seul style. Capsule inférieure à deux loges polyspermes.

Caractìres particulizrs. Pédoncules multiflores; feuilles linéaires lanceolées.

Histoire naturelle. Humble dans son port, l'Oldenlande à corymbes croissant fraternellement au milieu de plantes plus remarquables, serait négligée, si des vertus médicinales ne la tiraient de l'oubli auquel elle semble devoir être destinée. Mais ses propriétés la font rechercher et préférer à des espèces beaucoup plus éclatantes. 


\section{( 226 )}

d'abord couchées, ensuite elles se redressent et se divisent en rameaux longs d'environ six pouces, droits, lisses, faibles, tétragones.

Les feuilles sont opposées, étroites, lanceolées, lisses, ayant la nervure du milieu très-saillante, vertes en dessus, un peu blanchâtres en dessous, un peu scabres à leurs bords, sessiles, et longues d'environ un pouce.

Les stipules sont très-obtuses, opposées, formant autour de la tige une gaine qui réunit les feuilles par leur base. Elles sont terminées par trois filets courts et soyeux.

Les fleurs sont alternes dans les aisselles des feuilles, portées sur des pédoncules latéraux, nus, filiformes, de la longueur des feuilles, ils se divisent à leur sommet en quatre pédiculles presque égaux qui partent du même point, et forment une petite ombelle à quatre fleurs : quelquefois les pédoncules sont parfaitement simples, ou portent seulement deux ou trois divisions.

La corolle est petite et blanche, monopétale en forme de rayon. Le pistil devient un petit fruit ou coque ronde, qui se partage en deux capsules remplies de petites semences très-fines. (Encycl. méth.)

Asauyse chimieug. L'alcool et l'eau s'emparent également des vertus de cette plante. Son infusion aqueuse noircit la solution du sulfate de fer.

Propriétes médicinales. L'Oldenlande à corymbes est vermifuge. On l'emploie aussi dans les cataplasmes résolutifs, et contre les obstructions de la rate; cette plante peut être de quelque secours dans les affections goutenses, compliquées d'alonie du canal alimentaire . 


\section{(227)}

qui prédisposent à une diathèse vermineuse. Elle fait quelquefois partie des espèces pectorales ì la fin des catarrhes pulmonaires, lorsqu'il s'agit de donner du ton à la membrane muqueuse.

Mode d'administration. On administre l'Oldenlande en poudre à la dose de deux gros, ou en infusion, faite à froid, à la dose d'une once par chopine de véhicule. Je préférais employer les fleurs, les sommités et les graines.

Nota. On trouve encore aux Antilles, $1^{\circ}$ l'Oldenlande à feuilles de serpolet, Oldenlandia serpylloides (Gnadeloupe); $2^{\circ} 1^{2} \mathrm{Ol}=$ denlande uniflore, oldenlandia uniflora (Jamäque); 30 l'Oldenlande à longues fleurs, oldenlandia longiflora. Lam. (Martinique),

EXPLICATION DE LA PLANCHE CINQUANTIEME.

La plante est de grandeur naturelle. 


\section{(228)}

\section{POURPIER TRÈS-AMER.}

\section{(Stomachique anthelmintique.)}

Synonymit. Portulaca maritima amarissima, rotundifolia. Plum., tom. 3, pag. 146.

En espagnol, Verdolaga.

$\left.\begin{array}{l}\text { En portugais, Beldroega. } \\ \text { En anglais, Purslane. }\end{array}\right\}$ (Flor. du d. D.,Sc. méd.)

Garactìres géneriougs. Un calice imparfait, une corolle à cinq, souvent à quatre pétales; de six à douze étamines; un style court; une capsule s'ourrant transversalement.

Garactìres particuliers. Feuilles opposées charnues elliptiques, à base des pétioles vaginée, fleurs rouges axillaires; sessiles, à cinq pétales stelliformes , tige en corymbe, six étamines.

Histoire naturelle. Plumier parait seul avoir indiqué et décrit cette plante; car parmi beaucoup d'espèces de ce genre que j'ai analysées, aucune à la comparaison, ne parait permettre de rapprochemens entre cette espèce et beaucoup d'autres déjà connues. Ce pourpier, sans cesse arrosé par l'onde salée, se plaît sur le rivage de la mer, et n'est employé qu'en médecine; son amertume extrême, en éloigne les oiseaux de mer et des rives, et le nègre même, qui recherche avec soin les autres espèces de pourpier pour les calalous, dont il fait sa nourriture, craint souvent d'y faire entrér celui-ci. 


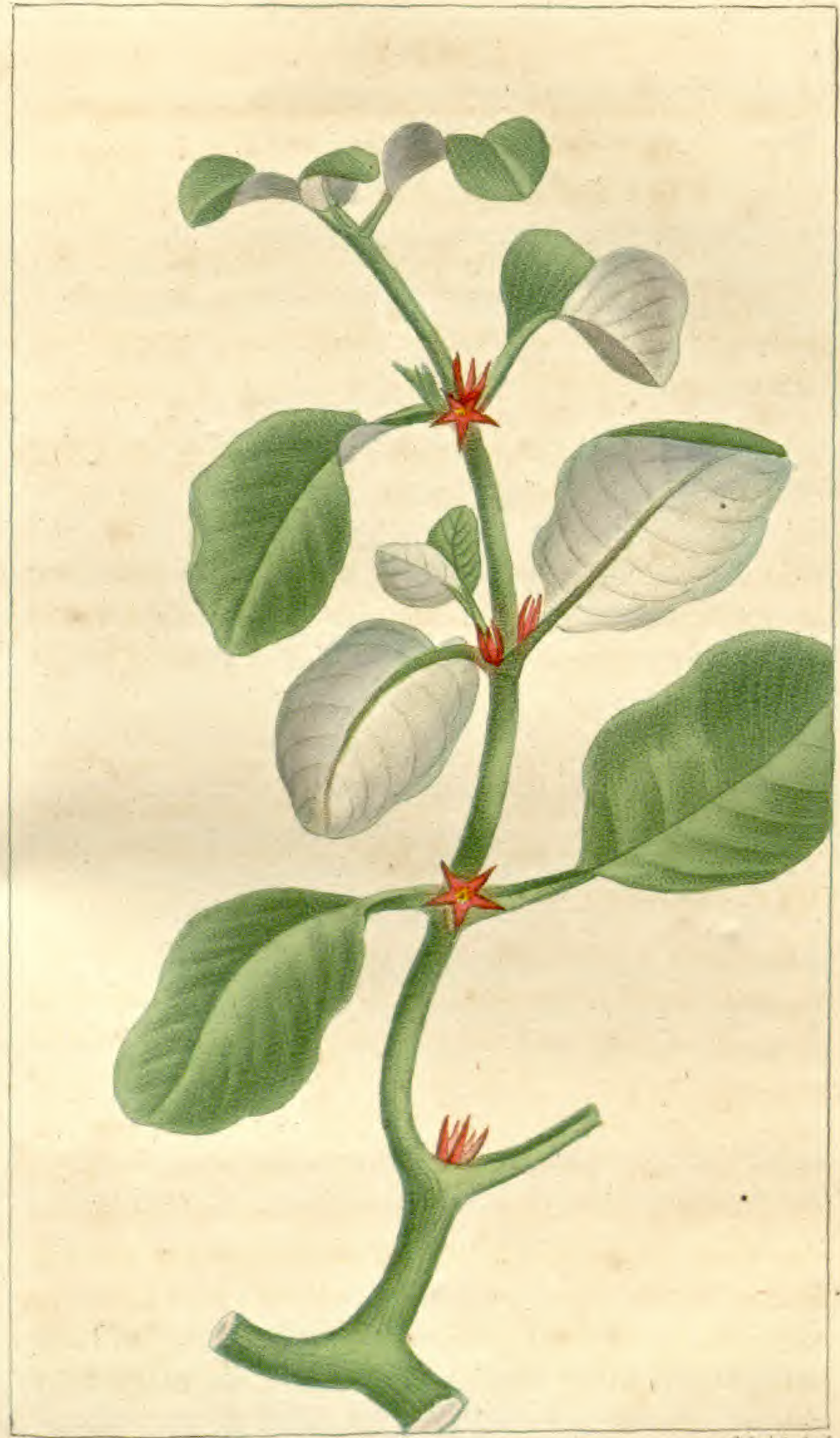




\section{$(229)$}

Caractikns physiedes. Les tiges du pourpier amer, sont glabres cylindriques, d'abord couchées, puis fournissant des rameaux disposés en corymbe, c'est-àdire partant du mểme point; ceux-ci sont redressés , et d'un vert jaune.

Les feuilles sont opposées, elliptiques pétiolées, épaisses, charnues, succulentes. Le péliole, moitié de la grandeur de la feuille, est creusé en goutière à sa base, qui est fort large, et presque ámplexicaule, ce qui fait paraître les feuilles supérieures comme perfoliées. Vertes en dessus, argentées en dessous. Les flurs prennent naissance dans cetle gaine pétiolaire. Elles y sont disposées au nombre de deux à quatre sessiles, à cinq pélales terminés par une pointe droite et piquante; elles sont stelliformes, d'un beau rouge; les étamines sont au nombre de six, de la couleur des pétales. Ces fleurs s'ouvrent pendant le jour, et se ferment à la fraicheur des nuits.

Aux fleurs succèdent des capsules oblongues s'ouvrant transversalement.

Analyse chimique. Ce pourpier donne une petite quantité de tanin, une eau acide adsolument inodore, mais légèrement mucilagineuse. Son âcreté première disparait par l'effet de la coction.

Propnítís mídicales. Ce pourpier, loin d'être raffraichissant, cumme plusieurs autres espèces de ce genre, est doué d'une qualité amère qui le rend tonique et stimulant des membranes muqueuses, c'est pourquoi on l'emploie dans les cas d'atonie et d'engorgement de ces parties, dans toutes les circonstances, en un mot, où il s'agit d'exciter les organes 
(23o)

digestifs. On le prescrit avec beaucoup d'avantages, dans les affections vermineuses.

Mode d'administration. Son suc exprimé se donne à la dose de deux à quatre onces. Poupée Desportes le prescrivait à celle d'une demie poignée par pinte de décoction.

EXPLICATION DE LA PLANCHE CINQUANTE-UNIÈME.

Le dessin de la plante est exécuté de grandeur naturelle. 
PI. D2.

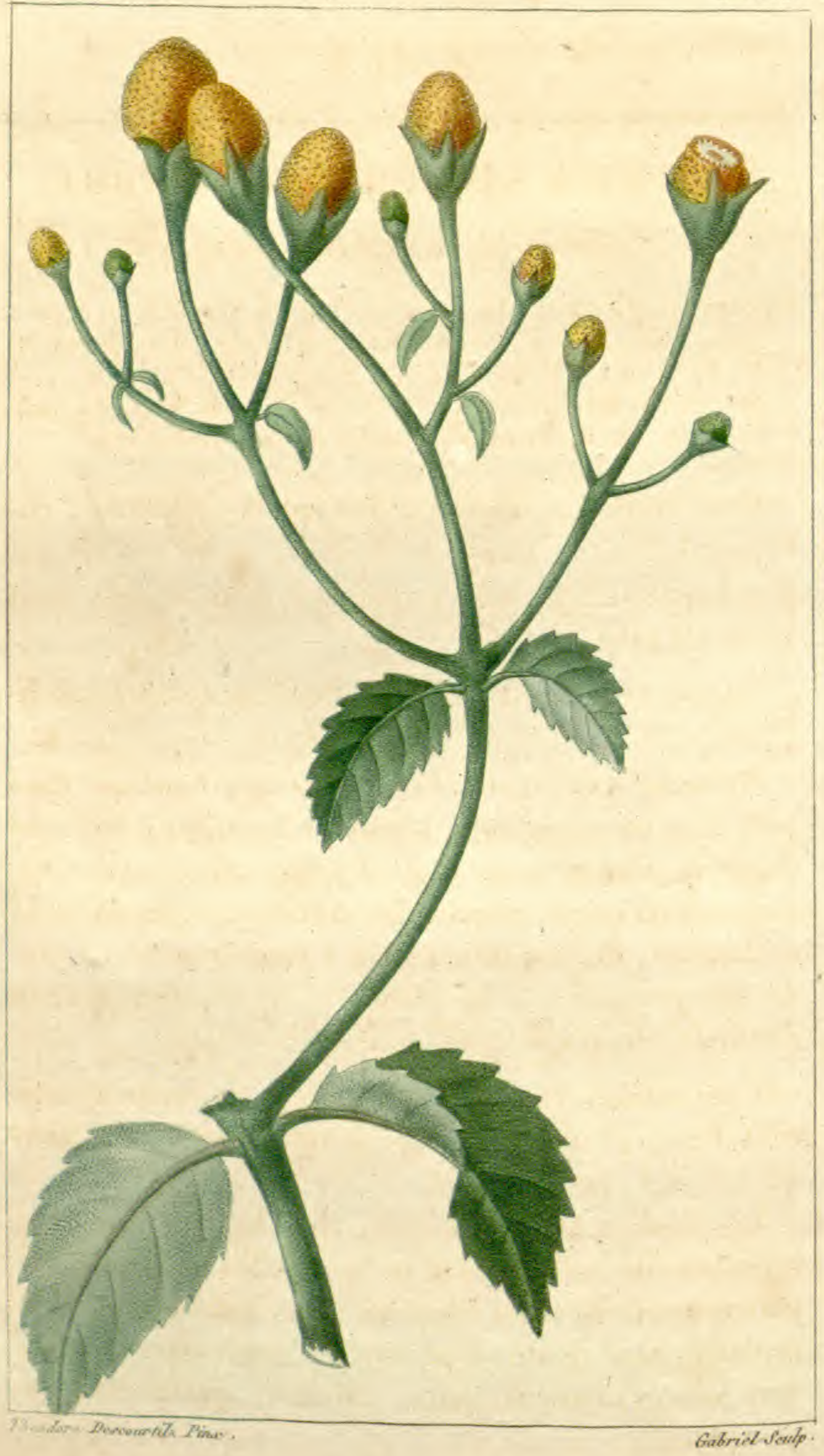

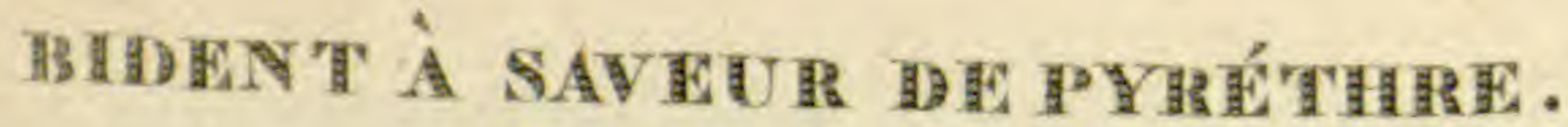




\section{(23I)}

\section{BIDENT A SAVEUR DE PYRÊTHRE.}

\section{(Stomachique anthelmintique.)}

Syronymie. Cresson du Para. - Bidens fervida, - Bidens foliis subcordatis, serrulatis, petiolatis, flore luteo $N$. - Spilantus oleracea. Lin. Syngenesie Polygamie. Santolina humifusa pyretri sapore. Pum. gen. ro, vol. IV, pag. 46. - Jussieu, famille des Corymbifères.

Caractiores géneriques. Réceptacle paillassé, conique; calice de plusieurs folioles, deux extérieures plus longues. Semences solitaires à deux arêtes, dont l'une est plus longue.

Caractères particuleres. Feuilles comme cordiformes, dentées en scie (Joliclerc).

Historke natunele. Les bidens ayant quèlque rapport avec les santolines, plusieurs botanistes leur ont donné ce dernier nom; mais il nous suffit de faire remarquer ici que la plupart des santolines appartiennent à l'Europe, et au continent de l'Amérique nord, tan-

- dis que presque tous les bidens ne se trouvent qu'aux Antilles et dans quelques contrées de l'Asie.

Caractimes physiques. Lés tiges de cette espèce sont basses, longues de sept à huit pouces, cylindriques vertes, peu feuillées.

Les feuilles sont opposées, rhomboỉales, pointues à l'extrémíté, arrondies à la base; elles terminent dès pétioles environ aussi longs qu'elles; leur contour est grossièrement denté; leur surface supérieure est lisse vert pâle, l'inférieure jaune grisâtre, quelquefois tomenteuse. 


\section{( 232$)$}

Les pédoncules sont nuds, allongés; portant à leur. base une petite bractée linéaire caduque.

La fleur est grosse, hémisphérique ou conique, composée d'une quantité de fleuronş très-serrés, séparés par des paillettes, et d'un jaune d'or.

Proprietís mípicinales. Le bident à saveur de pyrêthre, est une plante ấcre et échauffante, qu'il ne faut employer qu'avec prudence. Poupée Desportes, Chevalier, et autres praticiens, nous l'ont indiqué comme hydragogue et sialalogue; mais je lui ai reconnu des prepriétés anthelminiqués bien plus certaines: cependant, pour prévenir tout danger, on ne doit pas l'administrer, quand la diathèse vermineuse est accompangée d'un état d'inflammation des visères abdominaux; car l'usage en serait dangereux. On se sert de la racine comme masticatoire.

Propréités chimeves. L'eau et l'alcool s'emparent facilement des principes iconstituans de ce bident. Le dernier menstrue surtout retient son principe aromatique. L'infusion aqueuse contenant du tanin, noircit en y ajoulant du sullate de fer.

Mode d'admixistration. La préparation daphis or dinaire de ce bident, consiste à le faire prendre en infusion théiforme, et en décoction par clystères; dans ce dernier cas, on peut monter la dose jusqu'à une once pour une chopine d'eau; tandis que poup en obteniriune infusion salutaire et incapable de nuire, on ne peut la permettre qu'à la dose d'un demi-gros pour qualre onces d'eau bouillante; on en fait aussi un syrop qu'on donne aux enfans par cuillerées à café.

IXPLICATION DE LA PLANCHE CINQUANTE-DEUXIËME.

Le dessin est exécuté de grandeur naturelle. 


\section{( 233 )}

\section{ANGELIN A GRAPPES. \\ (Stomachique anthelmintique.)}

Srrorme. Andira racemosa, andira foliis impari-pinnatis; foliolis oppositis, lanceolatis, integerrimis, floribus racemosis. - Andira vulgó angelin. Pis. Bras. pag. 175. Angelin racemosa foliis nucis. juglandis Plum. m. 121 .

Caractères botanioues. Fleurs petites, sessiles, disposées en grappe paniculée et terminale, sur des pédoncules velus. Galice monophylle, court, à cinq petites dents; étamines réunies dans leur partie infé rieure; ovaire ovale oblong. Pédicule, chargé d'un style en aleine, et hors de la gaine formée par les filets des étamines. Fruits ovö̈des pédiculés, terminés par une pelite pointe, munis d'une côte longitudinale, pubescens, durs, presque ligneux (Encycl. méth.)

Histoine maturelie. Les formes extérieures de l'Angelin à grappes rappellent à l'Européen expatrié, de doux souvenirs, puisque de loin il croit voir un arbre du pays qui l'a vu naître, le noyer, avec lequel l'Angelin a beaucoup de ressemblance. Cet arbre se plait dans la plaine et sur les mornes boisés, où on le rencontre fréquemment.

Caractènes pirysietes. Cet arbre s'élève jusqu'a cinquante pieds, sa tête est vaste et touffue, son tronc a environ trois pieds de diamêtre, son bois est dur, et d'un rouge noirâtre à l'intérieur.

Les rameaux sont garnis de feuilles alternes, ailées avec impaire, et composées de sept ou neuf folioles lancéolées, pointues, très-entières, opposées et portées chacune sur un pétiole court.

Les fleurs sont petites, disposées en grappes paniculées aux extrémités des branches. Elles produisent des fruits de la grosseur d'un ceuf de pigeon, ovoïdes. s4e Livraison. 
Pl. if.

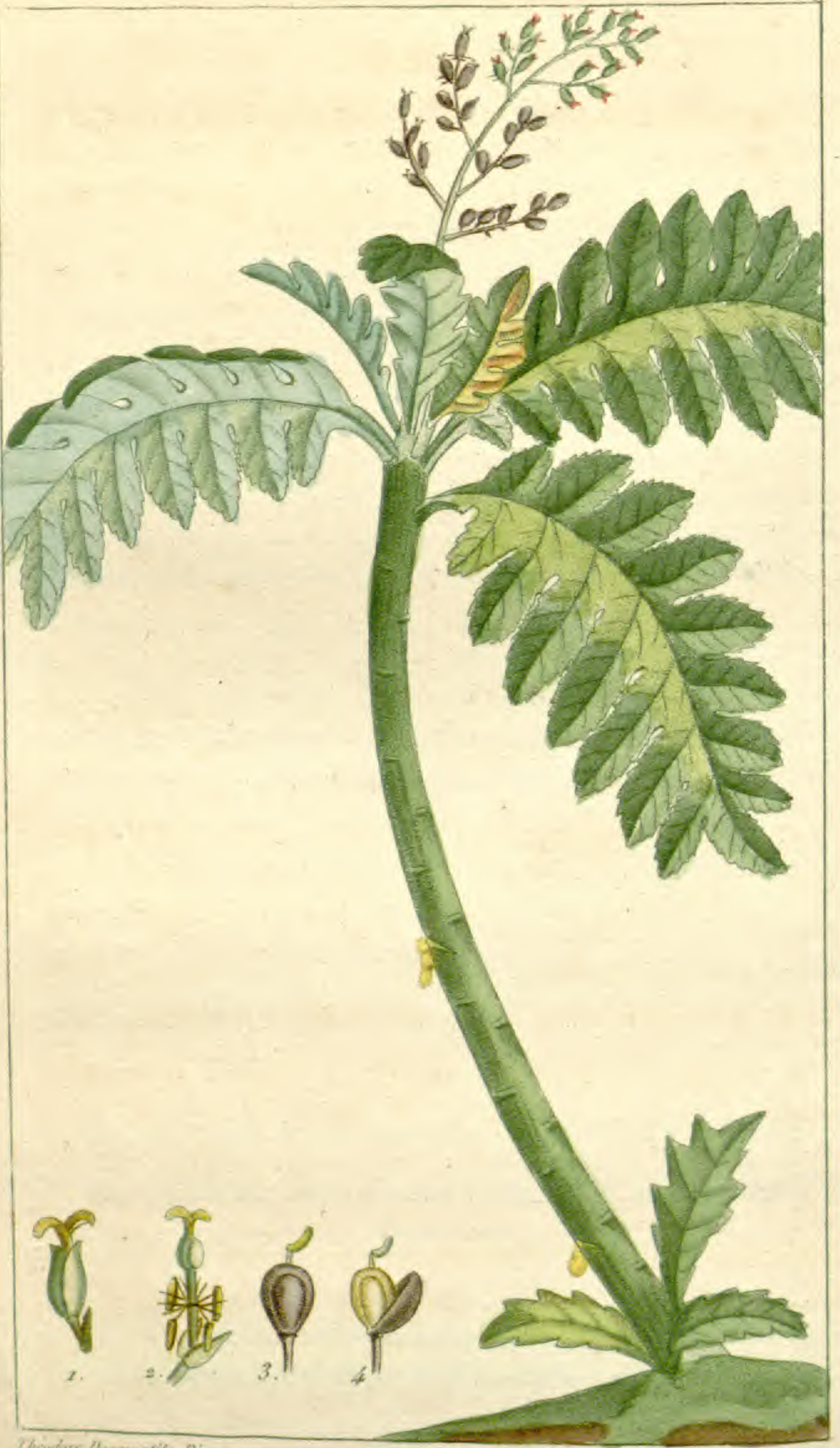

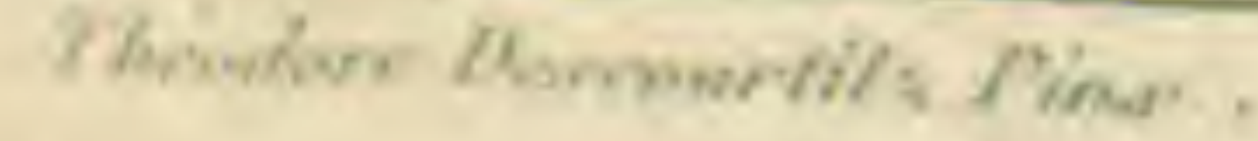

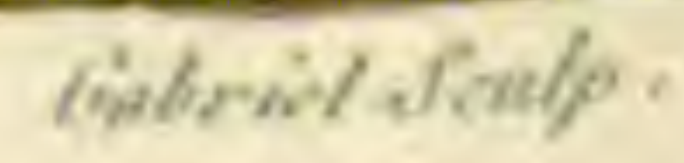

HOCCONHA C H H 


\section{(234)}

verts au commencement, ayant leur superficie parsemée de petits points blancs, et munis d'une côte longitudinale d'un seul côté; cette carêne a l'aspect d'une suture. Ce brou renferme une coquedure, rousseâtre, qui contient une amande amère et d'un mauvais goût.

Analyse cmmeve. L'écorce, le bois et le fruit do l'Angelin, au rapport de Pison, sont amers comme de T'aloës. L'eau dissout celte partie amère, tandis que l'alcool se charge de la partie résineuse. C'est tout ce que ma mémoire peut me rappeler. Mon travail exécuté avec M. Prampein, chimiste altaché au gouverneur de Saint-Domingue, ayant été perdu par suite des funestes évènemens de celte colonie infortunée.

Proprítés mídicinales. On accorde à l'écorce, au bois et surtout à l'amande des fruits de l'Angelin des propriétés anthelmintiques; mais le danger que l'on court en outrepassant la dose convenable, fait que ce vermifige ne peut être administré que par un homme de l'art.

Mode d'administration. L'écorce et le bois mis en poudre, se donnent depuis douze jusqu'à trente six grains. Quant au noyau pulvérisé, il ne peut être prescrit qu'audessous du poids d'un scrupule, car il devient délétère à plus forte dose.

EXPLICATION DE LA PLANGHE CINQUANTE-TROISIÈME.

Le dessin est réduit aux deux tiers de grandeur naturelle.

Fig. 1. Fleur entière.

Fig. 2. Fleur décomposée.

F g. 3. Ovaires et Étamines. 


\section{BOCGONIE FRUTESCENTE.}

\section{(Stomachique anthelmintique.)}

Synonymie. Bocconia frutescens. Lin. Dodecandrie monogynie. - Bocconia frutescens chelidonii foliis majoribus, floribus racemosis. V. L. Poupée-Desportes: - Bocconia. hort. ceiff. 202. - Jacq. amer 149. - Bocconia racemosa spondilii folio tomentoso. Plum. gen. $35 \mathrm{r}$, vol. 4 , pag. 19. - Trew. erh. t. 4. - Bocconia racemosa, foliis majoribus, sinuatis, racemis terminalibus. Brown. jam. 244. - Chelidonium majus arboreum, foliis quercinis. Sloan. jam. hist. $x$, pag. 195. t. - Cocoxihuitl. herm. max. 158. - Juss. fam. des papavéracées.

Caractères générieues. Calice caduc, ordinairement diphylle; corolle communément tétrapétale; étamines définies, 1 ovaire; 1 style ou stigma; 1 capsule; graines attachées aux cloisons de la capsule; tiges herbacées, rarement ligneuses; feuilles alternes.

Caracteres particuliers. Cal. 3 feuilles caduques, concaves aiguës; corolle 0 , étam. 8 ou 10 filets très-grèles dont 4 sans anthères, 1 style; 2 stig. ; ovaireporté sur un pédicelle, péricarpe charnu, comprimé. uniloculaire, Bivalve. (Lamark.)

Historre naturelle. Arbrisseau indigène à la Jamaïque, à l'île de Cuba, à Saint-Domingue et autres. sles antilles, la Bocconie frutescente s'élève à la hauteur de huit à neuf pieds, et a du rapport avec les par- 


\section{( 236 )}

vots et les chélidoines, quoique sa fructification l'en éloigne. Sa tige est creuse et remplie de moëlle comme celle du sureau d'Europe, it en transude un suc jaunâtre, dont on se sert pour teindre de cette couleur. On le trouve dans les bois, et dans les savanes humides.

Caractínes physigees. Son tronc est inégal, creux, et rempli de moëlle, il est divisé supérieurement en quelques rameaux cylindriques, cassans, et marqués de cicatrices que laissent les feuilles après leur chute. Toutes ses parties sont pleines d'un suc jaunâtre semblable à celui de la chélidoine.

Les feuilles sont assez grandes, alternes, ovales, oblongues, sémi pinnatifides, sinuées, à découpures ovales et dentées inégalement, vertes, et glabres endessus, d'une couleur glauque en-dessous, avec un duvet rare; et portées sur des pétioles courts. Ces feuilles ont 16 ou 17 pouces de longueur, sur une largeur de près de 6 pouces, et donnent à cet arbrisseau un aspect assez agréable.

Les fleurs sont pétiolées, verdâtres, nombreuses, disposées en panicule ample, et pyramidale. Chaque rameau en porte une à son extrémité. La fleur consiste en un calice de deux pièces ovales, oblongues, concaves, et caduques, et d'un vert gai; en douze ou seize étamines jaunes, dont les filets horizontaux portent autant d'anthères linéaires et pendantes, aussi longues que les folioles du calice; en un ovaire supérieur obrond, pédiculé, surmonté d'un style épais et sémi-bifide, ayant deux stigmates ouverts et réfléchis, 


\section{( $23 j)$}

Le fruit (qui paraît être une silique charnué) est̂. bvale oblong, pointu aux deux bouts, muni d'un petit rebord longitudinal de chaque côté, ce qui le fait paraître aplati. Il est d'un pourpre violet, et contient une semence de même forme et verdâtre. (Ency. méth. )

Analyse chmreve. Le suc, couleur de safran, est piquant, âcre, caustique, un peu amer, d'une odeur forte, volatile et nauséeuse.

Proprítéts médicinales. La Bocconie excite vivement le canal alimentaire, aussi l'ordonne-t-on dans 1'hydropisie, les atrophies mésentriques, et dans 1'ictère. Son suc déterge les ulcères, et les dartres; mais sa principale propriété est d'être vermifuge et purgative.

Mode d'administration. On ordonne la Bocconie en décoction à la dose de deux ou trois gros de sa racine dans une livre et demie d'eau. On la fait prendre aussi en infusion vineuse, comme amère, et propre à fortifier et stimuler les voies digestives. Le suc de la plante étant plus héroïque, se donne à petite dose. Un gros dans du bouillon de poulet, suffit comme tonique, administré deux fois par jour.

On obtient un bon collyre détersif, par la combinaison de quelques gouttes de ce suc dans une once d'eau, quel'on emploie contre les ulcères des paupières. Les feuilles pilées et infusées en eau de vie fournissent un vulnéraire et un bon résolutif.

Une once des feuilles de Bocconie et de tabac vert, deux gros de racine de dentelaire, et une once de mus 


\section{( 238 )}

riate de soude, offrent une très-bonne lation, contre certaines espèces de dartres.

EXPLICATION DE LA PLANCHE CINQUANTB-QUATRIÈME.

La Bocconie est représentée au quinzième de grandeur pour faire voir son port.

Fig. I. Fleur non épanouie.

Fig; 2. Fleur en état d'inflorescence.

Fig. 3. Semence revétne de sa partie corticale.

Fig; 4. Semence à moitié nue. 
$P 1.55$

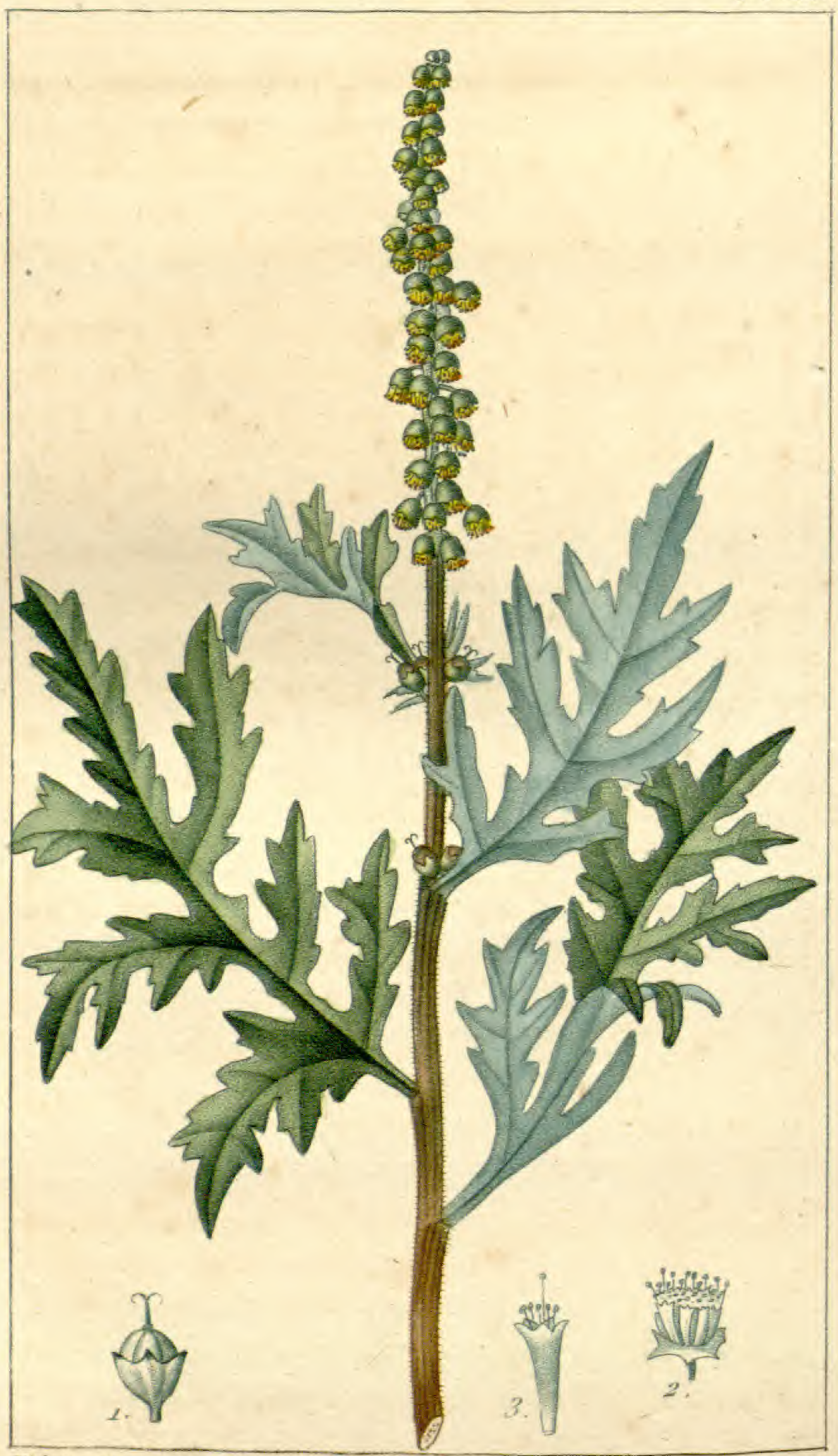

Theodere Damourtila Pinde.

Gubriddiculp:

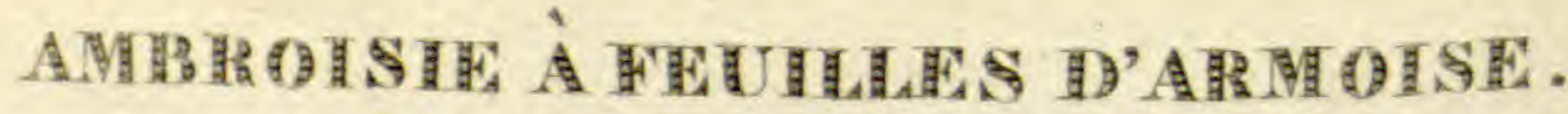




\section{(239)}

\section{AMBROSIE A FEUILLES D'ARMOISE.}

\section{(Stomachique vermifuge.)}

Synonymie. Ambrosia artemisifolia elatior. Lin. monoëcie Pentandrie. - Ambrosia maritima artemisiæ foliis inodoris elatior. Herm. Iugdb. 32. - Tournefort, Flosc., sect. r, 438, raj. suppl. rog.-Ambrosia frutescens, matricariæ facie. inodora. Poup.-Desp. Jussieu, famille des corymbifères. - Atyonaragle en Caraïbe.

Caracterres génériques. Fleurs conjointes et monoïques. Mâle, calice commun, monophylle aplati, corolles monopétales tubulées, trifides, infundibuliformes, fleurons munis de cinq étamines à anthères droites, style filiforme, terminé par un stygmate orbiculé et membraneux. (Réceptacle nû.)

Femelle. Calice monophylle, entier, te ventre à cinq dents, uniflore, corolle nulle, noix surmontée d'un style bifide, formée du calice endurci, monosperne.

Caracteres particuliers. Feuilles bipinnatifides, grappes paniculées terminales, composées uniquement de fleurs mâles, les fleurs femelles dans l'aisselle des feuilles supérieures.

Historne naturelle. L'ambrosie à feuilles d'armoise se rencontre aux Antilles, tantôt sur les montagnes, et tantôt sur le bord de la mer; d'ou vient qu'on lui a donné les épithètes de montana et de maritima. Celle plante digne d'occuper une place dans le sanctuaire d'Hygie, est communément employée par les médecins 


\section{(240)}

et par les nègres, ce qui prouve en faveur de ses propriétés.

Caractiores physiques. La tige de celte ambrosíe est branchue, pubescente, et s'élève jusqu'à quatre ou cinq pieds. Les feuilles sont alternes d'un vert un peu blanchâtre surtout intérieurement, profondément pinnatifides, pointues, et à découpures dentées ou incisées. Elles ont quatre à six pouces de long sur trois pouces ou plus de large, et sont munies de pinnules jusqu'auprès de la tige qui les porte, ce qui les fait paraître à peu près sessiles.

Les fleurs mâles forment, par leur disposition, des épis verdâtres ou jaunâtres terminant les rameaux et la tige. Chaque fleur semble renversée, et tournée vers la terre.

Analyse chimque. En évaporant la décoction d'Am * brosie, on oblient une subtance résineuse, un acide végétal et un principe amer.

Propniétés Ménicinales. Plusieurs praticiens des Antilles m'ont assuré y avoir administré avec succès cette Ambrosie dans le traitement des fièvres intermittentes, ce qui prouve qu'elle est douée de vertus toniques et stimulantes, des voies digestives. Elle n'est pas moins recommandable dans les affections gouteuses qui dérivent de l'atonie de cet organe, et dans les leucorrhées chroniques qui supposent défaut d'action des membranes muqueuses du vagin. Poupée-Desportesl'indique comme un excellent résolutif; d'après ma propre expérience, je puis assurer l'avoir employé avec avantage comme anthelmintique. 


\section{$(24 x)$}

Mode d'admintatation. Selon l'indication a remplir, on donne l'Ambrosie en poudre à la dose d'un demi-gros; en infusion à celle d'une once par chopiné d'eau. On retire l'essence par la distillation des fleurs et des sommités dans l'alcool. Elle se donne depuis un gros jusqu'à deux dans une verrée de son infusion. L'extrait del'Ambrosie, qu'on obtient par la macération des feuilles dans l'eau, et préparé suivant les règlęs de l'art, se prescrit depuis un gros jusqu'à deux

EXPLICATION DE LA PLANCHE CINQUANTE-CINQUIB̀ma

Fig. 1, Fleur femelle.

Fig. 2. Fleur mâle.

Fig. 3, Fleur vue au microscope. 


\title{
$(242)$
}

\section{PASSIFLORE A FEUILLES DE LAURIER.}

\author{
Vulg. Ponme de Liane. \\ (Stomachique vermifuge.)
}

Srvorrme. Passiflora laurifolia. Lin. Gynandrie pentandrie. - Tourn. class 6. rosacées, sect. 3. - Jussieu, famille des cucurbitacées. - Passiflora foliis indivisis ovatis, integerrimis, petiolis biglandulosis, involucris Dentatis. I.in. amœn. acad. 1, pag. 220 , fig. 6. - Mill. Dict. $\mathrm{n}^{2} 16$. Jacq. obs. I, pag. 35.-Hort. vol. 2 , 162, et amer. Pict. pag. I1 3 , tom. 219. - Granadilla fructueitriformi, foliis oblongis. Tourn. 241. - Clematis indica, fructu citriformi, foliis oblongis. Plum. amer. 64, tab. 8o. - Raj. suppl. 341. - Petiv. gaz tom. 11/4, fol. 1. - Passiflora arborea laurinis foliis, americana. Plut. alm. 282 , tab. 2 I r, fol. 3. marquieras. Merian. surin. 21, tab.21 (Encycl.méth, a

Caractères géneriques. Trigyne; calice monophylle coloré en dedans; cinq pétales colorés, nectaire en couronne; baie pédiculée. ( Jol)

Caractìres particuliers. Feuilles sans divisions, ovales, très-entières, pétiolées, à deux glandes, involucres dentés.

Historke naturelle. C'est au milieu des forêts enchanteresses des Antilles qu'on trouve en abondance des. pommes-lianes, dont les ramiers et les perroquets sont très-friands. Ces fruits d'un jaune d'or, et les magnifiques fleurs naucées de couleurs éclatantes et variées, sont suspendues à des tiges ligneuses qui grimpent jusqu'au sommet des grands arbres, en s'y attachant parleurs vrilles, et se répandent de tous côtés jusque sur leur cime. Le nègre marron se repait avec délices do 
Pl.S6.

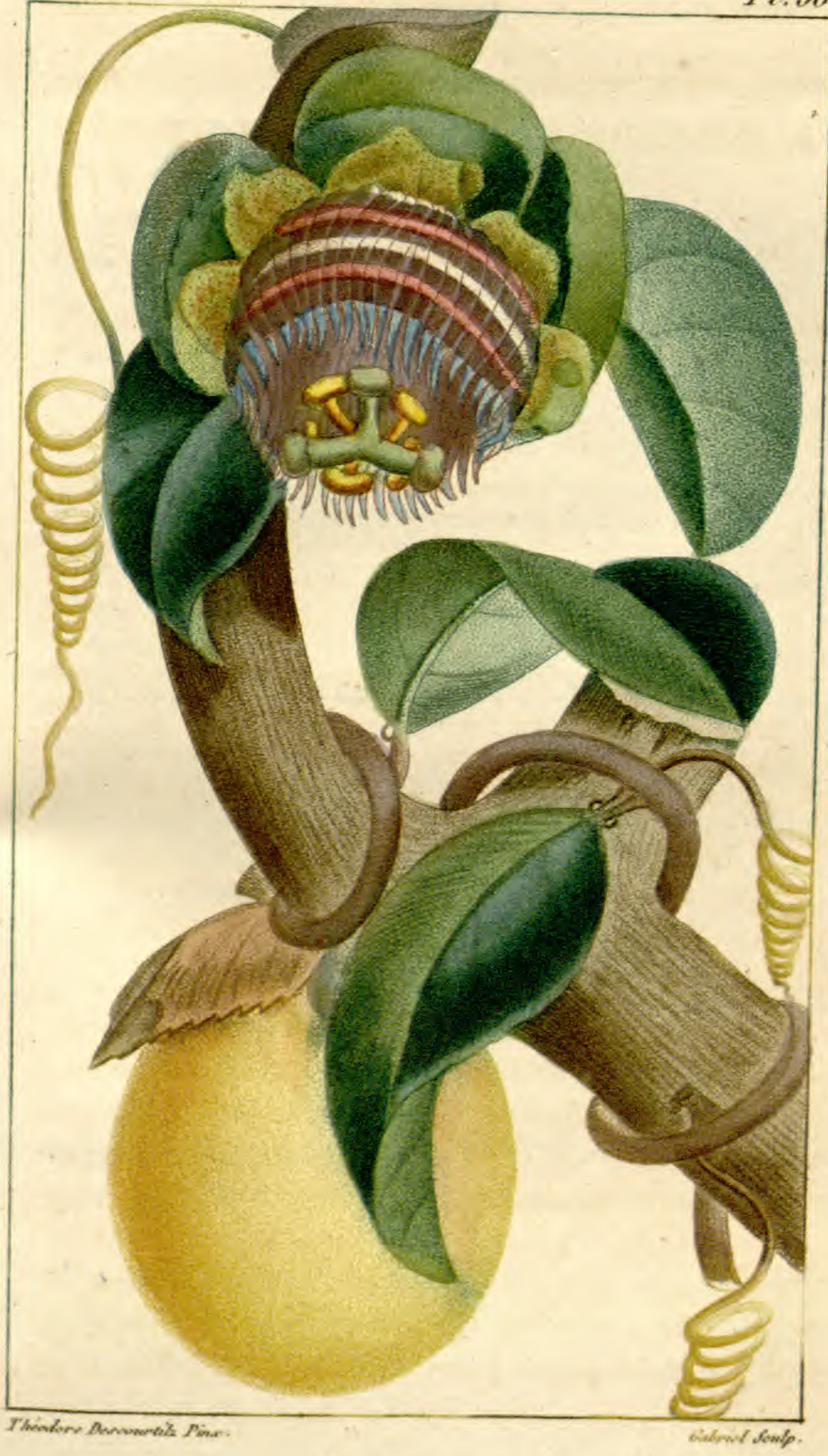

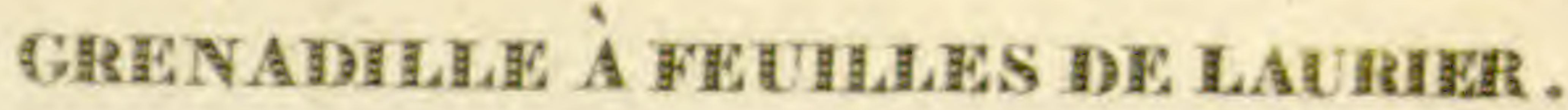




\section{( $\left.24^{3}\right)$}

leurs fruits rafraichissans, tandis que les dames créoles préparent arec son suc, un rob qui peut fort bien remplacer la gelée de groseille.

Caractères physiques. Les jeunes rameaux de cette liane sont herbacés, cylindriques, verts; luisans, ses feuilles sont simples, ovales oblongues, un peu pointues, entières, lisses d'un vert agréable, et ont deux pouces et demi ou trois pouces de longueur; leur pétiole est court, et chargé de deux glandes au sommet. Les pédoncules sont axillaires, solitaires, et portent chacun une fleur mêlée de blanc, de pourpre, et de violet; d'un aspect agréable. Elles sont fort odorantes, et présentent tous les caractères du genre.

Galice monophylle à sa base, ouvert, coloré inté-" rieurement, divisé en 5 folioles ovales profondes, pétaliformes.

Cinq pétales oblongs, planes, ouverts, coloré, attachés à la base du calice, et de même dimension que ses folioles; une couronne particulière en anneau à sa base, frangée à son bord, ou en deux ou trois rangées de filets dont les extérieurs sont plus longs, insérés à la partie interne du calice, entre les pétales, et le support des organes sexuels.

Cinq étamines dont les filamens attachés sous l'ovaire, au sommet de son pédicule, sont très-ouverts sémirefléchis, et portent des anthères transversalement placées. L'ovaire supérieur est arrondi, élevé au-dessus du réceptale sur un support colomniforme droit et cylindrique. Cet ovaire est couronné de trois styles ouverts, épaissis vers leur sommet, ayant la forme de clous, et à stigmate en tête, ce qui a fait donner à celte fleur le nOM de FLEUR DE LA PASSION. 


\section{(244)}

La collerette ou involucre de la pomme de Liane est aussi grande que la fleur; elle est composée de trois folioles ovales, concaves, vertes, et dentées sur les bords.

Le fruit est de la grosseur d'un œuf de poule; d'un jaune citron dans sa maturité, répandant une odeur agréable, et contenant, sous une peau molle et un peu épaisse, une pulpe très-suave, légèrement acide (enc. métho).

Analyse chimtoue. Les fruits de la pomme de Liane, contiennent une pulpe qui fournit de l'acide malique. Les feuilles, au contraire, recèlent une partie extractive amère, et une certaine quantité de Tannin.

Propriétés médicinales. Outre que les fruits de la pomme de Liane sont rafraichissans, qu'il rétablissent l'appétit, chez les personnes d'un tempéramment échauffé, on les permet dans les fièvres angéïoténiques, ataxiques, adynamiques; ce ne sont pourtant point ces propriétés secondaires qui m'ont engagé à placer cette plante dans cette classe, mais elle jouit d'une propriété plus recommandable dans les affections vermineuses, où ses feuilles ont acquis une réputation bien méritée.

Mode d'administration. Les feuilles, réduites en poudre, se donnent depuis un gros jusqu'à deux, dans une verrée d'infusion de la même plante.

EXPLICATION DE LA PLANCHE CINQUANTE-SIXIÈMR.

La tige grimpante de la Pomme de Liane, portant feurs et fruits est réduite à moitié grandeur naturelle. 


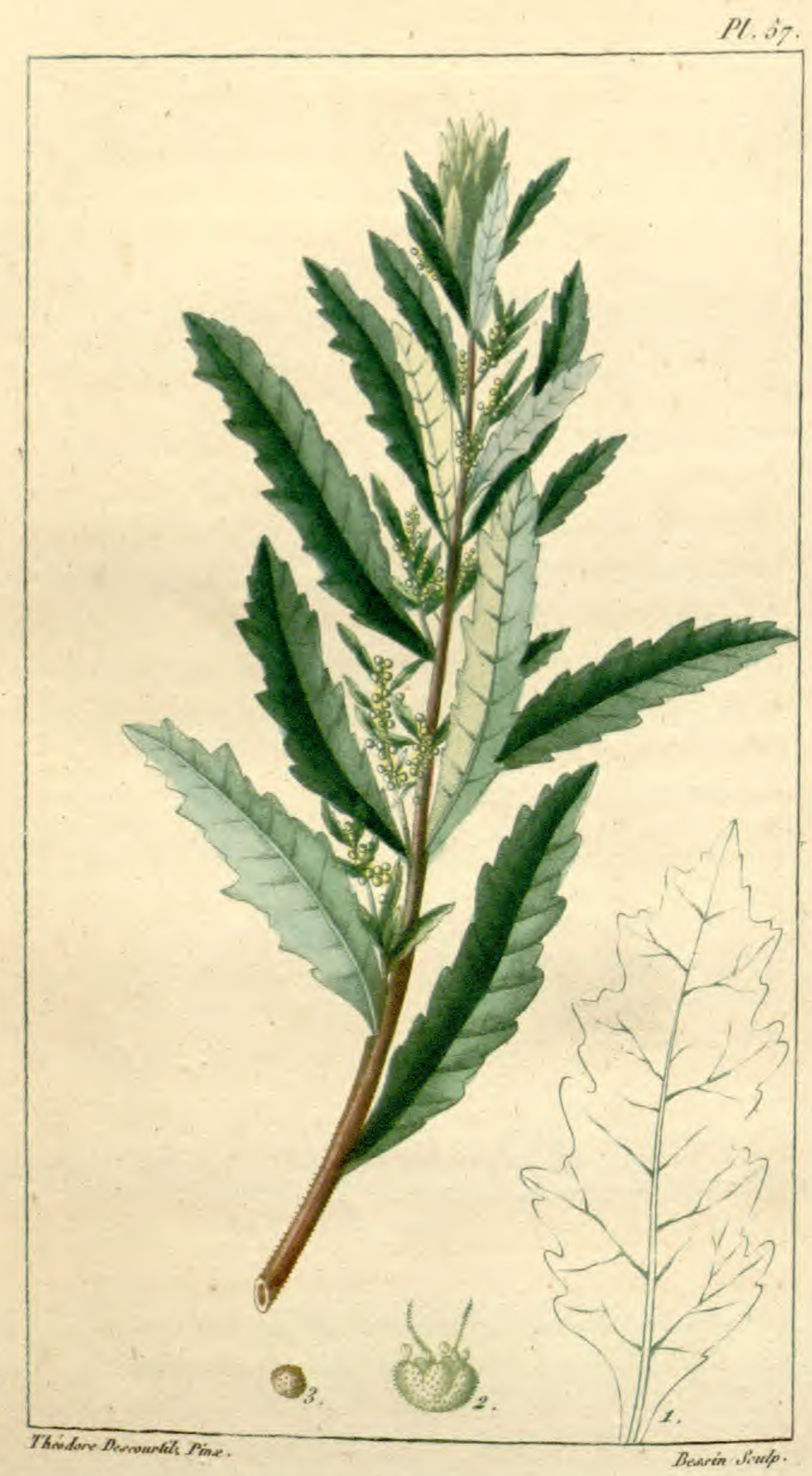

ANSE期目N A 


\section{$\left.(2\}^{5}\right)$}

\section{ANSERINE ANTHELMINTIQUE.}

\section{(Stomachique vermifuge.)}

Syxonyme. Chenopodium anthelminticum, Lin. Pentandrie Dyginie. - Chenopodium foliis ovato. - Oblongis, Dentatis; racemis aphillis. Lin. - Kalm. Canad. 2. p. 283. - Chenopodium Lycopi-folio, perenne Dill. Elth. 77. I c. 66. f. 76. - Tournef. Cl. 15. Fleurs à étamines. Sect. 2. Jussieu. Famille des Arroches.

Caragtènes géneriquas. Calice quinquefille, pentạgone; corolle nulle; une semence lenticulaire supérieure, cinq étamines, deux styles.

Caractimes particuliers. Feuilles ovales, oblongues, dentées; grappes sans feuilles, vivace.

Historre naturelle. Moins odorante que l'Ámbroisie ou thé du Mexique, dont il est parlé plus loin; l'Anserine anthelmintique cachée sous des herbes plus élevées qui recouvrent les savanes ou les terrains incultes, n'en est pas moins recherchée, à cause de ses propriétés éminemment vermifuges.

Caragtines physiques. Sa tige est haute de trois pieds, droite, dure, épaisse comme le doigt à sa base, rougeâtre dans sa moitié inférieure, striée, légèrement velue, et divisée en quelques rameaux jusque vers sa partie moyenne.

Ses feuilles sont alternes, ovales, lancéolées, rétré cies en pétiole à leur base, dentées en leurs bords prèsque comme celle du lycope d'Europe, vertes des deux côtés, et médiocrement velues en-dessous.

$15^{\circ}$ Livraison. 


\section{( 246 )}

Les fleurs naissent en pelites grappes nues, verdâtres, et redressées, situées dans les aisselles des feuilles supérieures, le long des rameaux et de la tige.

Analyse chimeve. Le principe amer est saisi par l'eau, tandis que l'alcool s'empare également de l'esprit aromatique. Les infusions noircissent par l'addition du sulfaie de fer.

Propniétits médicinales. On attribue une propriété tonique à l'Anserine anthelmintique, c'est pourquoi elle doit particulièrement fixer l'attention des praticiens comme vermiluge, parce qu'elle possède cette vertu à un haut degré.

Mode d'administration. On la donne en nature et en poudre, à la dose de douze à trente grains; en infusion à celle de deux gros à demi-once.

Les pharmaciens en préparent un sirop ou une gelée au moyen de laquelle on parvient à vaincre la répugnance qu'ont les enfans pour les médicamens, celui-ci, masqué par la douceur, devenant attrayant pour eux.

On peut encore faire digérer les feuilles et les sommités dans le vin, et en préparer une eau distillée et des loocks.

EXPLICATION DE LA PLANCHE CINQUANTE-SEP TIÈME.

Le dessin est de grandeur naturelle.

Fig. 1. Racine et partie inférieure de la tige:

Fig. 2. Fleur grossie.

Fig. 3. Calice.

Fig, 4. Graine, 
Pl.58.

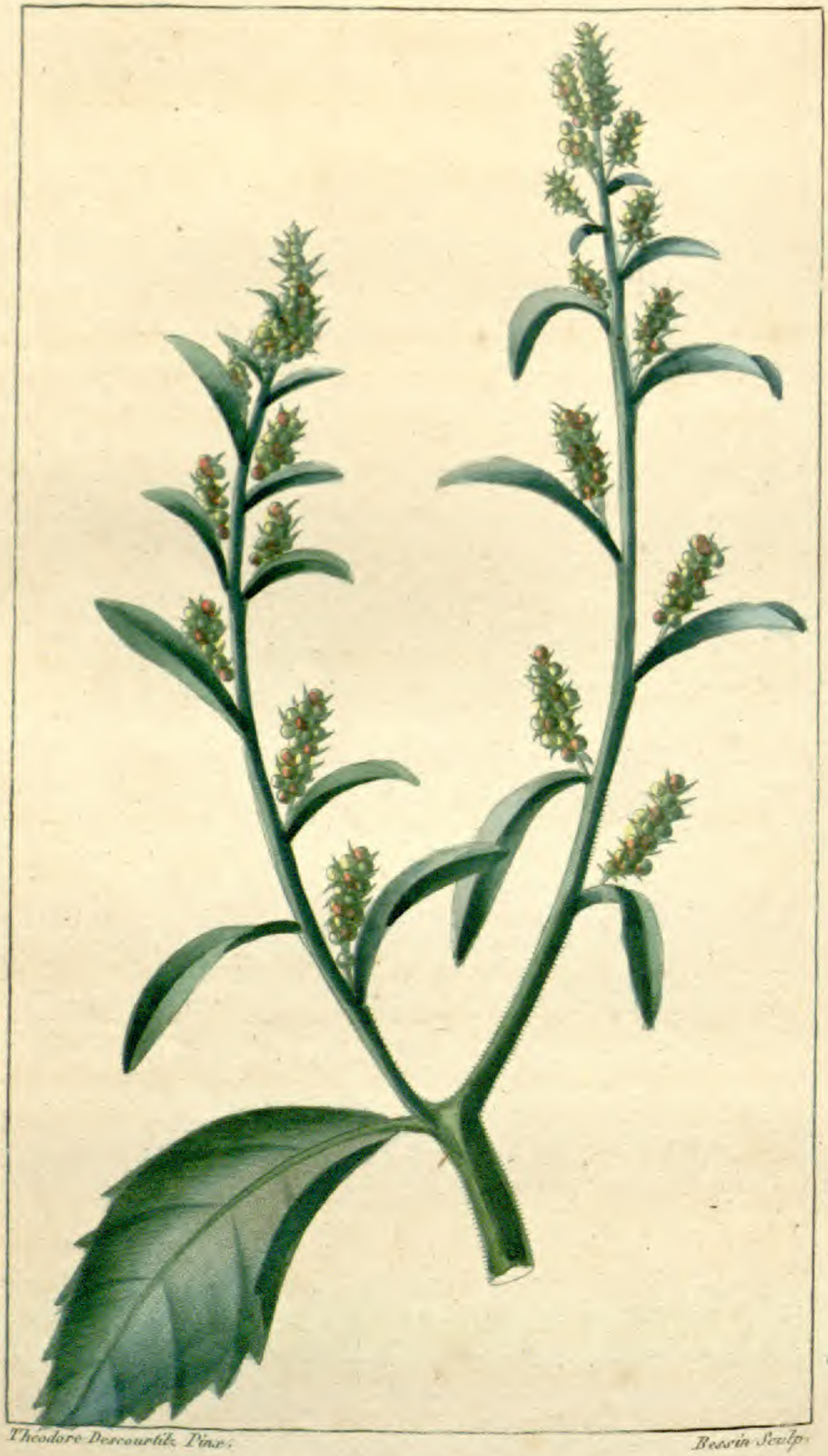

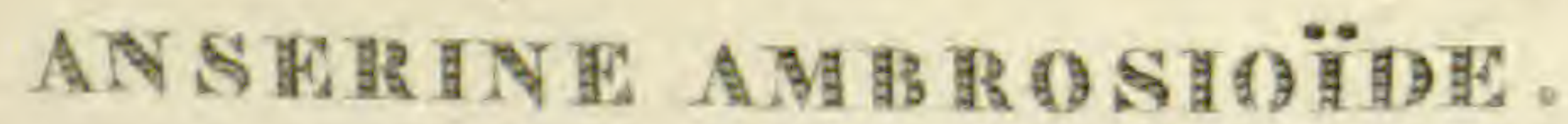




\section{$(247)$}

\section{ANSERINE DU MEXIQUE.}

(Stomachique vermifuge.)

Sraomyme. Vulg. Ambroisie, ou thé du Mexique. Chenopodium ambrosioides. Lin. - Chenopodium foliis lanceolatis dentatis, racemis foliatis, dentatis simplicibus; Lin.-Hort. Cliff. 84.-Dict. $\mathrm{n}^{\circ} 5$. - Botrys ambrosioides Mexicana. Bauh. Pin. 138. et App. 5 16. - Chenopodium ambrosioïdes mexicanum, Tourn. 506.-Atriplex odora suave olens mexicana moris. Hist. 2. p. 6o5. Sect. 5 Tab. 3r. f. 8. (Enc. Meth.) - Tournef. Cl. 15. Fleurs à etamines sect. 2.-Juss. Famille des arroches.-En espagnol, Bien Grenada. - En anglais, Jerusalem oak. (Fl. du d. D. Sc. méd.)

Caractìres génériques. Calice pentaphylle, pentagone; corolle nulle; une semence lenticulaire supérieure.

Caractères particuliers. Feuilles lancéolées; dentées; grappes feuillées simples (ann. Jolycl。)

Histoire naturelik. Cette humble plante croft sur les bords de certaines rivières limpides et profondes, parmi des milliers d'espèces differentes qui sont destinées à y végéter, et servent de lit de repos aux crocodiles qui se plaisentà y recevoir $l^{2}$ impression de la chalear et de la lumière. Sont-ils surpris? Froissant l'Ambroisie en s'élançant dans l'onde, elle décèle leur présence par son odeur aromatique, qu'on peut comparer à celle du Botrys d'Europe. Il transude de toutes les parties 


\section{( 248 )}

de l'Anserine du Mexique un suc balsamique qui les rend gluantes et résineuses, et en écarte les insectes.

Caractereses prysigues. La racine est oblongue, fibreuse, et pousse une tige droite qui s'élève à. la hauteur d'un à deux pieds. Cette tige est verdâtre, cannelée, feưlllée dans toute sa longueur, garnie de rameaux axillaires, dont les inférieurs sont les plus longs, et chargée d'un duvet pen abondant, court, assez semblable à une poussière.

Les feuilles sont alternes, lancéolées, pointues aux deux bouts, munies de quelques dents écartées dans leur moitié supérieure, privées de pétioles distincts, minces, vertes des deux côtés, et plus longues que les intervales qui les séparent. Les supérieures et celles qui naissent sur les rameaux florifères sont étroites et très-entières.

Les fleurs sont verdâtres, disposées en petites grappes menues et feuillées, situées dans les aisselles des feuilles; le long des branches et dans toute la partie supérieure de la tige.

Analyse chimiove. Cette plante contient une fécule colorante, et une résine légèrement aromatique, âcre, piquante et amère.

Proprírtés médicinales. Chevalier et Poupée-Desportes, en ont apprécié les vertus comme incisive, expectorante, hystérique et résolutive, ces deux anciens praticiens la recommandaient dansle second degré de la pneumonie, hors la période inflammatoire ; dans l'asthme humide, l'orthopnée, et les flatuosités. On 


\section{( 249$)$}

lindique dans l'encyclopédie méthodique comme sudorifique, diurétique, emmenagogue, et stomachique. L'Emery vante l'infusion de ses feuilles contre l'hemoptisie passive, et certaines maladies des femmes en couches.

S'il m'est permis d'en indiquer l'usage, je conviendrai avec vérité l'avoir employée avec un succès constant et spécifique dans les affections vermineuses, et pour la guérison des ulcères atoniques.

Modi d'a DMinistration. Usant de celte plante comme de la préeédente, nous y renvoyons le lecteur, afin d'éviter des répétitions.

EXPLIGATION DE IA PLAÑCHE CINQUANTE-HCITIEME.

Le dessin est de grandeur naturelle. 


\section{$(250)$}

\section{RICIN ARBORESCENT.}

\section{(Stomachique vermifuge.)}

SYnonymin. Vulg. Ricin d'Afrique à tige genouillée. Ricinus Africanus maximus, Caule geniculato, rutilante. Tournef. Inct. R. herb. 542. - Ricinus Africanus, foliis peltatis, serratis, lobis maximis, Caule 'geniculato ; capsulis echinatis. mill. Dict. $\mathrm{n}^{\circ} 5 .-$ ricinus ruber. rhump. Amboine, vol 4. pag. 97.- Tournefort. cl.15. fleurs à étamines. Sect. 5. - Jussieu fam. des euphorbiacées. - Lin. monoëcie Syngenesie monadelphie.-En espagnol, Ricinus. - En portugais, Ricino. - Les Américains-Espagnols le nomment figuerillo, c'est-à-dire petite figue. - En anglais, common Palma-Christi. — Liamahen-alama. - Lamourou en Caraïbe.

Caractìres génériques. Mâle; calice en cinqparties; corolle nulle; étamines nombreuses; les fleurs de ce sexe placées inférieurement sur la grappe.

Femelle; Calice en trois parties; corolle nulle; ovair e supérieur; trois styles bifides; capsule à trois loges, hérissées de pointes; une semence dans chaque loge.

Plante dicotyledone, fleurs incomplettes, monoïques, disposées en un épi paniculé; fleurs femelles placées supérieurement.

Caractìnes particuliers. Tige fléchie, genouihée, feuilles en bouclier; comme palmées, dentées en scie, pourvues de glandes sur leur pétiole.

Histoira Naturelle. Les espèces de Ricin sont communes en Egypte, dans les Indes, et en Amérique; on 


\section{( $25 \mathrm{I})$}

les a naturalisées en Europe et même en France. Le mot Ricin, vient de la ressemblance qu'ont les grains de cette plante, avec la tique des chiens de chasse, nommée en latin Ricinus. Les Garaïbes l'appellent encore Karapat du nom qu'ils donnent à la tique; tandis que le mot Palma-Christiindique la forme des feuilles palmées dẹ ce sous-arbrisseau, qu'on croit avoir été jettées en Egypte sur le passage de Jésus-Christ. Ce grand Ricin, qui s'élève aux Antilles à la hauteur de douze à vingt pieds est très-rameux, et entièrement distinct de l'espèce communis, dont les feuilles sont nuées de couleurs vives et de nervures d'un rouge foncé, et les tiges purpurines, transparentes sous la couche poudreuse qui les recourre.

Ce Ricin, à tige genouillée, a les mêmes habitudes que celui qu'on cultive en Europe. Il se plait sur le bord des eaux; il en existe une forêt, au pied d'une colonnade de palmiers qui fait l'ornement de l'habitation Rossignol-Grammont, près des Gonaïres'(ile St-Domingue). Ces touffes ombragent la rivière de la Quinte, dont les eaux paisibles et par fois tumultueuses, étant tiédies par le soleil, et ne pouvant plus rafraichir les racines de ces arbrisseaux, privent leurs feuilles molles et onctueases de leur soutien, et les font paraitre fannées depuis huit heures du matin jusqu'à cinq heures de l'après-midi.

L'huile qu'on retire, par expression, des semences de cette espèce de Ricin, sert à éclairer les cases à nègres, et les ateliers d'indigoterie, de sucrerie et. auires. Les feuilles chauffées produisent un sac huileux, qui joint à celui de l'orango sure procure un: cirage très-brillant. 


\section{$(252)$}

Quoique les propriétés médicinales soient les mêmes, dans les deux espèces que nous avons à décrire, cependant, afin de faire connaitre les distinctions spécifiques, nous renvoyons le lecleur à la classe des Purgatives Laxatives, N. 127.

Caractìnes physiques. Les racines du Ricin à tige genouillée sont traçantes et fibreuses, peu ramifiées.

La tige à arliculations rapprochées, fléchies en zigzagg, et d'un rouge pâle, uni, et non couverte de cette substance pulvérulente qui existe dans l'espèce citée plus haut; les branches sont tortueuses et parviennent à la hauteur de douze à vingt pieds, cette tige est creuse et cylindrique.

Les feuilles sont amples, pourvues de longs pétioles, courbès, alternes, palmées, lisses et moëlleuses à leurs deux surfaces; garnies de nervures, et pavoisées; d'un vert sombre en-dessus, l'une couleur blanchâtre endessous; à sept ou neuf lobes inégaux, ovales lancéolés, dentés en scie; les pétioles sont cylindriques, et pourvus de trois glandes à leur sommet.

Les fleurs élevées sur une tige particulière et comme formant des épis axillaires et terminaux, composés de plusieurs panicules partielles munies de bractées pelites et membraneuses.

Le calice est petit, d'un vert glauque, les fleurs mâles, qui sont les plus rapprochées de la base de la grappe, offrent une quantité d'ètamiues dont les anthères sont d'un jaune souffre.

Les fieurs femelles consistent en un fruit à trois capsules réunies, couronnées par un style trifide, d'un rouge de sang. Leur extérieur est muni de pointes 


\section{( 253 )}

molles et subulées, et toute cette surface est d'un vert sombre el glauque.

Les semences luisantes aplaties, d'un gris cendré, tachées de noir; on de fauve sur un fond noir, renferment une amande blanche bilobée, grasse, douceâtre, âcre, et qui excite des nausées. Quand ce fruit est mur, il s'ouvre de lui-même en novembre, et jette au loin ses graines.

Afalyse chimeve. Les fruits du Ricin, dépouillés de leur partie corticale, qui est âcre et brûlante, contiennent une huile douce, étant récente, mais qui en rancissant devient si caustique qu'elle brûle la gorge, ce qui la rend purgative. On l'obtient par expression et par décoction. Ces semences, de nature émulsive, contiennent du mucilage et de la fécule.

Les Caraïbes préparent l'huile de Ricin en torréfiant la graine; ils la concassent; puis ils la vannent; ils ôtent la pellicule et l'embrion, puis ils la font bouillir dans l'eau, en enlevant à mesure, l'huile qui surnage, au moyen de coton ou de coquilles.

Cette huile a les propriétés chimiques des autres huiles végétales; et se rancit facilement en se combinant avec l'oxigène de l'athmosphère.

Propritéts ménicinales. Les Ricins fournissent une huile anthelmintique et purgative, que les Anglais, suivant Marchy, appellent huile de castor; et d'autres peuples huile de Kerva ou de figuier infernal.

Dans son état de pureté, elle offre à la médecine l'un des plus puissans moyens à employer contre les vers ascarides, lombrics, et surtout contre le twnia lata. Cullen et Roques recommandent son usage à la 


\section{( 254 )}

dose d'une à deux onces, dans les coliques nerveuses causées par un embarras intestinal qu'elle fait cesser comme par enchantement.

Les graines par elles-mêmes possèdent des qualités vénéneuses, et médicamenteuses. Leurs qualités émulsives, oléagineuses, et adoucissantes, sont produites par le perisperme, tandis que, celles âcres, brûlantes et nauséabondes, paraissent résider uniquement dans l'embryon (c'est au moins le sentiment du rédacteur de l'article Ricin dans la Flore du dict. des Sc. méd.), de sorte qu'elles jouissent de propriétés bien différentes, selon qu'elles conservent ou sont privées de cet organe central, essentiellement vénéneux, auquel elles doivent la propriété d'exciter le vomissement, de provoquer une violente purgation, et d'altérer les membranes muqueuses de l'appareil digestif.

Le résultat des expériences faites par M. Orfila sur les animaux, prouve que cette substance agit à la manière des poisons âcres, en irritant violemment l'organe, tandis que son action sur le systême nerveux n'est que secondaire. Une ou au plus deux semences, prises inconsidérément, occasionnent des superpurgations, des érosions accompagnées d'écoulement de sang par l'anus, et l'on ne peut voir sans frémir, des nègres en prendre jusqu'à quatre et six pour se purger, mais s'ils échappent à une mort presque certaine, des infirmités sont bientôt la punition de leur funeste inexpérience. D'après ce qui précède, on sent l'avantage, dans la pratique, des huiles extraites du perisperme, et le danger mortel d'employer intérieurement celle où l'embryon a fourni l'huile de sa substance.

Les huiles de Ricin diffèrent en couleur, d'après leur 


\section{( 255 -)}

confection. Gelles qui sont les moins colorées, sont, dit Mâchy, les moins purgatives. On la regarde d'une bonne qualité et non sophistiquée lorsqu'elle estépaisse, visqueuse, douce et presqu'insipide. Elle est aussi, d'après la remarque d'Alibert, d'une couleur glauque viridescente, et analogue à la couleur du Ricin. Elle égale les huiles animales par sa pesanteur spécifique.

L'huile de Ricin séjournant sur ses fèces, y acquiert une dégénérescence caustique qui la rend dangereuse à employer. Pison dit que les Brasiliens en font un usage habituel contre les maladies froides; elle résout les tumeurs, et dissipe les coliques et les flatuosités, si on l'administre en frictions. C'est de cette même manière que les nègresses l'emploient en lavemens et eu embrocation sur la région ombilicale dans les maladies vermineuses de leurs enfans. Ils la vantent aussi dans la cure de la gratelle et des autres maladies cutanées, mais on préfère les feuilles macérées dans le vinaigre.

Lorsqu'on est assuré do la qualité de l'huile, il n'est pas de meilleur moyen pour expulser le meconium des nouveaux nés, qui leur occasionne tant de coliques; elle est précieuse à employer dans les néph rites, les iléns, les constipations, les hernies étranglées et la colique saturnine; elle facilite la sortie des calculs biliaires engagés dans les canaux cistique et cholédoque.

L'huile de Ricin oủ on a fait bouillir de la cévadille, produit un effet sûr dans le phtiriase, en faisant perir la vermine qui entretient celte dégoûtante maladie. Les Garaibes appliquent ses feuilles chauffées, sur le front, dans les céphalagies, et contre les douleurs 


\section{( 256 )}

arhtritiques. Les nègres concassent de deux à quatre grains dans une verrée d'eau, et osent indiquer ce superpurgatif dans les fièvres !!!! Les feuilles pilées sont employés comme émollientes dans les ophtalmies, pour les abcès, les panaris, et autres inflammations locales.

Mode d'administration. On donne l'huile de Ricin pure et récente à la dose d'une à deux cuillerées à bouche (une demie once à une once) que l'on peut renouveller d'heure en heure jusqu'à ce qu'on obtienne le succès qu'on en attend. On ne donne aux enfans que la moilié de la dose. Pour prévenir le vomissement, qu'elle occasionne quelquefois, et faire que cette potion soit moins désagréable au goût, on emploie l'intermède de la gomme arabique, qui rend cetle huile miscible à l'eau de canelle, de gingembre, ou de fleurs d'orangers. Le succès est encore plus certain dans les affections vermineuses, si l'on ajoute à ce mêlange un demi-gros d'éther sulfurique, on fait, dans les même cas, des embrocations sur la région ombilicale avec l'huile de Ricin, si l'expulsion des vers tardait à avoir lieu, M. Charpentier de Cossigny, dit, qu'on peut employer cette huile en plus grande quantité, jusqu'à deux ou trois onces pour les adultes; on peut aussi l'associer à un syrop.

Les nègres vantent beaucoup l'usage d'un gros do poudre de citron, dans une once d'huile de Ricin.

Selon Buchan, on purge avec succès les personnes nerveuses qui ne peuvent faire usage des moyens irritans, avec

Huile récente de Ricin. . . . une once. 


\section{$(257)$}

Mêlez avec un jaune d'œuf :

Ajoutez : Eau commune. ..... un verre.

Eau de fleurs d'orangers. deux gros.

Syrop capillaire. .... une once.

Battez le tout.

EXPLICATION DU LA PLANCHE CINQUANTE-NEUVIÈUE.

Tige du Ricin gcnouillé, chargée de fleurs et de fruits, réduite au huitième de grandeur naturelle, et peinte à midi, au moment où le soleil force la feuille de se faner et de courber son pétiole, pour reprendre le soir son port et sa vigueur. 


\section{$(258)$}

\section{GRENADILLE A TIGE QUADRANGULAIRE.}

\section{(Stomachique anthelmintique.)}

Synonтme. Passiflora quadrangularis. Lin. Gynandrie pentandrie. - Tournefort D. B. rosacèes. Sect. 2. - Juss. fam. des cucurbitacèes. - Passiflora foliis indivisis sub cordatis integerrimis, petiolis sex glandulosis, caule membranaceo tetragono. Lin. - Jacq. Amer. 25r. t. 143. et pict. 113. t. 218 . Mill. Diet. $n^{\circ}$ 20. Passiflora foliis amplioribus cordatis, petiolis glandulis sex, caule quadrangulo alato. Brwr. fam. 327 . (Enc. meth.).

Ganactères génírieues. Trigyne: calice pentaphille; corolle à cinq pétales; nectaire en couronne; baie pédiculée.

Caractìres panticuliers, Feuilles sans division, comme cordiformes, très-entières, veinées; pétiole à six glandes, creusé en gouttière; involucres très-entiers. (Jolycl.)

Histome naturelle. Cette magnifique grenadille. doit être caractérisée, moins par la quantité des glandes qu'on remarque sur ses pétioles, que par la nature particulière de sa tige à quatre faces, qui la distingue de toutes ses congénères. La beauté éclatante de ses grandes fleurs la fait rechercher des curieux pour les treillis et les berceaux dont elle fait l'ornement.

Ses fruits assez estimés, font partie des desserts des colonies. Cette plante cependant, dit Jacquin, a l'in- 


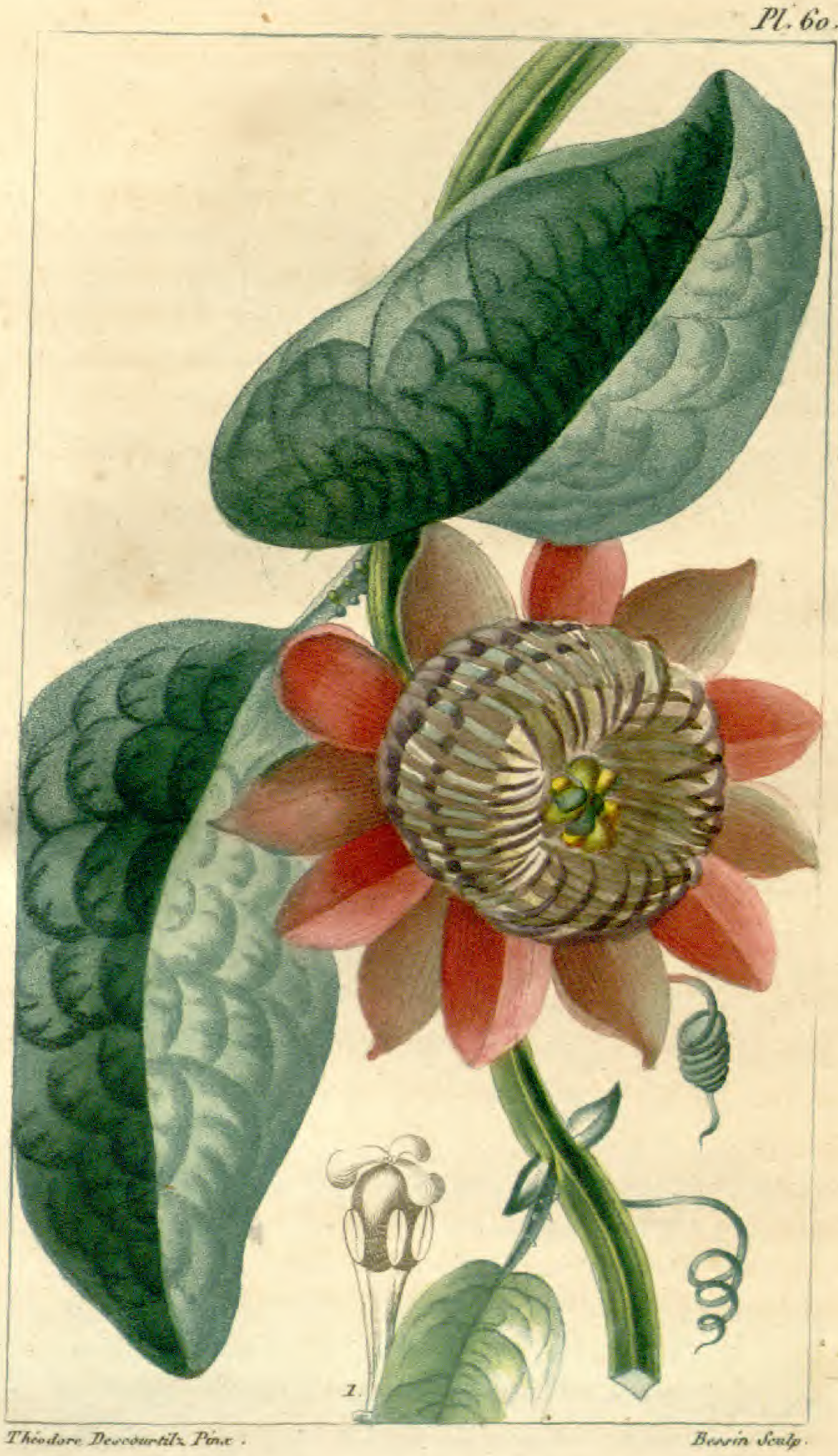

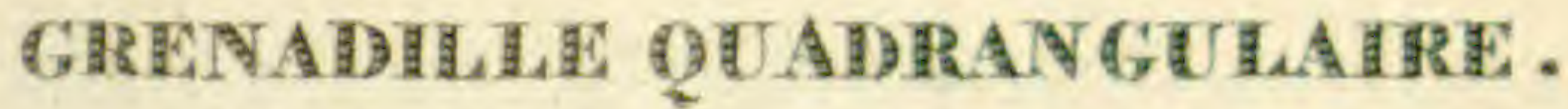




\section{( 259$)$}

convénient de réfugier les serpens venimcux qui se plaisent sous son feuillage pendant la chaleur, et y épient le reste du jour, les animaux dont ils font leur nourriture.

Garactìres physiques. Les tiges sont persistantes, sarmenteuses, grimpantes, quadrangulaires, et ont leurs angles tranchans, un peu membraneux et comme ailés.

Les feuilles sont larges, presqu'en cœur, arrondies à leur base; ovales, acuminées, entières, lisses, trèsglabres, grossièrement veinées, d'un vert le plus sou vent sombre, portées sur des pétioles creusés en goutière et chargés de six glandes spiniformes.

Les pédoncules sont axillaires, courts, solitaires, terminés par une large fleur, très-belle, très-odorante.

L'involucre a ses trois folioles ovales pointues, entières à leur bord, beaucoup plus courtes que la corolle.

La corolle est composée de cinq pétales de la grandeur des folioles du calice, et ainsi que ces derniers d'une couleur de rose très-agréable, plus ou moins vive, quelquefois mélangée de verdâtre.

La couronne est formée d'un seul rang de filamens variés, par anneaux, de blanc, de violet pâle et de pourpre foncé.

Le fruit est ovoïde, plus gros qu'un œuf d'oie, d'un vert jaunâtre, d'une odeur agréable. La pulpe qu'il contient, est renfermée dans une pellicule qui se sépare facilement de l'écorce. Elle est d'une couleur aqueuse, douce, transparente, acidule, d'une saveur agréable, légèrement odorante, et contenant un grand nombre de graines disséminées vers le centre. 


\section{( 260$)$}

Axalyse chmpeve. Je n'ai point de résultat à offrir en faveur de cette grenadille, que les circonstances ne m'ont point permis d'analyser.

Proprítés médicinales. Cette grenadille quadrangulaire jouit aux Antilles d'une réputation pareille à celle de la pomme de liane (grenadille à fleur de laurier); mais ne l'ayant pas mise en usage daus ma pratique aux Colonies, j’engage ceux qui me succéderont dans les observations de botanique usuelle, à fixer sur cette belle plante toute leur attention.

Mode d'administration. On s'en sert à défaut de la passiflore à feuilles de laurier; mais je ne lui crois pas les mêmes vertus.

EXPLICATION DE LA. PLANCHE SOIXANTIÈME.

La planche est réduite aux deux tiers de grandeur naturelle. 


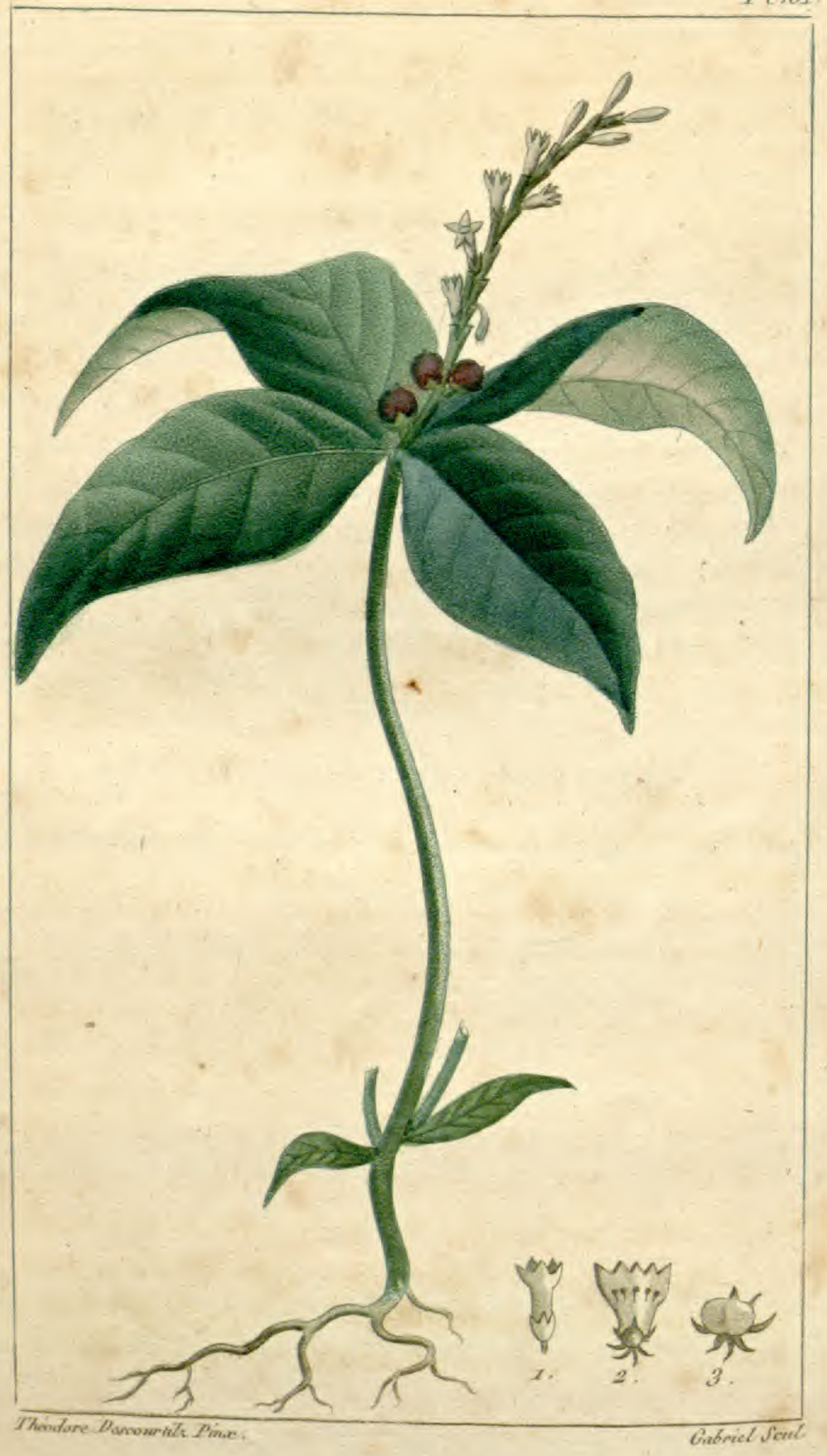

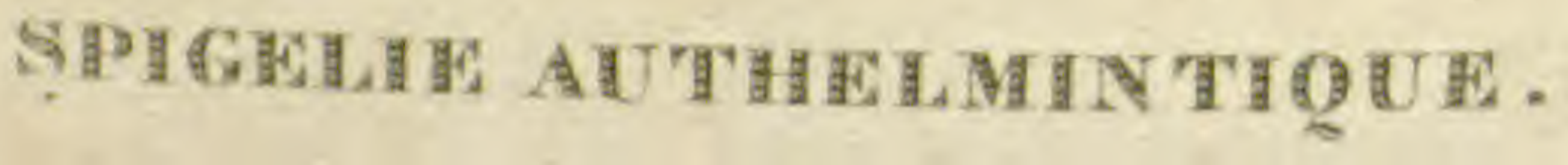




\section{$(26 r)$}

\section{SPIGÉLIE ANTHELMINTIQUE.}

\section{(Stomachique vermifuge. )}

Srnonymie. Poudre aux vers ou Brainvilliers (nom d'une négresse empoisonneuse) indian Pinke.-Spigelia anthelmia. - Lin. Pentandrie monogynie, - Juss., Fam. des gentianées. - Spigelia herbæ Paridis facie, quadrifolio, floribus spicatis violaceis, fructu, testiculato, arapabaca Plum. gener, amer. pag. 10, t. 3r. - Spigelia Caule herbaceo, foliis lanceolatis, sessilibus; summis quaternis majoribus. Lam. III. gener, vol. I, pag. $474, n^{\circ} 2153$, tab. 107. - Adanson fam. 29. les Jasmins. Sect. 5. Spigelia Caule herbaceo foliis summis quaternis-Linamæn-acad-vol. 5 pag. 133. tab. - Mater. med 59. Wild. Spec. Plant, vol, 1 , pag. $824, n^{\circ}$ I. - Spigelia Caule erecto, foliis quaternis sessilibus, Spicis terminalibus. Miller. Dic. $n^{\circ}$ n. - Spigelia quadrifolia, Spicis terminalibus. Brwn. Fam. pag. 156 , tab. 37 , f. 3. - Barrer. fr. equinox. pag. 15. - Brazcel parsis. Petiv, gazoph. tab. 59 , fig. 10.-Arapabaca Brasiliensibus dicta planta. Marcg. Brasil. 46. (Enc. méth.)

Caractères généripues. Corolle infundibuliforme; capsule didyme à deux loges polyspermes.

Garactères particuliers. Tige herbacée; feuilles supérieures quaternées. Ann. (Joliclerc.)

Histoire naturelle. Ce genre, dit Jaume SaintHilaire, en considérant la préférence qu'a donné la trop fameuse Brainvilliers à une de ses espèces, est réellement énergique comme anthelmintique, mais de$16^{\circ}$ Livraison. 


\section{( 262 )}

mande une application raisonnée, et la plus grande prudence. Quelques commères (et elles sont trèsmultipliées dans notre ile) préparent encore ce syrop avee précaution, il est vrai, mais san's connaissance de cause, et l'administrent avec un appareil vraiment sépulcral : malgré tous leurs soins, il en résulte toujours des accidens très-graves. Heureusement que nos médecins instruits l'ont isolée, et que cette plante est abandonnée aux nègres empoisonneurs. Cependant, comme elle se multiplie très-vite, et qu'on ne l'arrache pas avec assez de précaution, il en résulte aussi qu'elle se trouve mêlée parmi les fourrages, quelquefois involontairement, mais le plus souvent dans l'intention de nuire, el que les chevaux et d'autres animaux domestiques en deviennent les victimes. Les souffrances des animaux dans leur agonie présentent quelque chose de plus qu'affreux.

Cette plante annuelle croit naturellement et avec abondance aux Antilles, au Brésil, à la Martinique, à Cayenne, et dans beaucoup d'autres iles de l'Amérique. On la cultive en serre chaude en Europe.

Caractères physiques. Les racines de la spigélie anthelmintique sont traçantes, fibreuses, et produisent une lige droite, assez forte, herbacée, glabre, cylindrique, presque simple, striée; haute d'environ un pied et demi. De l'aisselle des feuilles sortent quelques rameaux très-simples, semblables aux tiges.

Les feuilles sont sessiles, opposées, lancéolées, entières à leurs bords, glabres à leurs deux faces, aignës à leur sommet; quatre feuilles amples et opposées en croix terminent les tiges et les rameaux. 


\section{( 263 )}

Les fleurs sortent du centre des feuilles supérieures; elles sont terminales, disposées en épis médiocrement ramifiés à leur base, un peu grêles, peu alongés, munis de bractées. Chaque fleur est presque sessile, presque unilatérale, de couleur un peu herbacée. Le calice est partagé en cinq découpures aiguës : le tube de la corolle renflé à sa partie supérieure, le limbe à cinq lobes ovales, acuminés; le fruit est une capsule à deux lobes, en forme de testicules (dit Nicolson), surmontés dans leur milieu d'un style persistant, et contenant beaucoup de graines très-fines (Encycl. méth.). Toutes les parties de la plante exhalent une odeur vireuse et fétide.

Anatyse chimique. N'ayant pas trouvé l'occasion de soumettre la Spigélie aux analyses chimiques, je ne puis faire connaître ses parties constituantes, qu'il serait cependant intéressant de désigner.

Propriétes médicinales. Outre les vertus fébrifuges, peut-être trop hasardées par Brown, on accorde généralement en Amérique à la Spigélie, la supóriorité sur tous les autres vermifuges; on la préfêre à la Jamaïque à tous les autres remèdes de ce genre. Ce n'est pas uniquement comme anthelmintique qu'elle est employée avec avantage, son succès est aussi prononcé dans les affections spasmodiques ou nerveuses; et lorsqu'il s'agit de provoquer une transpiration salutaire. Cependant, on ne doit confier son emploi qu'à des mains prudentes et exercées; sa vertu délétère en faisant un poison mortel, si l'on outrepasse la quantité qu'on doit en prescrire. L'assoupissement, le délire, les ris sardoniens, la dilatation de la pupille, et autres 


\section{( 264$)$}

symptômes propres à l'empoisonnement par les narcotiques, sont les tristes résultats de l'emploi mal combiné de cette substance $\mathrm{v}$ śnéneuse. Toutefois, elle agit à la manière de l'opium dans le tétanos et autres maladies convulsives. Quels secours puissans ne retire-t-on pas maintenant en Europe des extraits d'aconit napel, de belladone, de stramoine, etc.?

Mode d'administration. Deux gros de la plante suffisent pour une livre d'infusion aqueuse, a laquelle on ajoute du sucre, et le jus d'un citron; la dose est alors de quatre à six onces pour un adulte, auquel on en administre deux onces, deux autres fois dans la journée, jusqu'à ce que ce médicament produise son effet. La dose, pour les enfans et les valétudinaires. doit être réduite d'après l'âge et la constitution du malade. On prescrit à ceux qui ne peuvent faire usage de cette infusion nauséeuse, la poudre à la dose de huit à quinze grains, incorporée avec du miel ou de la confiture, pour les enfans; et d'un demi-gros pour les adultes. On prolonge l'usage pendant plusieurs jours, s'il est nécessaire, après lesquels on fait donner un léger purgatif.

EXPLICATION DE LA PLANCHE SOIXANTE-UNIÈM.

La Spigélie est représentée moitié de grandeur naturelle.

Fig. x. Fleur entière.

Fig. 2. Feur ouverte.

Fig. 3. Capsule. 
11.62.

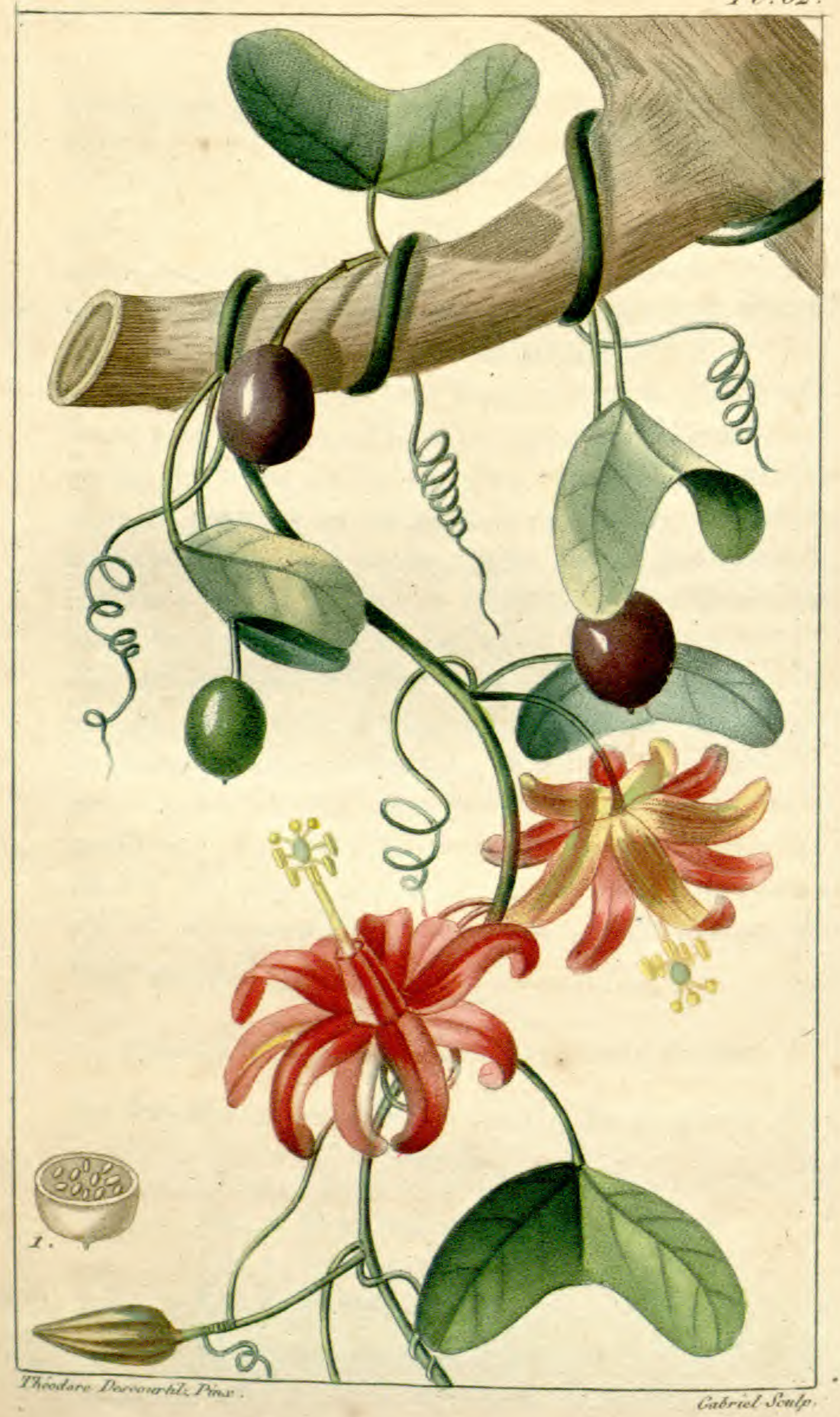

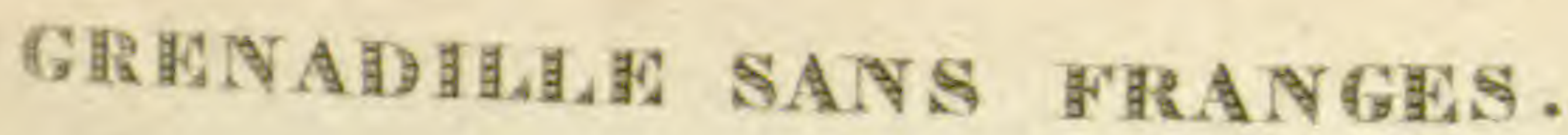




\title{
$(265)$
}

\section{GRENADILLE SANS FRANGES.}

\author{
Vulg. LIANE a GALÇON. \\ (Stomachigue vermifuge.)
}

SYnonyme. Passiflora murucuïa.Lin. Gynandrie Pentandrie. - Tournef. cl. Rosacées. Sect. 2. - Jussieu. Fam. des Cucurbitacées. - Passiflora foliis Bilobis obtusis basiindivisis subtus punctatis corona floris tubulosa. N. (Enc. méth. ) Murucuïa folio lunato. Tournef. 21 4. t. 125. Clematis indica. Flore lunato.Plum, amer, 72. t. 87, t. 2 , pag. 10.-Ray suppl. 342. - Peter. gaz. t. 113 , f. 5. -Passiflora, Lin. amæn. acad. 1. pag. 223. - Miss. Dict. $n^{\circ}$ 14. - Marigouia Passiflora Seu murucnia, lunato folio, flore ruberrimo. Plum. Liane à calçow. En Caraïbe Mercoya-marigouia-murucuïa-et merecoy.

Caractéres genteriques. Trigyne; calice pentaphylle; cinq pétales; nectaire en couronne; baie pédicelée.

Caractìres particuniers. Feuilles à deux lobes, obluses, sans divisions à la base; nectaire monophylle. tubulé.

Histoine naturelle. La forme des feuilles bilobées de cette grenadille, représentant une culotte, lui a fait donner le nom de liane à caleçon. Cette jolie plante grimpe, et, au moyen de vrilles dont elle est munie; elle s'attache aux arbres, forme des arcades mobiles, des colonnades riches et élégantes par la beaulé des fleurs pourpres variées de bleu qui les décorent, et qui flattent l'odorat par le parfum qu'elles exhalent. L'ceil àdmirateur n'a plus rien à désirer pour la majesté du 


\section{( 266 )}

spectacle, quand à ces torsades naturelles on voit s'enlacer en spirale le grand quamoclit à fleurs d'un blanc de neige; la grenadille frangée, à grandes fleurs concentriquement rayées de zones bleues, blanches, violettes, pourpres et aurores, et les sphères dorées de ses fruits contraster avec éclat sur la belle verdure du feuillage : on croit alors voir réunies toutes les couleurs de l'arc-en-ciel. Quelle leçon pour un peintre, ami de la belle nature!!! Enfin, tout autour de soi

....... Des feuillages

Entrelacés dans des berceaux, Forment un dôme de rameaux

Dont les délicieux ombrages

Font goûter dans des lieux si beaux

Le frais des plus sombres bocages.

Lefranc de Pompigan.

Caractènes physiques. "Le défaut de couronne frangée dans les fleurs de cetle espèce, et le tube conique qui la remplace, présentent une singularité si grande, que Tournefort a jugé à propos de séparer cette plante des autres Grenadilles pour en faire un genre particulier. „

Ses sarmens sont grêles, cylindriques, grimpent néanmoins sur les haies auxquelles ils s'attachent par leurs vrilles.

Ses feuilles sont petites, à deux lobes obtus, en croissant, entières à leur base, glabres des deux côtés, et ont en-dessous trois nervures avec quelques points glanduleux. Elles n'ont qu'un pouce ou un pouce et demi de largeur, et ont des pétioles courts, dépourvus de glandes.

Les pédoncules sont axillaires, solitaires, ou quel- 


\section{( 267 )}

quefois geminés, portant chacun une fleur de plusieurs couleurs. Les pétales sont d'un rouge écarlate trèsvif : ils sont oblongs, réfléchis; les folioles du calice sont pétaliformes, de la couleur de la corolle intérieurement, d'une teinte rosée, viridescente à leur base, à leur surface inférieure; la couronne est un tube conique tronqué, non divisé, s'élevant au milieu de la fleur, plus court que les pétales et d'un pourpre violacé. Ce tube, qui n'a rien de commun avec le tube calicinal des autres espèces de Grenadilles, donne passage au faisceau doré qui supporte les organes sexuels s'élevant au-dessus du tube d'une fois sa longueur. L'inflorescence a lieu toute l'année.

Le fruit est une petite baie ovoïde, pendante à un Iong pédicule, violette dans sa maturité, renfermant une pulpe succulente et une infinité de petites graines noires, rudes au toucher. (Encycl. méth. )

Analyse chumeve. Les parties constituantes du murucuïa m'ont offert les mêmes résultats que ceux de la passiflore à feuilles de laurier. (Voyez ci-dessus.)

Propriétés médrcinales. La Grenadille sans frange a, je crois, usurpé aux Antilles une réputation anthelmintique, dont il m'est permis de douter, l'ayant, dans plusieurs circonstances, éprouvée sans succès aux doses qui m’avaient été prescrites par les praticiens du pays, et qui sont les mêmes que celles que j'ai indiquées à l'article Passiflore à feuilles de laurier. Il n'en est pas de même de ses propriétés sudorifiques, hystériques et apéritives, qu'on ne peut lui contester sans injustice. Dans ce premier cas, Poupéo Desportes 


\section{( 268 )}

l'unissait au gayac, au bois de fer, au bois a pians (voyez ces mots), on bien il l'employait seule.

Dans le second, il composait avec les feuilles du murucuia des bourgeons d'avocatier, d'herbes à cloques ou de racines de pois puant, de celles du tamne puant, ou du schoenanté, une tisane hystérique, recommandable dans la suppression des lochies.

Enfin ce zélé praticien estimait apéritive la décoction des feuilles et des fruils de la Grenadille sans frange, a laquelle on ajoutait un gros de limaille de fer par pinte de liquide.

Mode d'administration. La dose des feuilles el des racines est d'une pelite poignée par pinte de décoction, tandis que douze baies suflisent pour la même quantité de liquide.

EXPLICATION DE LA PLANCHE SOIXANTE-DEUXIL̀ME.

Fig. 1. Fruit ouvert. 


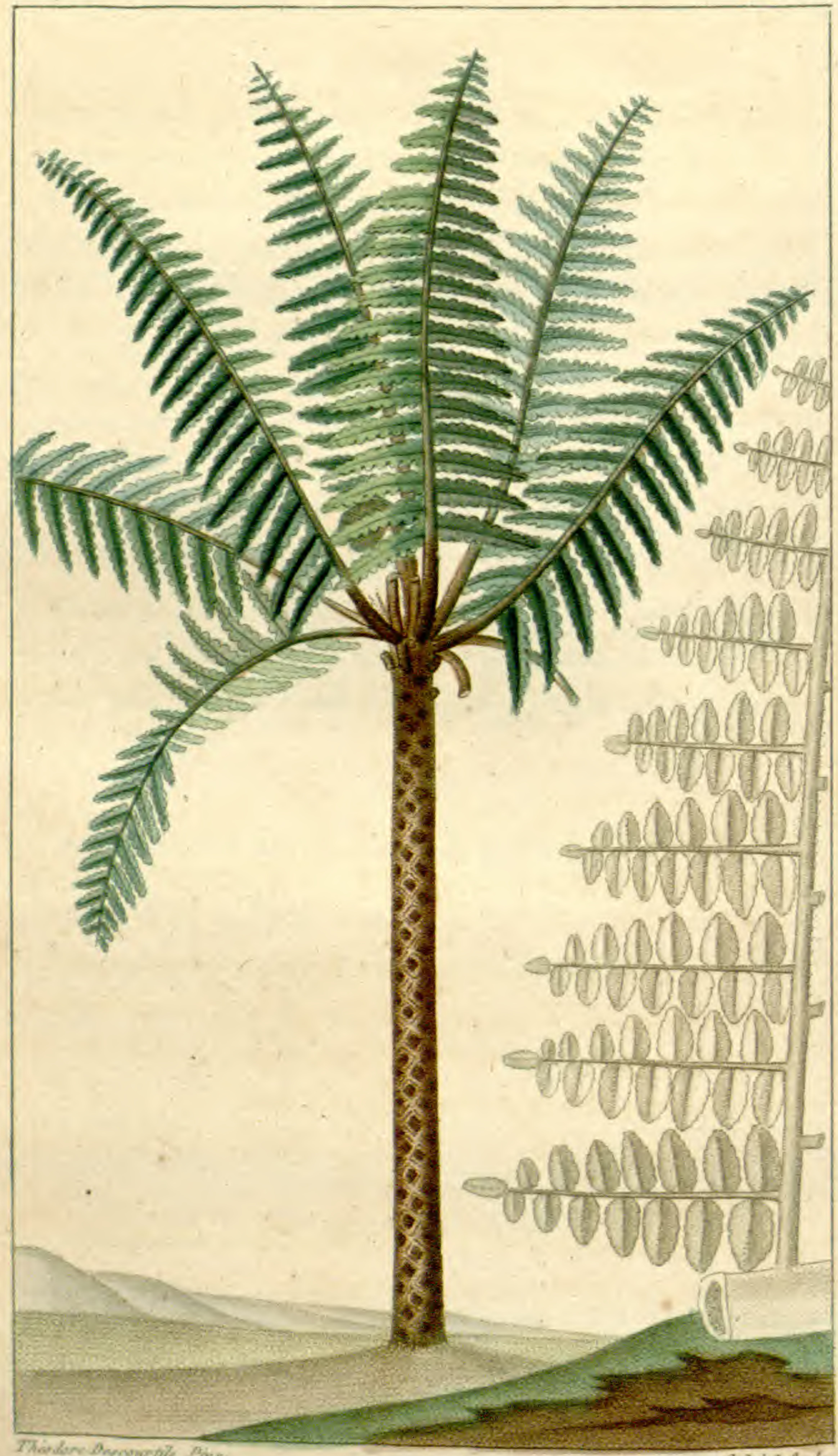

Gabriel frombe 


\section{$(269)$}

\section{POLYPODE EN ARBRE.}

\section{(Stomachique vermifuge.)}

Synonymie. Fougère arbre. - Polypodium arboreum. Lin. Fougères. - Tournef. cl. apètales sans fleurs. Sect. t. Jussieu, Fam, des fougères. - Polipodium frondibus pinnatis, serratis, caudice arboreo, inermi Lin. Syst. Plant. vol. 4 pag, $426 . n^{\circ} 59 .-$ Filix arborescens, Pinnulis dentatis, Plum. amer. 1. tab. 1. 2. - Tournef. inst. herb. 537 . -Filix arborescens primis dentatis Petiv. Filix $4 \mathbf{i}$, tab. $\mathbf{1}$, fig. I. 3. - Polypodium arboreum maximum, fronde tenuiore; caudice durissimo. Brwn. Jam. ro4.- Palmi filix. Postium? Rhumph. Amboin. liv. 10. - En espagnol, Helecho. - Alberi del felce (arbre de la fougère) d'Oviedo. - En anglais, Fern-Polypody.

Caracteres géneriques. Jeunes feuilles roulées en spirale; fructification placée par points sur le revers des feuilles,

Cabacteres particuliens. Fructification réunie en petits groupes distincts, et épars sur la surface inférieure de la feuille; feuilles bipinnées, dentées en scie; tige arborescente, inerme (vivace).

Histoire naturelle. Amie des forêts humides et ombragées, on y rencontre toujours celte belle fougère arborescente, ou sur le bord des ruisseaux et des cascades, dont l'onde vive et pure entretient sa fraicheur.

A votre suite, o nymphes bocagères, J'allais fouler les naissantes fougires. 


\section{(270)}

G'est une de ces belles plantes qui, fière de son élévation, semble vouloir rivaliser avec les palmiers dont elle a l'aspect, la grâce et la majesté. On la trouve à Saint-Domingue, à la Jamaïque, à la Martinique, et dans beaucoup d'autres îles des Antilles, ou on emploie ses tiges pour former les palissades du pays.

Caractìnes physinues. La tige, ou plutôt le tronc de cette fougère, est droite, cylindrique, inerme, couverte d'écailles membraneuses et grises figurées en réseau, au-dessous desquelles on aperçoit un fond tanné; ces enfoncemens proviennent de la cicatrice qu'ont laissé les anciennes feuilles après leur dépérissement; les vestiges des pétioles subsistent encore audessous des magnifiques panaches de verdure qui couronnent cette tige, qui s'élève jusqu'à dix et douze pieds sur environ six pouces de diamètre. Dans cette espèce de fougère, la tige, qui n'cst autre chose que le nœud vital de la plante, étant dépourvue du feuillage qui la couronne, périt infailliblement. Il en est de même des palmiers.

A l'intérieur, on trouve à la place de la moëlle une chair très-blanche, assez ferme, d'un goût douceâtre, pleine d'un suc blanc et visqueux, et entourée d'un lassis de veines noires, ondées, et dures comme du bois.

- Les feuilles, au nombre de huit à quinze, couronnent la cime de la tige. Elles sont amples, longues de six à dix pieds, deux fois ailées, d'un beau vert, glabres, garnies à leur base d'écailles roussâtres ou argentées, sonlenues par un pétiole presque de la grosseur du bras à sa base, diminuant iosensiblement 


\section{(271)}

d'épaisseur, muni latéralement de folioles alternes ou opposées, rapprochées, longues de deux pieds, divisées en pinnules linéaires presque point confluentes, étroites, obtuses, longues de six à huit lignes, finement crénelées à leurs bords dans toute leur longueur.

La fructificdtion est composée d'un double rang de globules arrondis, capsulaires, placés dans la longueur des pinnules (Encycl. méth.).

Analyse chimioue. Le sulfate de fer noircit la décoction de toutes les parties du Polypode en arbre. Elles fournissent un extrait aqueux d'une saveur amère et astringente; plus, un principe extractif résineux. Les racines donnent un mucilage, du tannin, et un peu d'acide gallique. Les cendres de cette fougère contiennent beaucoup d'alkali végétal.

Proprítís mínicinales. Douée des mêmes propriétés médicales que la fougère d'Europe, le Polypode en arbre est employé dans les affections vermineuses. On choisit de préférence la poudre de sa racine ou de son écorce; les feuilles sont estimées pectorales; ses racines contenant du mucilage sont quelquefois employées comme diurétiques sédatives. Les naturels des Antilles recommandent, dans les hépatites-et les splénites, l'application d'un cataplasme fait avec les racines pilées de cette fougère arborescente.

On attribue au Polypode en arbre beaucoup d'autres vertus que je ne consigne point ici, parce que je les crois imaginaires. G'est gratuilement, je pense, qu'on lui accorde des propriétés contre les maladies arthri tiques, le scorbut, les vésanies, lés obstructions, et beancoup d'affections chroniques. Pour conserver à 


\section{( 272 )}

cette plante tous ces éloges fastueux, il faudrait l'avoir employée senle, et sans l'intermède d'autres substances plus hérö́ques auxquelles on l'associe, et qui font loute sa renommée.

Mode D'administration. On prescrit comme vermifuge la poudre des feuilles ou des racines du Polypode en arbre, à la dose de deux gros pour quatre onces d'eau de mer ou d'eau salée; on la prescrit quelquefois dans du vin blanc ferré, contre les atrophies mésentèriques, oul'engorgement des glandes decet organe.

EXPLICATION DE LA PLANCHE SOIXANTE-TROISILME.

Le Polypode est réduit au vingtième de sa grandeur naturelle.

Fig. 1. Partie d'un pétiole commun supportant une ramille sur laquelle sont rangées les fevilles. 
11.64.

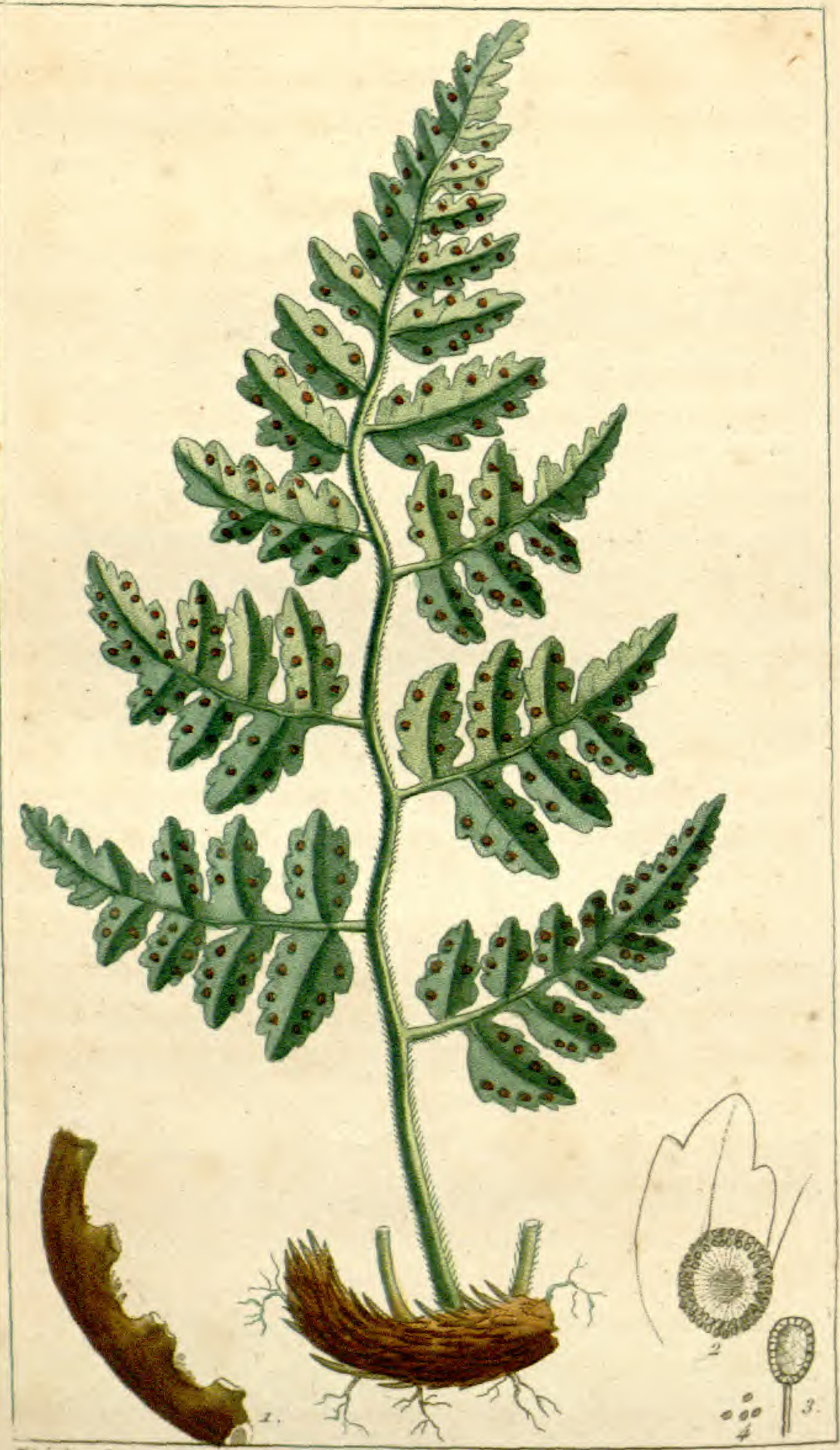

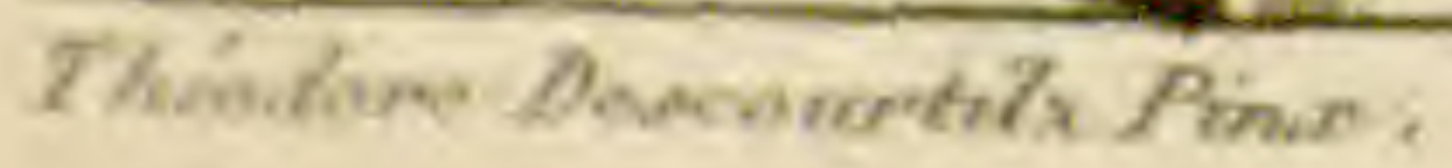

Gitbried Perly. 


\section{$(2,5)$}

\section{POLYPODE ADIANTHIFORME.}

\section{Vulg. Calaguata.}

\section{(Stomachique vermifuge.)}

Sy onxm г. Polypodium adianthiforme; Forster. - Juss. classe 1. ordre 5 fougères, - Aspidium coriaceum. Swartz. - Aspidium coriaceum; frondibus bipinnatis apice simpliciter pinnatis coriaceis, pinnulis oblongo-lanceolatis, obtusè serratis, inferioribus subpinnatifidis, stipite aspero. Wildenw, class. 34. Cryptogamie. Fougères, En espagnol Calahuala (Flore du dict, d, sc. méd.)

Ciaractères générieuns. Aspidium. Capsules réunies en groupes épars, arrondis, placés sur le revers des feuilles, un tégument ombiliqué qui se fend latéralement.

Caractìres panticuliers. Tige souterraine, traçante, cylindroïde, écailleuse, rousseâtre, fibreuse. garnie de fibrilles grêles, qui se subdivisent en filamens capillaires.

Histoire naturelie. Le mot calaguala est le nom vulgaire de cette espèce de fougère, qui n'est désignée que depuis très-peu de temps, et dont M. Turpin a fait connaître tous les caractères avec vette exactitude et cette précision que l'on rencontre dans tous sès écrits.

Cette plante se plait sur les rochers, ou sur le bord des bois frais et touffus des Antilles. En cueillant lo Polypode, je me rappelai les vers charmans de Léonard, sur la fougère:

Vous n'avez pas, verte fougère,

L'éclat des fleurs qui parent le printemps;

Mais lenr beauté ne dure guère :

Vous êtes aimable en tout temps. 


\section{( 274$)$}

Vous prêtez des secours charmans

Aux plaisirs les plus doux qu'on goûte sur la terre;

Vous servez de lit aux amans,

Aux buveurs vous servez de verre.

- Les vraies racines de calaguala, dit Turpin, sont ces fibrilles répandues le long de la tige souterraine; celle-ci, que l'on trouve dans les pharmacies, présente encore d'un seul côté des espèces de chicots, qui ne sont autre chose que les supports des feuilles tombées. Dans cet état (continue le célèbre botaniste), les tiges sont presque totalement dépouillées de leurs écailles. " La racine de calaguala est d'un usage très-répandu dans les colonies françaises, anglaises, espagnoles et portugaises.

Caracteres physiques. Les racines du polypode adianthiforme offrent une souche cylindrique, rousseâtre, écailleuse, garnie de fibres grèles, divisés en filamens capillaires. Au milieu est une moëlle spongieuse, de couleur de miel.

Les pétioles sont droits, alongés, hérissés d'aspérités dans toute leur longueur, soutenant des feuilles fermes, coriaces, d'un vert foncé en-dessus, plus pâle en-dessous, deux et presque trois fois ailées; les pinnules oblongues, lancéolées, à dentelures obtuses.

La fructification est disposée en forme de petits tubercules brunâtres, chacun d'eux conlenant un grand nombre de petites capsules ovales, comprimées, réticulées, entourées d'un anneau élastique arliculé, et soutenues par un pédicule capillaire. Le tégument est fixé seulement par son ombilic, et se déchire à son bord extérieur (Encycl. méth.). 


\section{$(275)$}

Analyse chimeve. Les racines de la calaguala se mâchent facilement; on leur trouve d'abord une saveur douceâtre, qui se change,bientôt en une amertume très-prononcée, accompagnée d'une émanation rance et huileuse. Leur analyse a fourni à M. Vauquelin : $2^{\circ}$ par l'alcool, un pou de sucre et une huile âcre et peu volatile; $2^{\circ}$ par l'eau, beaucoup de mucilage coloré en jaune, d'une saveur douce et muqueuse; $3^{\circ} \mathrm{par}$ l'acide nitrique affaibli et à froid, un peu d'amidon; $4^{\circ}$ par l'incinération, du muriate de potasse et du carbonate de chaux. La matière qui paraît avoir le plus d'action surl'économie animale, dit Alibert, est l'huile âcre qui se dissout dans l'eau à l'aide du mucilage et du sucre.

Pnopnítés médicinales. On ne peut refuser sans injustice des propriétés à la racine fraîche du polypode adianthiforme; elle est employée constamment avec succès aux Antilles, sans pourtant mériter les éloges fastueux que certains auteurs se sont plù à lui accorder. Elle agit suivant les cas où elle est appliquée, comme anthelmintique, sudorifique, anti-syphilitique; les personnes affectées de rhumatismes chroniques, de coliques nerveuses et de vomissemens bilieux, n'ont qu'ù se louer de son usage.

Mode d'administration. On préfère employer la décoction de cette racine, qui s'ordonne depuis deux gros jusqu'à une once pour deux livres d'eau, avec réduction d'un tiers. Cette décoction se boit ordinairement froide, si ce n'est en cas de maladie vénérienne; alors on la boit chaude, matin et soir, à la dose d'une verrée, édulcorée avec le syrop commun, ou de pré- 


\section{( 276 )}

férence celui de salsepareille. En poudre, sous forme d'électuaire, la dose est depuis un demi-gros jusqu'à un gros. L'infusion dans du vin est quelquefois prescrite à la dose de deux gros par livre de liquide.

EXPLICATION DE LA PLANGHE SOIXANTE-QUATRIÈme.

Le Polypode adianthiforme est représenté de grandeur naturelle.

Fig. r. Racine telle qu'on la vend dans le commerce. Fig. 2. Dent d'une folliole, sur laquelle on distingue le cercle que forment les parties de la fructification, en brisant l'enveloppe qui les retenait.

Fig. 3. Capsule et son pedicelle grossi.

Fig. 4. Graines ou sporules renfermées dans la capsule. 


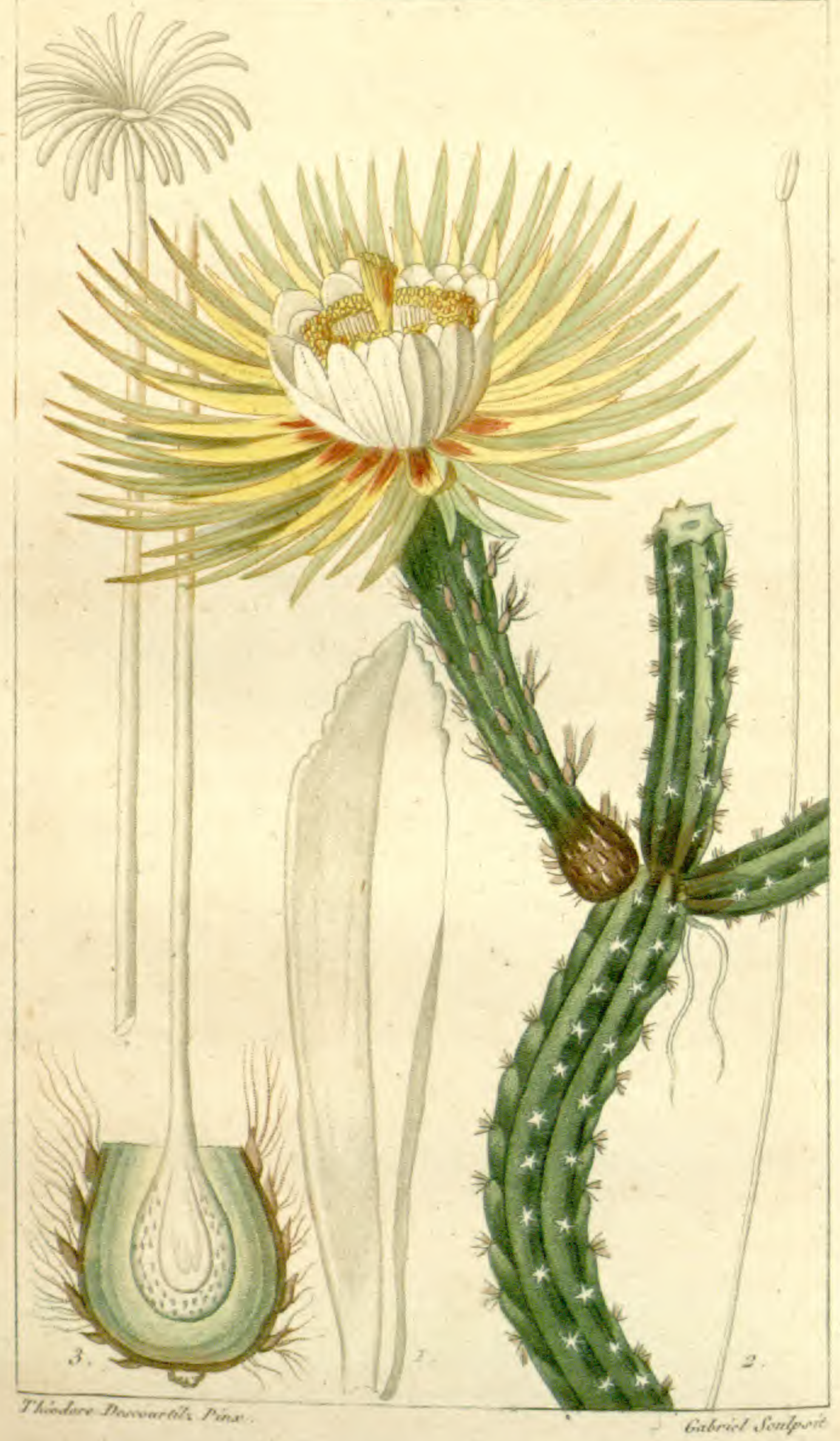

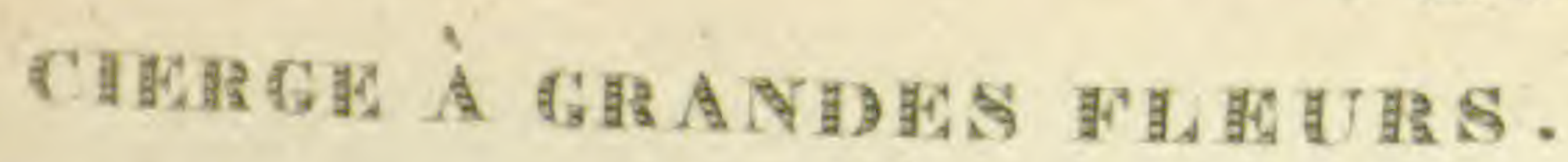




\section{( 277 )}

\section{CIERGE A GRANDES FLEURS.}

\section{(Stomachique vermifuge).}

Srnonymr. Cacte serpent.- Cactus grandiflorus. Lin. (Trew. 31. Vel. du mus. Red. Pl. gr. 52.) - Cactus repens subquinquangularis. Lin. Herm. Par. 120. Knon. Del. r. t. f. 6. - Cereus scandens minor polygonus articulatus Mill, ic. t. $9^{\circ}$. - Cereus gracilis scandens ramosus plerumque sexangularis, flore ingenti atque fragranti. Trew. - Cereus americanus major articulatus, flore maximo noctu se aperiente. 8. Suavissimum odorem spirante. Volk. Hesp. pag. 135, t. 154 . - Melocactus repens, pentagonus, flore albo, fructu rubro. Plum. Spec. 20. Burm. amer. t. 199, f 1. - (Encycl. meth. ) Lin. Icosandrie monogynie.-Tournefort. Melòcactus, appendix. - Jussieu, famille des Cactes. Cacius, selon M. Delaunay, vient du verbe grec Kaiò, brûler, parce que la piqûre des épines cause des douleurs brûlantes.

Caractères génériques. Calice monophylle, supérieur, imbriqué; corflle à pétales nombreux; baie à une loge, polysperme.

Caracteres particuliens. Cierge rampant, à radicules latérales, et à cinq angles. (Jamaïq. vivace. Jolycl.).

Histoine naturelle. L'astre de la nuit peut seul éclairer et recevoir les suaves émanations du Cacte Serpent. Chaque soir, une fleur s'épanouit au moment où le soleil disparait dans l'onde; nourrie, pour ainsi dire, par un air frais, pur, et un peu humide, elle brille de tout son éclat, et répand autour d'elle, une odeur agréable, tant que dure la nuit; mais hélas, $7^{*}$ Livraison. 


\section{( $\left.27^{8}\right)$}

l'époque du réveil de la nature est le signal de son des-. sèchement; elle se ferme au lever du soleil pour ne plus s'épanouir, ayant concentré dans son ovaire les principes de sa reproduction dans les germes de l'espérance. La tige incisée fournit un suc laiteux sous forme de globules tuberculeux, qu'on néglige dans le pays, et qui ne sont guères remarqués que par les praticiens. On rencontre fréquemment cette belle espèce à la Jamaïque et à la Véra-Crux. Elle demande la serre chaude, et se multiplie par boutures, ou éclats.

Canactìres particuliers. Les tiges du cacte serpent sont cylindriques, rameuses, serpentantes, verdâtres, à cinq ou six côtes peu saillantes et munies sur ces mêmes côtes de petites épines rayonnantes et fasciculées.

Les boutons sont velus, les fleurs sont latérales, fort belles, d'une odeur très-suave, et ont sept ou neuf pouces de diamêtre. Leur calice est fort grand, long, tubuleux et écailleux dans sa partie inférieure; composé à son sommet, de folieles étroites, linéairesligulées, pointues, jaunâtres, disposées sur plusieurs rangs, ouvertes, et qui semblent former une couronne autour de la fleur. Les pétales sont blancs, nombreux, lancéolés, et disposés sur plusieurs rangs, en une belle rosette concave. Le style est plus long que les étamines, et son stygmate est divisé en une vingtaine de lanières affectant une disposition infundibuliforme.

La parlie inférieure du calice, qui est chargée d'écailles barbues se change en un fruit ovoide, un peu plus gros qu'un œuf d'oie, courert de tubercules écailleux, charnu, d'une couleur orangée, rempli de très- 


\section{(279)}

petites semences, et d'une saveur acidule fort agréable. (Encycl. méth.)

Analyse chimique. Ce Cacte, ainsi que ses congénères, fournit un suc latescent, gommo-résineux, desséché et concrêté par l'action de l'air et de la chaleur. Ce suc concret est inodor, mais soumis à la mastication, il devient progressivement âcre, brûlant et nauséeux. Il contient une watière extractive, de l'albumine, et un principe très-volatil et péniblement expansif pour l'odoral. La cansticité réside dans la partie résineuse, qni est combinée dans le suc lạiteux avec égale parlie de gomme, ce qui rend sa teinture alcoolique douée de toutes les verius héroïques. Cette gomme résine s'enflamme.

Propriktes mbicicinares. Le suc des Cacles est âcre, vénénenx à haute dose, et il faut toute la prudence d'un médecin, pour savoir l'appliquer avec avanlage dans les maladies cù les hydragogues sont indiqués. Cette substance, mise en contact avec la peau pendant un certain temps, excite un prurit insupportable, des érosions, des pustules, et peut, au besoin, remplacer le garou; elle devient sternutatoire si par la combustion, on en a composé l'air factice d'un appartement: mais ces mauvaises plaisanteries irritent les membranes muqueuses, et peuvent aftliger les témoins de ces scènes ridicules, d'Angines, de coryza, d'hémoptysie; assertion reconnue par les accidens qu'éprouvent les ouvriers qui pilent toutes les substances âcres et volatiles.

Ainsi encore une fois, il faut regarder le sic de tous les cierges comme très-dangereux, et seulement 


\section{( 280$)$}

admissible, en pharmacie, formulé par un homme de l'art, ou l'on doit s'attendre à voir le malade, victime d'une audacieuse impéritie, succomber après d'horribles souffrances cardiaques, des vomissemens excessifs, une dyssenterie douloureuse et tous les symptômes del'empoisonnement par un caustique. Aussi malgré sa haute réputation comme vermifuge, je n'ai jamais osé l'employer qu'émoussé avec le syrop mucilagineux de graines d'ooli, ou de fleurs de gombo, alors je n'ai jamais eu à me repentir de son administration.

Pendant mon exercice de médecin en chef, prisonnier des nègres révoltés, n'ayant aucune espèce de médicamens à notre disposition, puisque toutes les pharmacies avaient été brûlées, et forcé de mettre à contribution les ressources végétales du pays, j'employais extérieurement le suc des cierges comme escarotique, et comme propre à remplacer, dans ces cas d'urgence, le nitrate d'argent dans la carie des os, et pour la repression des chairs fongueuses. Je le faisais entrer dans la composition des linimens excitans contre la paralysie, les affections rhumatismales chroniques et autres maladies qui réclament les irritans.

Mode d'administration. Intérieurement j'administrais comine vermifuge, pour un adulte, le suc concret de cierge serpent, a la dose de deux à dix grains dans deux onces de syrop mucilagineux. J'employais de préférence, comme plus diffusible, la teinture alcoolique, à la dose de dix à trente gouttes, pour la même quantité de syrop.

RXPLICATION DE LA PLANCHE SOIXANTE-CINQUIEMR. Le dessin est au cinquième de grandeur naturelle. 


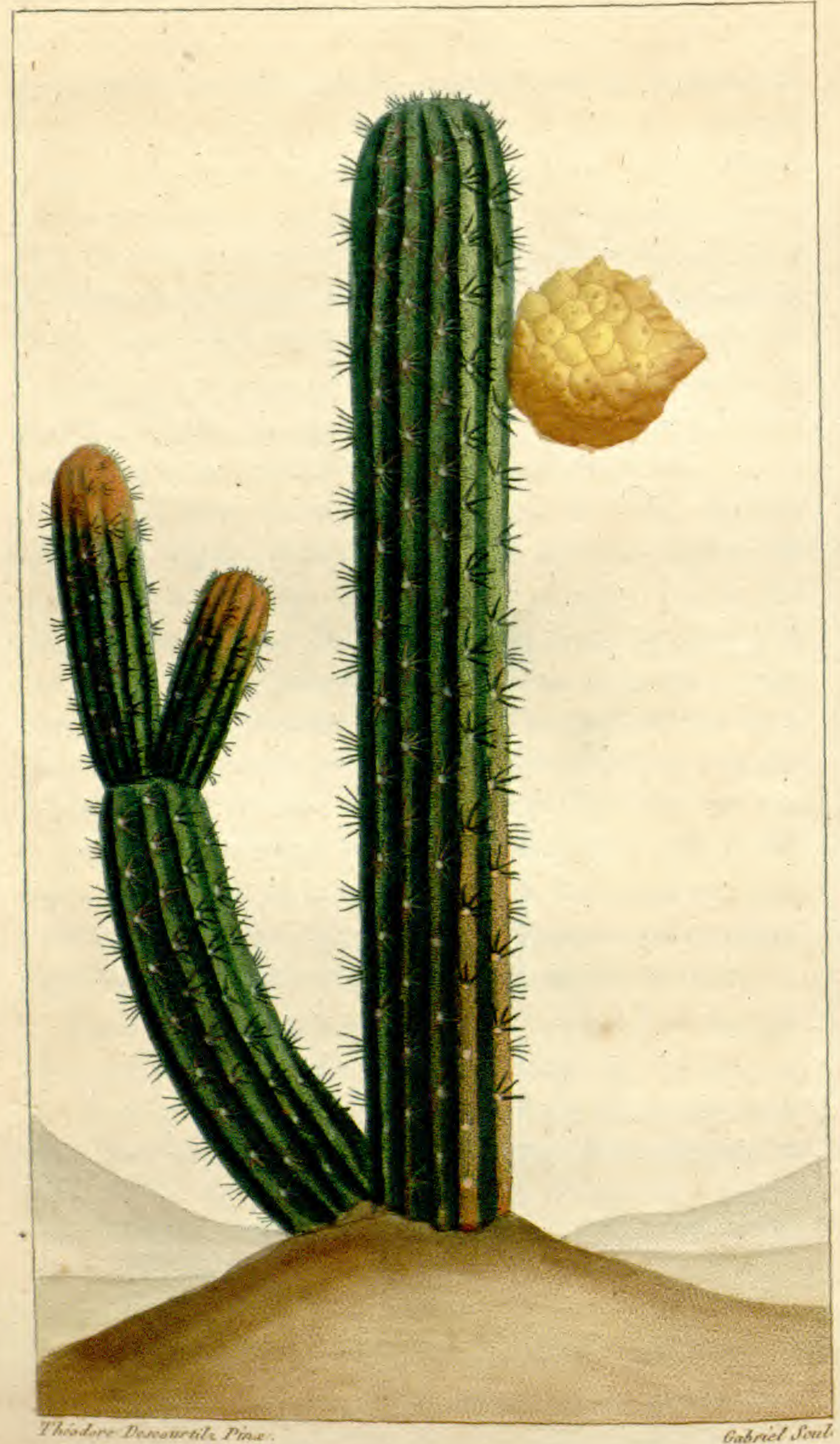




\section{$(281)$}

\section{CIERGE DIVERGENT.}

Vulg. Cardasse ov pomme Torche.

(Stomachique vermifuge).

SY N ONIMIE. Cactus divaricatus. - Cactus spinosissimus, trunco Erecto, striato, apice ramoso ; ramis rectis, striatis, undique vergentibus, fructu aureo, tuberculato. $n$. - Melocactus cereiformis, spinosissimus, ramosissimns fructu aureo tuberoso. Plum. melocactus arbo rescens, folio ftriato spinosissimo, fructu aureo tuberoso. Plnm. Spec. 19. - Burm. amer.tab. 195. (Encycl. méth.) Lin. Cactus pentagonus. Icosandrie monogynie. - Tournefort melocactus, appendix. - Juss. famille des Cactes.

Garactìres géneriques. Galice monophylle, supérieur, imbriqué; corolle à pétales nombreux; baie à une loge, polysperme.

Caracteres particuniers. Cierge redressé, se soutenant par lui-même; à cinq angles; long et articulé. (Jolycl.)

Histoire naturblle. Habitans des plaines arides, où la nature semble animer à regret un lieu consumé par les rayons de l'astre du jour, les cierges divergens préfèrent un sol inculte et sablonneux pour la prospérité de leur végétation singulière et curieuse. Vivant en société, ces colonnes végélales forment des massifs impénétrables dont les animaux sauvages, les Iguanes et les Crocodiles peuvent seuls pratiquer les détours 


\section{$\left(2 S_{2}\right)$}

hérissés d'épines, pour s'y repaître de leurs fruits et y chercher une retraite.

Mille oiseaux effrayans, mille corbeanx func̉bres De ces lieux désertés habitent les ténèbres.

(BOILEAT)

C'est au milieu de ces fourées dangereuses, que le chasseur intrépide entrainé par sa passion, pénètre avec audace pour y donner la mort à ces animaux qui veulent an vain se soustraire à son adresse. Au milieu de ces colonnes verles et épineuses, flanquées de fleurs diversement colorées et panachées, el de fruits dorés, qui appaisent si souvent la soif du chasseur, on voit des liges de cactes desséchées et conservant encore assez de gomme résine pour servir de torches anx nègres pè hurs, ou à ceux plus tranquilles, qui, après les travanx de la cullure, passent avec leur femme et leurs cofans, les soirées et une partie de la nuit chinta (assis) aniour d'un feu d'épis de mais ou de bouse de vache, pratiqué au milieu du local, et destiné par sa fumce épaisse, à écarter les miriades de moustiques qui s'opposent à leur sommeil. Les tiges de cardasse , et colles th bois chand lle, sont les pâles flambeaux qui éclairent ces réduits enfumés.

Canactimes physigues. Le Cactier divergent est à côles ou cannelé, et n'est pas composé de ramifications applaties. Sa lige est droite, un peu plus épaisse que la jambe, hatte de trois à cinq pieds, assez dure, verdâtre, à cannelures droites et nombreuses, affreusement hérissée d'épines très-aiguës, rayonnanles ei frèsmultiplées. Elle donne naissance ì des rameaux surlesquels il en parait bientôt d'autres, et qui divergent tous ou 


\section{$(283)$}

s'écartent de la tige principale. Ces rameaux sont droits et de même dimension dans toute leur longueur, et finissent en manière de cône arrondi. Ils sont également cannelés et très-épineux.

Les fleurs viennent naturellement vers le sommet des rameaux, elles sont jaunes, quelquefois panachées de rouge, sessiles, situées sur les angles; le calice est divisé en dix parties, ses cinq divisions extérieures sont obtuses.

Les étamines sont nombreuses, un peu plus longues que la corolle; les anthères sont petites et à deux lobes.

If succède à ces fleurs, des fruits globuleux, charnus, un peu plus gros que le poing, d'un jaune d'or, et garnis de tubercules verruqueux pointus. Leur pulpe est blanche, douceâtre, et remplie d'une quantité de petites semences brunes, ou noirâtres, suivant le degré de leur maturité. (Enc. méth.)

Analyse chimpoe. Le suc gommo-résineux de celto espèce jouit des mêmes vertus que celui du cierge précédent, et de certains Cactiers dont les propriétés corrosives existent dans la partie résineuse.

Proprítés mípicinales. Ce que je viens de dire du cierge à grandes fleurs, je dois le répéter pour le cacte divergent dont il s'agit ici. Je ne puis trop recommander la plus grande réserve dans son usage, afin d'éviter des regrets tardifs que pourrait susciter son emploi inconsidéré.

On emploie extérieurement le suc récent de cette espèce, comme topique dans le traitement de la teigne, contre l'odontalgie, pour détruire les verrues et comme dépilatoire. 


\section{( 284$)$}

Mode d'admisistration. On modère l'énergie du sue des Cactes par la dessication ou sa macération dans le vinaigre, et on l'emploie aux mêmes doses, dans le même cas, et de la même manière que l'espèce précédente.

J'ai ordonné avec succès en embrocations sur le bas ventre, un liniment d'huile de rivin battue avec le suc de la tige de ce Gacte.

EXPLICATION DE LA PLANCHE SOIXANTE-SIXIÈME.

Le dessin représente un cierge divergent sur un terain de Hatte. Il est réduit au vingt-quatrième de grandeur naturelle. 


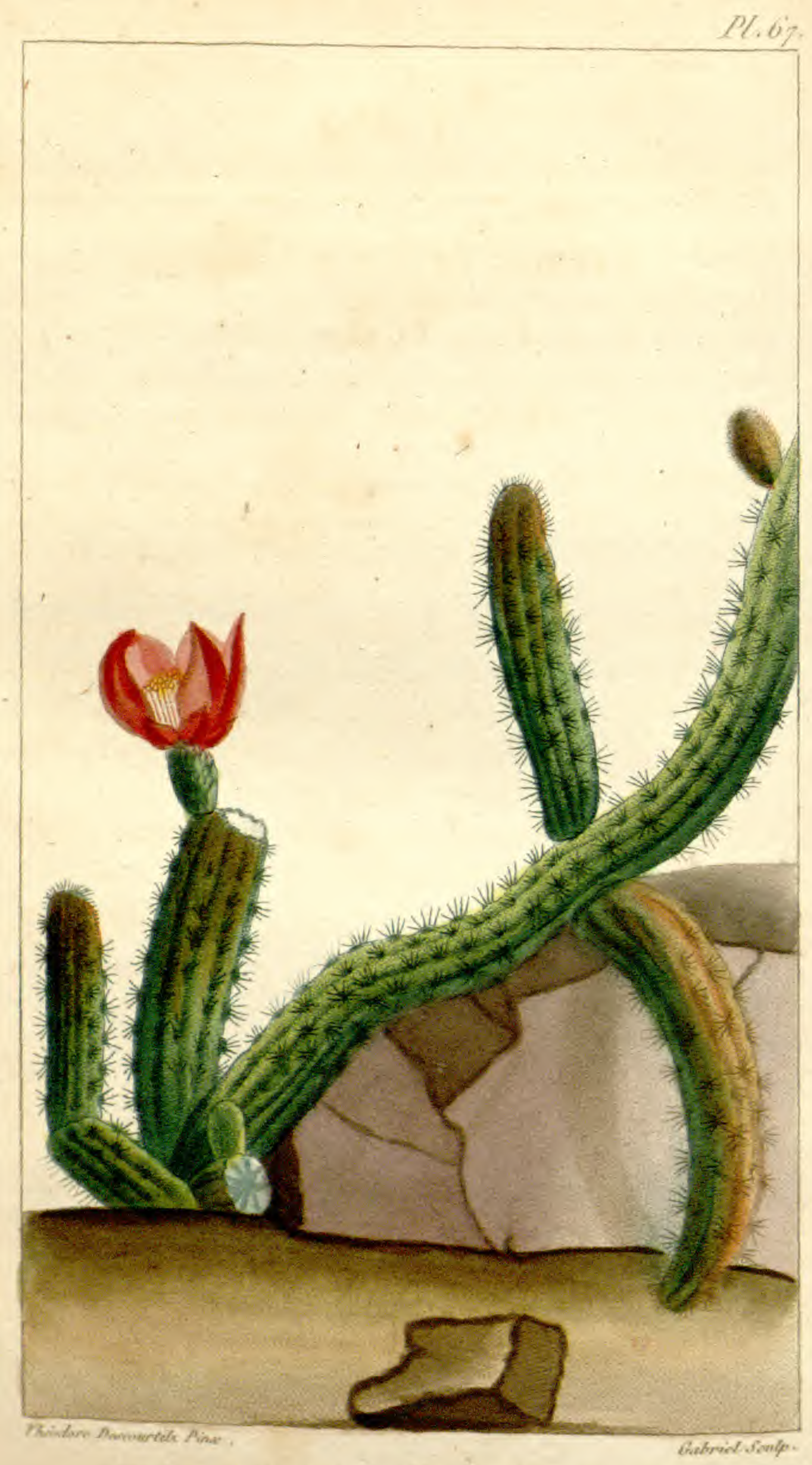

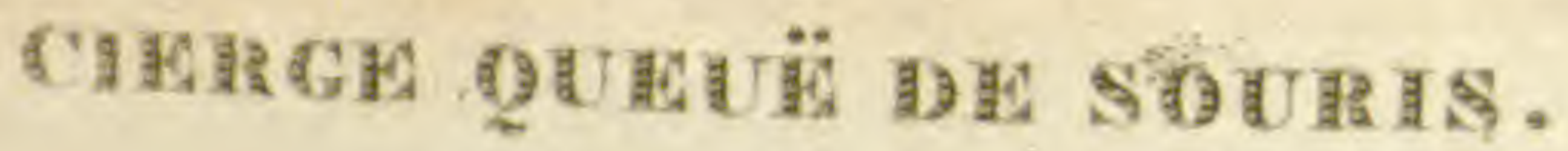




\title{
( 285 )
}

\section{CIERGE QUEUE DE SOURIS}

\author{
Vulg. Liane a vers.
}

\section{(Stomachique vermifuge).}

Symonyuie. Cactus flagelliformis. Lin. Icosandrie monogynie. - Cactus repens decemangularis Lin. mill. Dict. no 12.-Sub-cereo. Kniph, cent, 1. t, 12.-Knorr. Dell. r. t. f. 8. - Cereus minor, seandens polygonus, spinosissimus, flore purpureo-Ehret-Sel. 2. f. 2. Trew. Ehret. t. 3o. - Ficoïdes americanum. S. cereus minime serpens americana. Pluk. Alm.. 148. tab. 158. f. 6. - Sloan. Jam. Hist. 2. pag.158. Raj. Dendr. 22. (Encycl. méth.)-Cactus peruvianus scandens et repens flore coccineo, fructu Luteo-Plum-Tournef, Cactus appendix. - Jussieu, famille des Cactes. Acoulerou des Caraïbes.

Caractères génériques. Calice monophylle, supérieur, imbriqué, corolle à pétales nombreux, baie à une loge, polysperme.

Garactìres particuliers. Gierge rampant, à radicules latérales, à dix angles. Amérique méridionale. (vivace.)

Historre naturelle. Ce cierge, que l'on nomme aussi cactier à tiges de fouet, beaucoup plus petit que le cierge à grandes fleurs, pourrait lui être préféré sous le rapport des fleurs plus nombreuses, et dont la couleur ponceau éclatante est aussi plus durable; mais elles sont plus petites et moins odorantes.

Cette plante singulière fait l'ornement des rochers; 


\section{( 286 )}

qu'elle pare de sa belle végétation, et ses tiges pendent souvent sur leurs flancs, ou s'échappent à travers leurs crevasses. C'est en ces endroits, escarpés et périlleux, que les nègres vont les détacher pour obtenir de leur préparation des médicamens auxquels ils accordent la plus grande confiance.

On se sert journellement aux Antilles, dans les habitalions et sur les hattes, du suc de ce cierge pour détruire les vers des ulcères qui affligent l'espèce humaine et les animaux. Nous regrettons, à cel égard, de ne pouvoir donner ni la figure, ni la description de la cévadille qui lui est bien préférable; mais on n'en connait encore que les effets énergiques, indiqués dans la thérapeutique d'Alibert, avec le talent qu'on admire dans tous ses ourrages. Cette poudre se vend communément aux colonies, mais elle n'y arrive du Mexique que désorganisée et mutilée de manière à ne pas reconnaître l'espèce de plante qui la produit, et qu'on pense être un Varaiag (veratrum).

Caractìres physiques. La racine de la liane à vers, pousse des tiges cylindriques, cannelées, de la grosseur du petit doigt, articulées, serpentantes, grimpantes, et longues de trois à cinq pieds. Elles sont abondamment chargées et même hérissées de petites épines faibles, à peine piquantes, et disposées en paquets stelliformes sur des points élevés ou tuberculeux.

Les fleurs sont latérales, sessiles, oblongues, d'un rouge vif et éclatant. La partie inférieure ou tubuleuse de leur calice, est chargée de petiles écailles étroites, aiguës et barbues dans leurs aisselles. Les pétales et les folioles supérieures da calice sont des parties ob- 


\section{$(287)$}

longues, acuminées à leur sommet, également colorées, et qui ne se distinguent entr'elles, que parceque les inlérieures sont plus larges que les autres.

Les étamines sont de la longueur des pétales intérieurs, elles ont des filets írès-blancs, et de petites anthères jaunes; le style est de la longueur des étamines, et n'est point divisé à son stygmate.

Analyse chimiove. A la vue, a l'odorat el à la dégus. talion, je crois la liane à vers pourvue des mêmes principes constituans, que les espèces précédentes, mais je ne l'ai point analysée au laboratoire.

Proprititís médicinales. Le médecin da roi à SaintDomingue, M. Poupée Desporles, nous a indiqué l'un des premiers, les propriètés anthelminliques du cierge à queue de souris. "On coupe, dit-il, ses tiges; il en distille un suc blanchâtre un peu acide, qui est estimé un excellent vermifuge. " Comme je me méfiais de tous les sucs laiteux, j'aroue que je me suis dispensé le plus possible de prescrire ce médicament. Cependant j'ai voulu éprouver la protestation du savant confrère, et je me suis convaincu que ce moyen réussissait souvent dans des circonstances où d'autres vermifuges avaient échoné.

Mode d'administratron. Une demi-cuillerée du suc de la tige du cactier à queue de souris, boullie dans une ence de syrop de gomme, ou une demi-once d'huile récente de ricin, suffit pour un cnfant de cinq à sept ans, on triple la dose pour un adulte.

Voici la formule de M. Desportes, d'après M. Laborie, chirurgien très-expérimenté. "Liane à vers coupée par pclits morceaux, cinq à six poignées; faites macérer 


\section{( 288 )}

pendant vingt-quatre heures sur cendres chaudes dans trois livres d'eau; faites distiller. La dose est d'une à deux cuillerées. La méthode d'employer cette plante seule, ne laisse aucun doute sur ses propriétés anthelmintiques.

Nota. Une autre espèce du même genre, nommé Cactier parasite, eactus repens teres striatus muticus. Lin. - Opuntia minima flagelliformis. (Plumier.) pend du tronc des grands arbres, et perd ses épines en vieillissant. On la substitue à la première, dont elle a les mêmes vertus.

EXPLICATION DE LA PLANCHE SOIXANTE-SEPTIEMM.

La plante est représentée de grandeur naturelle. 


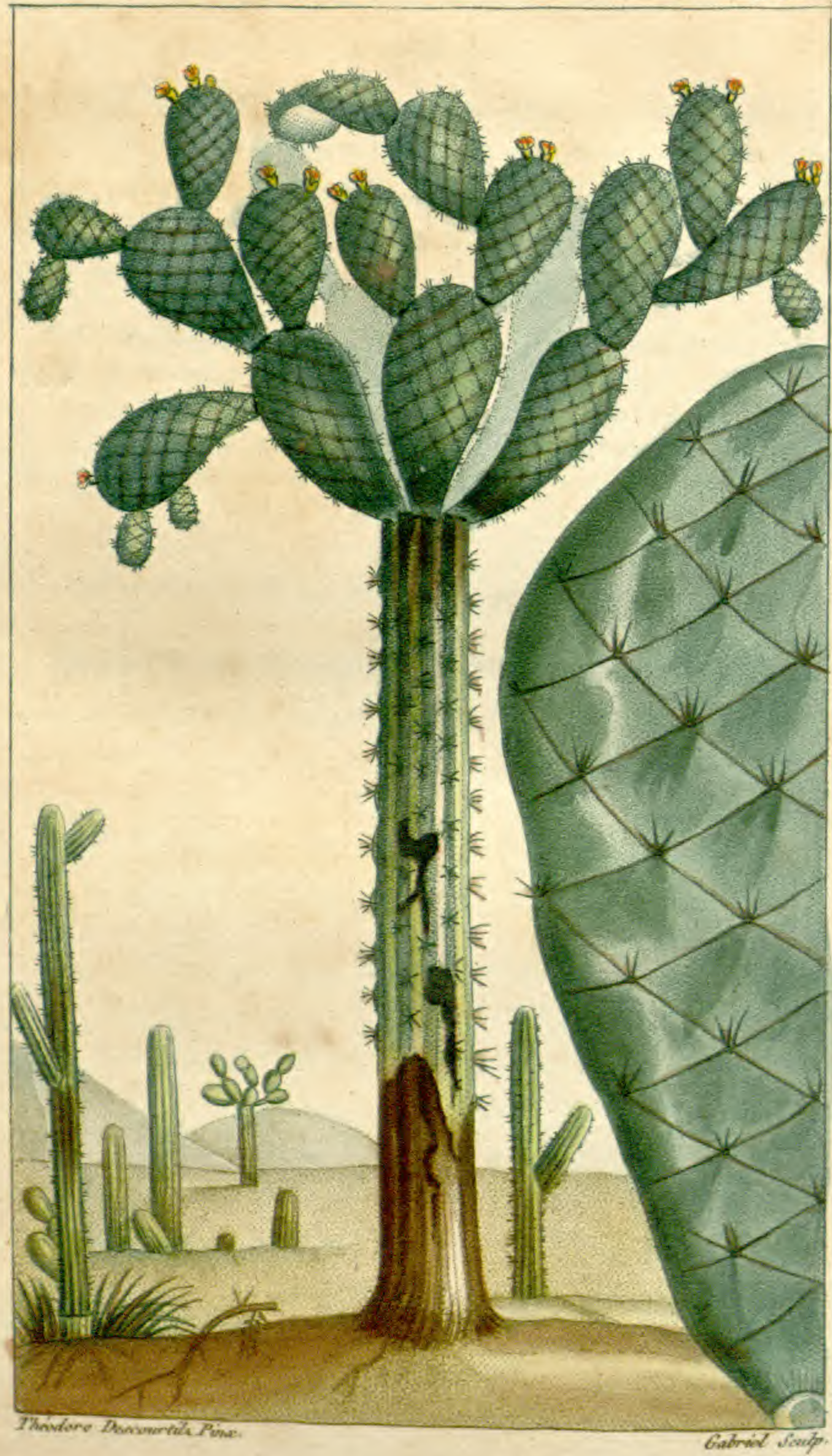




\section{$(289)$}

\section{CACTIER RÉTICULÉ. \\ Vulg. Cictier patte de tortue. \\ (Stomachique vermifuge).}

Synonyaie, Cactier Patte de Tortue. - Cactus trunco spinosissimo, ramis superioribus palmatis, et articulatis, floribus luteis, fructu sub-luteis glabris. Des. - Opuntia arbor excelsa, foliis reticulatis, Flore flavescente. Plum. Mest. t. 3, pag. 29. - Burm. amer. tab. 194-Lin. Icosandrie monogynie. - Tournefort. Cactus. Appendix. - Juss. fam. des Cactes.

Garactìres génériques. Calice monophylle, supérieur, imbriqué, corolle à pétales nombreux : baie à une loge polysperme. (Jolyc.)

Caractilnes particuliers. Cierge se soutenant par lui-même; tige arborescente, hérissée d'épines, supportant des articulations foliiformes réticulées.

Historre na turelle. C'est au milieu des savanes solitaires et brûlées, et sur les mornes arides et sans verdure, que l'on rencontre avec surprise le Cactier à tronc hérissé, qui n'offre pour feuillage que des palmes semblables à celles de la raquette (cactus oppuntia), articulées les unes sur les autres et reticulées. Sur ce sol aride et hérissé des épines du Cacte rampant, on voit á peine quelques branches grêles de mimose ou de parkinsonie. G'est au milieu de ces déserts silencieux que plasieurs castes de nègres confient ordinairement à la terre les dépouilles de leurs semblables. Là

Près des tombes, Ie triste amant des ténébres, Trouble seul leur repos de ses plaintes funèbręs. 


\section{( 290 )}

Caractères physiques. Ses racines traçantes, sont peu profondes, et formen $i$ sur la terre un bourrelet duquel s'élève une lige arborescente, ou ironc non ligneux; mais offrant à l'intérieur une cavité remplie par une moëlle entourée et contenue par des fibres sousligneuses, recouvertes d'une écorce tendre, d'abord laileuse, mais qui se dessèche lorsque la lige a fourni les articulations supérieures qui forment sa couronne. Dans son dernier terme d'accroissement, elle a de dix à quinze piêds de haut. Celte tige est verdâtre, fouettée çà el là, de taches d'un violet sombre, et hérissée de faisceanx d'pines disposées circulairement, el dégradée par des crevasses qui annoncent sa vélusté, et que l'activité végélale se trouve particulièrement fixée dans les articulations supérieures.

Les arliculations placées au sommet du tronc, s'étendent en tous sens, et s'articulent les unes avec les autres, de manière à fogmer, pour ainsi dire, des espèces de rameaux; elles sont applaties, à bords arrondis, ovales oblongues, irrégulières dans leurs contours, revêtues des deux côtés de saillies ou nervures superficielles et saillantes disposées en réscau, $\Lambda$ l'angle de chaque maille se trouve un tubercule cotonneux garni de quelques épines très-faibles et fort courtes.

Les fleurs naissent aux parties supérieures, ou latérales de ces palmes, elles sont assez grandes, d'un jaune orongé porté sur leur ovaire. Il leur succède un fruit mamelonné d'un beau jaune contenant une pulpe blanche, renfermant une infinité de petites semences noires.

Anatyse chimique. Le suc laiteux qui transude de toutes les parties de la plante, semble indiquer ses pro- 


\section{(29r)}

priétés absolument identiques avec celles des autres cierges.

Proprí́tés médicirales. Les naturels di pays sachant trouver des ressources dans la majeure partie des végétaux qui ș'offrent à leurs regards, emploient le suc récent des pattes de tortue, dans les affections vermineuses, en frictions sur le bas ventre; pour détruire les lombrics, et dans les dysuries atoniques, où cette irritation mécanique produit un effel prompl et éprouvé.

L'écorce broyée de la racine en décoction, purge les nègres; et ses vapeurs, dit-on, soulagent les douleurs rhumatismales et otalgiques. Ces propriétés nous ont été certifiées par plusieurs praticiens des Antilles, mais comme je me méfie toujours des vertus spécifiques souvent exaltées par l'exagération et l'empyrisme, je laisse à ceux qui me succèderont dans le noble exercice de la médecine, le soin de prononcer en pareil cas.

Mode d'administiation. La dose de la racine en décoction est de deux onces pour purger un adulte; celle du suc, à l'extérieur, est de deux à quatre gros.

eXPLiCATION DE LA PLANCHE SOIXANTE-HUITİMe.

Le Cacte hérissé est réduit au vingtième de grandeur naturelle. Il eșt représenté sur un terrain aride, connu sous le nom de Hatte, et ou seulement il peut végéter.

L'articulation séparée est réduite au huitième de sa grandeur naturelle. 


\section{PLANTES VERMIFUGES,}

RAPPORTÉES DANS D'AUTRES CLASSES.

On ne trouve guères de végétaux doués de vertus anthelmintiques, directes, que dans les classes de stomachiques aromatiques, des stom. amers ou fébrifuges et dans les diverses espèces des classes purgatives.

FIN DU PREMIER VOJUME. 


\section{TABLE DES MATIËRES}

CONTENUES DANS LE PREMIER VOLUME.

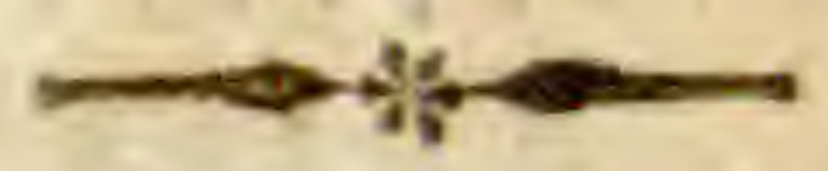

Discours préliminatri. .............. pag. I

\section{PREMIERE LIVRAISON}

Sommaire des Stomachiques aromatiques.......... ib. Acacie odorante............... pl. 1, pag. 5 Abricotier des Antilles............. pl. 2, pag. 8 Croton Cascarille................ pl. 3, pag. Ix Roucouyer.................... pl. 4, pag. 15

\section{DEUXIÈME LIVRAISON.}

Sommaire des Sirops fébrifuges............ pag. $2 x$ Quassie amère................. pl. 5, pag. ${ }_{25}$ Poincillade................... pl. 6, pag. 27 Cutronier des Halliers. ............. pl. 7, pag. 31 Cytise épineux................. pl. 8, pag. 37

\section{TROISIÈME LIVRAISON}

Bois laiteux à feuilles de citnoniers.... pl. 9, pag. 4i Manglier chandelle.............. pl. 10 , pag. 45 Acacie à quatre feuilles........... pl. is, pag. 5 r Parkinsonie................... pl. 12, pag. 54

\section{QUATRIÈME LIVRAISON.}

Quinquina Piton................ pl. 13, pag. 57 Quassie Simarouba................ pl, 14, pag. 66 Gentiane à longs pédoncules.......... pl. 15 , pag. 72 Gentiane verticillée............... pl. 16 , pag. 76 


\section{( 294)}

\section{CINQUUEME LIVRAISON.}

Indigotier franc ............. pl. 17 , pag. 81 Bignone à feuilles ondées........... pl. 18, pag. 87 Trophis d'Amérique............. pl. 19, pag. 90 Gentianelle pourprée............ pl. 20, pag. $9^{3}$

\section{SIXIÈME LIVRAISON.}

Sommaire des Sirops anti-scorbutiques....... pag. 97 Cocotier................... pl. 21, pag. 99 Détails du Cocotier............... pl. 22, pag. I11 Ménianthe................. pl. 23 , pag. 112 Mangoustan.................. pl. 24, pag. 116 SEPTIEME LIVRAISON.

Manguier............... pl. 25, pag. I2I Curcuma à racines tubereuses....... pl. 26 , pag. 127 Ben olé̈fère................... pl. 27, pag. 13i Latanier épineux .............. pl, 28, pag. 135

\section{HUITIEME LIVRAISON.}

Caprier à grosses siliques........... pl, 29, pag. 14. I Mourellier-cerisier........... pl. 3o, pag. 145 Ketmie acide ou oseille de Guinée... pl. 51, pag. $14^{8}$ Oxalie à fleurs jaunes .............. pl. 32 , pag. 153

\section{NEUVIEME LIVRAISON.}

Raplie vinifère,.$\ldots \ldots \ldots \ldots \ldots \ldots$, pl. 35, pag. 15 7 Grenadille bleue................ pl. 34, pag. 16r Grenadier sauvage ............... pl. 35, pag. 165 Ananas conique.............. pl. 36 , pag. $\mathbf{1 7 0}$

\section{DIXIEME LIVRAISON.}

Poivrier à ombelles.............. pl. 37 , pag. 177 Oranger âcre ou sür, ,......... pl. 38, pag. 18r 


\section{( 295$)$}

Hydrocotile à ombelles............ pl. 39, pag. 185 Drymis aromatique........... pl. 40 , pag. 186

\section{ONZIÈME LIVRAISON.}

Cresson de Savane commun......... pl. 41, pag. 195 Cresson de Savane petit.......... pl. 42, pag. 197 Cakilé de Saint-Domingue......... . pl. 45, pag. 199 Cléome Triphylle.............. pl. 44, pag. 202

\section{DOUZIĖME LIVRAISON.}

Auguine amère.............. pl. 45, pag. 207 Agedarack bipinné............ pl. 46, pag. 2 so Papayer commun............... pl. 47, pag. 215 Détails du Papayer............. pl. 48, pag. 220

\section{TREIZIÈME LIVRAISON.}

Dolic à poils euisans........... pl. 49, pag. 221 Oldenlande à corymbes........... pl. 5o, pag. 225 Pourpier très-amer............. pl. 51, pag. 228 Bident à saveur de Pyrèthre........ pl. 52, pag. 25I

\section{QUATORZIÈME LIVRAISON.}

Umari ou Angelin à grappes........ pl. 53, pag. 235 Bocconie Chélidoine............. pl. 54, pag. 235 Ambroisie à feuilles d'armoise....... pl. 55, pag. 239 Passiflore à feuilles de laurier...... pl. 56, pag. 242

\section{QUINZIÈMIE LIVRAISON.}

Ansérine anthelmintique.......... pl. 5y, pag. 245 Ansérine ambrosioide............. pl. 58, pag. 247 Ricin arborescent .............. pl. 59, pag. 250 Grenadille quadrangulaire......... pl. 6o, pag. 258 


\section{( $\left.29^{6}\right)$}

\section{SEIZIÈME LIVRAISON.}

Spigelie anthelmintique......... pl. 61, pag. $26 \mathrm{r}$ Grenadille sans franges.......... pl. 62, pag. 265 Polypode en arbre.............. pl. 63, pag. 269 Calaguala.................. pl. 64, pag. $27^{3}$

\section{DIX-SEPTIÈME LIVRAISON.}

Cierge à grandes fleurs.......... pl. 65, pag. 257 Cierge divergent............ pl. 66, pag. $28 \varepsilon$ Cierge queue de souris........... pl. 67 , pag. 285 Cactier patte de tortue ........... pl. 68, pag. 289

FIN DE LA TABLE DU TONE PBEMIER。 